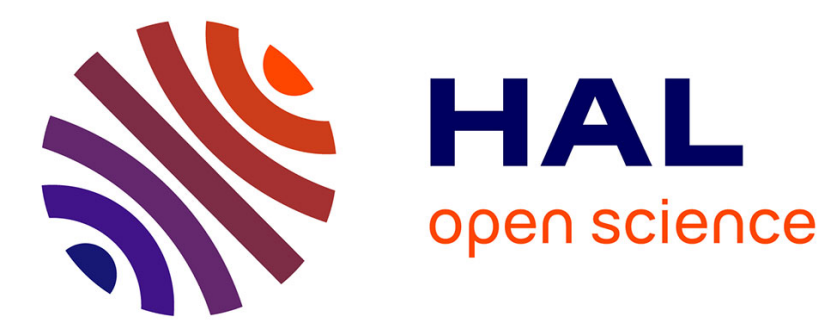

\title{
Improving, Bypassing or Overcoming Representation?
} Jean-Benoit Pilet, Camille Bedock, Pierre-Etienne Vandamme

\section{To cite this version:}

Jean-Benoit Pilet, Camille Bedock, Pierre-Etienne Vandamme. Improving, Bypassing or Overcoming Representation?. Frontiers in Political Science, pp.145, 2021, 10.3389/978-2-88971-901-3 . hal03507188

\section{HAL Id: hal-03507188 \\ https://hal.science/hal-03507188}

Submitted on 3 Jan 2022

HAL is a multi-disciplinary open access archive for the deposit and dissemination of scientific research documents, whether they are published or not. The documents may come from teaching and research institutions in France or abroad, or from public or private research centers.
L'archive ouverte pluridisciplinaire HAL, est destinée au dépôt et à la diffusion de documents scientifiques de niveau recherche, publiés ou non, émanant des établissements d'enseignement et de recherche français ou étrangers, des laboratoires publics ou privés.

\section{(1)(1) $\$(0)$}

Distributed under a Creative Commons Attribution - NonCommercial - ShareAlikel 4.0 


\section{IMPROVING, BYPASSING OR OVERCOMING REPRESENTATION?}

EDITED BY: Jean-Benoit Pilet, Camille Bedock and

Pierre-Etienne Vandamme

PUBLISHED IN: Frontiers in Political Science
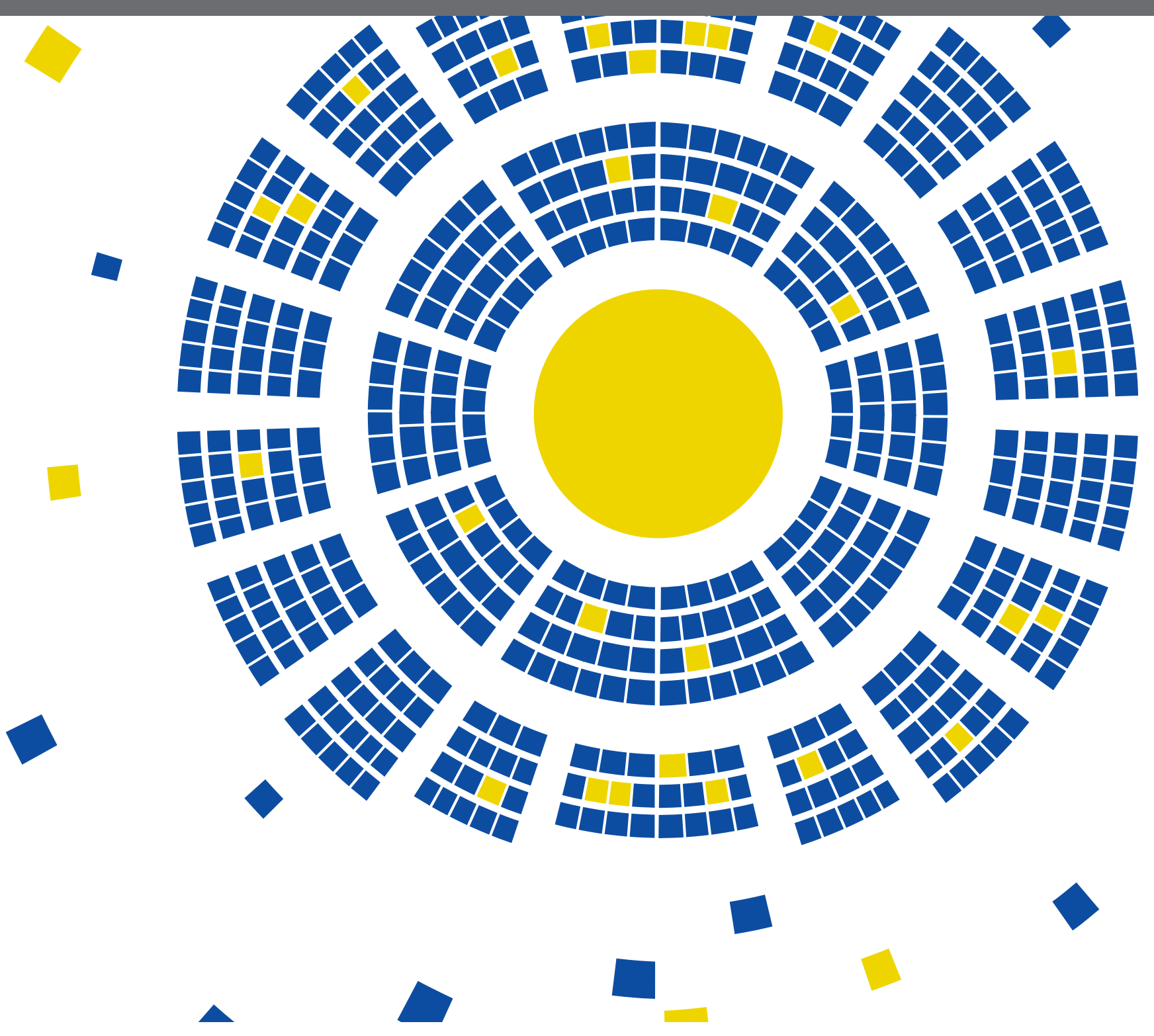


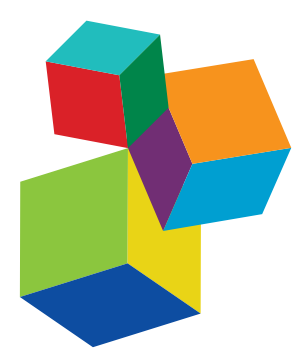

Frontiers eBook Copyright Statement

The copyright in the text of individual articles in this eBook is the property of their respective authors or their respective institutions or funders. The copyright in graphics and images within each article may be subject to copyright of other parties. In both cases this is subject to a license granted to Frontiers.

The compilation of articles constituting this eBook is the property of Frontiers.

Each article within this eBook, and the eBook itself, are published under the most recent version of the Creative Commons CC-BY licence.

The version current at the date of publication of this eBook is CC-BY 4.0. If the CC-BY licence is updated, the licence granted by Frontiers is automatically updated to the new version.

When exercising any right under the CC-BY licence, Frontiers must be attributed as the original publisher of the article or eBook, as applicable.

Authors have the responsibility of ensuring that any graphics or other materials which are the property of others may be included in the

CC-BY licence, but this should be checked before relying on the

CC-BY licence to reproduce those materials. Any copyright notices relating to those materials must be complied with.

Copyright and source acknowledgement notices may not be removed and must be displayed in any copy, derivative work or partial copy which includes the elements in question.

All copyright, and all rights therein, are protected by national and international copyright laws. The above represents a summary only.

For further information please read Frontiers' Conditions for Website

Use and Copyright Statement, and the applicable CC-BY licence.

\section{About Frontiers}

Frontiers is more than just an open-access publisher of scholarly articles: it is a pioneering approach to the world of academia, radically improving the way scholarly research is managed. The grand vision of Frontiers is a world where all people have an equal opportunity to seek, share and generate knowledge. Frontiers provides immediate and permanent online open access to all its publications, but this alone is not enough to realize our grand goals.

\section{Frontiers Journal Series}

The Frontiers Journal Series is a multi-tier and interdisciplinary set of open-access, online journals, promising a paradigm shift from the current review, selection and dissemination processes in academic publishing. All Frontiers journals are driven by researchers for researchers; therefore, they constitute a service to the scholarly community. At the same time, the Frontiers Journal Series operates on a revolutionary invention, the tiered publishing system, initially addressing specific communities of scholars, and gradually climbing up to broader public understanding, thus serving the interests of the lay society, too.

\section{Dedication to Quality}

Each Frontiers article is a landmark of the highest quality, thanks to genuinely collaborative interactions between authors and review editors, who include some of the world's best academicians. Research must be certified by peers before entering a stream of knowledge that may eventually reach the public - and shape society; therefore, Frontiers only applies the most rigorous and unbiased reviews.

Frontiers revolutionizes research publishing by freely delivering the most outstanding research, evaluated with no bias from both the academic and social point of view. By applying the most advanced information technologies, Frontiers is catapulting scholarly publishing into a new generation.

\section{What are Frontiers Research Topics?}

Frontiers Research Topics are very popular trademarks of the Frontiers Journals Series: they are collections of at least ten articles, all centered on a particular subject. With their unique mix of varied contributions from Original Research to Review Articles, Frontiers Research Topics unify the most influential researchers, the latest key findings and historical advances in a hot research area! Find out more on how to host your own Frontiers Research Topic or contribute to one as an author by contacting the Frontiers Editorial Office: frontiersin.org/about/contact 


\section{IMPROVING, BYPASSING OR OVERCOMING REPRESENTATION?}

Topic Editors:

Jean-Benoit Pilet, Université libre de Bruxelles, Belgium

Camille Bedock, UMR5116 Centre Émile durkheim Science Politique et Sociologie Comparatives, France

Pierre-Etienne Vandamme, Université libre de Bruxelles, Belgium

Citation: Pilet, J.-B., Bedock, C., Vandamme, P.-E., eds. (2021). Improving, Bypassing or Overcoming Representation?. Lausanne: Frontiers Media SA. doi: 10.3389/978-2-88971-901-3 


\section{Table of Contents}

04 Editorial: Improving, Bypassing or Overcoming Representation?

Pierre-Etienne Vandamme, Jean-Benoit Pilet and Camille Bedock

06 Why Voting Does Not Imply Consenting

Laetitia Ramelet

17 Political Support in Times of Personalized Politics. A Qualitative Inquiry of French Citizens' Representations About Political Actors and the Political Regime

Charlotte Dolez

30 Citizens' Contrasting Aspirations About Their Political System: Entrustment, Participation, Identification and Control Camille Bedock

45 Do Citizens Perceive Elected Politicians, Experts and Citizens as Alternative or Complementary Policy-Makers? A Study of Belgian Citizens Jean-Benoit Pilet, David Talukder, Maria Jimena Sanhueza and Sacha Rangoni

63 Advisory, Collaborative and Scrutinizing Roles of Deliberative Mini-Publics

Maija Setälä

73 Citizens' Assemblies for Referendums and Constitutional Reforms: Is There an "Irish Model" for Deliberative Democracy?

Dimitri Courant

93 Can the Recall Improve Electoral Representation?

Pierre-Etienne Vandamme

106 Political Representation in Liquid Democracy

Chiara Valsangiacomo

120 Claims of Representation: Between Representation and Democratic Innovations

Petra Guasti and Brigitte Geissel

132 Is It Interests, Ideas or Institutions? Explaining Elected Representatives' Positions Toward Democratic Innovations in 15 European Countries Nino Junius, Joke Matthieu, Didier Caluwaerts and Silvia Erzeel 


\title{
Editorial: Improving, Bypassing or Overcoming Representation?
}

\author{
Pierre-Etienne Vandamme ${ }^{1 *}$, Jean-Benoit Pilet $^{1}$ and Camille Bedock ${ }^{2}$ \\ ${ }^{1}$ FNRS, Université Libre de Bruxelles, Brussels, Belgium, ${ }^{2}$ UMR5116 Centre Émile Durkheim Science Politique et Sociologie \\ Comparatives, Aquitaine, France
}

Keywords: representation, democratic innovations, participation, citizens, political theory

Editorial on the Research Topic

Improving, Bypassing or Overcoming Representation?

The discussion and empirical analysis of the increasing citizen dissatisfaction with existing representative institutions has become a central concern for political science in recent decades (Rosanvallon, 2006; Papadopoulos, 2013; Merkel, 2014; Thomassen, 2016). Political theory has also contributed to this debate by focusing increasingly on non-elective forms of participation and representation (Saward, 2009; Kuyper, 2016; Landemore, 2020). Paradoxically, there has not been a significant dialogue between political theory and empirical research that would aim to understand whether these non-elective forms of participation and representation are to be conceived as a complement, a diversion or even a full-blown alternative to electoral representation (Peters, 2016). Is representation dispensable? What are the alternatives to existing institutions? How are existing institutions and their alternatives perceived by citizens, parties and elected representatives? The aim of the present collection of articles was precisely to address these questions by means of a dialogue between political theory and empirical work on actors' perceptions.

A first set of articles deals with citizens' perceptions of their democratic institutions and with their normative aspirations. A theoretical contribution by Ramelet explains why citizens' participation in elections cannot meaningfully be interpreted as a form of consent to being represented, or to being represented through elections. As revealed by the empirical literature, voting can be motivated by a diversity of motivations, including strategic and expressive ones. Hence, the only way of knowing what citizens think about representation and elections and whether they see electoral representation as a legitimate embodiment of democratic ideals is to directly ask them. This is precisely what three other contributions to this e-book do.

Dolez examines citizens' representations of political actors and of their political regime through couple interviews with French citizens. She finds citizens mainly dissatisfied with political actors-and only indirectly with the regime -, who aspire to a better representation, but do not really question the delegation of power to representatives and fail to imagine alternatives to electoral representation. In the same spirit, the contribution by Bedock tries to understand citizens' aspirations about democracy through in-depth interviews with French citizens. She highlights four ideal-typical aspirations: entrustment of personalities distinguishing themselves from the mass and capable of surmounting partisan quarrels to govern efficiently; control and sanction of representatives who are usually detached from social reality and risk abusing from their privileges; identification with representatives who should be more diverse to better represent neglected interests; and finally more participation by citizens in decision-making to increase social progress. None of these discourses rejects representation entirely, but the latter three do question the way it currently works. The contribution by Pilet et al. and his colleagues also highlights a plurality of visions of democracy among citizens. Interestingly, it also shows that most citizens aspire to a governance model where decision-making power is shared by a plurality of actors: elected representatives and experts, elected representatives and citizens, or even experts and citizens. Hence, it seems to be the monopoly over representation by elected politicians that is questioned, more than representation or elections as such. 
A second set of articles explores different alternatives to traditional representative institutions and their role. The most often discussed is the new form of representation offered by deliberative mini-publics with randomly selected citizens. As Setälä explains in her contribution, these can perform a variety of functions aiming at improving electoral representation rather than replacing it: they can provide the advisory input resulting from an inclusive deliberative process in the process of political will-formation; organize deliberative collaboration between ordinary citizens and elected representatives; or scrutinize the work of elected representatives-each of these options coming with specific challenges that she discusses. Ireland recently witnessed several experiences with mini-publics, discussed in Courant's contribution. Interestingly, they evolved from a collaborative model, mixing randomly selected citizens with elected representatives, to a model that bypasses electoral representation: recommendations by the citizens' assembly are validated or rejected in a national referendum. Courant argues that Ireland is an interesting case of relatively strong institutionalization of deliberative mini-publics, but also highlights some limits of the Irish experiences and warns against the temptation to try to import their "model".

While sortition can be seen as offering an alternative form of political representation-not necessarily incompatible with elections -, other democratic innovations aim at improving electoral representation itself. This is the case of the recall, or the possibility for citizens to remove elected representatives from office before the end of their term. In his contribution, Vandamme argues that this mechanism could be a response to citizens' demand for more control over their representatives. However, because it is important for representatives to keep some room of maneuver and to avoid a systematic contestation of electoral results by sore losers, he argues that the recall is better conceived as a last resort mechanism that should not be too easy to enact. Valsangiacomo, however, presents and defends a very innovative model of representation-liquid democracy -, where citizens can choose either to be represented by "proxies" of their choice, subject to instant recall, or to vote directly on issues they are particularly interested in. This is meant to offer the best possible compromise between representation and direct legislation. Should such a model be adopted, however, it would importantly reshape the representative dynamic and, as she argues, bring political parties closer to interest groups.

\section{REFERENCES}

Bengtsson, Å., and Christensen, H. (2016). Ideals and Actions: Do Citizens' Patterns of Political Participation Correspond to Their Conceptions of Democracy? Gov. Oppos. 51 (2), 234-260. doi:10.1017/gov.2014.29

Kuyper, J. W. (2016). Systemic Representation: Democracy, Deliberation, and Nonelectoral Representatives. Am. Polit. Sci. Rev. 110 (2), 308-324. doi:10.1017/s0003055416000095

Landemore, H. (2020). Open Democracy: Reinventing Popular Rule for the TwentyFirst Century. Princeton, New Jersey: Princeton University Press. doi:10.2307/ j.ctv10crczs

Merkel, W. (2014). Is There a Crisis of Democracy? Democratic Theor. 1 (2), 11. doi:10.3167/dt.2014.010202

Papadopoulos, Y. (2013). Democracy in Crisis? Politics, Governance and Policy. London: Palgrave. doi:10.1007/978-1-137-34920-0

Peters, Y. (2016). Zero-Sum Democracy? the Effects of Direct Democracy on Representative Participation. Polit. Stud, 64 593-613. doi:10.1177/ 0032321715607510
Faced with this diversity of possible innovations, one question that arises is how representative claims can be authorized outside the framework of general elections. This question is taken up in the contribution by Guasti and Geissel, that traces representative claims in the election of a council of foreigners, in a participatory budgeting experience and in a referendum, all in Germany. One of their findings in all three cases is a significant discrepancy between the claimed constituency, the actually affected audience, and the legally enfranchised constituency, showing how claim-making is usually fractured and incomplete in representative processes.

Finally, anyone interested in the potential of democratic innovations to transform representative institutions is confronted with the question of what can motivate political actors to initiate such experimentations that have the potential to challenge their monopoly over representation. In their contribution, Junius et al. and his colleagues show that it is usually a combination of ideology, strategic interests and institutional factors that explain elected representatives' attitudes towards democratic innovations. Among other findings, left-wing parties are more supportive of different innovations, while opposition parties, and parties in consensual democracies in particular, are more favorable to referendums.

Overall, this collection of articles helps us see the diversity of possible innovations to traditional representative institutions and the different ways in which they can be articulated with the latter. Among other things, it also shows that a questioning of electoral representation does not necessarily entail a rejection of representation or elections. However, what seems more and more questioned by citizens and theorists is the monopoly of elected representatives over decisionmaking and their degree of independence. In that respect, the various contributions that are included here can enter in direct dialogue with studies on how to reform contemporary democracies to include new elements of citizens' participation, in various ways (Bengtsson and Christensen, 2016; Landemore, 2020).

\section{AUTHOR CONTRIBUTIONS}

All authors listed have made a substantial, direct, and intellectual contribution to the work and approved it for publication.

Rosanvallon, P. (2006). La contre-démocratie. La politique à l'âge de la défiance. Paris: Seuil.

Saward, M. (2009). Authorisation and Authenticity: Representation and the

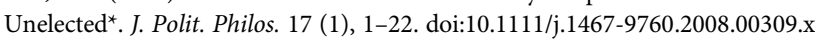
Thomassen, J. (2016). "What's Gone Wrong with Democracy, or with Theories Explaining Why it Has?", in Citizenship And Democracy In an Era Of Crisis. Editors P. Thomas, R. Sigrid, S. Rüdiger, and Z. Sonja. (London: Routledge), 34-52. doi:10.4324/9781315750248

Conflict of Interest: The authors declare that the research was conducted in the absence of any commercial or financial relationships that could be construed as a potential conflict of interest.

Copyright (C) 2021 Vandamme, Pilet and Bedock. This is an open-access article distributed under the terms of the Creative Commons Attribution License (CC BY). The use, distribution or reproduction in other forums is permitted, provided the original author(s) and the copyright owner(s) are credited and that the original publication in this journal is cited, in accordance with accepted academic practice. No use, distribution or reproduction is permitted which does not comply with these terms. 
OPEN ACCESS

Edited by:

Pierre-Etienne Vandamme, Université libre de Bruxelles, Belgium

Reviewed by: Herve Pourtois, Catholic University of Louvain, Belgium Dominique Leydet, Université du Québec à Montréal, Canada

${ }^{*}$ Correspondence: Laetitia Ramelet laetitia.ramelet@gmail.com

Specialty section: This article was submitted to Elections and Representation,

a section of the journal

Frontiers in Political Science

Received: 07 April 2020

Accepted: 04 August 2020

Published: 17 September 2020

Citation:

Ramelet L (2020) Why Voting Does

Not Imply Consenting.

Front. Polit. Sci. 2:5.

doi: 10.3389/fpos.2020.00005

\section{Why Voting Does Not Imply Consenting}

\author{
Laetitia Ramelet* \\ Swiss Graduate School of Public Administration, University of Lausanne, Lausanne, Switzerland
}

One of the reasons that elections have come to be so widely valued across the globe lies in their perceived ability to increase citizens' consent to be governed by their representatives. Yet, inversely, one may ask what election results tell us about citizens' consent. For instance, to what extent can election winners be assumed to enjoy citizens' consent? Does voting automatically imply consent to the outcome of the election? What does abstention mean? This paper addresses the question of what election results reveal about citizens' consent, from an empirically informed normative perspective. The question is of political importance, because the connection between voting and consenting is often exploited for political gain, and because representative institutions are now being increasingly questioned by citizens themselves. I plead for caution in any endeavor to interpret election results in terms of consent, and I argue that it would be wrong to assume, by default, that voters intend their vote to express consent. Rather, voters' motives can only be ascertained by asking voters about them, and cannot be deduced from their sole act of voting. In addition, much variation is to be expected regarding what is being consented to, and to what degree.

Keywords: consent, elections, legitimacy, representation, authority, turnout, sortition

\section{INTRODUCTION}

Elections are currently the dominant practice to select the very few of us who make decisions binding for everyone. However, in accordance with the concerns of the present research topic, there is an inevitable gap between, on the one hand, the institutional need for a system with procedures to settle the question of who gets to rule, and on the other, the complexity of citizens' own perspectives and relations to politics. One of the reasons that elections have come to be so widely implemented and valued across the globe lies precisely at the crossroads of these two dimensions: in their perceived ability to secure citizens' consent to be governed by their representatives, at least better than other systems can (Luhmann, 1983; Hampton, 1993; Manin, 1997; Przeworski, 2018). Yet, inversely, one may ask what election results tell us about citizens' consent (by election results, I mean both winners' score and turnout). For instance, to what extent can election winners be assumed to enjoy citizens' consent? Does voting automatically imply consent to the outcome of the election? What does abstention mean?

These questions are not only important to understand the functioning of representation, but also because the connection between voting and consenting can be exploited for political gain. Not by chance do most authoritarian regimes prefer to rely on (the pretense of) electoral procedures to provide democratic support for their claims to power (Von Soest and Grauvogel, 2017). However, even in free democracies, election results are often instrumentalized by various political actors (and their adherents), typically to support one's claims to legitimacy or to discredit one's opponents. 
Thus, claims to have the backing of a "silent majority", or to represent "the people" better than others, are not rare. Furthermore, in the current context of increasing questioning of representative institutions (which lies at the core of this research topic), the problem is all the more worthy of attention that it seems to mirror many citizens' actual preoccupations. It may also be of interest for the lively debates around sortition (Landemore, 2013; Vandamme and Verret-Hamelin, 2017; Courant, 2019; Bedock and Pilet, 2020), either as a substitute for or as a complement to elections, to attain a clearer picture of the connection between consent and elections, notably to assess what may get lost, in terms of consent, if we dispense of elections.

This paper thus seeks to address the question of what election results tell us about citizens' consent, from an empirically informed normative perspective. Thereby, it pleads for caution and nuances in any endeavor to interpret election results in terms of consent. I argue that it would be a mistake to presume voters' consent simply on the basis of their votes and that much variation is to be expected regarding what may be consented to and with what intensity. As we will see, with the help of the empirical literature, there is evidence of a great diversity in the motives and assessments of voters. These can only be ascertained by asking voters about them, and cannot be deduced from their sole act of voting. The same goes for abstention. The analysis starts with a philosophical definition of political consent, followed by an exposition of the reasons that election results may reveal something about it. From this perspective, three possible objects of consent are considered: consent to elected representatives' rule, consent to elections as a procedure, and consent to membership in a democratic community. Last, it remains to examine what abstention can indicate about consent.

For these purposes, a dialogue between the theoretical and empirical literature proves to be particularly fruitful, in the spirit of the present research topic. While philosophical contributions allow us to grasp the contours and workings of political consent, studies on electoral behavior identify general patterns regarding the motives behind voters' choices. This empirical literature investigates the various recurring factors influencing vote choice ${ }^{1}$ and turnout ${ }^{2}$ and, as part of such vast enquiries, the more specifically political motives underlying both. Political motives include the meaning attributed by a voter to their vote (or their abstention), as well as their evaluation of the candidates, the election results, and, more generally, their attitudes toward representative institutions. It is on the latter type of findings that the present paper will focus, as these are the elements that bring us the closest to the potential connection between a

\footnotetext{
${ }^{1}$ Factors influencing voter choice notably include "cleavages" (Lipset and Rokkan, 1967) within society [e.g., traditionally, socioeconomic disparities or, more recently, a gap between the "winners" and "losers" of globalization (Kriesi et al., 2008; Hooghe and Marks, 2018)] as well as preferences regarding specific issues that are seen as particularly important at the time of an election (Enelow and Hinich, 1984; Bélanger and Meguid, 2008).

${ }^{2}$ Among the many determinants of turnout, studies report, for instance, individual characteristics (such as age, education, social networks, political interest, or a sense of civic duty), institutional variables (such as compulsory voting), as well as characteristics of the election (such as campaign expenditures and closeness of the election) (Brady et al., 1995; Blais, 2000; Franklin et al., 2004; Blais and Daoust, 2020; for an overview of the literature, see Stockemer, 2017).
}

citizen's vote and their consent. I will, of course, not be able to provide a comprehensive analysis of this abundant literature. More modestly, my objective will be to warn about the intricacies of the interpretation of consent from election results.

\section{CONSENT, ELECTIONS, AND LEGITIMACY}

To begin, a few words are necessary to clarify what is meant here by political consent, which I define as a citizen's mental acceptance of his or her political condition. The term "political condition" comprises the institutionalized political power relations to which a citizen is subject. In a representative democracy, this refers to two main dimensions: authorities' power on the one hand, and fellow citizens' power on the other. While authorities possess the power of making or enforcing decisions that affect the citizen, his or her fellow citizens have the power of selecting (some of the) rulers and participating in certain public decisions, which also affects him or her. Both dimensions converge in the state's commands, which at times can express the will of both authorities and the majority of participating citizens. By "mental acceptance," I mean that one consents when one agrees internally to being subjected to one's authorities and fellow citizens, or in other words, when one is favorably inclined toward their power over oneself. All citizens may be subject to the state's power. However, in the case of the consenting citizen, this is not rooted exclusively in the state's brute coercive means. Rather, it also appears to the citizen to be morally appropriate and to constitute a reasonable source of constraints upon him or her.

A few remarks are in order to situate this definition within the literature on consent theory. The ambition to place consent at the center of political life derives from the rich tradition of early modern consent and contract theories (most emblematically, Grotius's, Hobbes's, Pufendorf's, Locke's or Rousseau's) and has a long legacy. In particular, my definition owes much to Horton (2012) and Greene's (2016) recent contributions, which view political consent as an internal, psychological phenomenon, although they do not mention the element of acceptance described above. Thus, according to Horton, political consent is rooted in citizens' "beliefs and attitudes" toward their institutions and rulers: "it is about the acknowledgment of [the] state as having authority-recognizing the right of the state to exercise state power by making laws, pursuing policies and enforcing them on its citizens" (Horton, 2012, p. 141) $)^{3}$. According to Greene, political consent stems from an individual's "positive governance assessment" on the performance of their rulers and institutions (Greene, 2016, p. 81) ${ }^{4}$. Readers familiar with contemporary consent theories will also notice that this definition of consent as acceptance is distinct from the conception of consent employed in philosophical debates on political obligations. There, political consent is envisaged as a citizen's voluntary commitment to obeying a state's laws and authorities

\footnotetext{
${ }^{3}$ See also p. 142: "Thus, I consent to, or more properly recognize or acknowledge, the state as legitimate."

${ }^{4}$ See also: "a regime is legitimate insofar as it achieves actual quality consent to rule based on positive governance assessments" (p. 81).
} 
(see e.g., Pateman, 1979; Simmons, 1979; Klosko, 2005, 2018). However, most philosophers agree that such commitments are rarely made in practice (or at least not in meaningful circumstances), making consent of limited use when accounting for citizens' obligations and authorities' legitimacy ${ }^{5}$. I address some elements of these discussions below because certain philosophers have considered whether the act of voting counts as an act of consent in this obligating sense (Steinberg, 1978, p. 113131; Simmons, 1979, p. 91-93; Singer, 1994, p. 49, 50; Klosko, 2018, p. 352; Abizadeh, 2020, p. 4). However, my concern here is with consent as acceptance, which proves to be a more suitable candidate when accounting for legitimacy.

This brings us to the normative value of political consent. In keeping with the rich tradition of consent theory, if consent is required for a state's legitimacy, this is because the state embodies authorities' and fellow citizens' power over an individual citizen (in a democracy). This vast power can restrict individuals' freedom of action and can collide with the fact that all people are moral equals-unless they consent to these hindrances. Thereby, I concur with Horton and Greene again in the claim that political consent constitutes the source of the state's moral legitimacy. In Horton's words, legitimacy here means a state's "right" and "authority to govern" its subjects (Horton, 2012, p. 130). In Greene's, it refers to a regime's "appropriate standing to exercise power over its subjects” (Greene, 2016, p. 77). On her account, legitimacy results from the sum of "a high proportion" of individuals' actual consent: the more people consent, the more legitimate is a state (Greene, 2016, p. 87). Conversely, the less consent, the less legitimacy. This, of course, is not to say that such legitimacy provides complete justification for a state's powera point worth mentioning here, as the present paper focuses on the availability of consent. For this, certain conditions of justice also apply regardless of citizens' consent (including respect for human rights and the fair treatment of the state's citizens and residents at least; Horton, 2012, p. 135-137, Greene, 2016, p. 85) ${ }^{6}$. There is also the question of how informed such consent should be to be considered valid, which is a matter of debate. In any case, rulers should not manipulate consent via indoctrination and misinformation (Beetham, 1991, p. 8-11).

Given this general picture of consent and legitimacy, consent appears essential to the justification of political power, but it is also particularly tricky to identify, as a psychological phenomenon not openly accessible to others. This raises the question of what constitutes a potential sign of consent. In this paper, I approach this issue from the perspective of what election results reveal about citizens' consent. I do not suggest that election results are the only-or even the best-source of

\footnotetext{
${ }^{5}$ As Simmons puts it (Simmons, 1979, p. 100): "The challenge, then, seems to remain open to the modern-day consent theorist to show us how government by consent can be made a reality. In any event, however, the more plausible alternative is to turn our attention from consent to other possible grounds of political obligation."

${ }^{6}$ This distinction between legitimacy and justice is summarized as follows by Douglass (2020, p. 52), for whom, on the one hand, legitimacy refers to "the grounds for some person or body having the authority to rule," and, on the other, "questions of justice" relate to "how that authority should be exercised" (in reference to Kukathas).
}

such information. Rather, I aim to examine which relevant clues they can provide about consent, particularly in the light of the questions raised the introduction: to what can extent election winners be assumed to enjoy citizens' consent, and does voting imply consent to the election's outcome?

\section{ELECTIONS AND CONSENT}

Why consider election results (winners' score and turnout) as a potential source of information on such consent at all? I believe that an important reason to begin with lies in the institutional functions of elections as a designation mode for rulers. Historically, as Manin has shown (Manin, 1997, p. 83-90), it is largely due to their ability to embody the ideal of the "consent of the governed" that elections were established across Europe (and notably, favored over sortition). No later than with Locke's Second Treatise of Government was the close connection between them emblematically posited ${ }^{7}$. There is, arguably, a strong case for the belief that citizens will be more contented with their political condition if they get to choose their rulers, sanction them and even "fire" them in case their governance is deemed unsatisfactory. Conversely, this mechanism provides a strong incentive for representatives to govern responsively to citizens' preferences and needs if they want to stay in office, which is supposed to increase consent $t^{8}$. Thus, if elections were introduced to favor consent, it is worth examining what their outcome can tell us about it. First, regarding vote choice, election results seem to provide some information regarding whom citizens wish to see in power. Winners have obtained many votes, as well as more votes compared to other candidates. As such, it is possible (albeit uncertain) that winners might enjoy many citizens' approval. When this is the case, these citizens might consent to these individuals' power. Second, regarding turnout, the act of voting itself may signal a positive perception of the procedure, regardless of who receives citizens' votes. Again, when this is the case, these voters might consent to the winners' rule.

What speaks in favor of the latter hypotheses is that we know, from the empirical literature, that certain citizens locate the very meaning of the act of voting in its expressive dimension: of one's preferences for certain candidates, and/or certain policies, or one's care for the community's political decisions and institutions,

\footnotetext{
${ }^{7}$ In Locke's view (Locke, 2013), the legislative power should be composed of elected representatives (except in a direct democracy) to ensure citizens' consent to their laws, which constitutes a necessary condition for these laws' binding force (Second Treatise, \$134). When the legislators, or the government subordinated to them, fail to rule up to the task entrusted to them by the people (i.e., their society's preservation and common good), the people is free and well-advised to appoint new ones, see $\$ 212-223$.

${ }^{8}$ As Hampton puts it, voting can be seen as a "controlled revolutionary activity": Protest and opposition can be expressed and thus contained within the system itself, instead of turning into resistance to it (Hampton, 1993 p. 390, 391). In a similar vein, Luhmann considers elections as a channel for the expression of dissatisfaction, and therefore a suitable mechanism for the "absorption of protest" (Luhmann, 1983, p. 171). See also Przeworski (2018, p. 16), "We consent to being coerced-we could not live together peacefully unless we are coerced-because we can decide who should exercise coercion and how. People are free because they can choose their rulers," and Achen and Bartels (2016, p. 1): "In the conventional view, [d]emocracy makes the people the rulers, and legitimacy derives from their consent."
} 
among many possible motivations (Winkler, 1993; Jones and Hudson, 2003; Rogers et al., 2013) ${ }^{9}$. Such cases of "expressive voting" are often considered to provide one explanation (if not the only one) for the fact that many people make the effort to vote in spite of the very low likelihood for one single vote to break a tie, in reference to the famous "paradox of voting," an offspring of rational choice theory (Dowding, 2005; Geys, 2006; Aytaç and Stokes, 2019) ${ }^{10}$. This confirms that there are indeed attitudes and intentions of interest for our question at stake. However, it should be specified from the outset that election results can only be considered as a valid source of information when competition is fair for all potential candidates, the procedure is clean, and public information on the results is accurate $^{11}$. Fraud and misinformation make election results inapt to reveal anything on consent from the outset, which points to an important qualification to any connection between consent and election results.

The following analysis begins with the dimension of consent to representatives' rule, as the people being in power, and then moves to consent to the validity of elections as a procedure, which also touches upon the question of consent to one's belonging to a political community. In practice, these three dimensions may be combined in a single citizen's view. This may hold particularly in a context where representatives and institutions enjoy a high, enduring rate of consent. Nevertheless, as we will see, they point to distinct objects of consent and aspects of political legitimacy that are not always simultaneously given. The three dimensions have close affinities with Easton's notion, familiar to political scientists, of support for one's incumbents, institutions and national community (Easton, 1965, 1975; Norris, 2011), that may be useful to describe the intensity of consent (see below).

\section{CONSENT TO REPRESENTATIVES' RULE}

Let us start with the question of whether voting for someone implies consenting to that person's rule.

At first sight, voting for a candidate or a party seems to be congruent with an adhesion to that candidate's or party's ideals and goals in general, and/or to more specific policy proposals on that campaign. The best scenario is that of a re-election

\footnotetext{
${ }^{9}$ Fieldhouse warns us that it proves difficult to measure the various motives separately underlying a vote (Fieldhouse, 2018, p. 3): "Whilst the theoretical basis for expressive voting is well established, demonstrating it empirically is more difficult. The crucial problem is differentiating expressive motives from instrumental motives when, more often than not, they coincide. For example, people who have a strong preference for a set of policies are also likely to identify with a party advocating those polices."

${ }^{10}$ As Rogers, Fox and Gerber put it (Rogers et al., 2013, p. 91): "In a typical state or national election, a person faces a higher probability of being struck by a car on the way to his or her polling location than of casting the deciding vote. Clearly, traditional models cannot fully explain why and under which conditions citizens tend to vote."

${ }^{11}$ See Przeworski (2018, p. 45): "the belief that elections express active consent of free individuals obviously depends on whether people have a real chance to choose governments, most importantly, whether they are able to remove the incumbent rulers by the act of voting." See also Dahl (1971, p. 3) on what constitutes fair elections.
}

with such a mindset, as the voter is in a good position to judge the previous performance of the candidate(s). Likewise, on the aggregate level, stability over time of the parties in power may suggest a certain satisfaction with the status quo, provided new parties or candidates really stand a chance of entering the game. In some of these cases, voting for someone may even have an expressive function. For instance, so Franklin et al. (2004, p. 42) and Guerrero (2010, p. 274), elections are not only about who wins, but also about the winners' score. Communicating this support may be sensible, considering that the more votes a candidate (or party) has received, the more credibility he (it) will obtain. According to Huddy et al. (2015, p. 3), voting may also mean affirming one's social identity, as well as one's "emotional attachment" to a party and the people it represents ${ }^{12}$. This may well go along with the wish to "protect and advance group status," by contributing to the group's electoral victory (id.). In such cases, it seems plausible to infer this person's consent to being represented by the candidate or party of her choice from her vote. However, importantly for our concern, by far not every vote for a certain candidate or party fits this "ideal" description. Let us consider a few tricky situations for consent's interpretation to see what this means.

There are, to begin, cases in which a citizen votes for a candidate or party that they do not see as the best overall option. At times, the chosen option remains one they adhere to, as in certain cases of "strategic voting": A voter does not vote for their favorite party (or candidate) because it is unlikely to win seats, but the voter opts instead for a larger party (or a more popular candidate) that they prefer among the perceived relevant options (Blais and Degan, 2019). Yet a more problematic case is that of the citizen who votes not so much for a candidate or party as against another candidate or party (Medeiros and Noël, 2014; Caruana et al., 2015). Thus, according to Caruana et al. (2015, p. 775), negative partisanship "may motivate individuals to engage in behaviors that disadvantage their disliked party, regardless of the benefits expected for a preferred party (if they have one)." As a recent example, in the election of the French president Emmanuel Macron in 2017, many French citizens claimed to have voted against his adversary Marine Le Pen (and her party the Front National) rather than for him (and his En Marche!), in spite of doubts, sometimes strong ones, as to his suitability for the office ${ }^{13}$. Clearly, picking the lesser evil is far from enthusiastic support.

In this vein, another interesting type of example is that of the "protest vote." As Alvarez et al. (2018) have shown, there are several different types of protest votes, but the general idea is that a voter may cast a protest vote for a controversial party (or

\footnotetext{
${ }^{12}$ See also Fieldhouse (2018) and Hamlin and Jennings (2019, pp. 337-339) on voting as the expression of identity.

${ }^{13}$ For testimonies, see in the media e.g., Annabel Benhaiem, "Ils veulent rappeler à Emmanuel Macron qu'ils ont voté contre Marine Le Pen et non pas pour lui," Huffpost, 08.05.2017 (retrieved December 18, 2018 https://www.huffingtonpost. $\mathrm{fr} / 2017 / 05 / 08 /$ ils-veulent-rappeler-a-emmanuel-macron-quils-ont-vote-contrema_a_22075163/) or Olivier Bénis, "Présidentielle: un vote contre (le FN) face à un vote contre (le système)," franceinter, 07.05.2018 (retrieved December 18, 2018, https://www.franceinter.fr/politicalitique/presidentielle- un-vote-contre-lefn-face-a-un-vote-contre-le-systeme).
} 
candidate) to signal their discontent with other, more established parties (or candidates) ${ }^{14}$. In certain cases, this motive converges with an adhesion to the chosen party's position on issues considered to be important by the voter (Passarelli and Tuorto, $2018)^{15}$. Yet, in other cases, quite interestingly for our concerns here, a protest vote stems from the wish to send "a targeted signal of disaffection to one's most-preferred political party" (Kselman and Niou, 2011, p. 396). This does not necessarily entail a genuine endorsement of the chosen party's position, but is, first and foremost, intended to incite one's usual party to revise their positions on certain issues. (There are also protest votes aiming to communicate a general dissatisfaction with the dynamics of the current electoral system. I will return to these cases below).

Next, another example questioning the equation of a vote for someone with consent to her being in office is what, exactly, it means to consent to this candidate's rule. Selecting a candidate (or party) does not mean approving of all of her previous actions, nor of all of her agenda and intentions for her future mandate. If small divergences are frequent, a more dramatic example illustrates this point even more effectively. Jair Bolsonaro's election to the Brazilian presidency in 2018 fueled much controversy due to numerous problematic statements on his part, such as homophobic insults and allusions to the appeal of brute violence. This fed a widespread worry that voting for him implied consciously endorsing grave disrespect for human rights. Yet many Brazilians claimed to have voted for him out of a hope for more safety for the country, and in spite of other of his positions that they in fact condemned (whether this is a normatively coherent stance is a distinct question $)^{16}$. Hence, supporting a candidate (party) need not entail adhesion to all the aspects of her (its) rule, and may come with quite diametric judgments on her quality. This again evokes various possible degrees of consent.

These examples raise the question of how much support is necessary to speak of consent at all. My answer is that this cannot be determined without consulting the voter on the meaning he attributes to his vote, and his expectations. Indeed, as argued above, what constitutes political consent is determined by the individual's own perspective. Setting an independent threshold for what counts as consent or not only drives us away from it. What these scenarios suggest, however, is that political consent may come with various degrees of support, ranging from resignation to adhesion.

\footnotetext{
${ }^{14}$ See Kselman and Niou (2011, p. 414) for a noteworthy similarity between strategic voting and protest voting: "While strategic voters abandon their mostpreferred party in order to affect the current election's outcome, protest voters do so for the sake of downstream quality improvements."

15 "Political protest matters in voting behavior, but the groundbreaking result in the case of the M5S (the Five Star Movement in Italy) is that dissatisfaction with the system and/or elite performance has a stronger effect when coupled with ideological or issue preferences" (Passarelli and Tuorto, 2018, p. 10).

${ }^{16}$ In the media, see e.g., Diogo Rodriguez, "Why people vote for Jair Bolsonaro," Brazilian Report, 28.08.2018 (retrieved December 12, 2018, https://brazilian. report/power/2018/08/28/esther-solano-jair-bolsonaro/) or Chantal Rayes, "La peur et la corruption, piliers du succès de Bolsonaro," Le Temps, 26.10.2018 (retrieved December 12, 2018, https://www.letemps.ch/monde/peur-corruptionpiliers-succes-bolsonaro).
}

The possibility of accepting rulers one does not like is part of the very basic features of representative institutions, insofar as such actions flow from a more encompassing consent to the procedure of elections. If available, consent to the procedure can facilitate overall consent, even for citizens who voted for a candidate or party that did not win the election. In a proportional mechanism, this can also account for overall consent, in spite of the fact that many representatives were elected by other citizens than one's self ${ }^{17}$. This brings us to the question of whether casting a vote may be a potential sign of consent to elections as a collective decision-making mode qualified to confer legitimacy. What does an individual's participation, and on the aggregate level, turnout, reveal about consent?

\section{CONSENT TO ELECTIONS AS A PROCEDURE}

In what follows, I aim to show why, even if there may be good reasons in the abstract to consent to the outcome of an election one has participated in, this nonetheless depends again on the citizens' own perception of it, and on the context of the election. It seems quite intuitive that one's participation may proceed from one's faith in the legitimating function of the procedure, and go hand-in-hand with an inclination to accept the elected candidates' rule ${ }^{18}$. This raises the question of whether citizens "show consent by voting" (Brennan, in Brennan and Hill, 2014, p. 26). For instance, according to Miles (2015, p. 366), voting may provide a "means for the public to express their consent to be governed", as a positive assessment of a general "procedural fairness" characterizing authorities' governance ${ }^{19}$.

To begin, a good case in point is the citizen who votes out of civic duty-for instance, out of the conviction that one must do one's share in the collective decision-making efforts, or that one's right to vote is to be cherished, or that democratic institutions require high rates of participation to have their valuable effects, or even to subsist (Jones and Hudson, 2003; Blais and Galais, $2016)^{20}$. It seems likely that those who see moral worth in the procedure are, in principle, willing to accept its outcome for this very reason.

Moral motives aside, is there a more general "conceptual connection between voting and consenting," as Singer would have it (Singer, 1994, p. 50)? According to this argument, voting means accepting the results even if one did not vote for the winners: either because one acknowledges the legitimacy of the

\footnotetext{
${ }^{17}$ In fact, both Anderson et al. (2005, p. 139, 140) and Martini and Quaranta (2019, p. 357) find "losers" to be more satisfied with the rules of the game in proportional systems than in majoritarian ones. More on "loser's consent" below.

${ }^{18}$ For a theory of procedures as a decisive source of legitimacy, see Luhmann (1983).

${ }^{19}$ See also p. 373: "For some, voting is tacit political system endorsement-an act which signifies consent to be governed. When these people feel valued by their system of government, they are more likely to vote. For these individuals, voting is not motivated by a desire to influence the outcomes of elections, nor by a sense of civic duty; rather, voting expresses validation of the system."

${ }^{20}$ Note that asking a citizen whether she considers voting to be a civic duty may induce a social desirability bias toward a positive answer, which makes it more complex to track her actual motives (Fieldhouse, 2018, p. 5).
} 
procedure, or out of respect for the other citizens' judgments and preferences.

What first speaks in favor of the argument is that it is, indeed, one of the characteristics of consent to be compatible with very diverse feelings. One may agree to something without enthusiasm, without liking the consented option, or without holding it for the best on $\mathrm{e}^{21}$. Thus, if one values one's institutions and/or one's fellow citizens' choice, one may accept the results as legitimate even if one finds them disappointing, or even infuriating. This possibility is confirmed by the literature on "losers' consent," i.e., those whose favorite candidates do not make it to the seat of power, or at least not to a dominant position. In their cross-national study, Anderson et al. (2005) find that losers tend to be less supportive of their authorities than winners, yet not up to the point of losing faith in the system. At least, this seems to hold as long as they believe they have a chance of winning next time ${ }^{22}$. To further highlight the compatibility of consent to procedure and low satisfaction with its results, let us mention Dompnier and Berton's observation that opponents of the French prime minister's party tend to be "more critical of the democratic rules, but only when applied to the French case and without rejecting them" (Dompnier and Berton, 2012, p. 341). This evidences that attitudes toward a system's core values and principles must be distinguished from attitudes toward their implementation in a specific context, which points to further subtleties regarding consent's object. In a similar vein, one may be discontented with the options available in one particular election without questioning the legitimacy of the procedure overall. Thus, Balme et al. speak of a widespread paradox "opposing the sacralisation of elections with a criticism of elected representatives" (my translation, Balme et al., 2003, p. 447).” This occurs when one values the opportunity to vote as a civic right in the abstract but is dissatisfied with the "constrained" options available in a particular election ${ }^{23}$. In sum, all of this pleads for

\footnotetext{
${ }^{21}$ On this point, see Wertheimer $(2000$, p. 569), Owens (2011, p. 412, 413) and Schnüringer (2018, p. 22) on consent in interpersonal ethics.

${ }^{22}$ One of the study's overall conclusions is that losers are "almost uniformly less positive in their evaluations than winners," but nonetheless, that "more losers are satisfied with the functioning of democracy than dissatisfied" (Anderson et al., 2005, p. 159). Their indicators are the following: respondents' overall satisfaction with democracy, belief in the fairness of the last elections, and assessment of the responsiveness of parties to the population's concerns. For the similar conclusion that losing entails lower support for the system, see also Rich and Treece (2018) on Germany, but for more positive results on losers' support of democracy, see Esaiasson (2011), according to whom it is more accurate to conclude that winners usually "become more supportive," while losers "retain their level of support from before the election" (p. 103). We also know from this literature that how deeply losing affects one's attitudes toward the system is influenced by various contextual factors. For instance, still according to Anderson et al. (2005, p. 108, 109), losing is more tolerated in established democracies than in more recent ones (in their study, former communist countries in Europe). Martini and Quaranta also observe that incumbents' positive performance also impacts positively upon positive losers' attitudes (Martini and Quaranta, 2019). As another factor, both Anderson et al. (2005, p. 139, 140) and Martini and Quaranta (2019, p. 357) find losers to be more satisfied with the rules of the game in proportional systems than in majoritarian ones.

23 "L'adhésion au vote s'accompagne d'une insatisfaction profonde et largement partagée quant à son exercice pratique. Le choix électoral est jugé ardu et l'information défaillante, car il est difficile de connaître l'ensemble de l'offre électorale. Au-delà de la difficulté technique et politique à s'orienter parmi les
}

a distinction between consent and approval (or support): While approval of the incumbents seems likely to produce consent to their power, it is no necessary condition for it. Hence, consent to the procedure can be available in spite of low support for the elected candidates.

A second way to make the case for an inference from citizens' electoral participation to their consent to the procedure is to appeal to the point of an act of vote. According to Singer (1994, p. 50), it is "reasonable to assume" that voters consent to the procedure (at least in general), because otherwise it would be pointless to vote: "What would be the sense of having a vote if no one ever accepted the result of the vote?" To my mind, the first problem with this argument is its reliance on a presumption of the voter's coherence, in addition to a statement on what coherence entails (such as "voting is only intelligible if one is ready to accept the results"). As argued above, this position tends to set aside citizens' actual attitudes, while it is precisely their own perspective that matters to consent. As a second objection, the argument loses of its appeal in conflictual contexts (even in a fair election without fraud). This can happen when the election exacerbates important divisions within the political community, or if the winners are deemed profoundly dangerous by some of the voters. If one considers their rule to be very detrimental to the common good, one may cast doubt on the value of elections at all, which erodes consent to the procedure. One may come to question the very principle of elections, or alternately, a more specific aspect of one particular system. As to the latter, one example consists of rejections of the American electoral college system, after an elected president wins, thanks to the majority of state electors, in spite of having obtained fewer individual votes than his rival ${ }^{24}$.

These scenarios raise the question of whether it is possible to vote without even considering the procedure as legitimate from the outset. I believe this can be the case when one sees that particular election as illegitimate (while recognizing the value of elections in principle), due to the presence of a contestant that should not even be considered as a potential ruler, in one's view. This typically applies to individuals who hold that a legitimate ruler must fulfill some substantive conditions, in addition to procedural ones, such as a genuine commitment to the respect of human rights or a lack of corruption. For them, it may be sensible to cast a vote in spite of their potential dissent, merely in the hope of some causal influence, at least in the expressive function of the vote. We may also invoke Aytaç's and Stokes's "theory of costly abstention" (Aytaç and Stokes, 2019, p. 28): When a person really cares about the outcome of an election, the idea of abstaining can make her feel internal "dissonance" and "disutility" for not

programmes, le personnel politique est tenu en suspicion: 'On vote pour quelqu'un mais on sait pas ce qu'il y a derrière'. Les groupes expriment également un hiatus entre l'offre électorale et leurs attentes, ils ont le sentiment de faire des choix contraints: 'Si je trouve par exemple que toutes les têtes de liste proposées ne sont pas en adéquation avec ce que moi je voudrais, je peux pas voter non plus pour mon voisin. [... ] J'ai pas le choix, c'est ces gens-lä' (Balme et al., 2003, p. 445).”

${ }^{24}$ See e.g., Andrew Prokop, "Why the Electoral College is the absolute worst, explained," in Vox, 19.12.2016 (October 25, 2019), https://www.vox.com/policyand-politics/2016/11/7/12315574/electoral-college-explained-presidentialelections-2016. 
participating, in spite of her awareness of the little impact of her vote (Aytaç and Stokes, 2019, p. 56). Yet in any case, the answer to this question can only be given by the voter himself, for the same reason as above: it is the citizen's own vision that counts for consent, which cannot be replaced by speculation on the sensibleness of his motives. What these cases reveal, however, is that consent cannot simply be inferred from participation.

\section{CONSENT TO MEMBERSHIP IN A COMMUNITY}

It emerges from these examples that another object of consent must be examined, namely one's relationship to one's fellow citizens. To what extent does the act of voting manifest consent to membership in one's political community?

Let us start with cases supporting such a hypothesis. According to Winkler (1993, p. 331), voting is sometimes understood as "a meaningful participatory act through which individuals create and affirm their membership in the community" and their "sense of attachment" to it. Thus, voting may be an occasion to concretize one's feeling of belonging to one's political community. Identification with one's community may also be correlated with the view that voting constitutes a civic duty (Blais and Galais, 2016, p. 61). As we have seen above, this sense of duty can be positively linked to one's acceptance of the results. Indeed, when the communitarian incentive to vote favors an inclination to accept elections results (if not approve of them), this brings us back to consent to elections as a valid procedure, but seen from a different angle. This time, valuing the procedure may be due to a certain deference for one's fellow citizens' voices, and a willingness to let the majority's preferences and decisions win.

These cases confirm that a sense of citizenship may provide an incentive to vote, but do not suffice to establish a causal connection between consent to membership in one's community and voting. However, what they illustrate is how the three main dimensions of consent (to rulers, procedure, community) can be closely interrelated. One's feeling of belonging to a community may be a source of consent to elections as a relevant decisionmaking procedure, and hence to the winners' rule. Note that this does not mean that consent to membership in the community is a necessary condition for consent to procedure. Less engaged citizens may consent to the procedure for practical benefits of coordination, among an aggregate of individuals that they feel no particular moral or affective ties with, while accepting their share of influence.

However, other cases exemplify how these three objects of consent (to rulers, procedure, community) can also come apart. Some protest votes are not only addressed as a warning to a certain party, but more broadly as an "expression of dissatisfaction with mainstream parties and/or mainstream politicians," and "with politicians as a class and political institutions more generally" (Birch and Dennison, 2019, p. $111,112)$, or in other words, with a perceived political “establishment” (Gabriel, 2017, p. 288) ${ }^{25}$. This may go hand in

25 "Für viele Wähler scheint das Votum für eine Protestpartei Ausdruck einer hand with an identification with "the people" on the other, who would be poorly represented by a "corrupt elite" comprising representatives, but also more generally the powerful (Mudde, 2007, p. 23, 65, 66; Gabriel, 2017, p. 294). In such cases, consent to membership in the community seems to be available without consent to its current authorities, a tension that finds its expression in the protest vote. This may still be compatible with consent to elections as a procedure, unless this situation is attributed to representative institutions themselves, which points to another gray area. Overall, what we can conclude is that consent to membership in the community can be available both with or without consent to elected candidates' rule. Hence, it does not qualify as an obvious source of consent to representatives' power.

\section{ABSTENTION, CONSENT, AND LACK OF CONSENT}

Now that we have seen a variety of nuances related to the relationships between voting and consenting, it remains to address those that exist between abstention and consent. Abstention is, in fact, quite paradigmatic of the problems pertaining to the interpretation of consent. It proceeds from very diverse motives that may just as well point to consent or a lack of it, as well as various shades in between. Like participation, abstention is influenced by various individual factors (such as age or level of education, for instance), but also, and more interestingly for our concern, by political ones (Braconnier and Dormagen, 2007; Dris-Ait Hamadouche, 2009; Dupuis-Déri, 2020, p. 109-112). As Hill observes (Hill, 2002, p. 85, 86), even though abstention is sometimes interpreted as some form of "tacit consent," 26 the plurality of factors conditioning abstention makes it difficult to deduce anything from it at first sight:

Silence is at best ambiguous. It can mean many things. It may mean: I'm homeless and find it difficult to register'; I'm experiencing an economic crisis and am too demoralized to vote'; I'm ill'; I'm isolated'; I'm a new migrant'; "I have literacy and numeracy problems"; I'm immobile'; I'm a young voter alienated from the political system'; "I have low feelings of either internal or external political efficacy (or both)" or even I'm perfectly satisfied with things as they are'. But it is difficult, if not impossible, to

Entwicklung und Misstrauen gegen die gesellschaftlichen und politischen Führungsgruppen zu sein. Wie Oskar Niedermayer in einer kürzlich gemeinsam mit Jürgen Hofrichter publizierten Analyse der Wahlerfolge der AfD aufzeigte, entscheidet sich mancher deutsche Wähler weniger auf Grund seiner Zustimmung zu den inhaltlichen Angebote für diese Partei, sondern weil er 'von anderen Parteien enttäuscht ist und Ihnen einen Denkzettel verpassen will' (Niedermayer und Richter, 2016, S. 283;" Gabriel, 2017, p. 288).

26 "It is often suggested that abstention is tolerable (even desirable) because it is really a form of political expression connoting tacit consent to the regime. Those who conceive voting purely as a mechanism for registering dissatisfaction, regard the silence of the abstainer as an eloquent expression of contentment with the political system. Such claims are problematic because largely speculative and in some cases, counter-factual: in the USA, for example, the 1996 National Election Study found that non-voters tended to be twice as dissatisfied as voters about the state of democracy in America (Wattenberg, 1998, p. 3). We also know that abstainers tend to perceive government as unresponsive and that their vote will be ignored; accordingly, they abstain" (Hill, 2002, p. 85). See also Ragsdale (2017) on American nonvoters. 
perceive which of these categories is explaining the abstention of any particular person.

Regarding the connection between abstention and satisfaction, Bühlmann et al. (Bühlmann et al., 2003, in a study of Swiss elections to the National Council in 1999) observe it to hold for nonvoters with high rates of trust in rulers and institutions (approx. 10\% of non-voters), as well as for non-voters who consider themselves "incompetent" on political matters but are confident in others' judgments (4\%). This tendency thus makes it very easy to instrumentalize abstention in favor of the status quo. Yet abstention can just as well result from dissatisfaction, with various aspects at that. Thus, still in Bühlmann et al.'s study, non-voters uninterested in politics tend to be distrustful of current rulers, but generally satisfied with democracy (33\%). This sounds compatible with consent as the acceptance of one's political condition overall. However, a more problematic type of non-voter is not only suspicious of rulers' competence and good intentions, but also dissatisfied with democracy in general (7\%). As Kemmers observes (Kemmers, 2017, in a study on the Dutch 2012 parliamentary elections and "populism"), such distance from the system can take the specific form of a rejection of political parties and the way political power is organized around them. This provides a good ground for abstention: "it is not at all self-evident that an ideal-typical populist citizen could be persuaded to vote for any party, even one that claims to challenge the establishment," because even the latter would remain bound by "the rules of the game" (Kemmers, 2017, p. 383) ${ }^{27}$. Ryabchuk (2016, examining South African national elections in 2014), and Schultheis (2017, interviewing German long-term unemployed non-voters) also refer to feelings of low political efficacy that reveal a very negative perception of the ability of rulers and procedure to change anything, no matter whom one votes for. This invokes again the distinction between the available offer in a specific campaign and the general principles of elections. It is nonetheless difficult to determine without asking each of these persons whether they no longer consent at all to their political condition, or whether they still consent, albeit to a very low degree. Yet all these cases plainly illustrate that abstention can be explained by motives and attitudes that do not bode well for consent. Interestingly, abstention can sometimes even be intended as a "message to the world of politics" (Kemmers, 2017, p. 385) or as a "demonstrative political statement" (Schultheis, 2017 , p. 19, my translation). See this extract from one of Kemmers's interviews (Kemmers, 2017, p. 385):

\footnotetext{
${ }^{27}$ See also Hooghe et al. $(2013$, p. 249,250$)$ for a similar thesis, related to citizens' distrust in both officeholders and institutions: "First, a lack of political trust can lead to a decline in voter turnout. If the distrust remains limited to current office holders, this might serve as an incentive to vote as citizens will be motivated to replace current politicians with their challengers. In this way, voting opposition parties into power might in the long run lead to a renewal of trust in the political system among the population. However, if distrust extends to the basic rules of democracy itself, there is less reason to vote since citizens no longer assume that their vote will make a difference. Especially with regard to the electoral process itself, Alvarez et al. (2018) have demonstrated that citizens are less motivated to vote if they do not believe the electoral procedure will be administered in a fair manner. While it might be true that political distrust will be associated with various non-institutionalized forms of political participation, it is most likely to deter electoral participation.”
}

It's just not true that you're not taking your civic responsibility if you don't vote. Not voting is also an expression of I'm through with it, I don't want this any more.' This is not my government, not my representation. And that's also an expression, that's also a form of voting ${ }^{28}$.

When voting is compulsory, a similar option is the use of blank or (intentionally) null ballots: these have been reported to express discontent with the available options, and "the political status quo-although not with democracy” (Cohen, 2018, p. 412, in 14 Latin American countries; Katz and Levin, 2016, in Brazil).

Some of these examples suggest that one may refuse to vote precisely because one does not wish one's vote to be taken as consent (see also Miles, 2015, p. 363). This reveals a perceived connection between voting and consenting, as well as of its potential for manipulation, or at least misperception. Thus, with a view to the legitimating appearance of a vote, Hanna (2009) makes the case for a moral obligation not to vote under certain circumstances, and Dupuis-Déri (2020) for a systematic abstention. Yet, as Hanna (2009, p. 283) and Ryabchuk (2016, p. 46) note, along with Kemmers's interviewee above, some actors may consider it strategic to discredit non-voters' silence as an irresponsible neglect of one's civic duty (to vote). This again attests that abstention can not only mean, but also be said to mean, pretty much everything and its contrary.

\section{CONCLUSION}

Overall, the general conclusion on the relationship between consent and election participation and results is that interpreting their results (winners' score, turnout) in terms of consent requires much circumspection, in spite of their apparent connection, and even when procedures are strictly respected. The combination of theoretical perspectives on consent and empirical findings on electoral behavior has shown why inferring consent simply from citizens' votes is not warranted. It is also wrong to assume, by default, that voters intend their vote to express consent, even though this can sometimes be the case. Rather, it is only by asking voters about the meaning of their votes that we can hope for certainty. This is all the more important, given that it is the citizens' own individual perspectives that count for consent and its legitimating effects. Therefore, it cannot be replaced by speculation on the sensibleness of their motives, or what they consider to be important.

In other words, little can be known about consent by simply looking at an election's results (winners, turnout). The vast amount of work required for a solid empirical case study on an election only confirms this (not to mention the fact that its findings are published quite a while after the election and are difficult to assess without the relevant research training). In a context of increasing citizen dissatisfaction with existing representative institutions, it seems timely to recall this uncertainty. The many examples discussed in the course of the analysis confirm that complex cases are not only interesting in theory, but also frequent in practice. Among the various

\footnotetext{
${ }^{28}$ Many more testimonies of abstention for political reasons can be found in Dupuis-Déri (2020).
} 
subtleties to take into account, I have highlighted the following. First, regarding the various objects of consent: Consent to elected representatives' rule (as these particular persons' rule), to elections as a procedure, and consent to membership in the community may be jointly available, but need not be. Second, political consent comes in degrees, ranging from resigned consent to convinced support, and including everything inbetween. Third, voting is compatible with a very low degree of consent, or even dissent. This is notably the case when a citizen is opposed to the available options, or with some of a chosen candidate's or party's positions, and sometimes also even to the procedure.

Before concluding with the meaning of these findings for relations between citizens and their representative institutions, allow me to point out possible implications for debates around the comeback of sortition as a designation mode for rulers (Landemore, 2013; Vandamme and Verret-Hamelin, 2017; Courant, 2019; Bedock and Pilet, 2020), although this is not the primary purpose of this paper. What emerges from this discussion is the potential to deactivate one objection against sortition: the objection that elections are necessary for legitimacy because they are the way citizens can express their consent to their rulers' power, and hence give them authority. We have seen that voting does not entail consent (nor does abstention), and is by far not unanimously considered to perform this function ${ }^{29}$. In addition, we have seen that consenting to an option does not mean regarding it as the best one, nor as the only one. This means that consent to elections as procedures does not, by itself, preclude potential consent to other procedures that may even be preferred, such as sortition. Nor is the conception of consent used in this paper incompatible with sortition. Arguably, if consenting means mentally accepting one's political condition (one's authorities and fellow citizens' power over oneself), there is no element here that rules out the replacement or combination of elections with sortition for such acceptance to be secured. These remain theoretical points at this stage, but they may be of some interest to continue the debate. This being said, I believe that a more decisive question to settle, if we acknowledge the importance of political consent for legitimacy, is an empirical one: namely, which of the two systems would obtain higher rates of consent. It remains, indeed, to address the classical assumption that being able to participate in the choosing of one's rulers, even to a limited extent, tends to increase consent to their power. There are, of course, other reasons, not directly related to consent, to ponder if we were to choose between elections and sortition, such as the ability of elections to give all citizens an equal share in the community's power (at least in terms of the possibility of controlling who should represent them), or the possibility for electoral competition to select rulers that had to acquire a significant knowledge of the political system and the issues to be addressed within it (in order to be elected). With these

\footnotetext{
${ }^{29}$ What is, however, well perceived is the potential for the instrumentalization of election results. One benefit of dispensing with elections may rest in shutting down this possibility, although this depends upon how severe the risk is estimated to be.
}

remarks, I am only considering the sort of arguments that may be advanced in reference to consent and the acceptance of the state's power.

To conclude, these final remarks are neither intended as a contestation of the legal weight of election results, nor of the authority of the winners to make decisions on behalf of the community. Nevertheless, as argued in the introduction, our need for legal procedures to designate rulers does not suffice to capture the many facets of citizens' experiences of and views on politics, as these follow their own logic. Due to this gap, representative institutions carry with them certain inherent risks of misinterpretation and opportunism: notably, including the risk of political actors availing themselves of the population's consent to their rule, as well as to some of their specific intentions and decisions; or the risk of conflating support, unenthusiastic consent, and the mere desire for some causal influence; or the risk of distorting some citizens' perspectives by selecting arbitrary criteria for the interpretation of election results. Hopefully, the present analysis provides reasons to avoid speaking in the name of citizens without properly consulting them, and keep in mind the distinctiveness of each citizen's point of view. In sum, we have more than enough reason to remain critical about what election results can tell us about citizens' consent.

\section{DATA AVAILABILITY STATEMENT}

The original contributions presented in the study are included in the article/supplementary material, further inquiries can be directed to the corresponding author/s.

\section{AUTHOR CONTRIBUTIONS}

The author confirms being the sole contributor of this work and has approved it for publication.

\section{FUNDING}

This article was written while I was working as a research and teaching assistant at the University of Lausanne, at the Faculty of Law, Criminal Justice and Public Administration.

\section{ACKNOWLEDGMENTS}

For insightful comments on earlier versions of this article and stimulating discussions about its topic, I would like to thank the three reviewers of this article, Pierre-Étienne Vandamme, Camille Bedock, Sandrine Baume, Clémence Demay, HenriPierre Mottironi, Simon Stückelberger, Hannah Werner, Ramon van der Does, as well as audiences in Bordeaux (2019), Lucerne (2019), and Geneva (2020). 


\section{REFERENCES}

Abizadeh, A. (2020). Representation, bicameralism, political equality, and sortition: reconstituting the second chamber as a randomly selected assembly. Perspect. Politics 1-16. doi: 10.1017/S1537592719004626 Available online at: https://www.cambridge.org/core/journals/perspectives-on-politics/ article/representation-bicameralism-political-equality-and-sortitionreconstituting-the-second-chamber-as-a-randomly-selected-assembly/ 4DC09D5CFA379C756E5F7E67C24A00B8

Achen, C., and Bartels, L. (2016). Democracy for Realists: Why Elections Do Not Produce Responsive Government. Princeton: Princeton University Press. doi: $10.1515 / 9781400882731$

Alvarez, R. M., Kiewiet, D. R., and Núñez, L. (2018). A taxonomy of protest voting. Ann. Rev. Political Sci. 21, 135-154. doi: 10.1146/annurev-polisci-050517-120425

Anderson, C. J., Blais, A., Bowler, S., Donovan, T., and Listhaug, O. (2005). Losers' Consent: Elections and Democratic Legitimacy. Oxford: Oxford University Press. doi: 10.1093/0199276382.001.0001

Aytaç, S. E., and Stokes, S. C. (2019). Why Bother? Rethinking Participation in Elections and Protests. Cambridge, MA: Cambridge University Press. doi: $10.1017 / 9781108690416$

Balme, R., Marie, J.-L., and Rozenberg, O. (2003). Les motifs de la confiance (et de la défiance) politique: intérêt, connaissance et conviction dans les formes du raisonnement politique. Rev. Intern. Politique Comp. 10, 433-461. doi: $10.3917 /$ ripc. 103.0433

Bedock, C., and Pilet, J. (2020). Who supports citizens selected by lot to be the main policymakers? A study of french citizens. Govern. Oppos. 1-20. doi: 10.1017/gov.2020.1 Available online at: https://www.cambridge.org/ core/journals/government-and-opposition/article/who-supports-citizensselected-by-lot-to-be-the-main-policymakers-a-study-of-french-citizens/ 4F2BAF2C2371977E6CCC2F6689AC2B1F

Beetham, D. (1991). The Legitimation of Power. London: Macmillan. doi: 10.1007/978-1-349-21599-7

Bélanger, R., and Meguid, B. (2008). Issue salience, issue ownership, and issuebased vote choice. Elect. Stud. 27, 477-491. doi: 10.1016/j.electstud.2008.01.001

Birch, S., and Dennison, J. (2019). How protest voters choose. Party Politics 25, 110-125. doi: 10.1177/1354068817698857

Blais, A. (2000). To Vote or Not to Vote. The Merits and Limits of Rational Choice Theory. Pittsburgh: University of Pittsburgh Press. doi: 10.2307/j.ctt5hjrrf

Blais, A., and Daoust, J.-F. (2020). The Motivation to Vote. Explaining Electoral Participation. Vancouver: University of British Columbia Press.

Blais, A., and Degan, A. (2019). "The study of strategic voting," in The Oxford Handbook of Public Choice, Vol. 1, eds R. D. Congleton, B. Grofman, and S. Voigt (Oxford: Oxford University Press), 292-309. doi: 10.1093/oxfordhb/9780190469733.013.14

Blais, A., and Galais, C. (2016). Measuring the civic duty to vote: a proposal. Elect. Stud. 41, 60-69. doi: 10.1016/j.electstud.2015.11.003

Braconnier, C., and Dormagen, J.-Y. (2007). La Démocratie de l'Abstention: aux Origines de la Démobilisation Électorale en Milieu Populaire. Paris: Gallimard.

Brady, H., Verba, S., and Schlozman, K. (1995). Beyond SES: A resource model of political participation. Am. Political Sci. Rev. 89, 271-294. doi: 10.2307/2082425

Brennan, J., and Hill, L. (2014). Compulsory Voting: For and Against. Cambridge: Cambridge University Press. doi: 10.1017/СBO9781139649742

Bühlmann, M., Freitag, M., and Vatter, A. (2003). "Die Schweigende Mehrheit: Eine Typologie Der Schweizer Nichtwählerschaft," in Schweizer Wahlen 1999. Elections fédérales 1999, eds P. Sciarini, S. Hardmeier, and A. Vatter (Bern: Paul Haupt), 27-58.

Caruana, N., McGregor, R., and Stephenson, L. (2015). The power of the dark side: negative partisanship and political behaviour in Canada. Canad. J. Political Sci. 48, 771-789. doi: 10.1017/S0008423914000882

Cohen, M. J. (2018). Protesting via the null ballot: an assessment of the decision to cast an invalid vote in latin America. Polit. Behav. 40, 395-414. doi: 10.1007/s11109-017-9405-9

Courant, D. (2019). "Sortition and democratic principles. a comparative analysis," in Legislature by Lot, Transformative Designs for Deliberative Governance, eds J. Gastil and E. Olin Wright. (London: Verso), 229-248.

Dahl, R. (1971). Polyarchy. Participation and Opposition. New Haven, London: Yale University Press.
Dompnier, N., and Berton, R. M. (2012). How durably do people accept democracy? Politicization, political attitudes and losers' consent in France. French Politics 10, 323-344. doi: 10.1057/fp.2012.20

Douglass, R. (2020). Hobbes and political realism. Eur. J. Political Theory 19, 250-269. doi: 10.1177/1474885116677481

Dowding, K. (2005). Is it rational to vote? Five types of answer and a suggestion. $\mathrm{Br}$. J. Politics Intern. Relations 7, 442-459. doi: 10.1111/j.1467-856X.2005.00188.x

Dris-Ait Hamadouche, L. (2009). L'abstention en Algérie: un autre mode de contestation politique. L'Année du Maghreb 263-273. doi: 10.4000/anneemaghreb.588

Dupuis-Déri, F. (2020). Nous Nirons Plus aux Urnes. Plaidoyer pour L'abstention. Montréal: Lux.

Easton, D. (1965). A Framework for Political Analysis. Englewood Cliffs: PrenticeHall.

Easton, D. (1975). A re-assessment of the concept of political support. Br. J. Polit. Sci 5, 435-457. doi: 10.1017/S0007123400008309

Enelow, J. M., and Hinich, M. J. (1984). The Spatial Theory of Voting: An Introduction. Cambridge: Cambridge University Press.

Esaiasson, P. (2011). Electoral losers revisited - How citizens react to defeat at the ballot box. Elect. Stud. 30, 102-113. doi: 10.1016/j.electstud.2010.09.009

Fieldhouse, E. (2018). Being a voter: developing a survey instrument for expressive voting. J. Elections Public Opin. Parties 29, 1-23. doi: 10.1080/17457289.2018.1530679

Franklin, M., Eijk, C., Evans, D., Fotos, M., Hirczy de Mino, W., Marsh, M., et al. (2004). Voter Turnout and the Dynamics of Electoral Competition in Established Democracies since 1945. Cambridge: Cambridge University Press. doi: 10.1017/CBO9780511616884

Gabriel, O. W. (2017). "Misstrauen und Protestwahl in europäischen Demokratien," in Parteien, Parteiensysteme und politische Orientierungen: Aktuelle Beiträge der Parteienforschung, ed C. Koschmieder (Wiesbaden: Springer), 287-306. doi: 10.1007/978-3-658-17922-9_14

Geys, B. (2006). 'Rational' theories of voter turnout: a review. Polit. Studies Rev. 4, 16-35. doi: 10.1111/j.1478-9299.2006.00034.x

Greene, A. (2016). "Consent and political legitimacy," in Oxford Studies in Political Philosophy, Vol. 2, eds D. Sobel, P. Vallentyne, and S. Wall (Oxford: Oxford University Press), 71-97. doi: 10.1093/acprof:oso/9780198759621.003.0004

Guerrero, A. (2010). The paradox of voting and the ethics of political representation. Philos. Public Affairs 38, 272-306. doi: $10.1111 / j .1088-4963.2010 .01188 . x$

Hamlin, A., and Jennings, C. (2019). "Expressive voting," in The Oxford Handbook of Public Choice, Vol. 1, eds B. G. Roger, D. Congleton, and S. Voigt (Oxford: Oxford University Press), 333-350. doi: 10.1093/oxfordhb/9780190469733.013.16

Hampton, J. (1993). "Contract and consent," in A Companion to Contemporary Political Philosophy, eds R. E. Goodin and P. Pettit (Cambridge, MA: Blackwell), 379-393.

Hanna, N. (2009). An Argument for Voting Abstention. Public Aff. Q 23, 275-286. doi: $10.2307 / 40441535$

Hill, L. (2002). On the reasonableness of compelling citizens to 'vote': the Australian case. Polit. Stud. 50, 80-101. doi: 10.1111/1467-9248.00360

Hooghe, L., and Marks, M. (2018). Cleavage theory meets Europe's crises: Lipset, Rokkan, and the transnational cleavage. J. Eur. Public Policy 25, 109-135. doi: 10.1080/13501763.2017.1310279

Hooghe, M., Marien, S., and Pauwels, T. (2013). Where do distrusting voters turn if there is no viable exit or voice option? The impact of political trust on electoral behaviour in the Belgian regional elections of june 2009. Govern. Oppos. 46, 245-273. doi: 10.1111/j.1477-7053.2010. 01338.x

Horton, J. (2012). Political legitimacy, justice and consent. Crit. Rev. Intern. Soc. Political Philos. 15, 129-148. doi: 10.1080/13698230.2012.651015

Huddy, L., Mason, L., and Aarøe, L. (2015). Expressive partisanship: campaign involvement, political emotion, and partisan identity. Am. Political Sci. Rev. 109, 1-17. doi: $10.1017 /$ S0003055414000604

Jones, P., and Hudson, J. (2003). Civic duty and expressive voting: is virtue its own reward? KYKLOS 53, 3-16. doi: 10.1111/1467-6435. 00106

Katz, G., and Levin, I. (2016). A general model of abstention under compulsory voting. Polit. Sci. Res. Methods 6, 489-508. doi: 10.1017/psrm.2016.49 
Kemmers, R. (2017). Channelling discontent? Non-voters, populist party voters, and their meaningful political agency. Eur. J. Cult. Polit. Sociol. 4, 381-406. doi: 10.1080/23254823.2017.1339203

Klosko, G. (2005). Political Obligations. Oxford: Oxford University Press. doi: 10.1093/0199256209.001.0001

Klosko, G. (2018). "Consent theory of political obligation," in The Routledge Handbook of the Ethics of Consent, eds A. Müller and P. Schaber (Oxon/New York: Routledge), 348-358. doi: 10.4324/9781351028264-31

Kriesi, H., Grande, E., Lachat, R., Dolezal, M., Bornschier, S., and Frey, T. (2008). West European Politics in the Age of Globalization. Cambridge, MA: Cambridge University Press. doi: 10.1017/CBO9780511 790720

Kselman, D., and Niou, E. (2011). Protest voting in plurality elections: a theory of voter signaling. Public Choice 148, 395-418. doi: 10.1007/s11127-0109661-2

Landemore, H. (2013). Deliberation, cognitive diversity, and democratic inclusiveness: an epistemic argument for the random selection of representatives. Synthese 190, 1209-1231. doi: 10.1007/s11229-012-0062-6

Lipset, S., and Rokkan,. S. (1967). Party Systems and Voter Alignments: CrossNational Perspectives. New York, NY: The Free Press.

Locke, J. (2013). Two Treatises of Government. ed P. Laslett. Cambridge: Cambridge University Press.

Luhmann, N. (1983). Legitimation durch Verfahren. Frankfurt am Main: Suhrkamp.

Manin, B. (1997). The Principles of Representative Government. Cambridge: Cambridge University Press. doi: 10.1017/CBO9780511659935

Martini, S., and Quaranta, M. (2019). Political support among winners and losers: Within- and between-country effects of structure, process and performance in Europe. Eur. J. Polit. Res. 58, 341-361.

Medeiros, M., and Noël, A. (2014). The forgotten side of partisanship: negative party identification in four Anglo-American democracies. Comp. Polit. Stud. 47, 1022-1046. doi: 10.1177/0010414013488560

Miles, M. R. (2015). Turnout as consent: how fair governance encourages voter participation. Polit. Res. Q 68, 363-376. doi: 10.1177/1065912915573282

Mudde, C. (2007). Populist Radical Right Parties in Europe. Cambridge: Cambridge University Press. doi: 10.1017/CBO9780511492037

Norris, P. (2011). Democratic Deficit. Critical Citizens Revisited. Cambridge: Cambridge University Press.

Owens, D. (2011). The possibility of consent. Ratio 24, 402-421. doi: 10.1111/j.1467-9329.2011.00509.x

Passarelli, G., and Tuorto, D. (2018). The five star movement: purely a matter of protest? The rise of a new party between political discontent and reasoned voting. Party Politics 24, 129-140. doi: 10.1177/1354068816642809

Pateman, C. (1979). The Problem of Political Obligation: A Critical Analysis of Liberal Theory. New York: John Wiley \& Sons. doi: 10.3817/0979041220

Przeworski, A. (2018). Why Bother With Elections? Cambridge: Polity Press.
Ragsdale, L. (2017). "Who are nonvoters?", in The American Nonvoter, eds L. Ragsdale and J. G. Rusk (Oxford: Oxford University Press), ch. 4. doi: 10.1093/acprof:oso/9780190670702.003.0005

Rich, T., and Treece, M. (2018). Losers' and Non-voters' Consent: Democratic satisfaction in the 2009 and 2013 elections in Germany. Govern. Opp. 53, 416-436. doi: 10.1017/gov.2016

Rogers, T., Fox, C. R., and Gerber, A. S. (2013). "Rethinking why people vote: voting as dynamic social expression," in The Behavioral Foundations of Policy, ed E. Shafir (Princeton: Princeton University Press), 91-107. doi: 10.1515/9781400845347-009

Ryabchuk, A. (2016). Voter abstention in South African 2014 elections: beyond the apathy argument. Transformation 92, 37-59. doi: 10.1353/trn.2016.0026

Schnüringer, H. (2018). "What is consent?," in The Routledge Handbook of the Ethics of Consent, eds P. Schaber and A. Müller (Oxon: Routledge), 21-31. doi: 10.4324/9781351028264-3

Schultheis, F. (2017). "Keine Wahl: Wenn langzeitarbeitslose Mitbürger der Demokratie den Rücken kehren," in Gib mir was, was ich wählen kann" - Demokratie ohne Langzeitarbeitslose?: Motive langzeitarbeitsloser Nichtwähler/innen, ed D.F.f.M.a. Rande (Cologne: Herbert von Halem), 9-22.

Simmons, A. J. (1979). Moral Principles and Political Obligations. Princeton Princeton University Press. doi: 10.1515/9780691213248

Singer, P. (1994). Democracy and Disobedience. Suffolk: Gregg Revivals.

Steinberg, J. (1978). Locke, Rousseau, and the Idea of Consent: An Inquiry Into the Liberal-Democratic Theory of Political Obligation. Westport, Conn.: Greenwood Press.

Stockemer, D. (2017). What affects voter turnout? A review article/meta-analysis of aggregate research. Govern. Oppos. 52, 698-722. doi: 10.1017/gov.2016.30

Vandamme, P.-E., and Verret-Hamelin, A. (2017). A randomly selected chamber: promises and challenges. J. Public Deliberation 13:5. doi: 10.16997/jdd.271

Von Soest, C., and Grauvogel, J. (2017). Identity, procedures and performance: how authoritarian regimes legitimize their rule. Contemp. Politics 23, 287-305. doi: 10.1080/13569775.2017.1304319

Wertheimer, A. (2000). What is consent? and is it important? Buff. Crim. Law Rev. 3, 557-583. doi: 10.1525/nclr.2000.3.2.557

Winkler, A. (1993). Expressive voting. N. Y. U. Law Rev. 68, 330-388.

Conflict of Interest: The author declares that the research was conducted in the absence of any commercial or financial relationships that could be construed as a potential conflict of interest.

Copyright (C) 2020 Ramelet. This is an open-access article distributed under the terms of the Creative Commons Attribution License (CC BY). The use, distribution or reproduction in other forums is permitted, provided the original author $(s)$ and the copyright owner(s) are credited and that the original publication in this journal is cited, in accordance with accepted academic practice. No use, distribution or reproduction is permitted which does not comply with these terms. 


\section{OPEN ACCESS}

Edited by:

Jean-Benoit Pilet,

Université Libre de Bruxelles, Belgium

Reviewed by:

Scott Pruysers,

Dalhousie University, Canada

Toni Rodon

Pompeu Fabra University, Spain

*Correspondence:

Charlotte Dolez

charlotte.dolez@sciencespo-lyon.fr

Specialty section:

This article was submitted to

Elections and Representation,

a section of the journa

Frontiers in Political Science

Received: 25 July 2020 Accepted: 27 November 2020

Published: 05 January 2021

Citation:

Dolez C (2021) Political Support in

Times of Personalized Politics. A

Qualitative Inquiry of French Citizens'

Representations About Political Actors and the Political Regime.

Front. Polit. Sci. 2:587276.

doi: 10.3389/fpos.2020.587276
Political Support in Times of Personalized Politics. A Qualitative Inquiry of French Citizens' Representations About Political Actors and the Political Regime

\author{
Charlotte Dolez* \\ Triangle, Institut d'Etudes Politiques de Lyon, Lyon, France
}

This article investigates how citizens speak about representative democracy and questions their perceptions of representation and of the democratic regime they live in, by mobilizing the distinction between diffuse and specific support, in a context of personalized politics. It shows that political actors and their performances are at the core of citizens' perceptions. I investigate citizens' representations of the political field through an original qualitative fieldwork, composed of couple interviews with French citizens, under the Sarkozy presidency. Studies about the political support of citizens often mobilize quantitative surveys to measure the degree of support and satisfaction. I rather choose the qualitative approach to grasp perceptions of political field through discussions about political and societal issues. Couple interviews offer an adequate framework to observe political opinions that are built in daily life. Representations of the political field are mainly dominated by the role of political actors. Political parties and institutions are rarely mentioned. Politicians are systematically held accountable, and are often criticized in citizens' discussions. The existing literature has often distinguished specific and diffuse support. My analysis tends to show that the weakness of the former through personalization can undermine the support for the regime. However, alternatives to representative democracy remain underexplored and even not considered. Overall, these representations depend on sociopolitical factors, such as political convictions or social backgrounds.

Keywords: dissatisfaction, representative democracy, political support, personalized politics, couple interviews

\section{INTRODUCTION}

Analyses of citizens' relationship to politics reveal a certain disaffection with politics through a number of indicators, such as the decline of electoral turnout in Western democracies (Franklin, 2004), partisan disaffiliation (Mair and Van Biezen, 2001) but also the increasing distrust in political leaders (Pharr and Putnam, 2000; Hay, 2007; Citrin and Stoker, 2018). In France, the distance between those who govern and those who are governed is growing and the feeling that "politicians do not care about people like us" now concerns nearly $85 \%$ of the population in 
2019 (when it concerned $40 \%$ of the population at the end of the 1970s) ${ }^{1}$. Recent studies show that populist movements and parties are largely based on an anti-elite discourse (Mudde, 2007), irreconcilably pitting "the people" against the political elites.

However, these findings should be qualified and put in perspective. First of all, available data does not show a massive and irremediable decline in political confidence: they rather show variations according to the institutions, actors and countries (Thomassen, 2016). Disaffection with politics can also be interpreted in different ways: some authors see it as a democratic renewal and a revitalization of commitment toward democracy, notably through the increase in protest practices and their increased legitimacy (Norris, 2011). These authors argue that we witness a transformation of the modes of the relationship with politics: "elite-directed" political activities would be replaced "elite-challenging” practices (Inglehart, 1977; Dalton and Welzel, 2014). Finally, a lot of studies insist on the legitimacy that citizens always give to democracy and their positive judgment about it (Norris, 2011; Grossman and Sauger, 2017 for the French case): the democratic regime is therefore not called into question, but representation experiences a "crisis." Some authors therefore evoke "the danger of deconsolidation" and see the political disaffection as structuring problems that could have irremediable consequences on the regime (Foa and Monk, 2016).

This distinction between regime and actors is thus particularly central to analyze the assessment of individuals' relationships to politics, and it also refers to Easton's distinction between diffuse and specific support (Easton, 1965). Diffuse support is a stable source of support for institutions and the political system: it is based on citizens' loyalty to the system, as well as the legitimacy they grant it. It is to be understood as "a reservoir of favorable attitudes or goodwill that helps members to accept or tolerate outputs to which they are opposed or the effect of which they see as damaging to their wants" (273). Diffuse support is conceived as a stock of trust and applies to the political system and the political community. Specific support, on the other hand, concerns political authorities and depends on the evaluation of the actions and performance of incumbents. It is therefore potentially more fluctuating than diffuse support. Some authors have therefore tackled the challenges of operationalizing these dimensions. Following Dalton (1999), Norris proposes indicators that enable to capture both types of support: adherence to democratic values and principles is an element in the assessment of diffuse support whereas satisfaction with the incumbent political leaders testifies to specific support (Norris, 2011). In this paper, specific support will be captured by dissatisfaction toward the political authorities (and especially politicians), whereas diffuse support will refer to a process of disaffection that can characterize citizens.

This paper deals with the central question of political support in contemporary democracies characterized by personalized politics. Do people only criticize the government's performances or does their disaffection go beyond specific actors and affect the support for the political regime? Do citizens make this distinction between actors, institutions and regime when they

\footnotetext{
${ }^{1}$ See the Political Trust Barometer of CEVIPOF, https://www.sciencespo.fr/ cevipof/sites/sciencespo.fr.cevipof/files/CEVIPOF_confiance_vague10-1.pdf.
}

talk about politics? Do they point to a crisis of representation, without questioning the democratic regime? Easton underlines the necessity to maintain the distinction between specific and diffuse support from a theoretical and empirical point of view, even if the difference can sometimes be tenuous (Easton, 1975). This paper assesses the distinction between diffuse and specific support in a context of personalized politics but shows how these two kinds of support can enhance or diminish each other. It also aims to anchor this reflection in the prism of people's sociopolitical characteristics. I then explore the ways in which citizens represent themselves in the political field, and the relationship they have with both institutions and political actors. What form(s) do citizens' criticisms and support for the political field take in their discourse? My analysis focuses on the ways in which people think about politics and democracy, according to their socio-political characteristics. It is based on a qualitative field, consisting of semi-directive interviews with couple, the details and issues of which I set out below.

\section{PERSONALIZATION AND POLITICAL SUPPORT}

I choose to specifically question the links between the process of personalization that has been observed for several decades in contemporary democracies and political support. Indeed, citizens' satisfaction with politicians is seen as one of the central dimensions of specific support (Norris, 2011).

A lot of political science scholars study personalization since the 1970s. Farrell (1971) observed that "in almost all political systems, executive dominance and the personification of this domination in a single leader is a central fact of political life": the personality of the leaders thus becomes central in the apprehension of the political space and its functioning. Personalization (Renwick and Pilet, 2016) and presidentialization (Poguntke and Webb, 2005) characterize contemporary democracies-whether parliamentary, presidential or semi-presidential. By example, in France, this process of personalization took hold during the Fifth Republic and particularly with the direct election of the President of the Republic since 1965 (Delporte, 2008): the presidential election became the center of the French political life (Grunberg and Haegel, 2007). Some authors propose a further conceptualization of personalization, focusing on "centralized and decentralized personalization" (Balmas et al., 2014). This distinction makes it possible to refine the mechanisms of personalization in order to better understand who precisely benefits from transfers of power. "Centralized personalization implies that power flows upwards from the group (e.g., political party, cabinet) to a single leader (e.g., party leader, prime minister, and president)" and "decentralized personalization means that power flows downwards from the group to individual politicians who are not party or executive leaders (e.g., candidates, members of parliament, and ministers)" (37). The authors point out that centralized personalization is the most widespread phenomenon. The literature is also interested in personalization indicators and how these phenomena can be measured and evaluated. 
These indicators make it possible to distinguish between institutional personalization, media personalization and behavorial personalization, showing the spheres of the political space in which the personalization process takes place.

One of the major debates on personalization concerns the link that the phenomenon has with party change or decline (Rahat and Kenig, 2018). The dominant position is that personalization is linked to party decline, as attested by this definition of personalization as a "process in which the political weight of the individual actor in the political process increases over time, while the centrality of the political group (i.e., political party) declines" (Rahat and Sheafer, 2007, p. 65). The rise of personalization is associated with the decline in the centrality of political groups, such as political parties. Deciding on causality is not easy, but some authors argue for a strong connection between the two phenomena. For Balmas et al., "personalization implies a decline in the role of parties-a decline that is likely to be pronounced in some or all of the functions performed by political parties." Other authors, particularly party scholars, consider that the decline of parties does not necessarily imply forms of political personalization, as other collective actors may take over from the parties. While this point remains debated, empirical analyses nevertheless show many cases where personalized politics and party decline are linked. Electoral sociology literature also emphasizes the personality of candidates as one of the factors explaining electoral choices (Wattenberg, 1991), in a broader context of the decline in partisan identification and partisan dealignment (Dalton and Wattenberg, 2000), even if the "candidate effect" should not be isolated from partisan affiliation and ideological factors (Brouard and Kerrouche, 2017). Media contribute to reinforce the personalization in politics, by providing news media coverage on candidates and leaders rather than parties and organizations (Van Aelst et al., 2012).

Personalization implies a decline in the role of parties, or political parties have been central actors of the political space and its functioning. In this regard, some authors warn of the political consequences of personalization: "Personalization undermines political parties because it engenders support for an appealing leader, not for the ideas and programs of the party as an institution ... As the basis of political support, personalization is transitory and fragile. Massive shifts in support occur when leaders change or lose their novelty or reveal previously unpublicized qualities" (Mancini and Swanson, 1996, p. 272). In Easton's conceptualization, the political system receives inputs, i.e., citizens' demands, and produces outputs, i.e., laws and public policies (Easton, 1965). In these mechanisms, political parties constitute essential channels for expressing and taking into account citizens' demands. But the phenomenon of party decline calls this role into question, as political parties lose their monopoly of "affective and cognitive centrality" (Wattenberg, 1991). Therefore, through which channels does this transmission, necessary for the proper functioning of the political regime, take place? When political parties are no longer the "focal point of politics" (Rahat and Kenig, 2018, p. 211) but politicians are, this change questions major dimensions of political support. Are political leaders able to collect citizens' demands and deliver outputs? Do they hold the trust of citizens, compared to political parties that seem more stable and consistent? The viability and sustainability of the democratic system is here at stake. In a context of political personalization, the question of political support and functioning of the democratic regime deserves to be asked. My paper therefore questions the political consequences of political personalization and seeks to understand whether and to what extent personalized politics are able to provide the basis for political support and legitimacy, from an analysis of citizens' representations and opinions.

\section{MATERIALS AND METHODS}

Most studies focusing on political support rely on quantitative analyses. The issues of operationalization and measures are central to these explorations. The "SWD" (Satisfaction With Democracy) indicator ${ }^{2}$ is the recurrent measure used to evaluate general support (Quaranta, 2018). This measure has been criticized since it can have several meanings (Canache et al., 2001), particularly with regard to the object it concerns (regime, institutions, actors, outputs, etc.) (Ferrin, 2016). Some works choose to go through the evaluation of democratic principles, such as equal treatment, citizen participation, freedom of the media (Ferrin, 2016). The relationship to institutions and political actors is essentially captured through the level of confidence/trust that people have in them. By mobilizing national and international databases, these studies enable to assess the level, evolution and explanatory variables of these political attitudes and behaviors (Magalhaes, 2018). They report on individual variables, such as interest in politics, economic and social status, level of education, but also national characteristics, such as the length of time democracy has been established (Dalton, 2004) to explain support for the regime and institutions. The quantitative approach can be very useful to understand the level of satisfaction with democracy and the sociopolitical variables that explain the phenomenon. But it also imposes a way of framing the questions, preventing individuals from spontaneously talking about political actors and regime. My qualitative approach aims to go beyond this limit. I defend here the idea that a discussion framework encourages the collection of citizens' political representations and perceptions.

My article gives an account of the representations of individuals about the political field and the ways in which they talk about it, questioning the distinction between regime, institutions and actors. To do so, it mobilizes a qualitative analysis of a field survey composed of semi-directive interviews. I therefore rely here on interviews conducted as part of my doctoral thesis about the uses of information in the construction of the ordinary relationship to politics (Dolez, 2013). This fieldwork is composed of 27 semi-directive couple interviews conducted between 2010 and 2011 in France. Many way wonder to what extent empirical interviews dating from one decade ago are still relevant to address these questions in our contemporary context. In this period, Nicolas Sarkozy has been President of

\footnotetext{
${ }^{2}$ Standardized question in these surveys: "On the whole, are you very satisfied, fairly satisfied, not very satisfied, or not at all satisfied with the way democracy works in your country."
} 
the French Republic since 2007 and his way to exert this role was described as "hyper-presidency" (Maigret, 2008). In a French system characterized by a long trend of presidentialization, President Sarkozy is the embodiment of personalization (Neveu, 2012) and his presidency constitutes a favorable context to observe and understand the links between personalization and assessment of the political regime. Some authors propose to consider the Sarkozy presidency as the "symptom of a heavy tendency," that of the individualization of the political field (Le Bart, 2013). Subsequent presidencies, that of Holland and the current Macron presidency, have shown the same trend. The Political Confidence Barometer conducted by the CEVIPOF shows the extent to which, between 2009 and 2019, mistrust of politicians dominates. Politicians are mostly accused of being disconnected from everyday life and citizens and of being corrupt. During this period, the Presidents of the Republic and successive Prime Ministers have very low confidence levels, around $30 \%$ of the population. The years 2010 thus seem to be largely indicative of current trends (Cautrès, 2019). Admittedly, cross national analyses do not attribute a very high score to France in terms of political personalization (Rahat and Kenig, 2018, p. 199), yet individualized perceptions of the political field by citizens are very present.

Fifty four people have been interviewed and are individuals of various social backgrounds, places of residence, levels of political interest and ideological preferences. The interviews lasted between $1 \mathrm{~h}$ and $15 \mathrm{~min}$ and $4 \mathrm{~h}$. Interviewees come from a working (18), middle (20), or upper-class background (16). They live in different areas: Paris (8), the Paris region (16), and the Nord-Pas-de-Calais region (30). There are two reasons for this geographic diversification. First, the geographical variable makes it possible to evaluate the relationship of individuals to politics according to their territory, differentiated by the distance to the center of power. It enables me to take into account the distinction "center-periphery" which has been constituted as a central political cleavage (Lipset and Rokkan, 1967). Second, the geographical diversification is also a way to grasp individuals with various social backgrounds. My social networks are more diversified in terms of social backgrounds in the Nord-Pas-deCalais region, where I grew up and where a part of my family lives, contrary to Paris, where the proportion of higher education graduates is more important than in the rest of France. The recruitment of interviewees was 2 -fold. First, 40 interviewees were recruited through persons of my social networks that oriented me toward persons I didn't know. Second, 14 people were recruited by ads I put on the streets and in shops. The ad specified that I was looking for two people living together for an interview based on a discussion about society topics (see below). These participants were compensated up to 20 euros per person in gift vouchers. This compensation was an undeniable way to get access to working class people (10 out of 18), who are usually underrepresented in qualitative surveys. To interview on political topics lay citizens about who are not necessarily interested in politics, the compensation can facilitate the participation of socially diverse people (Duchesne and Haegel, 2004). The corpus has therefore been built on a logic of diversification, which makes it possible to exhaust the profiles and to obtain a varied panorama of relations with politics. The qualitative approach here allows us to grasp the representations and mechanisms of politicization of individuals.

The choice of a qualitative approach is compatible with the exploration of the relationship to politics and the political representations of citizens, as Brigitte Le Grignou points out: "claiming to grasp politics in its 'ordinary', everyday dimension implies recourse to observation, in-depth interviews, focus groups, or to qualitative techniques and methods alone likely to refine the data produced by questionnaires or surveys" (Le Grignou, 2003, p. 197). I chose to interview couples and to build the interview around discussion on political and social topics to observe, in interaction, people's perceptions and judgements.

Why using couple interviews? This familiar discussion framework refers to banal, everyday situations in discussions on political or social topics, and in this sense makes it easier for individuals to voice their opinions (Braconnier, 2012). Couple interviews also turn out to be an appropriate framework of discussion. This interview situation is less artificial than the face-to-face interview and enabled me to observe the interactions between citizens. Group interviews are particularly relevant in revealing arguments and belief systems (Kitzinger, 1994) or ways of approaching public problems (Comby, 2011). Group interviews therefore facilitate access to individuals' representations, as these are more easily expressed in conversations than in an interview. More specifically here, the couple framework is one of the major frameworks for constructing individuals' political visions. The couple framework seems to favor the expression of the opinions and representations of the interviewees. In fact, the face-to-face situation with the interviewer can be embarrassing for interviewees when they are confronted with a question they cannot answer. When there are two interviewees, interviewees can be supportive. However, the couple's setting can also be a constraint and may reflect certain biases. The presence of the couple has consequences on the content of the interview: in this sense, this interaction constructs what is said and what can be said for each of the participants. In some cases, couple interviews can reveal mechanisms of male domination, where, in the couple, men are usually more interested in politics than women (Sineau, 2013) and the former undertake the political work whereas the latter can censor themselves when talking about political issues.

Why building interviews from discussion topics (Gamson, 1992)? The interview guide was designed to offer both interviewees discussion topics, introduced as "society topics ${ }^{3}$." It therefore does not address directly the question of the

\footnotetext{
${ }^{3}$ Four society topics were successively proposed in order (except when one of the topics was spontaneously raised): the issue of undocumented migrants, pension reform, the role of the State in road safety and in the sharing of tasks between men and women. The diversification of themes was thought out with the aim of highlighting different dimensions of the relationship to politics (relationship to authority, to political actors and the framework of political action, to the possibilities of political change, to ideology, to the limits of politics, etc.). These subjects were easily accessible and resonated in the daily life of the respondents, some of which (such as pensions) were the subject of strong media coverage during the survey period. Each topic was introduced in a simple way: "there has been a lot of talk about such and such an issue, what do you think about it?" The standardization of the discussion themes allowed for comparisons between
} 
judgement and evaluation of institutions and political actors but the interview guide enables me to capture them thanks to a situation of discussion. In this sense, this use of the interview helps to avoid the pitfalls and criticisms that can arise when it comes to apprehending the relationship with politics. Nicolas Mariot wonders how political opinions and behaviors can be empirically grasped and indicates that "the interview forces reflexivity about practices" whereas in their everyday life, people do not need to justify their political practices (Mariot, 2010, p. 187). The interview would therefore tell interviewees to justify their behaviors and opinions and would thus struggle to grasp indifference to politics. In my case, the interviewees are not asked to produce a discourse specifically on the judgment of institutions, support for the regime or the relationship with political actors, but through discussions on political issues, they report representations, perceptions and opinions that provide information about these dimensions. In this way, I analyze the words they use and the elements they identify to talk about the political field. This detour through political issues is also a way to avoid domination effects by using a specialized vocabulary. I was indeed confronted with this issue in this study. At the end of the discussion, I asked a question on the evaluation of democracy: "We often wonder whether democracy works well in our societies, what do you think about it in the case of France?" This question did not turn out to be relevant, in particular because it might not be understood by some interviewees and might make them feel incompetent. A good example is the reaction of Patricia and Gérard to this question. Patricia, 50, is married to Gerard, 52. Holder of a vocational training certificate in carpentry, Gérard has been a roofer in a private company for 32 years. Patricia has a vocational training certificate in typing and is currently unemployed. In her last job, she worked as a domestic helper. They express little interest in politics, but the interview reports a lively discussion on the topics. To my question about democracy, they answer:

Patricia: "Wow!

Gérard: What is that democracy? ... It's, my memories, pfft... (silence)

Patricia: But democracy is for... In America there is democracy, it's in America..., for us here too there is democracy?

Gérard: Well yes, democracy is uh...

Patricia: Ah well, I don't know too much about that (silence)

Investigator: For example, do you need an opposition to a majority?

Gérard: Oh yeah, right, it's the government! Well, I don't know anything about it, I'm not a politician. I don't have 5 years of higher education"

This exchange shows the extent to which the wording of the question on the functioning of the regime is not adequate and echoes instead to an academic questioning ${ }^{4}$. The challenge is to

interviews without preventing participants from bringing up the subjects that (pre)occupied them in particular.

${ }^{4}$ Patricia's reply, in which she admits not knowing about the topic, could be inhibiting for the rest of the interview because she is put in default during the interview. This question is asked almost at the end of the interview, so it is not too damaging for the interviewees' willingness to talk. grasp people's representations and perceptions and to understand what structures them, beyond an assessment of their level of competence or political knowledge; to do this, issue-based discussions prove to be much more appropriate.

All interviews have been transcribed on small forms on which I wrote a verbatim of the interview and some elements of analysis, collecting forms by theme. I analyzed this qualitative material by putting together forms on the same theme, and compared by this way individuals. I focused here on the verbatim dealing with the identification of political actors, the evaluation of elected representatives, the perception of the democratic regime and the role of citizens, that are the main elements of analysis of this article. My analysis is conceived as an exploration of citizens' representations of the political field, around the articulation between regime, institutions and politicians. First, I show that representations and perceptions of the political field are generally based on the identification of individuals, rather than on collectives and institutions. My second point then deals with the implications of this personalized relationship, and questions, in this context, the relationship to representative democracy. Finally, the discussion part interrogates the relationship between specific and diffuse support, in a context of personalized politics.

\section{RESULTS}

\section{Dissatisfaction in the Context of Personalized Politics}

When people talk about the political system, politicians are the central actors. My qualitative analysis shows that politicians are the actors who are the most mobilized in the speeches and structure individuals' representations of the political field.

\section{Limited References to Political Parties and Movements}

Before showing how the reference to politicians structures the representation of the political field, it is worth emphasizing the very low level of mobilization of political parties in citizens' speeches. It is certainly difficult to base a demonstration on the absence of something, but political parties are very rarely mentioned in the discourse of the interviewees. This result thus argues for the thesis associating party decline with political personalization.

There are, however, special cases in which political parties are mobilized as such. One example is Stéphane, 32 years old. He lives in a house in a suburban area of a small town in the North of France with his partner Mathilde, 20. Stéphane studied history until the bachelor's degree, he is a worker in an automobile factory and is a trade union representative. He considers that "you have to stop talking about right and left (...) it means nothing to me. It's better to say $\mathrm{UMP}^{5}$ or socialist. Even on TV, people talk about right and left all the time. It's better to speak in terms of etiquettes." He draws a parallel with the trade union world where "labels" are important. In a context where right and left no longer seem to be points of reference, the names of the parties, as well as the names of the trade

${ }^{5}$ The then rightwing party, Union pour un Mouvement Populaire. 
unions, retain their relevance, particularly because Stéphane testifies to his knowledge of the proposals and ideological shifts of the organizations. Another case concerns Nordine, 38 years old. Together with Christelle, 36 years old, they live in a commune of Seine-Saint-Denis and have always lived in this department. Nordine holds a technical school certificate in electrical engineering and is a technical agent in the public sector. Throughout the interview, he evokes a strong criticism of politicians (see below) and, evoking childhood memories, he refers to the "communists": "Before the communists, they made these things [the $\mathrm{MJC}^{6}$ ] work, and I remember, I was a lot with the pioneers of France, so it was the communists and we used to go on holidays a lot. That doesn't exist anymore!" The reference to the communist party, through the social and popular education activities developed in the Parisian suburban cities, is in fact no longer relevant and does not remain a structuring element of his political discourse.

More generally, even though the majority of the interviewees do not refer to political parties, the difference between the right and the left is widely used to talk about the political field and the variations in political positions (Tiberj, 2004). This is all the more true among the interviewees who report entrenched political convictions, who position themselves either on the left or on the right and who define the characteristics of each of these camps. This is the case of Pedro, 45 years old. He lives with his wife and their two sons in a commune in the south-eastern suburbs of Paris. He studied mechanics and automation until the advanced technician's certificate and is a production manager in a private company. Pedro assumes a left-wing stance and gives a simple explanation of the differences between the left: "we play the solidarity card (...), sharing" and the right: "we play the card for ourselves, (...) making the most of it." This is also the case for Jean-Pierre, 64 years old, retired from a job as a quality inspector in the automobile industry. He lives with his wife Micheline, 60, in a town in the North of France. Jean-Pierre declares himself "neither left nor right" and not very interested in politics, but he also shows a reading of the political field through the left and the right lens. Commenting on the political alternation in France, he says: "I have noticed, we change the right one time and the left one time. On the one hand, we fill the coffers, on the other hand we empty the coffers (...) From my personal point of view, in 2012 the left will win, he [Nicolas Sarkozy, then president] has filled the coffers well, so we will empty them!" The representation between the left and the right opposing each other on how to manage public spending structures Jean-Pierre's vision ${ }^{7}$.

However, even if the terms right/left are still used by the interviewees, they seem, for a certain number of individuals, to have lost some of their relevance. The blurring of ideological boundaries between left and right then leaves room for the personalization of politicians. This is the observation made

\footnotetext{
${ }^{6}$ The MJC (Maison des Jeunes et de la Culture) are youth cultural centers in cities. ${ }^{7}$ This representation of the political space between left and right should be reassessed since the partisan system has been largely modified since 2017 (Gougou and Persico, 2017). At the time of the interviews and during the Sarkozy presidency, the political spectrum is deeply organized around the left/right cleavage.
}

by Marie-Thérèse and Thierry. Marie-Thérèse and Thierry live in a commune near Lens and both declare themselves "rather interested" in politics. Marie-Thérèse, 46 years old, is a reader trainer and is positioned on the left. Thierry, 48, has a technical school certificate in electricity and works as a logistics receptionist in a supermarket and says he is "neither left nor right." Thierry explains the irrelevance of the left and the right by saying that they are "just words," without ideological unity. Marie-Thérèse, following this remark, declares: "Today we are not really sure anymore, I find that people are looking for a person, in all political parties now it is a person who represents, it is not really an idea anymore, I have the impression that people are voting for a person (...). So it's also a danger, because there are people who sometimes speak very well but then in actions it's different. I don't know if today people still recognize themselves in parties a lot." In a mechanism quite close to the "third person effect $^{8}$ " Marie-Thérèse evokes the risk of personalization, caused by a loss of relevance of political parties. In this sense, she also confirms the observed processes of partisan disaffiliation and the rise of personalities in the structuring of the political field.

The reactions to what has been called "openness" in the constitution of the Fillon government in 2007, under the presidency of Nicolas Sarkozy, are indicative of the place taken by political figures. Interviewees with strong political convictions and a high degree of politicization judge negatively this undertaking, as the political camps defend an irreconcilable world view. The conflicting view of politics is especially characteristic of individuals who are politicized and have political convictions structured by ideological affiliation. For the other interviewees, openness is not questioned in principle. It is then judged positively, as Sylvestre and Catherine do. Sylvestre, 55, and Catherine, 53, live in a large house near the city center of a medium-sized town in Nord-Pas-de-Calais. Sylvestre is a liberal veterinary surgeon and his wife, who has a 4-years degree in Germanic philology, has worked for a few years as an English and Dutch teacher and has been a housewife for many years. They are both located in the center right and evoke this experience of openness:

Catherine: "at least they were remarkable people. And I liked that idea, they called it the openness to the left.

Sylvester: Mmh, mmh (of confirmation). It was even surprising because it wasn't planned (...) He [Nicolas Sarkozy] was very

\footnotetext{
${ }^{8}$ The "third person effect" has been highlighted in the work on the effects of the media (Davison, 1983): it suggests that the individual who expresses himself or herself feels protected from the persuasive or manipulative effects of the media, but that he or she considers these effects are very strong for other segments of society. This mechanism is, for example, particularly clear in Marie-Thérèse's case. She shows a committed activist stance-she does indeed have a strong associative commitment-advocating awareness of voting and information and the rejection of extremes. This stance is coupled with a certain elitism, even a kind of condescension toward the local population, "the locals," with whom she is in contact on a daily basis in her work as a teacher and teacher-trainer and in her numerous trips to various suburbs in the region. She thus reproaches them for their distant relationship to politics and their naivety in believing everything politicians say and promise.

${ }^{9}$ This refers to the decision of Nicolas Sarkozy, newly elected President of the Republic, to entrust key ministerial posts to political figures, members of the Socialist Party or associated with the left (whereas he is a right-wing President).
} 
criticized at the time (...)

Catherine: I was grateful that he dared to do something like that. Then it wasn't really anything else, I mean Martin Hirsch ${ }^{10}$ was still something.

Sylvestre: There was Bernard Kouchner ${ }^{11}$ at the Foreign Affairs Department.

Catherine: That was a nice idea, but then it has been politically exploited, so you end up getting everything dirty. Well, maybe that was it, I'm naive, but maybe it was also a real openness."

Catherine thus shows that she believed in this openness, and defends a less conflictual, more consensual vision of politics, relying on "remarkable" personalities. This aspiration to a nonconflictual vision of politics is shared by British citizens (Clarke et al., 2018).

Political parties are therefore very little present in individuals' representations of the political field. In the French context, the distinction between left and right remains mobilized, even if it loses its relevance and seems less structuring than it could be. The loosening of these points of reference is part of a perception of the political field dominated by political leaders. Specific support focuses on political actors, without precising if these actors are individual or collective. My analysis clearly shows that for citizens, individual actors matter (and not collective ones), because they mobilize spontaneously them when talking about politics.

\section{A Deep Dissatisfaction Toward Politicians' Performances}

Collective organizations are not mobilized in the representations of the political field. By contrast, politicians are often mobilized. In this regard, they are unanimously held accountable and are also, for some interviewees, systematically criticized. Easton places the issues of outputs and accountability at the heart of its conceptualization of specific support. Specific support then depends on positive or negative evaluations of the authorities. This centrality of political actors is found among all the interviewees. Depending on their level of politicization or the existence of political convictions, this reference is deployed in different ways. From an empirical point of view, it is necessary to listen to people to catch their perception about political action because evaluations "may also be stimulated not by explicit actions on the part of the authorities but by their perceived general performance" (Easton, 1975, p. 438).

Jean-Jacques and Claudine are two interviewees characterized by strong left-wing political beliefs. They show an important level of politicization and attention to public affairs. Jean-Jacques, 58, and Claudine, 54, live in an apartment in the 11th arrondissement of Paris. Both holders of a Master's degree in public law, JeanJacques is a senior manager in a property management company and Claudine is a claims inspector in the insurance industry. Throughout the interview, they adopt a stance of analysts and

\footnotetext{
${ }^{10}$ Martin Hirsch was appointed High Commissioner for active solidarity by President Sarkozy in 2007. He used to be the president of a charity for the underprivileged.

${ }^{11}$ Bernard Kouchner is a doctor and a politician who used to be a member of the Socialist Party.
}

critics. They are constantly pointing out the problems and issues that society faces, linking them to their knowledge and using economic and political theories. For Jean-Jacques and Claudine, difficulties that France is experiencing are due to structural constraints and the organization of power. But politicians are still largely part of their discourse, in that they are accused of incompetence and lack of creativity. They are therefore not up to the economic, social, and ecological challenges facing the contemporary world. Jean-Jacques and Claudine then question the uniformity of the elite education, which prevents them from proposing new and innovative solutions. The couple does not have a vision of the political field structured solely by politicians, as they account for the role of institutions, particularly the European institutions, but criticism of the elites is a key point in their discourse.

Some interviewees, for their part, systematically perceive the political field through the criticism of its actors. It is a way of making sense to situations that seem illogical or incomprehensible. More broadly, these interviewees mobilize a reading perspective that puts their feeling of exclusion from political action at the heart of their perceptions. They all feel excluded from social measures and public spending, and for some of them, they declare that they are subject to a significant tax burden, but don't benefit (or not enough) from State services. These interviewees come from the working classes and also from the middle classes. They often encounter rather difficult living conditions, which make the feeling of not being considered in society stronger. Citizens judge political action according to what the State and the government provide them personally. They call in question politicians in general, in that sense that they are responsible for political action, but also in a more personal way, as Gwendoline's speeches show. Gwendoline is 29 years old, she is married to Franck, 31 years old. They have four children and live in an apartment in a set of building bars in a small commune next to Valenciennes. Franck stopped school at the age of 14 and his wife has the general certificate of secondary education. They both currently receive the social inclusion income, Franck works from time to time (on average 1 day a week) as a temporary garbage collector. Gwendoline has not worked recently. Their interview is based on the denunciation of "foreigners" that Gwendoline considers responsible for her own personal difficulties, in a logic of competition with social aids. In order to make sense to the permanent discrepancies between promises, announcements and reality, she considers that all aid is given to foreigners. In this denunciation, Nicolas Sarkozy [President of the Republic at the time] is directly targeted. Gwendoline then mentions the steps she takes to obtain a new home.

Gwendoline: "We wrote to him [to Nicolas Sarkozy] on the Internet for an accommodation saying we were living in a twobedroom apartment with four children and he did not help us anyway. (...) And I have a friend, she's Arab, she wrote to Sarkozy and Sarkozy found her a house, I don't think that's normal! (...) Then they say that the French become racist but it's because of him!” 
The "Arabs"-who are confused in Gwendoline's remarks with "foreigners" - are a privileged target-especially in a context of crisis (Noiriel, 2006) - insofar as they too would be favored by the President's actions.

Gwendoline: "Yeah, he [Nicolas Sarkozy] gives more aid to foreigners than to French people. The French need it much more than foreigners. Also, he says there are not enough houses for people: he gives them to others, to foreigners, rather than helping the French!

(...) He [Nicolas Sarkozy] is not there to help the French, he is not there to help us. In fact, he does what he wants, he wants it to start all over again like in the old days, the rich on one side, the poor on the other. We have been sidelined, we are low class for him, that's all."

The President of the Republic is therefore directly and personally held responsible accused of favoring other categories of the population ("foreigners", "rich") at the expense of Gwendoline and her family. He is the person in charge of political action, and therefore the main target of criticism.

The interviews thus reveal a general perception of a decline in the ideological structuring of political debates and the weak presence of political parties as landmarks. Most of the relationship with the institutional world is, in fact, envisaged through politicians, sometimes without any connection to more structuring reference points. The latter are then both key players and heavily criticized. Interviews show a weak specific support which goes together with personalized politics.

\section{The Implications of Personalization}

What are the implications of such a critical perception of politicians? The challenge here is to understand the consequences of these politician-centered representations, both on citizens' opinions and on support for representative democracy.

\section{Personalization and Politicization}

First of all, my interviews show that personalized politics and a high level of criticisms toward political leaders can have consequences for citizens' political orientations of citizens.

Indeed, the systematic mistrust and accusation of politicians can lead to a willingness to settle certain issues individually rather than collectively. This mechanism is particularly present in Nordine (38, technical officer). Throughout the interview, Nordine denounces the politicians in charge of exercising power. He points out the difference between the circulation of impressive amounts of money on the political scene and the fact that he and his household receive nothing from the State. He finds it difficult to understand how such sums of money can be mobilized in a context of economic crisis when political leaders often claim the necessity to cut expenses. On the issue of retirement pensions, the challenge is precisely for him to understand the discrepancy he perceives between the amounts of money wasted by politicians (political scandals, travel expenses of ministers, etc.) and the need to extend the contribution period for retirement. He gives meaning to this paradox by being suspicious of politicians who only want to fill their own pockets. For him, more money is needed since politicians have deliberately misappropriated the money spent on pensions. Nordine feels he has been deceived by politicians. This creates a political demand which is not compatible with the left-wing position that he declares at the beginning of the interview. Indeed, the lack of trust for politicians leads him to formulate the idea that some issues hitherto managed by the State should be taken care of by the citizens themselves, individually, so as to prevent any dishonest action by politicians. Here, the widespread mistrust of politicians supports a mechanism in favor of the withdrawal of the state or even depoliticization.

Another implication concerns the criteria used to judge politicians. All the interviews mention, to varying degrees, political scandals and accusations of corruption or crime among politicians. Politicians are repeatedly criticized in the interviews for their lack of integrity (Lascoumes, 2010). For the majority of the interviewees, honesty is one of the central criteria for judging elites and one of the qualities necessary for claiming power, even if it goes beyond ideological orientation. Régis' comments bear witness to this. Régis, 52, has been living with Fatima, 50, for 12 years. They have an 11-years-old son and they live together in an apartment in a recent building not far from the center of a medium-sized town in the North of France. Régis dropped out of school in 4th grade and is an unskilled worker in a large car factory in the region. Régis and Fatima have a very ideological reading of political problems and issues, positioning themselves on the left and against the brutality of the liberal system. They show disappointment with left-wing governments and are very critical of current politicians, who lack of strong political beliefs and are disconnected with reality. They analyze the political issues, by linking them to a well-founded criticism of the liberal system. Régis defends a conflicting vision of politics, between the left and the right. However, when discussing the government and its constitution, he indicated that it is necessary to have "especially honest people, whoever they are." Integrity thus takes precedence over ideological orientation, and the exemplary nature of the politician replaces the conflicting vision of politics and governance.

\section{Citizens and Representative Democracy}

How, in this context, is the place of the citizen thought out? What are the consequences of negative evaluations of politicians for representative democracy? In fact, people consider the regime and their role in it differently according to their sociopolitical characteristics. Three perceptions have been identified and show different democratic linkages between those who govern and the governed.

A first group of people consider the democratic regime exclusively through the figure of political leaders, in this context of personalized politics. This appeal to strong political leaders is linked to a rather catastrophic view of the country's situation. These people are characterized by personal experiences of significant social and financial difficulties and by a feeling of downgrading or abandonment. Their interpretation of the world and of political and social events is based on an anxious vision and shows very little optimism about the future. This vision mainly concerns interviewees aged 50 and over. Among these interviewees, political decisions are judged to be ineffective and 
not strictly applied. In this context, an authoritarian reassertion of the use of an effective leader is seen as the solution. What matters is that someone knows how to take the right decisions and, above all, how to enforce them. The authoritarian imposition of decisions thus proves to be a relevant solution to improve political action. For example, Marie-Paule (59 years old, former administrative agent, early retired in a situation of invalidity, positioning at the far right) thus indicates that she would like Nicolas Sarkozy to say that "during 5 years it is me and I impose things, you accept them, well so much the better, you do not accept them, well so much the worse!" For these people, politicians are accused of being too soft and not enough strict about rules compliance. But criticisms are not limited to politicians, they also concern the way democracy functions in our country, and the need for a strong Presidency. That said, this point of view is not totally free of ambivalence. Moreover, Marie-Paule considered earlier in the interview, with regard to the social protest about the pension reform (in 2010), that the demonstration was an important tool for the citizen and that it was essential to ask people's opinions before putting in place reforms. For this first type of perception of the democratic regime, the authority of a leader imposing one's decisions without referring to citizens is clearly considered, especially regarding the issues of security and justice.

A second group of people consider the democratic regime under the prism of power delegation. Even if they can be critical toward politicians, they do not question the legitimacy of representation. These people are usually interested in politics and position themselves at the center on the left-right scale. For these interviewees, as indeed for all the interviewees, politicians are not exempt from criticism, such as disconnection with reality, lack of honesty and the systematic search for positions of power at the expense of ethical political practice. Yet they declare that politicians are strongly legitimate. Decline in political ideologies, difficulties in mastering political issues and the lack of understanding and reference points in the political world may ultimately result in a legitimate delegation to political leaders. Politicians are thus seen as the organizers of political debates but also as those who are responsible for generating ideas and solutions to society's problems. Gérald's speech is typical of this position. Gérald is 56 years old, he is the IT director at the town hall of a medium-sized town in the North of France. He is at the center of the political spectrum. At the time of the discussion on the situation of undocumented migrants, Gérald has difficulty forming an opinion on this issue and, above all, in seeing how this situation could be resolved.

Gérald: "Most of these people came back with smugglers [...] we have to hunt for smugglers. But it's complicated, there's no solution ... I don't have any solutions, it's very complicated, that's for sure."

Gérald's hesitation in finishing his sentence "there is no solution" and the change to the personal pronoun "I" are, in my opinion, indicative of the mechanism of delegation and trust. Gerald cannot express the fact that there are no solutions, but simply that he does not have any: there are therefore certainly solutions that must be found by politicians, those who are responsible for doing so. This sentence then reflects the importance of political action and the role of politicians in the resolution of situations perceived as problematic. These individuals have trust in the ability of politicians to resolve difficulties and do their utmost to solve problems, even if they can raise doubts. Citizens seem to ultimately hope that politicians will take the right decisions, but they are still not sure about it.

Gérald: "It's necessarily up to the government to make the decision, because at a given moment, you have to trust the people, you have to think that they are sufficiently competent, after all the opinions they've taken to check their hypotheses (...) The government was elected to make decisions, well, it makes them and then you hope that it's not wrong."

In Gérald's view, it is clear that the government is the legitimate body to make decisions, but he nevertheless keeps some doubts about this capacity. In any case, in the management of public affairs, the citizen is not called upon to take a more important place than he currently has through voting.

Competence is therefore at the core of their political representations. For some interviewees, the principle of delegation remains the key mechanism of how democracy functions. To counter the negative evaluations of political outputs, they consider the role of "experts." Christine and Michel are quite typical of this position. Christine, 55, is married to Michel, 58. She is a liberal dental surgeon. Her husband, an insurer for 25 years, is currently the manager of a professional reintegration company. Coming back from a conference on the limits of democracy, the couple then mobilize the reflections they heard there. First of all, they lay the stress on the ignorance of politicians about some topics and the need to resort to experts who provide a reliable and truthful vision of the issues at stake. Michel then proposes that democracy should become "regulatory rather than participatory," which means that "depending on the opinions of experts, there are sometimes decisions that have to be taken that are not going to please and that cannot be taken according to a democratic mode of operation." He applies this to the question of pensions, where the whole population will say that they want to work less when it is necessary to lengthen the contribution period: "if we want it [the pension system] to hold, we have to make the decision, and that cannot be done with participatory democracy, where we ask everyone for their opinion (...)." The couple concludes by saying that "that's democracy, we have to keep it, but on certain points there are limits." The place of the citizen is seen here rather as an obstacle to effective and relevant decision-making, and the response to current challenges (the environment, for example) consists in giving a central place to experts, which echoes the principle at the core of the "stealth democracy" (Hibbing and Theiss-Morse, 2002).

The last way to consider the role of citizens in the democratic regime that I identified concerns a small part of the interviewees. For them, the principle of representation can be questioned and procedures where the citizens can participate more have to be considered. These people have strong political beliefs, often 
positioning themselves at the left wing and had experiences of associative or political involvement. This is the case of Christiane, 68 , retired after having worked as a nurse for a few years. She is a "very left-wing, anarchist" activist and has commitments to associations (housing rights, for example). When she talks about representative democracy, she keeps a watchdog position, because the elected representatives "may represent [her], but she does not expect $100 \%$ of them, [she] does not trust them $100 \%$ even if [she] voted for them." Christiane also proposes to set up a system of "popular vote," in which citizens are consulted regularly, since the election of representatives is not conceived as an end to citizen participation.

Widespread criticism of politicians can thus have consequences on the representations of the democratic system, seen mainly through its actors. The appeal to authoritarian leaders able to maintain law and order and also to listen to people's wills concern rather old citizens. They have a pessimistic perception of the situation, come from a working-class or middle-class background and have the feeling of downward mobility. In the second perception, delegation is seen as legitimate, and trust toward politicians or experts does not seem to be too much attacked, even if politicians remain the major targets of negative political evaluations. This perception concerns citizens who position at the center of the political scale, come from a middle-class background and have an average interest for politics. Finally, a few interviewees want to reassess the role of citizens in representative democracy. They usually are very interested in politics and have civic or political involvements, which explain why they want to give citizens' a more important role. The solutions induced by dissatisfaction with political performance vary, and the citizen's place in this reflection remains limited. For that matter, does this widespread dissatisfaction affect the level of diffuse support?

\section{DISCUSSION: WHEN A WEAK SPECIFIC SUPPORT UNDERMINES DIFFUSE SUPPORT}

I would like to question the implications of such a personalized and critical representation of the political field on the perception of the regime by reiterating the distinction between specific and diffuse support. More specifically, I argue that the weakness of specific support through distrust of politicians and dissatisfaction with government performance can ultimately undermine diffuse support through support for the regime and its functioning. Easton has already mentioned that "if discontent with perceived continues over a long enough time, it may gradually erode even the strongest underlying bonds of attachment" (Easton, 1975 , p. 445). He also points out that a low level of specific support can undermine the level of diffuse support and thus contribute to a much wider criticism of the regime and institutions. As stated in the section on methodological issues, the direct question on the functioning of the democratic regime is not necessarily relevant for collecting the representations and opinions of individuals on this subject. Responses to this question mainly show an attachment to the democratic regimewhen interviewees understand what it refers to. They value its principles, and often make a comparison with other countries or with more authoritarian regimes, denouncing them and considering themselves lucky. My analysis proposes to go beyond their answers to try to understand how the overwhelmingly critical judgement of politicians and their performance can have consequences for attachment to the regime.

The systematic perception of a gap between politicians and citizens, and between announcements of measures and their implementation, feeds the idea that citizens' demands are not considered.

The majority of interviewees underlines the disconnection between themselves and the elites: politicians lose all connection with reality when they are in power, and do not realize what citizens experience in their daily lives. The "them vs. us" opposition is particularly structuring in the discourse of the interviewees. Jean-Jacques and Claudine, who declare strong political beliefs and a high level of politicization, indicate that "the elite forgets the everyday life of the people." Isabelle and Pedro both declare themselves to be on the left, even if this political position is no longer as obvious as it was a few decades ago. They both criticize the standardization of politicians and Pedro says: "they are people from the same place so they all think the same. They come from the same schools, they have the same friends (...) so that's also what disconnected them [from the people]." For other interviewees, this disconnection is expressed in even more blunt terms. Gérard says he has little interest in politics and is "neither on the left nor on the right": the interview is dominated by his indignation toward the political system, multiplying the statements of misunderstanding and injustice. Speaking of Nicolas Sarkozy, Gérard retorts that "he doesn't care about us," highlighting, in a strong personalization, the indifference of the President of the Republic for the citizens. This disconnection is also expressed in the feeling that politicians are apart, with multiple advantages, which differentiates them from citizens. Some practices can thus be criticized by citizens, because they favor the current political establishment of politicians, without aiming at the general interest. In this sense, the following elements are denounced: the fact of changing ministries during reshuffles without this being associated with a specific competence on the perimeter of action, or the possibility for ministers to reclaim their municipal mandates once they have left the government. For Jean Pierre (64 years old, retired from a job as a quality inspector in the car industry), "that is not normal. If I was dismissed from Mr. [his company], I would go directly to the ANPE [National Employment Agency]. Why did they...? He's fired from the government (...) he's going to come back to take his place, that's not normal!"

The discrepancy can also be seen in the judgement of performance. Citizens highlight the distinction between promises and announcements made by politicians and actual implementation on the ground. People mention disappointment and even recurrent indignation about public action, which is either judged insufficient or does not live up to the announcements made. Grossman and Sauger also specify the characteristics of the French system that explain this discrepancy: 
for them, "the combination of the majority logic of the regime, its presidentialization and the use of a two-round voting system has largely contributed to inscribe in the French political landscape a fundamental contradiction between the need to raise high expectations among voters in order to hope to survive the first round and the observation of a powerlessness to satisfy them in the register of daily government action" (Grossman and Sauger, 2017 , p. 157). The two authors also show that the "honeymoon" available to the newly elected President is becoming shorter and shorter: the popularity curves are falling very quickly and there are many more people who do not trust the President than others (131). Gwendoline's comments are particularly illustrative of this discrepancy: she mentions a series of measures that were supposed to concern the unemployed, of which she and her husband are a part of.

Gwendoline: "He [Nicolas Sarkozy] says that there will be help for the Internet for the unemployed, for the telephone, we didn't get it! An EDF [Electricity supplier] help! We haven't seen it, the help, we haven't seen anything! (...) I had seen that on TV, in the newspaper, so he promised, he promised again and all in all, nothing has been done."

Here Gwendoline expresses her systematic disappointment with measures that feed her hope of being able to alleviate the financial difficulties she encounters on a daily basis. This gap between announcements and the application of measures is also reinforced by the development of selective and targeted social policies, at the expense of universal policies (Paugam and Duvoux, 2013). Access to aid is thus conditioned by thresholds and increasingly by the assessment of situations (Dubois, 2012; Lima, 2016). This can reinforce the impression of a gap between the announcements and reality, as Annie (47 years old, nurse) shows when she says, with regard to the aids put in place, that "there is always something that makes you not entitled to them."

The disconnection between politicians and citizens and the recurrent dissatisfaction with public action call into question more broadly the capacity of institutions to take into account the needs of the population and thus call into question the functioning of the regime. Rachel (21 years old, in training as a health care assistant) underlines this distance between the people and the political actors, by noting that the regime is certainly democratic but not very capable of establishing bridges between the two: "and if we do something, it won't go up to the president, we would perhaps like to have more control over the people higher up. (...) It's democratic but we are still too low." Beyond a deep dissatisfaction, it seems that means of communication between citizens and those who govern are not very effective. Trust and legitimacy (which are the two elements of Easton's diffuse support) toward the regime can then be damaged through a constant and massive dissatisfaction.

\section{CONCLUSION}

In a context of intense personalization, my article shows that citizens' representations of the political field are dominated by individual actors and the figure of politicians.
Politicians are at the same time the key players, the targets of criticism and those responsible for public action. Collective actors and institutions are still barely mobilized in the discourse and the latter are mainly perceived through the prism of politicians. This is why criticisms about politicians have consequences on the perception of the regime and democratic institutions.

This criticism is widespread among citizens, with varying degrees of intensity depending on how firmly political and ideological beliefs are rooted. Among those for whom the partisan structuring of the political space is weak, the negative judgment of politicians can be systematically mobilized as a reading grid of the world. While the literature has often separated negative evaluations of politicians' performances and the attachment to the democratic regime, my analysis suggests that the weakness of specific support may in fact undermine diffuse support. Indeed, mistrust of politicians, a feeling of disconnection with elites and widespread dissatisfaction with government performances maintain the idea of a problematic representation but also of an inability of institutions, captured through politicians, to take into account the needs and demands of citizens. In this system, citizens feel that they are not given much consideration. Individuals then differ in their vision of the political system: some value the use of an authoritarian leader who imposes decisions, while others insist on changes to the democratic system to give more room to experts and limit the expression of citizens. The principle of delegation to politicians is accepted and legitimate, but representation raises doubts and may require greater citizen control and stronger and more regular participation. Representative democracy is then faced with two options: to work for better representation or to give more space to citizens, in order to improve the ways of communication between citizens and their representatives.

\section{DATA AVAILABILITY STATEMENT}

The raw data supporting the conclusions of this article will be made available by the authors, without undue reservation.

\section{ETHICS STATEMENT}

Ethical review and approval was not required for the study on human participants in accordance with the local legislation and institutional requirements. Written informed consent for participation was not required for this study in accordance with the national legislation and the institutional requirements.

\section{AUTHOR CONTRIBUTIONS}

CD did the conception of the work, collected the qualitative data, analyzed the data, interpreted them, and wrote the entire paper.

\section{ACKNOWLEDGMENTS}

The author wants to thank Camille Bedock and Pierre-Etienne Vandamme, for their careful reading of previous versions of this article and their stimulating remarks. 


\section{REFERENCES}

Balmas, M., Rahat, G., Sheafer, T., and Shenhav, S. R. (2014). Two routes to personalized politics: centralized and decentralized personalization. Party Polit. 20, 37-51. doi: $10.1177 / 1354068811436037$

Braconnier, C. (2012). À plusieurs voix. Ce que les entretiens collectifs in situ peuvent apporter à la sociologie des votes. Rev. Française Sociol. 53, 61-93. doi: 10.3917/RFS.531.0061

Brouard, S., and Kerrouche, E. (2017). "L'effet candidat," in Analyses Électorales, eds Y. Déloye and N. Mayer (Bruxelles: Bruylant), 965-1009.

Canache, D., Mondak, J. J., and Seligson, M. A. (2001). Meaning and measurement in cross-national research on satisfaction with democracy. Public Opin. Q. 65, 506-528. doi: $10.1086 / 323576$

Cautrès, B. (2019). "Le soutien en demi-teinte des Français à la Cinquième République," in La $V^{e}$ Démystifiée, ed O. Duhamel (Paris: Presses de SciencesPo), 217-224.

Citrin, J., and Stoker, L. (2018). Political trust in a cynical age. Ann. Polit. Sci. 21, 49-70. doi: 10.1146/annurev-polisci-050316-092550

Clarke, N., Jennings, W., Moss, J., and Stoker, G. (2018). The Good Politician: Folk Theories, Political Interaction, and the Rise of Anti-Politics. Cambridge: Cambridge University Press.

Comby, J.-B. (2011). Ancrages et usages sociaux des schèmes d'appréhension d'un problème public. Analyses de conversations sur les changements climatiques. Rev. Franç. Sci. Polit. 61, 421-445. doi: 10.3917/rfsp.613.0421

Dalton, R. J. (1999). "Political support in advanced industrial democracies" in Critical Citizens: Global Support for Democratic Governement, ed P. Norris (Oxford: Oxford University Press), 57-78. doi: 10.1093/0198295685.003.0003

Dalton, R. J. (2004). Democratic Challenges, Democratic Choices: The Erosion of Political Support in Advanced Industrial Democracies. Oxford: Oxford University Press.

Dalton, R. J., and Wattenberg, M. P. (Eds.). (2000). Parties Without Partisans: Political Change in Advanced Industrial Democracies. New York, NY: Oxford University Press.

Dalton, R. J., and Welzel, C. (Eds.). (2014). The Civic Culture Transformed. From Allegiant to Assertive Citizens. Cambridge: Cambridge University Press.

Davison, W. (1983). The third-person effect in communication. Public Opin. Q. 47, 1-15. doi: $10.1086 / 268763$

Delporte, C. (2008). Quand la peopolisation des hommes politiques at-elle commencé? Le cas français. Le Temps des Médias 1, 27-52. doi: $10.3917 / \mathrm{tdm} .010 .0027$

Dolez, C. (2013). L'écume des news. Sociologie politique des usages des informations par les citoyens à partir d'entretiens de couple (Dissertation), SciencesPo, Paris, France.

Dubois, V. (2012). Ethnographier l'action publique. Les transformations de l'État social au prisme de l'enquête de terrain. Gouvern. Action Publique 1, 83-101. doi: $10.3917 /$ gap. 121.0083

Duchesne, S., and Haegel, F. (2004). L'enquête et ses Méthodes: les Entretiens Collectifs. Paris: Nathan.

Easton, D. (1965). A Systems Analysis of Political Life. New York, NY: John Wiley.

Easton, D. (1975). A re-assessment of the concept of political support. Br. J. Polit. Sci. 5, 435-457. doi: 10.1017/S0007123400008309

Farrell, B. (1971). Chairman or Chief? The Role of the Taoiseach in Irish Government. Dublin: Gill and Macmillan.

Ferrin, M. (2016). "An empirical assessment of satisfaction with democracy" in How Europeans View and Evaluate Democracy, eds M. Ferrin and H. Kriesi (Oxford: Oxford University Press), 283-306. doi: 10.1093/acprof:oso/9780198766902.003.0013

Foa, R., and Monk, Y. (2016). The danger of deconsolidation. The democratic disconnect. J. Democracy 27, 5-17. doi: 10.1353/jod.2016.0049

Franklin, M. (2004). Voter Turnout and the Dynamics of Electoral Competition in Established Democracies Since 1945. Cambridge: Cambridge University Press.

Gamson, W. (1992). Talking Politics. Cambridge: Cambridge University Press.

Gougou, F., and Persico, S. (2017). A new party system in the making? The 2017 French presidential election. French Polit. 15, 303-321. doi: 10.1057/s41253-017-0044-7

Grossman, E., and Sauger, N. (2017). Pourquoi Détestons-nous Autant nos Politiques? Paris: Presses de Sciences Po.
Grunberg, G., and Haegel, F. (2007). La France vers le bipartisme? La Présidentialisation du PS et de l'UMP. Paris: Presses de Sciences Po.

Hay, C. (2007). Why We Hate Politics. Cambridge: Polity Press.

Hibbing, J. R., and Theiss-Morse, E. (2002). Stealth Democracy: Americans' Beliefs About How Government Should Work. Cambridge: Cambridge University Press. doi: 10.1017/СBO9780511613722

Inglehart, R. (1977). The Silent Revolution: Changing Values and Political Styles Among Western Publics. Princeton, NJ: Princeton University Press.

Kitzinger, J. (1994). The methodology of focus groups: the importance of interaction between research participants. Sociol. Health Illness 16, 103-121. doi: 10.1111/1467-9566.ep11347023

Lascoumes, P. (2010). Favoritisme et corruption à la française. Petits Arrangements avec la probité. Paris: Presses de Sciences Po.

Le Bart, C. (2013). L'ego-politique; Essai sur Lindividualisation du Champ Politique. Paris: Armand Colin.

Le Grignou, B. (2003). Du côté du public. Usages et Réceptions de la Télévision. Paris: Economica.

Lima, L. (2016). Pauvres jeunes. Enquête au coeur de la politique sociale de jeunesse. Nîmes: Champ Social.

Lipset, S. M., and Rokkan, S. (1967). Parties Systems and Voter Alignments: Cross-National Perspectives. Toronto, ON: The Free Press.

Magalhaes, P. C. (2018). "Regime support", in The Routledge Handbook of Elections, Voting Behavior and Public Opinion, eds J. Fisher, E. Fieldhouse, M. N. Franklin, R. K. Gibson, M. Cantijoch, and C. Wlezien (New York, NY: Routledge), 416-428. doi: 10.4324/9781315712390-34

Maigret, E. (2008). L'hyperprésident. Paris: Armand Colin.

Mair, P., and Van Biezen, I. (2001). Party membership in twenty European democracies, 1980-2000. Party Polit. 7, 5-21. doi: $10.1177 / 1354068801007001001$

Mancini, P., and Swanson, D. L. (1996). Politics, Media, and Modern Democracy: An International Study of Innovations in Electoral Campaigning and their Consequences. Westport, CT: Praeger.

Mariot, N. (2010). Pourquoi il n'existe pas d'ethnographie de la citoyenneté. Politix 4, 165-194. doi: 10.3917/pox.092.0165

Mudde, C. (2007). Populist Radical Right Parties. Cambridge: Cambridge University Press.

Neveu, E. (2012). Les politiques de communication du candidat Sarkozy, in Les Politiques Publiques sous Sarkozy, eds J. J. De Maillard and Y. Surel (Paris: Presses de SciencesPo), 48-69.

Noiriel, G. (2006). Le creuset franÃß̧ais. Histoire de limmigration XIXÃ?-XXÃ? siÃ?cle. Paris: Seuil.

Norris, P. (2011). Democratic Deficit: Critical Citizens Revisited. Cambridge: Cambridge University Press.

Paugam, S., and Duvoux, N. (2013). La Régulation des Pauvres: du RMI au RSA. Paris: PUF.

Pharr, S. J., and Putnam, R. (Eds.). (2000). Disaffected Democracies. What's Troubling the Trilateral Countries. Princeton, NJ: Princeton University Press.

Poguntke, T., and Webb, P. (2005). The Presidentialization of Politics-A Comparative Study of Modern Democracies. Oxford: Oxford University Press.

Quaranta, M. (2018). How citizens evaluate democracy: an assessment using the european social survey. Eur. Polit. Sci. Rev. 10, 191-217. doi: $10.1017 /$ S1755773917000054

Rahat, G., and Kenig, O. (2018). From Party Politics to Personalized Politics? Party Change and Political Personalization in Democracies. Oxford: Oxford University Press.

Rahat, G., and Sheafer, T. (2007). The personalization(s) of politics: Israel, 1949-2003. Polit. Commun. 24, 65-80. doi: 10.1080/105846006011 28739

Renwick, A., and Pilet, J.-B. (2016). Faces on the ballot. The Personalization of Electoral Systems in Europe. Oxford: Oxford University Press.

Sineau, M. (2013). "Vote/Comportements politiques in Dictionnaire. Genre et science politique," in Concepts, Objets, Problemes, ed C. Achin (Paris: Presses de SciencesPo), 516-529.

Thomassen, J. (2016). "What's gone wrong with democracy, or with theories explaining why it has?" in Citizenship and Democracy in an Era of Crisis, eds T. Pogunkte, S. Rossteutscher, S. Zmerli, and R. Schmitt-Beck (London: Routledge), 34-52. 
Tiberj, V. (2004). Compétence et repérage politiques en France et aux États-Unis : une contribution au modèle de "l'électeur raisonnant". Rev. Franç. Sci. Polit. 54, 261-287. doi: 10.3917/rfsp.542. 0261

Van Aelst, P., Sheafer, T., and Stanyer, J. (2012). The personalization of mediated political communication: a review of concepts, operationalizations and key findings. Journalism 13, 203-220. doi: 10.1177/146488491142 7802

Wattenberg, M. (1991). The Rise of Candidate-Centered Politics. Cambridge: Harvard University Press.
Conflict of Interest: The author declares that the research was conducted in the absence of any commercial or financial relationships that could be construed as a potential conflict of interest.

Copyright (c) 2021 Dolez. This is an open-access article distributed under the terms of the Creative Commons Attribution License (CC BY). The use, distribution or reproduction in other forums is permitted, provided the original author(s) and the copyright owner(s) are credited and that the original publication in this journal is cited, in accordance with accepted academic practice. No use, distribution or reproduction is permitted which does not comply with these terms. 
OPEN ACCESS

Edited by:

Ignacio Lago,

Pompeu Fabra University, Spain

Reviewed by:

Ferran Martinez i Coma,

Griffith University, Australia

Lee Morgenbesser,

Griffith University, Australia

*Correspondence:

Camille Bedock

c.bedock@sciencespobordeaux.fr

Specialty section:

This article was submitted to

Elections and Representation,

a section of the journa

Frontiers in Political Science

Received: 18 May 2020

Accepted: 18 August 2020

Published: 22 September 2020

Citation:

Bedock C (2020) Citizens' Contrasting Aspirations About Their Political

System: Entrustment, Participation, Identification and Control.

Front. Polit. Sci. 2:563351

doi: 10.3389/fpos.2020.563351

\section{Citizens' Contrasting Aspirations About Their Political System: Entrustment, Participation, Identification and Control}

\author{
Camille Bedock* \\ Centre Emile Durkheim, Sciences po Bordeaux, Pessac, France
}

Empirical political science has increasingly focused on citizens' conceptions of their political system. Most existing studies draw upon large quantitative datasets which have produced contradictory results. Qualitative approaches are used more and more commonly to identify the general narrative produced by ordinary citizens on their political system, but they tend to underplay the variations found in their discourses. In this article, I use semi-directed interviews to explore citizens' contrasting aspirations about their political system. This article is based on 32 interviews conducted with French citizens across Fall and Winter 2017 and on 24 interviews conducted during the Yellow Vests movement in fall 2019. During these interviews, citizens were asked to define in their own terms what politics is, what it should achieve, what the flaws and advantages of their political system are and what should be changed. These citizens have produced four ideal-typical discourses, uncovering four distinct conceptions of what the political system is, how it legitimizes itself, what types of procedures it should lay on and what types of outcomes it should produce. Citizens' discourses heavily focus on alternative logics of political representation, which remains unavoidable to channel political decisions. They express four competing aspirations: entrustment, participation, identification, and control \& sanction. The two latter conceptions remain under-explored empirically.

Keywords: political system, democracy, citizens, representation, participation, control, identification

The conceptions of the political system of citizens who live in democracy is a topic that has attracted more and more concern in recent years. Quantitative research has underlined the existence of competing aspirations. Support for traditional representative democracy is challenged by a growing demand for citizen participation (Norris, 1999, 2011) and the prevalence of "stealth" democratic attitudes supporting the empowerment of experts and successful businessmen (Bengtsson and Mattila, 2009; Coffé and Michels, 2014; Fernández-Martínez and Fábregas, 2018). Qualitative approaches have adopted another perspective which focuses on the general narrative produced by ordinary citizens on their political system (Hibbing and Theiss-Morse, 2002; Clarke et al., 2018; Saunders and Klandermans, 2019).

How can we account for the contrasting aspirations expressed by citizens about their political system using qualitative methods? I argue that it is necessary to complement existing studies with qualitative analyses tackling specifically the variation found in the ideal-typical discourses produced by citizens on their political system. To do so, this article is based on individual interviews with French citizens, complemented with the use of interviews with Yellow Vests activists' conducted 
between 2017 and 2019. France is an interesting laboratory to explore this research question for several reasons. Firstly, France is a semi-presidential majoritarian democracy in which alternatives to representative democracy are limited, parties are particularly weak, where the presidential figure is dominant, and where a large part of voters are not represented in Parliament (Grossman and Sauger, 2010). Secondly, it is characterized by an intensive use of democratic reforms (Bedock, 2017), by the existence of important social movements challenging the current state of French democracy, and by a very low level of confidence in existing political institutions (Grossman and Sauger, 2017). Debates about the "right" political system are therefore unusually high on the agenda compared to other democracies. This enables an easier access to citizens' views on the political system during interviews.

By using an inductive and qualitative approach, I show that French citizens produce four ideal-typical discourses about their political system that reveal four distinct conceptions of what the political system is, how it legitimizes itself, what types of procedures it should lay on and what types of outcomes it should produce. My focus was on the political system in general. Easton defined it as the interactions through which values are authoritatively allocated in a society (Easton, 1965). We could also describe it as the decision-making process turning inputs into policy outputs. Even though we adopted this wide focus over the course of the inquiry, we found that citizens' discourses about the political system are mostly structured by alternative conceptions of political representation.

The first section comes back on the quantitative and qualitative empirical studies on citizens' aspirations about their political system, and on their limitations. The second section briefly presents the material and the thematic analysis. Sections The Aspiration to Entrustment, The Aspiration to Participation, The Aspiration to Identification, and The Aspiration to Control and Sanction discuss in turn the four aspirations emerging from our thematic analysis: entrustment, participation, identification, and control. For each of these conceptions, I analyze the definition of politics, the discourses about elected representatives, about the political process and about policy outputs identified in the discourses of the interviewees, before discussing the social and political properties of the individuals who held the most archetypical discourses.

\section{WHAT DO CITIZENS EXPECT FROM THEIR POLITICAL SYSTEM? EXISTING EMPIRICAL EVIDENCE}

\section{Participation, Expertise, and Representation: Three Competing Aspirations Identified by Survey Research}

In recent decades, many scholars have conducted surveys on citizens' preferences regarding how democracy should be organized (to name a few, see Bengtsson and Mattila, 2009; Webb, 2013; Coffé and Michels, 2014; Font et al., 2015; Caluwaerts et al., 2018). They show the co-existence of three models of democracy (Bengtsson and Christensen, 2016). The first modelthe participation model-implies that citizens should be actively involved in decision-making through extensive mechanisms of participation. The expertise/technocratic model insists on efficiency, values experts to take political decisions, and requires limited citizens' involvement. Finally, the representation/elitist model posits that elected representatives should remain in charge of political decisions and be accountable in front of their voters.

A growing share of the population supports the idea to give more opportunities to citizens to get involved in the political process, or even to make them the main policy-makers (Webb, 2013; Font et al., 2015; Bengtsson and Christensen, 2016; del Río et al., 2016; Gherghina and Geissel, 2017). Some studies focus on more specific instruments of participation, such as referendums (Bowler et al., 2007; Bengtsson and Mattila, 2009; Schuck and de Vreese, 2015; Bowler and Donovan, 2019), deliberative democracy (Neblo et al., 2010; Caluwaerts et al., 2018), or sortition to involve citizens or even replace politicians in the decision-making process (Bedock and Pilet, 2020). These studies all show that a significant proportion of individuals across various contexts support increased citizen participation in various forms, direct democracy being particularly popular. Other scholars insist on the pervasiveness of stealth democratic attitudes among ordinary citizens. Stealth democrats want independent experts or successful businessmen to take the most important decisions and reject partisan politics. The prevalence of stealth democratic attitudes has been observed in various contexts: the US (Hibbing and Theiss-Morse, 2002; VanderMolen, 2017; Medvic, 2019), Finland (Bengtsson and Mattila, 2009), the Netherlands (Coffé and Michels, 2014), or the UK (Webb, 2013; Stoker and Hay, 2017).

In other words, a large proportion of citizens across different countries seem not to consider that elections and representation are the only acceptable mechanism to take political decisions in democracy. These contrasting aspirations (participation, expertise, representation) are not randomly distributed. Several authors show that reforms reinforcing the role of citizens in the political process are supported by young, educated, politically interested and post-materialist individuals (Donovan and Karp, 2006; Bengtsson and Mattila, 2009; Norris, 2011; Dalton and Welzel, 2014; Schuck and de Vreese, 2015; Dalton, 2017). Other authors demonstrate that support for alternatives such as the empowerment of experts, lay citizens, or direct democracy is linked with a strong disenchantment with representative democracy (Bengtsson and Mattila, 2009; Neblo et al., 2010; Webb, 2013; Schuck and de Vreese, 2015; del Río et al., 2016; Bertsou and Pastorella, 2017; Gherghina and Geissel, 2018). Political orientation also matters: left-wing oriented individuals are more supportive of participatory mechanisms, whereas right-wing individuals are more prone to support technocratic mechanisms (Bengtsson and Mattila, 2009; Bertsou and Pastorella, 2017). Finally, recent studies have shown that individuals who are more politically and socially marginalized are more likely to support various alternatives to the political status quo (Ceka and Magalhães, 2020), such as the increased use of referendums (Bowler and Donovan, 2019) or sortition (Vandamme et al., 2018; Bedock and Pilet, 2020). 
Despite these general trends, existing results are often contradictory and implicitly assume that citizens who express support for alternative actors in surveys favor mechanisms that would strongly disrupt political representation. These pieces of work identify variations in the conceptions of the political system among ordinary citizens, but these variations are very dependent upon the indicators that are being used. Responses to survey questions about process preferences depend, to a significant extent, on the questions being asked. According to Clarke et al. $(2018,179)$, "if researchers ask questions designed to confirm stealth theories, they tend to achieve such confirmation; but if they ask questions designed to confirm alternative "sunshine" theories, they also tend to achieve such confirmation." Citizens have a harder time taking a clear position when they are presented with unfamiliar options and often express at once support for apparently contradictory options (Bengtsson, 2012). This calls for methodological approaches giving citizens "the opportunity to speak or write freely about formal politics without being guided by tightly worded survey instruments" (Clarke et al., 2018, 179).

\section{Stealth Democracy, Stealth Populism or Participatory Skepticism? Qualitative Evidence}

Another strand of research has used qualitative methods (in particular archives and focus groups) to identify how citizens speak about the political system in their own words. These studies have tempered the idea that citizens have become more assertive and more willing to participate outside of electoral politics (Norris, 1999, 2011; Dalton and Welzel, 2014).

Using focus groups conducted in the US in the early 2000s, Hibbing and Theiss-Morse have developed an influential study on "stealth democracy" (see supra.). They argue that surveys suggesting that people want to increase the power of ordinary citizens are misleading and only measure the intense distrust of American citizens of their political elites. During the focus groups, politicians were considered as knowledgeable but selfinterested and blinded by partisan considerations, whereas citizens were considered as too politically apathetic to become more involved in politics. Interviewees defined governing as good management rather than the representation of diverse interests. As a consequence, citizens expressed the will to be governed by independent experts or successful businessmen that would move decision-making away from clashing interests and be instinctively in touch with citizens' aspirations.

In a more recent study conducted in the United-Kingdom, Clarke et al. used archives comprising hundreds of letters from panelists about politicians, parties, and government, and compared the post-World War II period with the 2000-2015 period. They show the increasing prevalence of "anti-politics," i.e., "citizens' negative sentiment toward the activities and institutions of formal politics (politicians, parties, elections, councils, parliaments, governments" (Clarke et al., 2018, 2-3). They argue that already after the Second World War, British citizens' expressed a "stealth" understanding of democracy and saw parties as diversions from the general interest. Contrary to what Hibbing and Theiss-Morse suggested, British citizens do not want experts to be in charge, but statesmen who would work in grand coalitions. At the beginning of the twenty-first century, "a stealth understanding of politics has transformed into a stealth populist understanding, by which many citizens imagine "the people" - who largely agree and so just need action from competent, independent representatives-but also an incompetent and out of touch political elite" (Clarke et al., 2018, 262). The authors argue that what is expected from a "good politician" has changed over time: "many citizens came to expect politicians not only for the people (sincere, hardworking, able, moderate, strong), but also of the people (normal, in touch)". Other studies using focus groups show the importance of the national context-party configurations, current political institutions, recent social movements and more generally of current social and political events-to understand the differences in the way in which citizens see politics and their political systems (Saunders and Klandermans, 2019), but confirm the prevalence of "anti-politics" feelings.

These examples show the importance of not relying solely on survey research to analyze citizens' aspirations about their political system and invite political scientists to question their own understanding of democracy. Indeed, even more so since the "deliberative turn" taken by political theory (Goodin, 2008), political scientists tend to value deliberation as the best way to restore faith in politics, often assuming that most, if not all citizens, also share this view. All of these studies have one strong limitation: they focus on the single dominant narrative found in the countries investigated and not on the variations found in the ideal-typical discourses of citizens. Research conducted in Spain have started to challenge this dominant approach, focusing on the alternative forms of decision-making privileged by different groups of citizens. Although citizens do share a relatively similar understanding of the failures of their political system-blaming political parties and the professionalization of politics-not all groups favor the same alternatives (Ganuza and Font, 2018). Disadvantaged social groups are unconvinced about their own ability to get involved in the political process and skeptical of participatory democracy (García-Espín and Ganuza, 2017). By contrast, people who are engaged politically and vote for leftist parties tend to consider that the solution to the failures of the Spanish political system is more participation. Even if exploratory in nature, this article aims at showing that there may be a way to reconcile quantitative and qualitative approaches by considering at once the variety of conceptions and the social and political differences that could explain it-as done by survey research-and by analyzing a rich material enabling to dig deeper in people's discourses-as done by qualitative research.

\section{INTERVIEW COLLECTION AND THEMATIC ANALYSIS}

This article relies on individual interviews. Focus groups are more heuristic when one focuses on the shared understanding that interviewees have on a given topic in homogenous groups (Van Ingelgom, 2014), and on how interactions and disagreements enable to make these shared meanings emerge 
(Duchesne and Haegel, 2004). By contrast, I am interested in the differences and the variations found in the discourses of citizens about their political system, but also in the way in which these can be related with their socialization.

The following conclusions are mainly based on in depth qualitative interviews with 32 French citizens conducted in Fall 2017 about their visions of the political system, with individuals of various social backgrounds, generations, levels of diploma, places of residence, ideological preferences and political engagement. The main objective behind the selection of interviewees was to uncover the variety of discourses formulated about the French political system by diversifying as much as possible the profile of the interviewees (see Supplementary Appendix 1). To better understand one of the four aspirations that these interviews enabled to identify (see infra.), I also used elements of the 24 interviews conducted with activists during the Yellow Vests Movement with other colleagues (Bedock et al., 2020) in Spring 2019 as a complementary empirical material. This social movement has gathered a majority of individuals coming from disadvantaged social backgrounds as well as many people who mobilized for the very first time (Collectif d'enquête sur les Gilets jaunes, 2019).

Our two samples are not fully representative of the French population. For the 32 interviews with lay citizens, there is a gender imbalance in favor of men, individuals between 18 and 24 years old and people over 65 years old, people with a university degree and executives and professionals. This imbalance can be explained by the theme at stake, presented to the interviewees as "citizens' views about French politics." This can be intimidating for individuals lacking interest in politics and coming from a social and educational background who tend to lack a "sense of empowerment" in expressing opinions about the political world (Gaxie, 2007). By contrast, the sample of Yellow Vests interviewed is less educated, and more of them belong to working class backgrounds. In both samples, individuals self-identifying with the left are over-represented, which can be partly explained by fact that interviews were conducted face-to-face (Mayer, 2018) and by the over-representation of politicized individuals. Around a third of interviewees in both samples did not situate themselves ideologically during the interview, and $56 \%$ of our interviewees never had any political engagement (involvement in social movements, political associations, trade unions, parties, etc.). We did our best to diversify the profile of the interviewees to reach respondents who were distant from politics and who were closer to the right and the center. In both samples, we followed the principle of data saturation and planned interviews until no additional information was provided by new interviews (Ando et al., 2014).

The interviews lasted between $40 \mathrm{~min}$ and $2 \mathrm{~h}$ and $45 \mathrm{~min}$. First, we asked a series of questions to understand their social and professional background, their current news habits, their political socialization and their views about the most recent elections (the 2017 French presidential election and the 2019 European election for the Yellow Vests interviewees). This part aimed at characterizing the social and political background of the interviewee. In the second part, we focused on their conceptions of the political system: feelings about politics, the French political system, the ideal political system and the reforms that should be put in place. Finally, in the third and final part, interviewewees were presented vignettes of institutional reforms adopted in France or other countries and were asked to react about them. These reforms were chosen as ideal-typical reforms embodying various visions of democracy uncovered by political theory: direct democracy controlled by citizens (through recall votes in the US), deliberative democracy (through the citizens' assembly organized in Ireland since 2016), stealth democracy giving power to unelected experts (through the Autorité de la concurrence in France or technocratic governments in Italy) and representative democracy (through gender quotas reforms to promote women in politics in France).

All interviews have been fully transcribed verbatim and coded manually and inductively using the Nvivo qualitative analysis software, in order to identify and analyze the themes spontaneously evoked by interviewees when presented with the topic (see Supplementary Appendix 1 for a detailed presentation of the coding process). The codes were reviewed several times in order to make them consistent and stabilized. The same segment could refer to various themes at once. The codes were regrouped into overarching themes that are the ones used in this article to analyze the conceptions of citizens about their political system: the conception of politics, the evaluation of elected representatives, the conception of the political process and the conception of policy outputs.

We identify four ideal-typical discourses corresponding to four fundamental aspirations: one valuing entrustment to competent individuals above partisan considerations, one valuing participation of ordinary citizens in every step of the political process, one valuing identification and representatives who look like the general population and finally one discourse focusing on control and sanction of existing representatives. These four discourses should not be understood as rigid categories, but rather as contrasting aspirations among which citizens "navigate" when they verbalize their vision of what their political system is and ought to be. Citizens do have ambiguous and sometimes contradictory and opposite aspirations when it comes to the political system. As argued by Ewick and Silbey, "in order for something to be meaningful at all, it must contain, at least implicitly, an opposing or contrasting meaning" (Ewick and Silbey, 1998, 52).

In the following sections, we will discuss in turn the conception of politics, of the political representatives, of the political process and of policy outputs formulated by the interviewees.

Some individuals formulate discourses that are "closer" to the ideal-typical aspirations identified, and can be considered as paragons. We will examine the social background and the political socialization of these paragons, which give us interesting indications about the typical profile related to each of the four aspirations. 


\section{THE ASPIRATION TO ENTRUSTMENT Conception of Politics}

In the first discourse we identified, the adversarial and ideological character of politics is criticized as a diversion. Partisanship is rejected, with the implicit idea that it is possible to reach objective and universally acceptable solutions, very much in line with the "stealth aspirations" identified by several authors (Hibbing and Theiss-Morse, 2002; Clarke et al., 2018). $\operatorname{Lin}^{1}$ (female, 38, unemployed) argues:

"I don't like discourses involving too much the notion of conflict. (...) Everyone sticks to his guns, instead of thinking together about what we could do to, say, maximize advantages and limit drawbacks. Anyway, for me, political choices are only about this. It is about mediation. It's about picking the least worst or the best".

Good politics is associated with harmony, pragmatism, or even truth. For instance, Fabien (male, 38, winegrower) dislikes political debates on TV, because "as long as one does not face the truth, one cannot solve an issue." In this perspective in which one believes in the possibility to reach an acceptable, dispassionate and depoliticized agreement, politics mainly plays a role of guarantor preserving everyone's liberties. Christophe (male, 23, political science student) argues that:

"Politics shouldn't meddle in everything, quite the contrary. (...) Politics is law. It's people who must make laws to make sure that life in society goes on as well as possible. (...) Make sure things work, that's it. It's like a waiter when you're in a restaurant. It's very important that he's there but you should not see him".

\section{Vision of Political Representatives}

This conception of politics is related with an ideal vision of what political representatives should be like. Politicians should have exceptional qualities that put them aside from the mass of ordinary citizens. Politicians should be knowledgeable, master the art of talk and reject demagogy. This elitist conception of politicians is in line with the analysis of Manin about the inherently aristocratic nature of representative democracy which denotes "the lack of similarity between electors and elected" (Manin, 1997, 159). Lin (38, female, unemployed) draws a distinction between "statesmen" and politicians. According to her,

\begin{abstract}
"A statesman should be aware that everything he says, or everything he does will have an impact on the lives of many people. And even beyond, for future generations. (...) If a politician tells you that it is simple to be a politician, I think he does a very bad job!"
\end{abstract}

Another interviewee, Christian (71, male, former army colonel) underlines the many qualities he considers as indispensible to become president of the Republic: a good knowledge of

\footnotetext{
${ }^{1}$ The names of the interviewees were changed and replaced by similar surnames in terms of popularity by year and social and ethnic origins, based on the website https://dataaddict.fr/prenoms/.
}

French history, of economy, of public law, and a thorough general culture. His discourse refers to many French political personalities from Charles de Gaulle to François Fillon, Alain Juppé, Nicolas Sarkozy, Valery Giscard d'Estaing or Benoît Hamon, who are evaluated and dissected. He also refers to physical attitudes making people apt for the presidential function, underlying the necessity to have not only a mastery of the mind, but also of the body. For instance, talking about the debate opposing the right-wing contenders during the primary in autumn 2016 to select the presidential candidate, he said:

\footnotetext{
"Juppé drooled, at one point. And my friends (...) said, 'seeing a man who is not able to make a discourse without drooling, for me, this means that he's unreliable, he can't become president of the Republic!"
}

In other words, not everyone can (or at least, should) become a politician: only particularly gifted individuals should take this path. This can be related with findings of Clarke et al. who show that British citizens after the WWII expected politicians to be true statesmen, allying moderation, competence, sincerity, and leadership (Clarke et al., 2018).

\section{Vision of the Political Process}

In this discourse focusing on the entrustment of political decisions to particularly skilled individuals, the ideal political process is a system guaranteeing efficiency, stability, the ability to reform and the competency of those who take part in the political process. Interviewees proposed various reforms such as the suppression of useless levels of government, the cut of the number of representatives, the installment of a Senate composed exclusively of people who have studied law, or a 7-year term for the president of the Republic to give him more "political height." More generally, this discourse emphasized the need tend to defend the existing institutional status quo of the Fifth Republic, praising the ability of the current regime to "reform" against so-called conservative forces. For instance, Marion (25, female, lawyer in a hospital) defends the article 49.3 enabling the government to pass a law without a vote if there is no motion of no-confidence adopted with the following arguments: "there are decisions which should be taken rapidly." The stability of the regime is attributed to the current French constitution, and stability is used as the standard meter to evaluate the current political procedures.

Interviewees who held this discourse often formulate harsh judgments about their fellow citizens, considering that "the problem is not so much the political system, it's people!" (Alexia, 20, female, student in an engineering school). They argue that citizens have unrealistic demands toward politics which could create chaos and instability. Laws and policy-making is considered as "too complex" to allow the participation of lay citizens in the political process. Politicians in general and the President of the Republic in particular should be beyond partisan and vote-seeking considerations and embody the solemnity attached to the presidential function. More generally, in this discourse, interviewees support the existing procedures as long as they "work." Christophe (23, male, political science student) 
argues: "whether one agrees with the way it works, this is a different problem. In any case, it works." This implies, for instance, in the French case, the defense of the two-round majoritarian electoral system which limits the representation of small parties but facilitates the emergence of a strong parliamentary majority. More generally, the judgment of these interviewees on existing French institutions is in line with the dominant discourse of constitutional lawyers and political representatives on the Fifth Republic who strongly value the stability it has supposedly brought to the country.

\section{Vision of Policy Outputs}

This discourse values the search for a "middle ground" between interventionism and liberalism, in order to guarantee everyone a minimum quality of living. For instance, Lin (38, female, unemployed), argues:

"I think that ideally, the State should provide its citizens a space of life in which they have the freedom and the affluence to feed themselves, to have proper housing, to move about, and to create businesses".

Public policies are therefore mere providers of social and economic safety nets. The emphasis is put on individual freedom. The French State is judged as too costly, "too generous and too social" (Christian, male, 71, former military officer) and other citizens as prone to "abuse" the generosity of the State. This goes hand in hand with the notion of "managerial," or "steering state" coined by specialists of public policy (Clarke and Newman, 1997; Bezès, 2007).

\section{Paragon}

Christian is the interviewee who best typifies this aspiration to entrustment in our sample. He is born in 1946 and is a former army colonel. After having studied in a French military high school and embraced a military career, he studied law and developed a strong interest for political matters. Christian comes from a middle-class background: his father was in the army before becoming an insurance broker, and his mother worked for him as a secretary after having been a housewife. He defines his father as a "Gaullist," and his mother as "right-wing." None of them were ever involved in a political organization. Christian follows current affairs closely. He listens to a general interest commercial radio (RTL) everyday, reads regularly several conservative weekly newspapers (Le Point, Valeurs actuelles), and does not like television except for the history channel. He votes at every single election and considers voting as an absolute moral and civic duty, but has never been part of any association, political organization or trade union, or participated in demonstrations.

Christian corresponds well to the archetype of the "allegiant citizen" described by Dalton and Welzel (2014): he is deferent to authority, trusts current institutions, and strongly values conventional forms of political participation. He has a strong interest for politics and a good knowledge of French current affairs, but considers that his role as a citizen is mainly to select apt political leaders. His socialization (in his family, at school, and later in the professional world) revolves around the army, a universe structured by conservative values: authority, leadership and order.

\section{THE ASPIRATION TO PARTICIPATION Conception of Politics}

The second archetypical discourse encountered in our interviews can be thought as the reverse mirror of the first one. It revolves around one fundamental aspiration: participation. In this second discourse, politics refers primarily to "civic life." For instance, Bruno (male, trainer for a pharmaceutical company, 42) argues: "I think [politics] involves everyone. The life of the municipality, the life of the département, the life of the region, the life of France." In this perspective, politics is seen as inherently antagonistic, because it involves the confrontation of opposing visions of the common good. These clashing orientations require a thorough debate and the organization of a transparent discussion. Léa (Female, 36 , artist) argues that "politics is a time of debate. We can debate about different ideas to reach a compromise." This idealized vision of politics is often contrasted with what politics actually is, namely a pure quest for power. For JeanJacques (male, 69, former German teacher and administrative assistant) politics "is a noble word, (...) which is probably tarnished by the practice of politics as it is done today." Strikingly, this vision of politics is closely related to arguments developed in political theory by authors focusing on pluralism who argue that politics is a space of confrontation and negotiation between opposing interests in order to reach a compromise (Bellamy, 2002, 2012). These interviewees fully recognize the pluralistic nature of politics and democracy (Dahl, 1971).

\section{Vision of Political Representatives}

In this discourse, the main issue about politicians is the confiscation of power associated with the professionalization of politics. For Jean (male, 75, former English teacher) politics is “a cast, a court. (...) People coopting each other, people who have power thanks to their relations". These interviewees refuse the idea that all politicians are inherently corrupted, but consider that corruption is the consequence of the monopolization of power by a few individuals. According to Bruno (male, 42, trainer in a pharmaceutical company), "politics should not be a profession. It should be a personal engagement for the collective good limited in time and widely distributed. Once we do that, I think that rotten politics will no longer exist." Interviewees also expect politicians to have strong convictions, integrity, and to connect with ordinary people in order to defend their ideas. Personalization of politics and eloquent speakers are rejected. According to André (male, 65, former music teacher): 
"Politicians should become amateurs, that's it! And not only people who went to the right school, the ENA, ${ }^{2}$ schools in which they have been a bit brainwashed (...) At school they're taught that... One should not express doubts. (...) You ask a question, and there is always an answer coming out."

For Marie-Paule (female, 55, archeologist), politicians should be "normal people. Who are not pure egos. Who do not put their ego on the front, who are there for a function." In other words, politics should not be a profession, but a function, in which politicians are not exceptional individuals, but rather ordinary people temporarily engaged in a collective enterprise for the common good.

\section{Vision of the Political Process}

Logically following from this rejection of professionalization and personalization, political institutions are conceived as means to facilitate the de-personalization of the political process and the inclusion of citizens in decision-making. Some interviewees support the recognition of blank votes, others defend proportional representation, compulsory voting, participatory mechanisms, other still the development of checks and balances in the French political system or political education in secondary schools. These aspirations are put in perspective with the current functioning of the French political system, perceived as a "Republican monarchy", not inclusive, too personalized and lacking transparency. For instance, Jean (75, male, former English teacher) despises a system characterized by "opacity (...) There are rooms without doors and without windows, with a secret code. And only the holders of the code can enter".

All of these reforms are seen as means to guarantee inclusion, horizontality, proximity, transparency, and the reversal of the symbolic power between elected politicians and citizens. The political process is seen as having the potential of being an emancipatory instance. Citizens are seen as universally competent, and procedures should ensure that decisions emerge collectively. Solange (69, female, former biologist) argues:

\footnotetext{
"I think we're always less stupid when several people are involved. (...) There are plenty of people who have an opinion! But there are people who don't dare talking. And those who say: 'if you don't have the right words, you shouldn't speak'. That's part of what I call popular education. (...) [Politics] can be taught, it's like everything."
}

This inclusive discourse is strongly associated with the local level, perceived as a relevant political scale for citizens to become political actors on a day to day basis. Léa (36, female, artist) describes her ideal system as one "starting from the principle that we can be actors locally."

\footnotetext{
${ }^{2}$ National School of Administration. This is one of the most prestigious schools in France, training higher civil servants. A substantial part of the national political class has been trained in this school.
}

\section{Vision of Policy Outputs}

In this discourse, politics is seen as an instrument of social progress and equity. These interviewees relate the professionalization of politics and the confiscation of power with the implementation of policies that only benefit specific and privileged groups. For instance, Jean-Jacques (69, former German teacher) criticizes harshly the fact that "politics is more and more done by lobbies and CEOs in France and elsewhere." The policies advocated relate to welfare, public service, education, health or the environment, always with the idea that politics is an instrument of collective progress. Taxes are seen as necessary and positive, as they are the main resource allowing for social progress. At the same time, the interviewees who held this discourse often regretted the fact that the French welfare state was being dismantled, and criticized the rise of social inequalities. Elise (female, 69, former snack and bar tender) said to me: "Why don't we do anything? Why is the gap getting larger? We must change the world! (...) All the social progress earned by class struggle, this social progress is gone. Definitively gone." The aspiration to inclusion and participation relates, in terms of public policies, to the support for policies promoting social equality and the collective good more generally.

\section{Paragon}

Solange (69, former biologist) is the best archetypical example of this aspiration to participation. Born in 1948, she obtained a $\mathrm{PhD}$ in 1978 and worked as a research engineer. She has experienced a strong ascending social mobility as she comes from a working-class background: her father was a cabinetmaker and her mother a seamstress. Her media habits are typical of the intellectual and highly politicized individuals (Le Hay et al., 2011). She reads Libération (a national left-leaning daily newspaper) everyday, but she has also been a subscriber of Le Monde (the most prestigious daily newspaper in France) or Le Monde diplomatique (a monthly newspaper gathering many left-wing contributions). She does not own a television, defines herself as an "all-time adept of France Culture" (an intellectual public radio channel) and is an avid reader of political and economic essays. She started her political engagement by joining the $\mathrm{CFDT}^{3}$ in the 1970s as she felt close to the PSU (Socialist Unified Party, a self-managed political party $)^{4}$. She has been part of multiple political associations: ATTAC (Association for the Taxation of financial Transactions and citizens' action), an association for the recognition of blank ballots, or the International League for Human rights. During the interview, she situates herself very precisely in the intricacies of the French political left. She votes systematically at every election, often attends local political meetings, and has taken part in various demonstrations.

To use Dalton and Welzel's typology again, Solange is the embodiment of the "assertive citizen" (2014). She values and practices very diverse forms of political activities, distrust

\footnotetext{
${ }^{3}$ French Democratic Confederation of Labor.

${ }^{4}$ As underlined by Bourdieu $(1979,496)$, supporters of the PSU are typically found among the intellectual class and are characterized by the fact that they see everything through a political prism.
} 
authorities, strongly believes in the virtues of inclusion and participation and is very critical of existing French political institutions. Her interest in politics and her participatory conception of the political system was built over time in selfmanaged and highly politicized circles, in particular thanks to her trade union activities which led her to various other forms of political engagement on the left and made her particularly politically competent.

\section{THE ASPIRATION TO IDENTIFICATION Conception of Politics}

The third discourse could be summarized by the aspiration to identification, that is to say the will to have representatives who share characteristics with oneself. In the first two archetypical discourses presented above, politics is seen as a potentially positive force, with the ability to affect people's lives. In the third discourse, on the contrary, politics is associated with vanity, uselessness and ridiculousness. It lacks any concreteness and has no hold over people's lives. According to Arthur (male, 20, unemployed): "a lousy politician in government has never changed a thing." Consequently, in this perspective, citizens refuse to place any hope or expectations into politics. Talking about the last presidential elections, Basile (male, 24, designer) argues:

\footnotetext{
"I could never imagine that all of these promises could one day spill over onto me, or my closed ones, or the real life of people. (...) [Politics] bores me. It bores me, because it's a lot of efforts for nothing. It's like tilting at windmills".
}

\section{Vision of Political Representatives}

Interviewees holding this third discourse judge politicians primarily by comparing their socio-demographic characteristics with the characteristics of the general population and their own characteristics, noting the gap existing between the two categories. Current politicians are considered as identical, interchangeable, in politics for too long, or even "redundant." Elected politicians should resemble the general population, because individuals from a certain group are better suited to represent the interests of a specific segment of the people.

This idea goes hand in hand with the notion of "descriptive representation" coined by Pitkin, who argued that "a representative body is distinguished by an accurate correspondence or resemblance to what it represents, by reflecting without distortion" (Pitkin, 1967, 60). According to Faly (22, male, student in a business school) politicians are "the vast majority of the time people who have a certain age, who have been in politics for a while. So, from a physical point of view, yes, they all sort of lookalike (...) they are almost redundant." Talking about the qualities he sees in Emmanuel Macron, he argues "what attracted me is the fact that he is young. And therefore, for me, a young president is a good point because (...) I am fed up of seeing always the same faces." By contrast, another interviewee (Arthur, 20, male, unemployed) with working class origins strongly rejects Macron because "he is a banker." He voted for Philippe Poutou "because he is a worker, so he knows what a factory is." These two interviewees project certain desirable characteristics (age for the former, or social class for the latter) in order to reach a positive or negative judgment about given politicians.

\section{Vision of the Political Process}

As good institutions ensure that political representation is a mirror of society, interviewees support reforms in favor of the social, generational and sometimes ethnic diversification of elected representatives. This is in direct opposition with the first aspiration in which competence and stability should prevail over considerations such as representativeness and diversity. Manon (23, female, student in a nursing school), makes the following argument:

\begin{abstract}
"Getting interested [in politics] is complicated, because when we try we realize that people who do politics have nothing to do with us (...) Because someone talking about immigration, or this, or that, but who has all of his life lived in beautiful houses, with a lot of money, we wonder, "but what does he know exactly?"
\end{abstract}

Diversity is seen as a gateway to diffuse various personal experiences into the political debate, with the idea that the common interest and the legitimacy of the political process are linked with the ability of the institutions to encompass and aggregate diversity. Basile (male, 24, designer) defends a system in which people from different social backgrounds could enter politics, in order to reconnect citizens with politics. He considers that the root of political disenchantment is due to the lack of diversity: "Social diversity would enable people to identify themselves. (...) It would give us many more different ways of thinking." According to their own socio-demographic characteristics, some insisted more on social diversity, some on the over-representation of older people, or on the lack of representatives with foreign origins. For example, Amine (21, male, unemployed), who is originally from Maghreb, says that "it would be good if there were not only French people in the parliament." These interviewees consider that when someone has not experienced concretely a given situation, she is not able to elaborate good public policies. More generally, a good political system is a system in which individuals are legitimate because they have various personal backgrounds enabling them to take political decisions rooted on personal experience. Jane Mansbridge formulates a similar argument and argues that descriptive representation improves the quality of decision and deliberation and the legitimacy of the polity. She also considers also that descriptive representation can be understood not only as visible characteristics (being a woman, or being black for instance) but mostly as shared experiences (Mansbridge, 1999).

\section{Vision of Policy Outputs}

In the two previous conceptions, interviewees evaluated public policies by providing a general discourse on the general interest rather than relying on the evaluation of their own personal

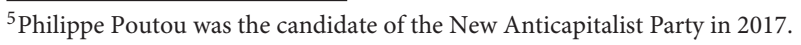


situation. Here, by contrast, the evaluation of policy outputs is based first and foremost on the perception that the State does too little for the social, ethnic or generational group one belongs too. As the political system only represents certain people, it also only provide policies and public services for certain segments of the population to the expense of other groups that do not have access to public decision - a belief that is, in fact, quite supported by empirical evidence (Bartels, 2018). For instance, Arthur (20, male, unemployed), who is a young unemployed working-class boy wants "economic change, employment. (...) Those who are concerned with unemployment are people my age. From 18 to 25 years old." Other interviewees also refer to their "generation": for instance, Basile (male, 24, designer), argues "we feel, our generation, that we have the all the bad sides." $\mathrm{He}$ agrees with the idea of paying taxes in principle but that he feels that other groups benefit from it, and he and his generation do not. Maelys (24, female, administrative assistant) also reproaches the French welfare state not to provide financial aids catered to people in her own situation: she graduated and is not entitled to any financial help before turning 25 . Faly (22, male, student in a business school, who is black) says he sometimes feels like a "sub-French" and considers that France is not supportive enough of its ethnic and religious diversity. More generally, these young interviewees advocated for policies addressed specifically at them. They evaluate policies based on egotropic considerations rather than sociotropic ones, to use a concept of economic voting.

\section{Paragon}

Basile is the most archetypical example of this discourse. Born in 1993, he comes from Paris and has a Higher National diploma in interior design. He started his first stable job one year before and still lives with his father (his parents are divorced). His mother is a teacher in a professional high school, and his father never really had a stable professional situation. He comes from a leftist and politicized family: his mother in particular is involved in Unbowed France and was part of a trade union during all of her career. Several of his relatives were communists. Basile clearly defines himself as left-wing and mentions demonstrations, strikes and sit-ins in which he took part when he was in high school. $\mathrm{He}$ is therefore clearly able to situate himself politically and is quite knowledgeable about politics. Despite this background, Basile is less and less interested in politics since he has started working. He used to read Le Monde on his smartphone, but uninstalled the app, and occasionally flips through newspapers that he finds at work. He does not have a TV and never listens to the radio. He votes very intermittently as he considers that elections do not change anything. He is not part of any political organization and justifies what he calls his own "individualism" by the powerlessness he feels about politics.

What dominates in Basile's interview is the discrepancy between his leftist convictions, his politicized environment, and the rapid loss of interest for political matters. This interview also reveals the deep-seated gap between what Basile expects from the political system and his perception of what it actually is, which leads to political apathy even if he comes from an environment making him predisposed to political engagement.

\section{THE ASPIRATION TO CONTROL AND SANCTION}

Citizens closer to this fourth and final discourse are particularly distant from formal politics which makes interviews about political questions quite difficult. Lay citizens who were closer to this discourse did express clear criticisms about the current system, but did not have very precise attitudes on the reforms that were needed. It is the reason why this fourth discourse can also be informed by the interviews done with a peculiar group of Yellow Vests: those who got involved for the very first time in a social movement. Indeed, these interviewees also used to share the idea that politics is an estranged world, but eventually joined the movement anyway and develop a structured discourse about their vision of the political system and their institutional aspirations (Bedock et al., 2020). Their discourses enable us to inform the attitudes of citizens who are distant from formal politics about the political system.

\section{Vision of Politics}

The fourth discourse is the one that involves the most negative vision of politics and political representatives. Politics is seen as a physically separate space, with its own impenetrable language. Citizens feel uninvolved as in the previous discourse, but more fundamentally, they are profoundly apart from a political world they do not understand, frequently using metaphors relating to physical distance. The strong disinterest for politics is linked with a perceived inability to decipher political discussions. With Jessica (female, 27, farm worker), I have the following discussion when I ask her what politics is about.

- “- J: Pffffffffft. It does not interest me at all in fact! No, not at all. - Me: Why doesn't it interest you?

- J: I don't know, it doesn't attract me.... First, I understand nothing. I tried, when there were the elections and so on, I tried to have a look but I understand strictly nothing. (...) It's their way of talking, of developing and so on, really too... Too much into their own language, I don't know if you see what I mean.

- Me: Yes, as if there were talking to themselves, or...

- J: Yes, that's it, exactly".

As a consequence, politics only relates to a few familiar characters, such as Emmanuel Macron or Marine Le Pen, but is just not part of everyday life. As Daniel Gaxie argued, "for categories weakly concerned by political questions (...) the feelings of misunderstanding and incompetence are mutually reinforcing and lead to self-disqualification" (Gaxie, 2007, 750).

\section{Vision of Political Representatives}

Politicians are perceived as an undifferentiated group benefiting from unjustifiable privileges, apart from the general population, and not living like ordinary people. The opposition between "us" (the people) and "them" (all politicians) is particularly pregnant, and refers to the inability of politicians to understand the ordinary conditions of most citizens because they inhabit "different spheres" (Clément, 40, male, builder). Politicians are 
seen as rich, bourgeois, disconnected, privileged, and corrupted. Still according to Jessica:

\begin{abstract}
“[Politicians] are in their world. (...) They don't live like us. They should put themselves in our shoes (...) I think they have not experienced the same miseries as us. For us, there are times at the end of the month when we have trouble feeding ourselves, but they don't have this problem. (...) They are too much into their little bubble of rich people, of posh people. (...) They're born with a silver spoon".
\end{abstract}

Behind this discourse lies the idea that politicians are not able to have empathy for "us," the "people," understood as a totalizing unit. Politicians are presented as completely socially homogenous, equally guilty and corrupted. This generalizing discourse is often "borrowed" from other people rather than fully incorporated by interviewees who tend to set themselves aside from politics. For instance, Gabin (20, male, waiter) tells me:

- "G: My relatives complain a lot. So I have a bad opinion because of that.

- Me: What do they complain about?

- G.: That the system is rotten. Really rotten. That's what comes out. (...)

- Me: Rotten in the sense... In what sense, do you know?

- G.: Sort of, but that's difficult to explain".

The privileges of elected representatives-whether real, or fantasized-are heavily criticized. For instance, Jean-Louis (69, involved in the Yellow Vests and former skilled-worker) tells us that "If I had been a politician, I would drive a Rolls Royce (...) I would make 10.000 euros a month!”

\section{Vision of the Political Process}

The interviewees who expressed the strongest disinterest for politics did not to formulate very precise expectations about the necessary reforms of the political system, but were overwhelmingly positive when ideas such as recall and direct democracy controlled by the citizens themselves are being discussed at the end of the interviews. The privileges associated with the elected function are seen as unbearable, undeserved, and aggravating the gap between the political class and ordinary citizens. The comparison between politicians and ordinary workers is often mentioned, in particular when we discussed recall. The threat of recall is seen as particularly positive, because it would turn politicians into ordinary workers who could be "fired" when they misbehave. Aurélien (male, 24, unemployed) argues that "they would work much more," Fabien (38, male, winemaker) that "if I hire an employee and he does a bad job, I fire him." Interviewees expect the political system to give them the possibility to control and sanction politicians and to prevent them from becoming a separate, lazy, privileged and often corrupt cast. The logical consequence of this generalized suspicion is the will to punish politicians who abuse their position of power when they are not held accountable by castigatory mechanisms. Direct democracy is not understood as a tool of permanent citizen participation, but rather as something that should be used punctually either to punish politicians while keeping a rather distant relationship to politics.

Yellow Vests activists' discourses help us to better understand what lies behind this will to control and sanction elected representatives. Recall and direct democracy are mentioned spontaneously by all of the Yellow Vests interviewed, as they are part of the demands of the Yellow Vests movement (Collectif d'enquête sur les Gilets jaunes, 2019). Despite the severity of the judgment made about elected politicians, these interviewees do not wish to do without them. The idea to delegate one's political power to elected politicians is accepted, but under very strict conditions: political mandates should be binding thanks to recall mechanisms to make politicians truly accountable (see Vandamme on recall in this research topic), representatives should seek to represent the general will of the people, and they should have not only a physical, but also a statutory proximity with their voters (Bedock et al., 2020). This statutory proximity involves a "normal" salary and the absence of privileges attached to the political sanction, but also the possibility to be "fired." In other words, representatives are conceived as simple delegates of "the people" who should be made accountable through recall mechanisms (Marx, 1871; Cronin, 1990).

\section{Vision of Policy Outputs}

In this final discourse, interviewees feel that existing policies drag down "the people" as a whole. The politicians are considered as an elite with unlimited rights, that wastes people's money and uses policies to strengthen its privileges. Talking about politicians, Cathy (49, female, medical secretary) argues that "they help themselves!" which prevents them from having in mind the interests of the people. These interviewees also resent what they perceive as a decline of the country, in which everything is more expensive, more difficult, in which they feel less and less secure and more and more excluded. Jessica (21, female, farm worker) mentions immigration, terrorism, the high cost of living in a discourse in which a diffuse fear of the future shows through. She expresses a deep pessimism about the future of her country: "the more it goes, the less we will have, France will be penniless, it will be really...We will really have nothing anymore." Mentioning the social benefits granted to immigrants according to a Facebook post she saw, she is convinced that politicians have organized a system in which some groups are granted more rights than "normal people."

Again, the opposition between "we" and "us" is structuring the discourse, "us" referring to self-serving politicians, or to immigrants, and more generally to social entities opposed to "the people." This discourse very much resonates with the "stealth populist" discourse which portrays "an incompetent and out-oftouch political elite (who act, the story goes, against the interests of the people" (Clarke et al., 2018, 262).

\section{Paragon}

Jessica is the archetypical examples of this fourth and final discourse. Born in 1990, she left school when she was 16 without any diploma. She has worked as a farm worker in vineyards for more than 10 years. She comes from a small and impoverished city and has never lived elsewhere. Jessica is a 
single mom. Her mother used to be a cleaning lady and her father a stonemason. She does not follow political issues and Facebook is her only source of information. She has never voted in any election. Jessica and all of her relatives have never been involved in any political organization, or participated in any political or social movements. Her socialization made Jessica particularly impervious to politics: she does not have a diploma and her family has always kept politics at arm's length. Her social situation is particularly difficult: she has a very physical, demanding and low-paid seasonal job, and is obligated to rely on her parents and on employment benefits to raise her daughter. She has no professional perspective and perceives this situation as fundamentally unfair. As a result, she rejects all individuals and groups that appear to take advantage of people like her.

\section{CONCLUSION AND DISCUSSION}

Table 1 summarizes our findings and the four aspirations expressed by French citizens about their political system. Two oppositions structure these four aspirations (see Figure 1). The first structuring dimension concerns the level of politicization of individuals, intended here as the ability to formulate general discourses and to enunciate general political principles (Hamidi, 2006). In the participation and in the entrustment aspirations, individuals formulate discourses based on general principles. Similarly, in these two discourses, interviewees formulate expectations about their political ideals. They do not refer to their own personal experience to formulate these ideals, but to moral and political values that should guide political action. By contrast, in the identification and in the control \& sanction aspirations, interviewees base their judgments about the political system on their personal experience. A fair political system should do more for people in their situation. When they refer to political representatives, they criticize them and express a negative judgment, but they do not refer explicitly to the ideal qualities that political representatives should have.

The ability to formulate general discourses appears to be linked with the level of political participation and involvement in public affairs. The description of the four paragons shows that the main political characteristic enabling to differentiate between the four discourses is the intensity and the nature of political participation. Political orientation also matters. Individuals who use various forms of political participation to express themselves (vote, but also demonstrations, activism in political organizations, etc.) and who are left-leaning tend to be much closer to the participation discourse. Those who are politically interested, who limit their participation to elections and situate themselves to the center or to the right are closer to the entrustment discourse. By contrast, individuals who express the identification and control \& sanction aspirations have a low level of political interest and involvement. What differentiates them is their level of education and their social position: individuals who are closer to the identification discourse are overall more educated, whereas interviewees who express the most bluntly the aspiration to control \& sanction are characterized by a low level of education and low-skilled jobs.
The second structuring dimension relates to the conception of the general interest. It opposes the participation and the identification aspirations that acknowledge "the plurality of reals" (Laski, 1917, 9) that should be accommodated in the political system and the entrustment and control \& sanction aspirations that have a unitary and non-pluralist vision of the general interest. The aspirations to participation and to identification are based on the belief that individuals have multiple and opposed interests based on their social background and life experience. On the contrary, the aspirations to entrustment and control \& sanction have one thing in common: the belief that "there are things that are either good or bad for the whole of society and political action can be either good or bad for a society in its entirety" (Caramani, 2017, 60). Those who were closer to the entrustment aspiration consider that general interest can be achieved by delegating political power to competent, a-partisan and moderate statesmen, whereas those who were closer to the control \& sanction discourse consider that general interest can be achieved by having the ability to punish political elites.

What is particularly striking in our inquiry is the fact that the discourses of French citizens revolve very much around the different logics of political representation, even though our research design dealt with the vision of the political system in general. Several citizens did not express very precise expectations or ideas about the institutional organization of the countrysuch as the electoral system, the balance of power between the executive and the legislative power, or the vertical organization of powers. This does not mean, however, that they did not have opinions about the political system: rather, these attitudes and discourses were structured by a more general reflection on the modalities of delegation of political power. All citizens we met implicitly or explicitly agree with the idea that political power should be delegated to representatives, but they had different visions about what this representative should do or look like. Political representation remains inescapable in the minds of our interviewees. This result was unexpected, as there is a heated debate in empirical and theoretical political science about the idea that political representation could be bypassed.

Each of the four ideal-typical discourses can be related with a vision of political representation discussed in political theory. Pettit underlines the existence of three types of representatives which can be related with three out of the four discourses: trustees, delegates, and proxies. Trustees are representatives who speak with authority for another, with the freedom to take their own political decisions with no direct control of the represented (Pettit, 2009). As underlined by Manin (1997), the representative government draws its legitimacy from the superiority of the representatives over the represented. This first vision of political representation closely resembles the entrustment discourse. Delegates can be compared with attorneys who act for their clients with the explicit or implicit direction of the represented. As Pettit underlines, "the control that the people exercise over such public representers may take an active, handson form, as when the representees impose suitable constraints on representers or give them explicit instructions. But it may often be just virtual in character, constituting a sort of hands-off, arm's length control" (Pettit, 2009, 72). This vision of political 
TABLE 1 | Summary of the four aspirations.

$\begin{array}{ll}\text { Participation } & \text { Entrustment }\end{array}$

Conception of politics: confrontation of opposed ideas

Vision of political representatives: punctual engagement for the general interest

Vision of the political process: institutions should promote inclusiveness, participation, and transparency

Vision of policy outputs: Politics as an instrument of social progress and equality

Characteristics of the paragon: higher education, intense and diverse forms of political participation, left-wing orientation

Conception of politics: Need to make society work by rejecting adversarial showdowns and partisanship

Vision of political representatives: personalities distinguishing themselves from the mass by their competences and qualities

Vision of the political process: need to encourage efficiency and stability

Vision of policy outputs: State as a guarantor of citizens' well-being

Characteristics of the paragon: interest in politics, right-wing orientation, political participation limited to the act of voting

\section{Identification}

Control \& sanction

Conception of politics: vain, useless activity unable to truly affect people's lives

Conception of politics: estranged and separate space with its own impervious language

Vision of political representatives: interchangeable and identical figures that most of the population cannot relate to

Vision of political representatives: privileged, out of the world, and corrupted bourgeois

Vision of the political process: need to diversify the recruitment of representatives to enable the emergence of diverse interests

Vision of the political process: need to cut the privileges and to strictly control political representatives through recall

Vision of policy outputs: State that does not represent the interests of certain groups

Characteristics of the paragon: young, educated, lack of political participation, and little interest in politics

Characteristics of the paragon: low level of education, low-skilled job, absence of political participation, and no interest in politics

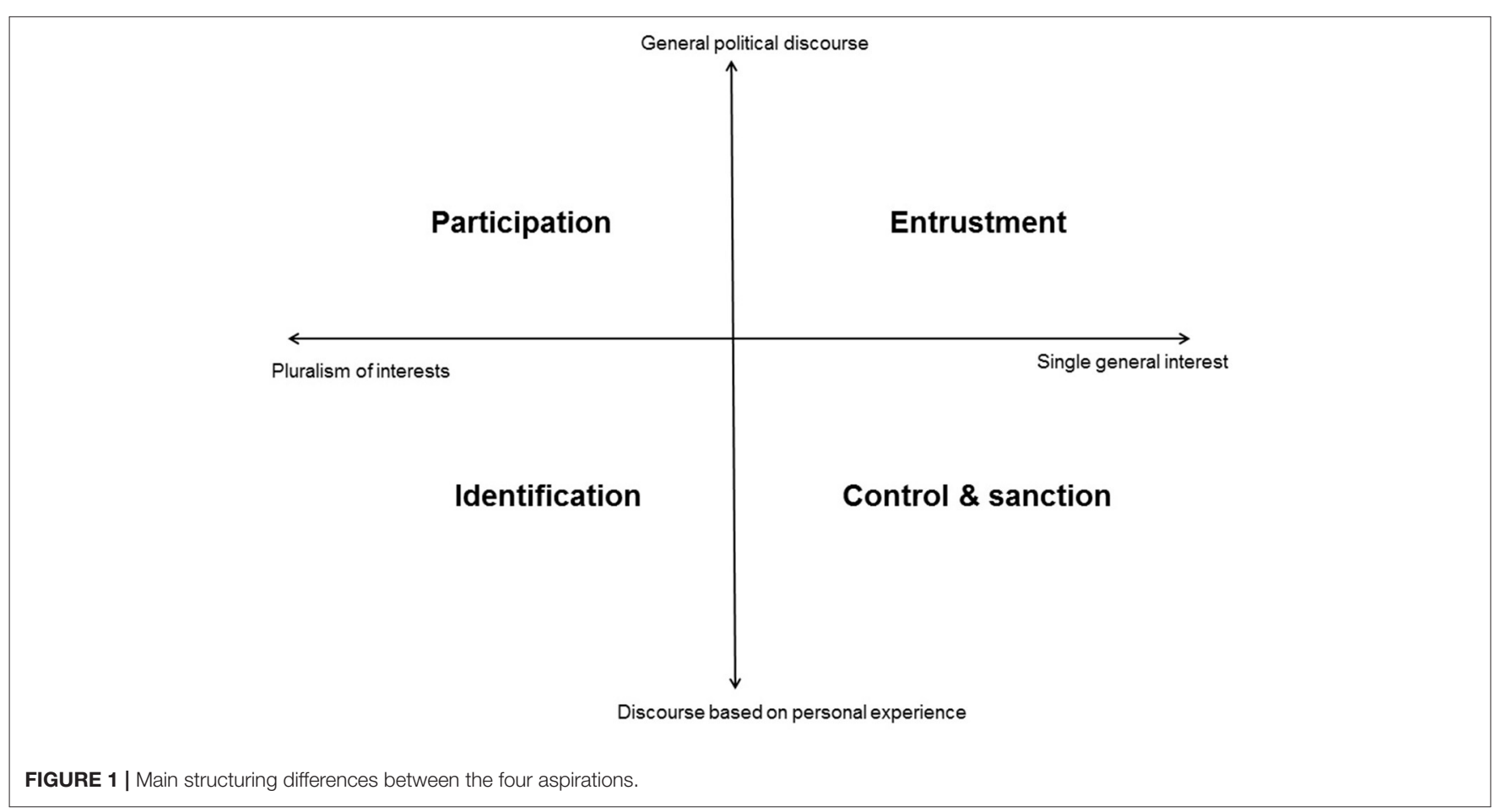

representation closely resembles the aspiration for control \& sanction. These two first conceptions of representation implicitly imply that representatives are able to represent a single general interest, either because they use their authority to take the best political decisions, or because they are supposed to implement the putative "will of the people" (Caramani, 2017).
Proxies are representatives who stand for the represented in the sense of epitomizing them (Pettit, 2009): their legitimacy stems from the fact that they act in the same way as the represented would, because they share characteristics and life experiences with them. This conception of representation shows through in the identification discourse. Finally, we can discuss 
a fourth conception of representation that is closer to the one expressed by interviewees in the participation discourse. It focuses on the link between electoral and non-electoral forms of representation. As underlined by Saward and others, representation is a process of making, accepting or rejecting representative claims (Saward, 2010; Guasti and Geissel, 2019a,b). Representation cannot be reduced to elections and to the action of political representatives, but also takes place in multiple other settings: citizens' assemblies, social movements, various political and non-political organizations, etc. In the participation discourse, interviewees do not want to get rid of electoral representation which remains the cornerstone of the political system, but they reflect upon the way in which citizens could be part of the political process not only during elections, but also more generally. Political representatives do not have the monopoly of representation and political decisions and representation is therefore understood as a more fluid process. These last two conceptions of representation rely on the idea that society is composed of multiple interests, and that the role of political representatives is to channel these diverse interests.

These results are, of course, exploratory in nature and rooted in the French context. As already underlined, France is a majoritarian, strongly adversarial semi-presidential democracy dominated by the figure of the President of the Republic. It leaves few opportunities for citizens to participate outside of elections. Parties, trade unions and other organizations are relatively weak compared to most West European countries, and French citizens are particularly critical of their existing institutions. In our analysis, three out of the four archetypical discourses identified express deep-seated criticisms about the functioning of French democracy. Our results largely echo previous findings in the UK (Stoker and Hay, 2017; Clarke et al., 2018) which may suggest that citizens in majoritarian democracies share similar views about their political system. Citizens in other national settings may be less severe and formulate alternative discourses. Saunders et al. note the importance of taking into account the institutional and political context when analyzing the conceptions of politics and democracy of lay citizens (2019). Existing studies, both quantitative and qualitative, suggest in particular that citizens in consensual democracies-that Lijphart famously qualified as "kindler and gentler" democracies Lijphart (1999)-have a more positive view of their political system, in particular when direct democratic procedures are in place (Ferrin and Kriesi, 2016; Saunders and Klandermans, 2019). For instance, Swiss citizens stand out because of their positive overview about their political system and the limited prevalence of antipolitics feelings. Future works should explore the impact of the national context on citizens' contrasting aspirations about their political system.

I used individual interviews in order to explore the discourses of lay citizens about their political system. Most qualitative studies on similar topics use focus groups, which are ideal to analyze the effect of context, group composition and group dynamics on the production of a shared understanding about a given topic. Individual interviews cannot achieve this, but enable to better understand the strong variations of the discourses of lay citizens and how these discourses are related to their social and political characteristics. This choice has enabled to pinpoint some of the limitations of the existing literature. For instance, the opposition between expertise and political representation, which has been underlined in many existing studies, is in fact a bit of a false opposition. There is no evidence in our qualitative interviews that individuals wish to make technocracy the guiding principle in the political system by replacing politicians by experts. However, several of our interviewees-those who aspire to entrustment-do share the belief that politics should be a-partisan and give more weight to competent, but elected, individuals, in particular when they believe that a consensus can be found on the general interest (Medvic, 2019). The opposition between representation and expertise (Bengtsson and Christensen, 2016) may relate to the evaluation of current politicians, but does not appear to express a true aspiration for non-elected technocracy, confirming a diagnosis already made in the UK (Clarke et al., 2018).

Most of the existing studies have identified the opposition between the aspiration to political participation and the aspiration to entrustment. For instance, Dalton and Welzel talked about the opposition between allegiant and assertive citizens (2014) to describe the shift from citizens who value current forms of political participation and those who want to participate more intensely. It is quite striking that the aspirations to identification and control \& punishment have been much less discussed in the existing literature. Pitkin had already pointed out the concept of descriptive representation (1967), which is key to legitimize democratic reforms such as gender quotas. However, the extent of this aspiration to identification has not been at the center of existing studies on democratic conceptions of the political system. The aspiration to control \& sanction, with mechanisms such as recall and delegate forms of political representation has not been thoroughly discussed in empirical contributions, with very few exceptions (Welp and Whitehead, 2020). We argue that these gaps may be due to the very social and political characteristics of individuals who share these two aspirations. Our article suggests that identification and control \& sanction are aspirations of individuals who do not participate a lot politically and/or who are socially marginalized. This result is sobering and suggests that political scientists themselves may have biases when they examine citizens' conceptions of the political system, which leads them to pay too little attention to the aspirations of the most marginal individuals in society. Future studies, in particular quantitative and comparative ones, should explore these two aspirations further in order to have a more complete picture of the conceptions of the political system of ordinary citizens in democracies.

\section{DATA AVAILABILITY STATEMENT}

The raw data supporting the conclusions of this article will be made available by the authors, without undue reservation. 


\section{ETHICS STATEMENT}

The participants provided oral informed consent for the publication of their verbatim quotes, in accordance with national legislation at the time of interview.

\section{AUTHOR CONTRIBUTIONS}

CB has written the article, collected transcribed and coded the 32 interviews with French citizens used as the main material for the article. CB, Tinette Schnatterer, Loïc Bonin and Tinette Schatterer have jointly collected and transcribed the 24 interviews with Yellow Vests used as a complementary material in Section The Aspiration to Control and Sanction of the article. CB and Tinette Schnatterer have coded these 24 interviews.

\section{REFERENCES}

Ando, H., Cousins, R., and Young, C. (2014). Achieving saturation in thematic analysis: development and refinement of a codebook. Compr. Psychol. 3:3.4. doi: 10.2466/03.CP.3.4

Bartels, L. M. (2018). Unequal Democracy: The Political Economy of the New Gilded Age. Princeton: Princeton University Press.

Bedock, C. (2017). Reforming Democracy: Institutional Engineering in Western Europe. Oxford: Oxford University Press. doi: 10.1093/oso/9780198779582.001.0001

Bedock, C., and Pilet, J. (2020). Who supports citizens selected by lot to be the main policymakers? A study of French citizens. 1-20. doi: 10.1017/gov.2020.1

Bedock, C., Bonin, L., Liochon, P., and Schnatterer, T. (2020). Une représentation sous contrôle : visions du système politique et réformes institutionnelles dans le mouvement des gilets jaunes. Participations 2.

Bellamy, R. (2002). Liberalism and Pluralism: Towards a Politics of Compromise. London: Routledge. doi: 10.4324/9780203007327

Bellamy, R. (2012). Democracy, compromise and the representation paradox: coalition government and political integrity. Gove. Opposit. 47, 441-465. doi: 10.1111/j.1477-7053.2012.01370.x

Bengtsson, Å. (2012). Citizens' perceptions of political processes: a critical evaluation of preference consistency and survey items. Revis. Int. Sociol. 70, 45-64. doi: 10.3989/ris.2012.01.29

Bengtsson, A., and Christensen, H. S. (2016). Ideals and actions: do citizens' patterns of political participation correspond to their conceptions of democracy? Gove. Opposit. 51, 234-260. doi: 10.1017/gov.2014.29

Bengtsson, A., and Mattila, M. (2009). Direct democracy and its critics: support for direct democracy and 'stealth' democracy in Finland. West Eur. Poli. 32, 1031-1048. doi: 10.1080/01402380903065256

Bertsou, E., and Pastorella, G. (2017). Technocratic attitudes: a citizens' perspective of expert decision-making. West Eur. Polit. 40, 430-458. doi: 10.1080/01402382.2016.1242046

Bezès, P. (2007). The "steering state" model: the emergence of a new organizational form in the French public administration. Sociol. Travail 49, e67-e89. doi: 10.1016/j.soctra.2007.10.002

Bourdieu, P. (1979). La Distinction: Critique Sociale du Jugement. Paris: Les éditions de Minuit.

Bowler, S., and Donovan, T. (2019). Perceptions of referendums and democracy: the referendum disappointment gap. Polit. Gov. 7, 227-241. doi: $10.17645 /$ pag.v7i2.1874

Bowler, S., Donovan, T., and Karp, J. A. (2007). Enraged or engaged? Preferences for direct citizen participation in affluent democracies. Polit. Res. Q 60, 351-362. doi: 10.1177/1065912907304108

Caluwaerts, D., Biard, B., Jacquet, V., and Reuchamps, M. (2018). "What is a good democracy? Citizens' support for new modes of governing," in Mind the Gap : Political Participation and Representation in Belgium, ed. K. Deschouwer (Colchester: ECPR Press), 75-90.

\section{ACKNOWLEDGMENTS}

$\mathrm{CB}$ wants to warmly thank Pierre-Etienne Vandamme, JeanBenoît Pilet, and Tinette Schnatterer for their careful reading of previous versions of this article and for their stimulating advice. CB warmly thanks Tinette Schnatterer, Loïc Bonin, and Pauline Liochon for their huge contribution to the fieldwork and the coding of the Yellow Vests interviews used as a complementary empirical material in this article.

\section{SUPPLEMENTARY MATERIAL}

The Supplementary Material for this article can be found online at: https://www.frontiersin.org/articles/10.3389/fpos. 2020.563351/full\#supplementary-material

Caramani, D. (2017). Will vs. reason: the populist and technocratic forms of political representation and their critique to party government. Am. Poli. Sci. Rev. 111, 54-67. doi: 10.1017/S0003055416000538

Ceka, B., and Magalhães, P. C. (2020). Do the rich and the poor have different conceptions of democracy? Socioeconomic status, inequality, and the political status quo. Comp. Polit. 52, 383-412. doi: 10.5129/001041520X156708238 29196

Clarke, J., and Newman, J. (1997). The Managerial State: Power, Politics and Ideology in the Remaking of Social Welfare. London: SAGE.

Clarke, N., Jennings, W., Moss, J., and Stoker, G. (2018). The Good Politician: Folk Theories, Political Interaction, and the Rise of Anti-Politics. Cambridge: Cambridge University Press. doi: 10.1017/9781108641357

Coffé, H., and Michels, A. (2014). Education and support for representative, direct and stealth democracy. Elect. Stud. 35, 1-11. doi: 10.1016/j.electstud.2014.03.006

Collectif d'enquête sur les Gilets jaunes (2019). Enquêter in situ par questionnaire sur une mobilisation en cours : une étude sur les gilets jaunes. Revue Française Sci. Polit. 69, 1-24. doi: 10.3917/rfsp.695.0869

Cronin, T. E. (1990). Direct Democracy: The Politics of Initiative, Referendum and Recall. New edition. Cambridge, Mass.: Harvard University Press.

Dahl, R. A. (1971). Polyarchy: Participation and Opposition. New Haven: Yale University Press.

Dalton, R. J. (2017). The Participation Gap: Social Status and Political Inequality. Oxford, New York, NY: Oxford University Press. doi: 10.1093/oso/9780198733607.001.0001

Dalton, R. J., and Welzel, C. (2014). The Civic Culture Transformed: From Allegiant to Assertive Citizens. Cambridge: Cambridge University Press. doi: 10.1017/CBO9781139600002

del Río, A., Navarro, C. J., and Font, J. (2016). Ciudadanía, políticos y expertos en la toma de decisiones políticas: la percepción de las cualidades de los actores políticos importan. Revis. Española Invest. Sociol. 154, 83-102. doi: $10.5477 /$ cis/reis. 154.83

Donovan, T., and Karp, J. A. (2006). Popular support for direct democracy. Party Polit. 12, 671-688. doi: 10.1177/1354068806066793

Duchesne, S., and Haegel, F. (2004). L'enquête et Ses Méthodes : Les Entretiens Collectifs. Paris: Nathan.

Easton, D. (1965). A System Analysis of Political Life. New York, NY: John Wiley \& Sons Inc.

Ewick, P., and Silbey, S. S. (1998). The Common Place of Law: Stories from Everyday Life. Chicago, IL: University of Chicago Press. doi: 10.7208/chicago/9780226212708.001.0001

Fernández-Martínez, J. L., and Font Fábregas, J. (2018). The devil is in the detail: what do citizens mean when they support stealth or participatory democracy? Politics 38, 458-479. doi: 10.1177/0263395717741799

Ferrin, M., and Kriesi, H. (2016). How Europeans View and Evaluate Democracy. Oxford: Oxford University Press. doi: 10.1093/acprof:oso/9780198766902.001.0001 
Font, J., Wojcieszak, M., and Navarro, C. J. (2015). Participation, representation and expertise: citizen preferences for political decision-making processes. Polit. Stud. 63, 153-172. doi: 10.1111/1467-9248.12191

Ganuza, E., and Font, J. (2018). Por qué la Gente Odia la Política?: Cómo Nos Gustaría Que se Tomaran las Decisiones Políticas. Madrid: Los Libros de la Catarata.

García-Espín, P., and Ganuza, E. (2017). Participatory skepticism: ambivalence and conflict in popular discourses of participatory democracy. Qual. Sociol. 40, 425-446. doi: 10.1007/s11133-017-9367-6

Gaxie, D. (2007). Cognitions, auto-habilitation et pouvoirs des « citoyens 》. Revue Française Sci. Polit. 57, 737-757. doi: 10.3917/rfsp.576.0737

Gherghina, S., and Geissel, B. (2017). Linking democratic preferences and political participation: evidence from Germany. Polit. Stud. 65, 24-42. doi: $10.1177 / 0032321716672224$

Gherghina, S., and Geissel, B. (2018). An alternative to representation: explaining preferences for citizens as political decision-makers. Polit. Stud. Rev. 17, 224-238. doi: 10.2139/ssrn.3264614

Goodin, R. E. (2008). Innovating Democracy: Democratic Theory and Practice After the Deliberative Turn. Oxford: Oxford University Press. doi: 10.1093/acprof:oso/9780199547944.001.0001

Grossman, E., and Sauger, N. (2010). The Institutions of the French 5th Republic at 50. London: Routledge.

Grossman, E., and Sauger, N. (2017). Pourquoi Détestons-Nous Autant Nos Politiques? Paris: Presses de Sciences Po.

Guasti, P., and Geissel, B. (2019a). Rethinking representation: representative claims in global perspective. Polit. Gov. 7, 93-97. doi: 10.17645/pag.v7i3.2464

Guasti, P., and Geissel, B. (2019b). Saward's concept of the representative claim revisited: an empirical perspective. Polit. Gov. 7, 98-111. doi: 10.17645/pag.v7i3.2103

Hamidi, C. (2006). Éléments pour une approche interactionniste de la politisation. Revue Francaise Sci. Polit. 56, 5-25. doi: 10.3917/rfsp.561.0005

Hibbing, J. R., and Theiss-Morse, E. (2002). Stealth Democracy: Americans' Beliefs About How Government Should Work. Cambridge: Cambridge University Press. doi: 10.1017/CBO9780511613722

Laski, H. J. (1917). Studies in the Problem of Sovereignty. London: Yale University Press.

Le Hay, V. L., Vedel, T., and Chanvril, F. (2011). Usages des médias et politique : une écologie des pratiques informationnelles. Reseaux 170, 45-73. doi: 10.3917/res.170.0045

Lijphart, A. (1999). Patterns of Democracy. Government Forms and Performance in Thirty-Six Countries. New Haven, CT: Yale University Press.

Manin, B. (1997). The Principles of Representative Government. Cambridge: Cambridge University Press. doi: 10.1017/CBO9780511659935

Mansbridge, J. (1999). Should blacks represent blacks and women represent women? A contingent "Yes." J. Polit. 61, 628-657. doi: 10.2307/2647821

Marx, K. (1871). La Guerre Civile en France. Montreuil-sous-Bois: Science Marxiste.

Mayer, N. (2018). Qualitatif ou quantitatif? Plaidoyer pour l'éclectisme méthodologique. Bull. Sociol. Methodol. /Bull. Méthodol. Sociol. 139, 7-33. doi: $10.1177 / 0759106318778821$
Medvic, S. (2019). Explaining support for stealth democracy. Representation 55, 1-19. doi: 10.1080/00344893.2019.1581076

Neblo, M. A., Esterling, K. M., Kennedy, R. P., Lazer, D. M. J., and Sokhey, A. E. (2010). Who wants to deliberate-and why? Am. Polit. Sci. Rev. 104, 566-583. doi: $10.1017 /$ S0003055410000298

Norris, P. (1999). Critical Citizens: Global Support for Democratic Government. Oxford: Oxford University Press. doi: 10.1093/0198295685.00 1.0001

Norris, P. (2011). Democratic Deficit: Critical Citizens Revisited. Cambridge: Cambridge University Press. doi: 10.1017/CBO9780511973383

Pettit, P. (2009). "Varieties of public representation," in Political Representation, eds. I. Shapiro, S. C. Stokes, E. J. Wood, and A. S. Krishner (Cambridge: Cambridge University Press), 61-89. doi: 10.1017/CBO9780511813146.005

Pitkin, H. F. (1967). The Concept of Representation. Berkeley: University of California Press.

Saunders, C., and Klandermans, B. (2019). When Citizens Talk About Politics. London: Routledge. doi: 10.4324/9780429458385

Saward, M. (2010). The Representative Claim. Oxford: Oxford University Press. doi: 10.1093/acprof:oso/9780199579389.001.0001

Schuck, A. R. T., and de Vreese, C. H. (2015). Public support for referendums in Europe: a cross-national comparison in 21 countries. Elect. Stud. 38, 149-158. doi: 10.1016/j.electstud.2015.02.012

Stoker, G., and Hay, C. (2017). Understanding and challenging populist negativity towards politics: the perspectives of British citizens. Polit. Stud. 65, 4-23. doi: $10.1177 / 0032321715607511$

Van Ingelgom, V. (2014). Integrating Indifference: A Comparative, Qualitative and Quantitative Approach to the Legitimacy of European Integration. Colchester: ECPR Press.

Vandamme, P.-É., Jacquet, V., Niessen, C., Pitseys, J., and Reuchamps, M. (2018). Intercameral relations in a bicameral elected and sortition legislature. Polit. Soc. 46, 381-400. doi: 10.1177/0032329218789890

VanderMolen, K. (2017). Stealth democracy revisited: reconsidering preferences for less visible government. Polit. Res. Q 70, 687-698. doi: $10.1177 / 1065912917712478$

Webb, P. (2013). Who is willing to participate? Dissatisfied democrats, stealth democrats and populists in the United Kingdom. Eur. J. Polit. Res. 52, 747-772. doi: 10.1111/1475-6765.12021

Welp, Y., and Whitehead, L. (2020). The Politics of Recall Elections. Basingstoke: Palgrave Macmillan. doi: 10.1007/978-3-030-37610-9

Conflict of Interest: The author declares that the research was conducted in the absence of any commercial or financial relationships that could be construed as a potential conflict of interest.

Copyright (c) 2020 Bedock. This is an open-access article distributed under the terms of the Creative Commons Attribution License (CC BY). The use, distribution or reproduction in other forums is permitted, provided the original author(s) and the copyright owner(s) are credited and that the original publication in this journal is cited, in accordance with accepted academic practice. No use, distribution or reproduction is permitted which does not comply with these terms. 


\section{OPEN ACCESS}

Edited by:

Hanna Wass,

University of Helsinki, Finland

Reviewed by:

Stefanie Reher,

University of Strathclyde,

United Kingdom

Francisco Cantu,

University of Houston, United States

*Correspondence: Jean-Benoit Pilet jpilet@ulb.ac.be

Specialty section: This article was submitted to Elections and Representation,

a section of the journal

Frontiers in Political Science

Received: 29 May 2020 Accepted: 19 October 2020 Published: 17 November 2020

Citation:

Pilet J-B, Talukder D, Sanhueza MJ and Rangoni S (2020) Do Citizens

Perceive Elected Politicians, Experts

and Citizens as Alternative or Complementary Policy-Makers? A

Study of Belgian Citizens.

Front. Polit. Sci. 2:567297.

doi: 10.3389/fpos.2020.567297
Do Citizens Perceive Elected Politicians, Experts and Citizens as Alternative or Complementary Policy-Makers? A Study of Belgian Citizens

\author{
Jean-Benoit Pilet*, David Talukder, Maria Jimena Sanhueza and Sacha Rangoni \\ Department of Political Science, Université libre de Bruxelles, Brussels, Belgium
}

In the scholarly literature, studies have underlined a link between citizens' low levels of support for elected politicians and demands for a greater role of other actors such as citizens themselves or independent experts in policy-making. Yet, what remains unclear is whether such demands to increase the role of these actors are rooted in a desire to replace entirely politicians, or whether citizens and experts are perceived as complementary to elected politicians. It is precisely what we explore in this article. Using data from 2019 Belgian Election survey, we conduct a latent profile analysis to see what models of governance emerge among citizens. First, we demonstrate that while some citizens indeed perceive politicians, citizens and experts as separate governing groups, others combine support for multiple actors. Building on the typologies that emerge, we conduct two complementary analyses. In the second section, we try to analyse how these different views regarding who should govern translate into support for specific institutional reforms consultative referenda, binding referenda, assemblies of citizens and a government of experts. Our results show that, in general, citizens tend to favor the mechanisms that empower the actors they support, for instance deliberative democracy mechanisms are preferred by those who are positive about citizens as policy-makers. Finally, in the last section we examine the impact of citizens' personal characteristics (age, gender, education, employment) and political attitudes (political interest, political knowledge, political trust, left-right) on belonging to each of the latent classes identified. We determine the main socio-demographic traits and/or political attitudes that predict the likelihood of belonging to one of the seven classes. For example, we observe that people who delegate decision-making to politicians and experts share better socio-economic conditions and have higher levels of political interest and political knowledge. We close our analysis by explaining the importance of taking into account such preferences for a mix of policy-makers (citizens, experts and politicians) in broader debates on models of democracy.

Keywords: democracy, citizens, democratic preferences, representative democracy, direct democracy, deliberative democracy, technocracy 


\section{INTRODUCTION}

For several decades, studies have shown that public support for elected politicians tends to be rather low (Dalton and Weldon, 2005; Marien, 2011). Some would even claim that citizens "hate" politicians (Hay, 2007; Grossman and Sauger, 2017). Previous studies have shown that citizens' low levels of trust in politicians may translate into support for a greater role of other actors in policy-making. For some, it triggers an increased public demand for a more active role of citizens in policy-making, via mechanisms of direct and deliberative democracy (Cain et al., 2003). Other scholars have singled out the desire of some citizens to empower actors such as independent experts or technocrats in shaping public policies (Hibbing and Theiss-Morse, 2005; Bertsou and Pastorella, 2017). Building on these views, recent studies have described public opinion in consolidated democracies as divided between those preferring elected politicians, to those favoring citizens or experts as core policy-makers (Bengtsson and Christensen, 2016; Gherghina and Geissel, 2017).

In this article, we build on this literature but propose a different view on citizens' evaluations of elected politicians, citizens and experts. Most previous work evaluated the three actors separately and asked citizens to declare which actor they would like to play the central role in policy-making. And citizens had to pick up one. Here, we opt for a different approach by examining more carefully whether some citizens may hold positive views toward more than one actor. An individual could, for example, hold negative evaluations toward elected politicians, while being positive toward both experts and citizens. Other citizens would remain positive about elected politicians but would at the same time be also positive about experts and/or citizens. In this article, we are especially interested in these more hybrid views on who should govern.

We then consolidate our analysis by confronting citizens' evaluation of the three sets of actors to support for institutional reforms that would empower citizens and experts (direct democracy, deliberative democracy and technocracy). Indeed, if representative democracy has to be transformed, it would require citizens' evaluation of potential policy-makers to be translated into demands for specific institutional reforms. Here again, we propose an approach that examine whether these instruments of governance are perceived as alternative or as complementary modes of decision-making. Some citizens may indeed see direct or deliberative democracy as antagonistic to technocracy or representative democracy. Yet other could be pushing for combining (or complementing) representative institutions with instruments of direct democracy, deliberative democracy or technocracy.

Using data from the 2019 Represent Belgian Election Study, ${ }^{1}$ we study citizens' evaluations of elected politicians, citizens and experts. We combine different methodological approaches. First, we try to identify different subgroups of citizens regarding how they evaluate the three actors. In order to do it, we use Latent Profile Analysis (LPA), which allows identifying groups made

${ }^{1}$ http://represent-project.be/ of respondent sharing the same patterns in their answers for the survey items that are relevant for our study (here, how they evaluate citizens, experts and elected politicians as policymakers). The next two steps build upon these latent profiles. We start by examining how support for various institutional reforms is associated with the latent profiles identified. We look at support for instruments of direct democracy (referenda), deliberative democracy (assemblies of citizens composed via sortition) and technocracy (government of experts). Finally, we use of multinomial regressions in order to examine whether some sociodemographic traits and political attitudes (political trust, political interest, left-right position) appear to be more associated with some of the latent profiles identified.

\section{THEORETICAL FRAMEWORK}

Many citizens are nowadays critical of elected politicians (Dalton, 2004; Norris, 2011; Armingeon and Guthman, 2013; Klingemann, 2013). Within this context, support for an increased role for other actors in policy-making is growing. On the one hand, a growing share of the population asked to activate the participatory instruments of democracy, in order to give more opportunities to citizens to be directly involved in the politicaldecision processes (Cain et al., 2003; Neblo et al., 2010). Other groups in society would rather call for empowering independent experts, technocrats or businessmen (Hibbing and Theiss-Morse, 2005; Bertsou and Pastorella, 2017). Building on these analyses, Bengtsson and Christensen (2016) have conceptualized the existence of three models of democracy. In the first model-the elitist model, democracy is primarily for citizens to select by means of elections the leaders who will govern. In the second model-the expertise/technocratic model-efficient leaders selected on basis of their expertise should be in charge of governing, whereas citizens' involvement should be strictly minimal. Finally, the third model-participation or pluralistic model-sees citizens' participation as central in democracy; therefore, citizens should be given a direct say in major political decisions.

Beyond the exact institutional arrangements to which these three models are attached, the central question is who should govern, or more precisely which actors do citizens perceive as having all required qualities to govern? Would it be elected politicians, citizens or independent experts? The question has already been asked in a few recent studies that used survey data. In Spain, Font and his colleagues asked respondents to declare which was the best form of decision-making. Respondents could choose between three actors, the people, experts and politicians (Font et al., 2015). In Germany, Gherghina and Geissel (2017) ran a similar study asking who should make important policy decisions. And they found that respondents were almost equally divided between those supporting elected representatives, experts and citizens.

Building on these earlier studies, we propose to analyse citizens' attitudes toward elected politicians, citizens and experts. Our general ambition is to look at citizens who would have a clear preference for one set of actors, but also to take into consideration those preferring models of governance that associate several types 
of actors. For example, we could imagine that some citizens would perceive both citizens and/or experts as a complement to the traditional logic of representative democracy, to come in support of elected politicians. Other citizens could be in favor of a much more reduced role of elected politicians. They want to bypass or overcome the representative logic, but they would be positive toward both citizens and experts, and not toward one of them only. In other words, there is definitely a need for richer and more complex accounts about how citizens evaluate elected politicians, citizens and experts as potential governors. Actually, this mix of actors is what we may observe already in most contemporary European democracies. Elected politicians and representative institutions remain the heart of the political system, but they often associate experts and citizens to policy-making. In most democracies, experts are invited to parliamentary hearings. Bodies of experts that are attributed a more formal role are also frequent. Regarding citizens, in many countries, referendums are institutionalized; and participatory forums of various kinds are also more and more frequently organized. It is therefore crucial to enrich the literature with analyses that take into account the possibility for elected politicians, citizens and experts to work together.

We will proceed in three steps. The first is to examine how citizens in Belgium evaluate the qualities of elected politicians, citizens and experts as potential governors. We focus on three qualities isolated as key elements in how citizens evaluate politicians: honesty, competence and capacity to apprehend societal needs (Kinder, 1986; Dalton, 2004; Seyd, 2015; Halmburger et al., 2019). Honesty is a moral trait referring to an actor's integrity and transparency, it has been previously framed as key source of trust (Bruckmüller and Methner, 2018). Competence is defined as an actor's "past political experience, ability as a statesman, comprehension of political issues, and intelligence" (Miller et al., 1986: 528). Finally, elected representatives' capacity to understand the needs of those they represent is central in theories of representation (Mansbridge, 2003). In previous studies, these traits prevail as the main criterions people use to judge or evaluate a politician (Kinder, 1986; Miller et al., 1986). On that basis, we identify how evaluations of elected politicians, citizens and experts combine in the minds of Belgian citizens, and extract the most common patterns.

Second, we examine how these evaluations of the respective qualities of elected politicians, citizens and experts translate into attitudes toward specific institutional reforms that could be introduced as a complement to traditional representative institutions. Previous studies associated directly some institutional arrangements with support for alternative (nonelected) actors. Font et al. (2015), for example, found significant correlations among Spanish citizens demanding for a more active role of citizens and support for mechanisms of direct democracy such as referenda or citizens' assemblies. Webb found the same kind of associations among British citizens (Webb, 2013). Bedock and Pilet (2020c) found that distrust in politicians was a key driver in France of support for sortition in politics. Schuck and De Vreese (2015) identified that cynicism toward politicians had an impact on support for referenda. In the same vein, a few studies have identified that citizens who were more negative about politicians were more open to reforms that would empower independent experts in policy-making (Font et al., 2015; Bedock and Pilet, 2020a). Yet, other studies have questioned these findings. First, several scholars have underlined that public support for referendums did not ascribe solely to participatory democrats. Other citizens, whose favorite policy-makers are experts or elected politicians may also believe that adding mechanisms of direct democracy to representative institutions could be positive. Indeed, they perceive referendums as a lever to keep representatives under stricter control of the people (Bengtsson and Mattila, 2009; Coffé and Michels, 2014). Recent research also demonstrated that support for consultative forms of deliberative democracy could be favored by citizens that are not especially distrustful of elected politicians or independent experts (Bedock and Pilet, 2020b). Finally, in their study of public support for technocratic governments, Bertsou and Pastorella (2017) showed that the share of citizens favorable to this model reached above 60pc in many European countries. Such high levels of support for technocratic governments are partially explained by negative evaluations of elected politicians. But support for experts goes beyond that. There are also citizens who do not fully reject elected politicians and who could still be calling for a greater role of independent experts or technocrats. These contrasting findings highlight the interest of examining in-depth how citizens' evaluation of elected politicians, experts and citizens as policy-makers associates with support for various forms of institutional reforms that would come in addition to representative institutions. In this study, we focus on three: referenda, citizen assemblies and government of experts. The rationale is that these reforms tap into three models of governance that may come as complement or alternative to representative democracy: direct democracy, deliberative democracy and technocracy. Once again, we would approach citizens' support for these three institutional reforms by examining not only public support for each of them but also how individuals may be in favor of a combination of such institutional reforms.

Finally, the last goal of the chapter is to understand what factors may differentiate among citizens holding different views regarding citizens, experts and elected politicians as potential policy-makers. Two main lines of explanation have been prevalent so far in previous studies on citizens support. The first one is that how citizens evaluate politicians, experts or citizens is related to how much resource they hold to participate politically. The more resources, the more support for empowering citizens themselves. In their study on support for referendum, Schuck and De Vreese (2015) refer to the "cognitive mobilization" hypotheses, but the same kind of logic is also found in several other studies (see Dalton, 2004; Bowler et al., 2007). Two types of resources have been examined. The first are objective resources related to individual sociodemographic profile. The main factors considered are age, gender, level of education and professional occupation. These factors have been central in studies of political participation for many years (see Brady et al., 1995). Recently, they were confirmed in studies on support for more direct forms of participation for citizens. Bedock and Pilet (2020c: 15) found in 
France that support for a model of democracy in which citizens would rule via referenda and assemblies randomly selected was lower among older, higher educated citizens, as well as among those with higher income. By contrast, it has appeared that less resources meant reduced support for delegating politics to elected politicians, but also to experts. In the Netherlands, Coffé and Michels (2014: 6) found that lower educated citizens were more sceptical toward elected politicians. Under a different lens, a study of British citizens revealed that age and education are negatively associated with positive evaluation of experts but also of elected politicians (Webb, 2013).

Next to objective resources, other scholars have examined subjective ones. The idea is that what matters is how competent one feels politically, and how much she is interested in politics. In Germany, Gherghina and Geissel (2017: 37) found that citizens who are more politically interested hold more positive evaluations of citizens as potential policy-makers (Gherghina and Geissel, 2017: 37). It has been confirmed in Spain by del Río et al. (2016: 93). The same kind of effect is observed when political knowledge increases (Bengtsson and Mattila, 2009: 1041-44).

The main competing line of explanation to the "cognitive mobilization hypothesis" is that support for alternatives to elected politicians is driven by political discontent, what Bowler et al. (2007) labeled the "enraged citizens" explanation (by contrasted to "engaged citizens"). Indeed, many studies have underlined that political trust was a strong correlate of citizens' evaluation of elected politicians, but also of other potential policy-makers such as experts and citizens. For instance, trust in institutions, trust in government or satisfaction with democracy are factors that have been shown to be significantly associated with citizens' views regarding who should or is entitled by citizens to be in charge of policies. Dalton (2004: 14) suggested that citizens calling for more direct participation where often showing rather low levels of political trust. Norris observed that citizens' low levels of trust $v i s-\grave{a}$-vis politicians is corelated to public support of representative institutions (1999: 20-21), which suggests a low support of elected politicians. Hooghe and Marien (2013: 145) pin-pointed that European citizens with higher political trust are more likely to take part in institutionalized forms of participation whereas citizens with lower political trust are more likely to engage in non-institutionalized forms of political participation. Similar results were drawn by Bedock and Pilet (2020a: 15) in France. In other words, evidence so far seems to indicate that lower political is often significantly associated with being more supportive of a growing role for citizens in policy-making.

In our study, we will test these two main theories and apply them to how citizens evaluate politicians, experts and citizens as policy-makers. We will also test a third factor that is not related to a specific theory but that has been found to be a correlate to preferences for models of government. This third factor is ideology, or rather citizens' political positioning on the left-right spectrum. An ideological leaning toward the left has been associated with a favorable view of citizens as policy-makers. In contrast, right-leaning citizens would be more sceptical toward citizens, and favor experts and elected politicians (Bengtsson and Mattila, 2009: 1041-44; Webb, 2013: 759; del Río et al., 2016: 93). We will test it here.

\section{DATA AND METHODOLOGY}

For our analyses, we are making use of the data collected by the 2019 Belgian Election Study coordinated by the interuniversity consortium Represent. ${ }^{2}$ A representative sample of Belgian citizens (based on age, gender and level of education criterion) was surveyed twice, first within the 4 weeks preceding the 2019 Federal Elections, and a second time in the 2 weeks that followed Election Day. The survey was conducted online, and respondents were recruited by a private polling company (TNS Kantar). Here, we are making use of the first wave of the survey with 7,609 respondents. $^{3}$

Generally-speaking, the Belgian context appears to be very appropriate for the analyses we propose in this paper. The topic of who should govern is very salient in the Belgian context. Trust in elected politicians is among the lowest across Western Europe (Eurobarometer, 2019). Within this context, debates regarding an increased involvement of citizens and independent experts in policy-making have become more salient. Citizens' direct participation has been mostly linked to two democratic innovations: referendums and deliberative mini-publics. The 2010 Constitutional reform authorized the organization of consultative referendums at regional level, reopening debates on direct democracy. Also, four regional assemblies have tested deliberative mini-publics composed of citizens selected by lot over the last 5 years: the Walloon parliament, the Brussels parliament, the parliament of the French-speaking community, and the parliament of the German-speaking community. Finally, in 2019, several prominent politicians claimed the formation of a government of technocrats as an alternative, if government to form a government among parties would fail. ${ }^{4}$

This context explains why the questionnaire of the Represent survey provides a large number of questions relevant for the analyses we propose to conduct. First, it contains three blocks of questions that are relevant to capture citizens' evaluations of elected politicians, citizens and independent experts as policymakers. Respondents were asked to rate to what extent the three actors are perceived as politically competent, honest/noncorrupt and able of understanding the needs of lay citizens. The exact wording of the questions is the following (see Table 1). Unfortunately, the Represent survey does not include questions allowing to determine whether respondents give more importance to one of the three traits. It would have been a very useful element in order to consolidate our analyses.

In addition to these evaluations of actors, the Represent survey also contains questions asking Belgian voters to declare to what extent they would support specific reforms, specifically direct, deliberative democracy and replacement of elected politicians by experts. The exact wording of these questions is the following.

\footnotetext{
${ }^{2}$ https://represent-project.be/

${ }^{3}$ The characteristics of the sample are similar to those on the average population. For more information on the distribution of the sample, see Appendix 1 in Supplementary Material.

${ }^{4}$ See for example, the president of the Flemish Christian-democrats $(\mathrm{CD} \& \mathrm{~V})$. https://www.rtbf.be/info/belgique/detail_et-pourquoi-pas- ungouvernement-belge-dirige-par-des-technocrates?id=10356948
} 
TABLE 1 | Descriptive statistics for respondents' evaluations of politicians, citizens and experts.

\section{Evaluation of politicians}

\begin{tabular}{llc}
\hline $\begin{array}{l}\text { Please indicate to what extent you disagree } \\
\text { or agree with the following statements. }\end{array}$ & Mean & $\begin{array}{c}\text { Standard } \\
\text { deviation }\end{array}$ \\
$\begin{array}{l}\text { 1 = Totally disagree; } 2 \text { = Somewhat } \\
\text { disagree; 3 = Neither agree nor disagree; } \\
\text { 4= Somewhat agree; 5 = Totally agree] }\end{array}$ & & \\
\hline 1. Politicians are corrupt & 3.984 & 0.996 \\
2. Most politicians are competent. & 4.632 & 0.946 \\
3. Politicians do not understand what is going on & 3.416 & 1.05 \\
in society. & & \\
\hline
\end{tabular}

Evaluation of citizens

\begin{tabular}{lcc}
\hline $\begin{array}{l}\text { We are now going to ask you a series of } \\
\text { questions on the way in which you evaluate } \\
\text { citizens and experts as political } \\
\text { decision-makers. [0-10 scale: } \mathbf{0}=\text { Totally } \\
\text { disagree; } \mathbf{1 0}=\text { Totally agree] }\end{array}$ & $\begin{array}{l}\text { Meandard } \\
\text { deviation }\end{array}$ \\
\hline $\begin{array}{l}\text { 1. Most citizens have all the competences } \\
\text { required to make political decisions. }\end{array}$ & 2.288 & 2.516 \\
$\begin{array}{l}\text { 2. Most citizens are honest } \\
\text { 3. Most citizens are capable of understanding the }\end{array}$ & 5.539 & 2.28 \\
\hline needs of people like me. & & \\
\hline
\end{tabular}

Evaluation of independent experts

\begin{tabular}{|c|c|c|}
\hline $\begin{array}{l}\text { We are now going to ask you a series of } \\
\text { questions on the way in which you evaluate } \\
\text { citizens and experts as political } \\
\text { decision-makers. [0-10 scale: } 0=\text { Totally } \\
\text { disagree; } 10=\text { Totally agree] }\end{array}$ & Mean & $\begin{array}{l}\text { Standard } \\
\text { deviation }\end{array}$ \\
\hline $\begin{array}{l}\text { 1. Most experts have all the competences } \\
\text { required to make political decisions. }\end{array}$ & 5.785 & 2.129 \\
\hline 2. Most experts are honest & 5.317 & 2.073 \\
\hline $\begin{array}{l}\text { 3. Most experts are capable of understanding the } \\
\text { needs of people like me. }\end{array}$ & 5.480 & 2.121 \\
\hline
\end{tabular}

a This group of variables were recoded into 0-10 scale for the LPA analysis (see section Different Groups of Citizens With Different Attitudes Toward Elected Politicians, Citizens and Experts. A Latent Profile Analysis) and the items 1 and 3 were reversed in order to mirror the other indicators of support for experts and citizens.

1. In general, are you for or against consultative referendums about important national issues? [0-10 scale: Strongly against; $10=$ Strongly in favor]

2. In general, are you for or against binding referendums about important national issues? [0-10 scale: Strongly against; $10=$ Strongly in favor]

3. In general, are you for or against the organization of consultative citizen forums on important national issues? A citizen forum is an assembly composed of around 30-50 citizens, selected at random, who meet and discuss a certain topic in order to formulate a recommendation that is then transmitted to the parliament [0-10 scale: Strongly against; 10 = Strongly in favor]
4. Regarding the following reform, could you indicate if you are completely against, somewhat against, somewhat in favor, or totally in favor (1-4)-Experts should take the major political decisions instead of politicians.

Descriptive statistics for these items are reported in Appendix 2 in Supplementary Material. They indicate a quite strong support among Belgian citizens for the four reforms. The mean scores of support for consultative referenda and for consultative citizens' assemblies is at or slightly below 7. Mean support for binding referenda is at 6.75 and for a government of experts is slightly below 3 (on a $1-4$ scale).

Finally, the Represent Election Study 2019 includes questions regarding respondents' sociodemographic traits (gender, age, education, professional occupation), political attitudes (political interest, political knowledge, left-right self-placement), and political trust (see Appendix 3 in Supplementary Material). In terms of sociodemographic traits, it shows that the sample is balanced in terms of gender (51.7\% of male, $48.3 \%$ of female) and of age. There is however a slight overrepresentation of respondents with a superior non-university degree or a university degree, as well as a relative under-representation of respondents who are inactive professionally. Nevertheless, the large sample size still guarantees that the $\mathrm{N}$ for these categories is sufficient to run robust analyses.

In terms of general political attitudes, we have four main variables: political interest, political knowledge, self-positioning on a left/right continuum, and political trust. For political interest, responses' mean situates on 5.46 on a $0-10$ scale where 10 reports high political interest. Political knowledge (0-6 scale) is based on six questions about the functioning of Belgian democracy, where one correct response translates into an extra point. The mean score for political knowledge is 3.13. Finally, the variable left-right (were 0 is left, and 10 is right) the mean value situates at 5.28.

In terms of political trust, the study contains two questions capturing citizens' trust in two institutional actors: political parties and federal parliament (Cronbach's alpha $=0.897)$. We have compiled these two indicators into an aggregate score using principal component analysis, which generated one principal component (eigen value $=1.81$ ) that account for $90.68 \%$ of the variance.

Building upon this large dataset, we run analyses in three steps. The first goal of the article is to understand more accurately how Belgian citizens evaluate elected politicians, citizens and experts regarding their qualities as potential governors. We rely upon respondents' evaluation of these three actors for three qualities: honesty, competence and capacity to understand societal needs. On that basis, we make use of Latent Profile Analysis (LPA) in order to identify subgroups of respondents sharing the same type of answers on the nine survey items evaluating citizens, experts and elected politicians.

In the next two steps, we build on these various subgroups identified via the Latent Profile Analysis (LPA). First, we examine whether belonging to each group translates into specific attitudes regarding support for institutional reforms (referenda, participatory budget and government of experts). 
Second, we run multivariate regressions examining whether belonging to a specific latent profile is a significant driver of support (or opposition) to the various institutional reforms examined when controlling for respondents' sociodemographic and political traits. Finally, in the last section of the article, we make use of multinomial regressions in order to detect which respondents' characteristics appear to affect significantly the likelihood of falling into the various latent profiles. We examine the impact of sociodemographic traits, general political attitudes and political trust.

\section{DIFFERENT GROUPS OF CITIZENS WITH DIFFERENT ATTITUDES TOWARD ELECTED POLITICIANS, CITIZENS AND EXPERTS. A LATENT PROFILE ANALYSIS}

In this section, we are using Latent Profile Analysis (LPA) to identify different profiles of respondents based on how they evaluate elected politicians, citizens and experts' qualities as potential policy-makers. LPA is an approach that aim to identify subgroups within the population based on their answer to a defined set of indicators (see Peugh and Xitao, 2013; Oberski, 2016 for a mathematical and detailed approach of the model) in this piece, those indicators are the nine items evaluating politicians, experts and citizens. As a specific case of finite mixture model, "the idea is that subjects fall into one of a finite number of discrete categories ("classes"), and that the classes differ with respect to values of the indicators" (Jackman, 2008: 139). The method assumes, therefore, that people can be classified with varying degrees of probabilities into specific categories that have different configural profiles of personal and/or environmental attributes (Spurk et al., 2020). It differs from classic clustering methods such as the $k$-means as in cluster analysis the respondent is either member of the cluster $\mathrm{k}$ or not (Peugh and Xitao, 2013) while with LPA class membership are treated as an unobserved categorical variable and is defined on the basis of the computation of a certain degree of probability (Spurk et al., 2020). Furthermore, LPA differs from factor analysis (FA) because LPA assume that the latent variable is categorical while FA assume that the latent variables are continuous (Vermunt and Magidson, 2004: 175).

For an illustrative purpose here under lies a generic LPA model developed in the article of Peugh and Xitao (2013).

$$
\sigma_{i}^{2}=\sum_{k=1}^{K} \pi_{k}\left(\mu_{i k}-\mu_{i}\right)^{2}+\sum_{k=1}^{K} \pi_{k} \sigma_{i k}^{2}
$$

In which $\mu_{i k}$ and $\sigma_{i k}^{2}$ represent profile-specific $(k)$ means and variances for variable $i$, and $\pi_{k}$ indicates profile density, or the proportion of $N$ participants that belong to profile $k$ (Peugh and Xitao, 2013: 618). According to Peugh and Xitao (2013) three assumptions underlie LPA models. First, samples drawn from a heterogeneous population produce data that are a mixture of $K$ profile-specific distributions. Second, observed y indicators are normally distributed. Third, the profile-specific mean vectors $\mu_{k}$ are the profile-specific $(k)$ observed variable means [see Peugh
TABLE 2 | Bayesian Information Criterion (BIC) scores for Latent Profiles Analyses with 1 to 8 profiles extracted.

\begin{tabular}{lcc}
\hline Number of profiles extracted & BIC & Difference in BIC \\
\hline 1 & 301516.46 & \\
2 & 291728.91 & -9787.55 \\
3 & 286344.88 & -5384.03 \\
4 & 284711.01 & -1633.87 \\
5 & 283483.55 & -1227.46 \\
6 & 282087.94 & -1395.62 \\
7 & 280645.09 & -1442.85 \\
8 & 279709.739 & -935.35 \\
\hline
\end{tabular}

and Xitao (2013) for a more detailed discussion regarding the mathematical foundation of LPA].

The model first provides random initial estimations on profile membership. Then the maximization step produces estimates of the maximum likelihood (ML) for the conditional table and the expectation maximization (EM) uses the estimated parameters to update the predicted values for the cell of the table until the parameters converge and stop changing (Oberski, 2016).

The number of latent profiles to be extracted is to be determined by combining goodness-of-fit statistics and the researchers own judgement when examining what could be the meaning of the various subgroups extracted in relation to the theoretical framework. Practically-speaking, we have extracted $2,3,4,5,6$, and so on latent profiles and compare the results. In terms of goodness-of-fit statistics, we should examine the Bayesian Information Criterion (BIC) computed as follow : BIC $=[-2 \log L+p \log (\mathrm{n})]$ which penalize non-parsimonious model. The goal is to have the lowest BIC as the smaller it is, the better the model fit the data. Yet, as we can see from Table 2, the BIC gets lower and lower every time the more latent profiles are extracted. We should therefore see when the marginal gain in BIC becomes less significant. In our case, it is when seven latent profiles are extracted. Going for eight latent profiles rather than seven would have a lower impact on the BIC's reduction. We would therefore opt for working with seven latent profiles.

We should then try to see how we could make sense theoretically of these seven latent profiles. In Figure 1 we report the mean value on each of the nine survey items for each of the seven latent profiles. We also add a line with the mean value for the overall sample.

But before exposing the seven latent profiles, it is important to take into consideration some aspects of this analytic tool. First, LPA tends to extract more easily clusters of respondents that deviate significantly from the mean. A majority of respondents hold attitudes that are close to the mean value. Respondents that remain close to the mean value of the full sample are harder to decompose with LPA, for this reason one of the profiles corresponds to median values. Moreover, as we have seen in Table 1 (see standard deviations), the distribution of answers is not very dispersed, especially for respondents' evaluation of elected politicians. This makes it even harder to interpret the meaning of the various latent profiles that we can extract. 


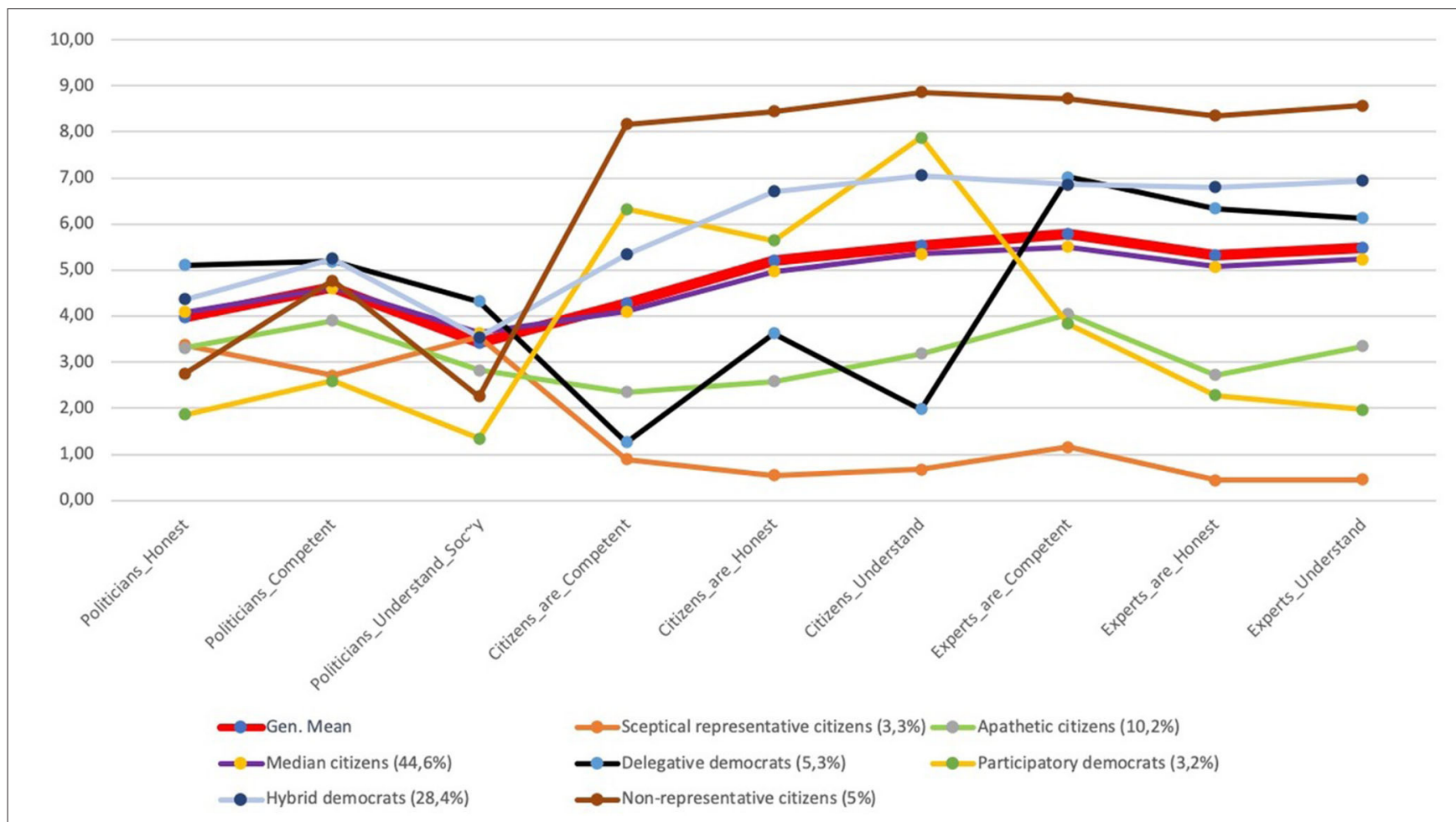

FIGURE 1 | Profile plots for 7-class LPA model.

Nevertheless, we will try to make sense of the seven latent profiles both empirically and theoretically. Empirically, we should pay attention to two elements. On the one hand, how each latent profile distinguishes itself from the other latent profiles in the absolute mean score for each set of actors. ${ }^{5}$ For example, examine if certain groups are more or less positive toward elected politicians than the other latent profiles. On the other hand, we shall compare within for each latent profile what are the mean scores for the three different actors (citizens, elected politicians and experts). Then, theoretically, we will try to connect the latent profiles extracted to what we may find in the literature on citizens' support for democratic models based upon experts, citizens or elected politicians (Bengtsson and Christensen, 2016). Building on these elements, here are the interpretations we propose for the seven latent profiles.

- The first profile (44.6\% of the sample) is composed of respondents whose answers are very close to the mean. We would refer to them as the median citizens. They hold rather low evaluations of elected politicians. They are slightly more positive about citizens and independent experts without making much distinction between the two. They form the

\footnotetext{
${ }^{5}$ In order to do it, we provide in Appendix 3 in Supplementary Material box plots reporting the mean scores on the nine indicators for all seven latent profiles with confidence intervals. Especially for the evaluations of elected politicians, it makes it easier to grasp when a latent profile holds evaluations that are significantly more positive or negative than the other latent profiles.
}

largest group for the methodological reasons inherent to LPA previously exposed.

- Regarding the second profile (28.4\%), we find respondents who, in absolute terms are rather negative toward elected politicians (mean score between 4 and 5 out of 10), and quite positive toward citizens and experts (mean score around 67). Yet, in relative terms, they are a bit more positive toward elected politicians than most other profiles. And they are among the most positive profiles for citizens and experts. We may refer to them as the hybrid democrats. We may suspect them to be in favor of a model that would keep some role for elected representatives, but that would be positive to enrich policy-making with a greater role for experts and citizens.

- The third profile (10.2\%) is composed of respondents who tend to hold negative evaluations of all actors. For the three sets of actors, their mean scores are low in absolute terms (between 3 and 4). They are among the most negative toward elected politicians, experts and citizens. As they do not appear to hold stronger preferences for any actor, we would refer them as the apathetic citizens.

- The fourth profile (5.3\%) is composed of respondents who distinguish themselves in three respects. First, they are especially negative in their evaluations of citizens. Second, their evaluations of elected politicians are the more positive of all latent profiles. Third, they hold significantly more positive evaluations of independent experts than most other profiles. We could call them the stealth democrats (Hibbing and TheissMorse, 2005) or delegative democrats (Caluwaerts et al., 2018). 
They are positive about actors to whom they could delegate policy-making, be them politicians or experts, while they are rather sceptical toward citizens.

- The fifth profile (5\%) is composed of respondents who especially distinguish themselves as the most positive toward both experts and citizens, while they are negative toward politicians (especially concerning their honesty and capacity to understand societal needs). We would therefore refer to respondents falling in this latent profile as the nonrepresentative citizens. We may suspect them to be in favor of a system that would center policy-making around citizens and experts, with a more limited role for elected politicians.

- The sixth profile $(3.3 \%)$ would be the sceptical representative citizens. They hold low evaluations of elected politicians. But they hold even lower evaluations of citizens and experts. The scores they give to these latter two sets of actors are approaching zero. They are the most negative of all latent profiles toward them. We might expect them to prefer a democracy based upon representative actors and certainly not upon citizens or experts. Yet, it does not mean that they are that positive about elected politicians.

- Finally, the seventh profile (3.2\%) would be the participatory democrats. They differ from the other latent profiles by being among the most positive in their evaluations of citizens. By contrast, they are the most negative toward elected politicians with very low mean scores (around 2) and the second lowest scores for experts (between 2 and 4).

Beyond their intrinsic values, these seven latent classes also confirm the added value of an approach that pays attention to the many ways public evaluations of citizens, elected politicians and experts as potential policy-makers may combine. The seven profiles extracted clearly shows that citizens' evaluations of elected politicians, independent experts and citizens should not be conceived as fully opposed alternatives. Belgian voters who hold (more) positive evaluations one of set of actors while being (more) distrustful about the two others are rare. The participatory democrats who hold positive views only about citizens are scarce (3.2\%). Sceptical representative democrats who distrust both citizens and experts, while being a bit less sceptical about politicians' qualities also exist but account for 3.3\% of the sample. Whereas, pure stealth or technocratic democrats who would only be positive toward experts are not identified.

By contrast, there are several profiles where respondents hold positive evaluations of more than one actor. We observe the presence of citizens who are positive about both experts and politicians (delegative democrats). We also find citizens who are sceptical about politicians but positive about both citizens and experts (hybrid democrats, non-representative democrats). The largest group extracted (median citizens) are also quite positive toward both citizens and experts. These three profiles account together for $43 \%$ of the sample. Yet, these profiles are not linearly connected to one model of democracy (representative, technocratic or participatory). They would rather situate themselves in a hybrid position between the technocratic and the participatory model (Bengtsson and Christensen, 2016). And they confirm that lines between these ideal-types are blurred.
Our findings also provide some clarification to previous studies that have been highly influential in the field. For example, they can help understanding who stealth democrats would be. According to Hibbing and Theiss-Morse (2005) stealth democrats are characterized by distrust in elected politicians, support for experts, and are opposed to a model of democracy that would call for too much participation from citizens. With our study, we rather show that there are indeed citizens quite positive toward experts as policy-makers. Yet, all of them tend to be also supportive of another actor. Delegative democrats want to combine a role for experts and for politicians, and are very negative about citizens. Non-representative citizens are positive toward experts and citizens and very negative toward politicians. This later group seems to be in line with what Webb claim in his study of stealth democrats in the UK. "It is quite conceivable that political actors who hold such (stealth democratic) views would be drawn to the idea that the ordinary and presumably virtuous people should at least occasionally be able to take decision-making power out of the hands of elites by recourse to referendums" (Webb, 2013: 761).

\section{LINKING CITIZENS' VIEWS REGARDING WHO SHOULD GOVERN AND SUPPORT FOR INSTITUTIONAL REFORMS}

The findings from the latent profile analysis that we have just exposed were about respondents' evaluations of the qualities of three potential actors of policy-making: citizens, experts and elected politicians. Yet, they do not directly tap into how such preferences translate into demands for institutional reforms. It is what we propose in this section by looking at how each latent profile positions regarding four specific institutional reforms: consultative referenda, binding referenda, assemblies of citizens composed via sortition, and a government of experts.

Research on citizens' preferences for the different models of democracy has often been linked with studies on public support for instruments of citizens' participation such as referenda or assemblies of citizens sorted by lot, as well as with support for technocratic governments or for the idea of experts taking the main political decisions (Mondak, 1995; Bengtsson and Mattila, 2009; Coffé and Michels, 2014; Grönlund et al., 2014; Font et al., 2015; Schuck and De Vreese, 2015; Bertsou and Pastorella, 2017; Bedock and Pilet, 2020c). Yet again, very few studies so far have examined whether and how some citizens may perceive these instruments as to be combined. One can, for example, be in favor of a growing use of referendums and for technocratic governments, or in favor of greater citizens' participation but without getting rid of elected representatives. An illustrative example is the study of German citizens Gherghina and Geissel conducted in 2017. They show that citizens who prefer elected politicians as core decision-makers are indeed supportive of elections, but they would also like to participate in citizens' consultations. Also, they argue that German citizens who wish for a greater role of citizens in policy-making are in favor of referenda, and citizen assemblies but also remain interested in 


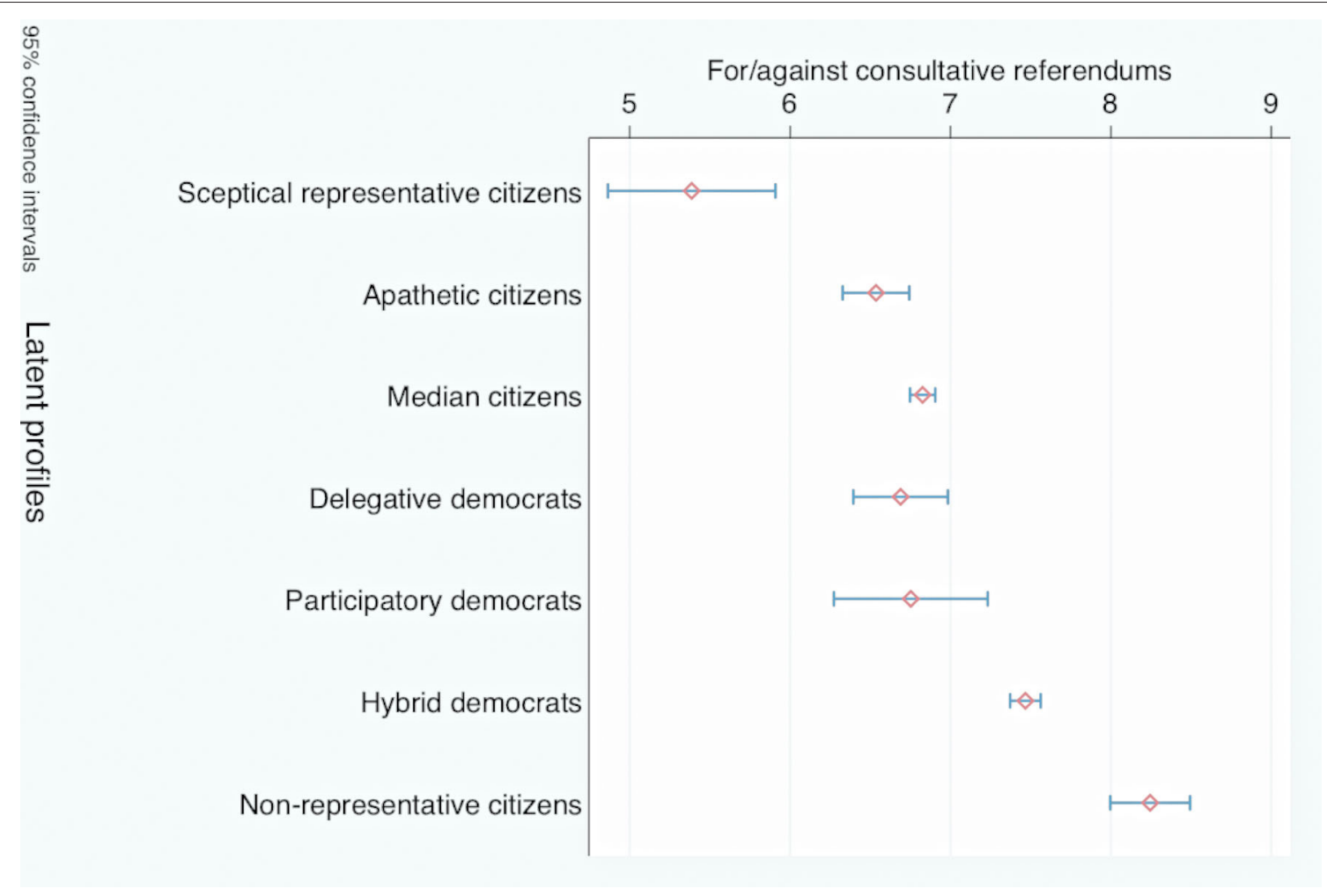

FIGURE 2 | Mean support for consultative referendums across latent profiles (0-10).

voting. Finally, those who favor experts would still like to vote in elections and support referenda.

We adopt the same kind of perspective in this section. We examine correlations between belonging to each of our seven latent profiles and attitudes toward four institutional mechanisms that are being debated in Belgium: consultative referenda, binding referenda, assemblies of citizens selected by lot and governments of experts (see Appendix 2 in Supplementary Material for descriptive statistics). We use respondents' support for each of these four mechanisms as our dependent variables. And we evaluate whether levels of support differ across the seven latent profiles.

In the four figures below, we report the mean levels of support for each one of the seven latent profiles. We also include confidence intervals. We can see that there are significant differences across latent classes for all four reforms. ${ }^{6}$ First, in Figure 2, we report the mean score regarding support for consultative referendum. All seven latent classes are rather in favor of the mechanism (mean score $>5$ ) but we can also observe significant differences between three clusters of latent profiles. First, three latent profiles present levels of support that do not present statistically significant differences with the median class. It is the case of the apathetical citizens, the delegative

\footnotetext{
${ }^{6}$ The following figures compare mean support across latent profiles for each reform examined separately. Box plots reporting for each latent profiles their support to each four reforms can be found in Appendix 4 in Supplementary Material.
}

democrats, and the participatory democrats. Two latent profiles are significantly more positive about consultative referenda: the non-representative citizens and the hybrid democrats. One latent profile, the sceptical representative democrats, are significantly less favorable to consultative referenda even if the mean score of support remains slightly above the median value (5 out of 10 ).

In order to make sense for these differences, it is important to go back to the evaluations of citizens, experts and elected politicians by the various latent profiles. In particular, what seems to make the difference are the evaluations of both citizens and elected politicians. Holding positive evaluations of citizens is clearly a crucial element. If it is not the case, like for the sceptical representative citizens, consultative referenda are perceived with more caution. By contrast, being very positive about the capacities of citizens leads to be more supportive of consultative referenda, this is the case for the non-representative citizens. Yet, how respondents evaluate elected politicians also matters. Being positive about both citizens and elected politicians may lead to also being supportive of consultative referenda, e.g., hybrid democrats, while being positive about citizens but very negative toward elected politicians, like participatory democrats, does not lead to very strong support for consultative referenda. Respondents in this last latent profile would not be very enthusiastic about a reform that would empower citizens but leaves the final word to politicians.

The second reform considered is the introduction of binding referenda at national level (Figure 3). Compared to what we 


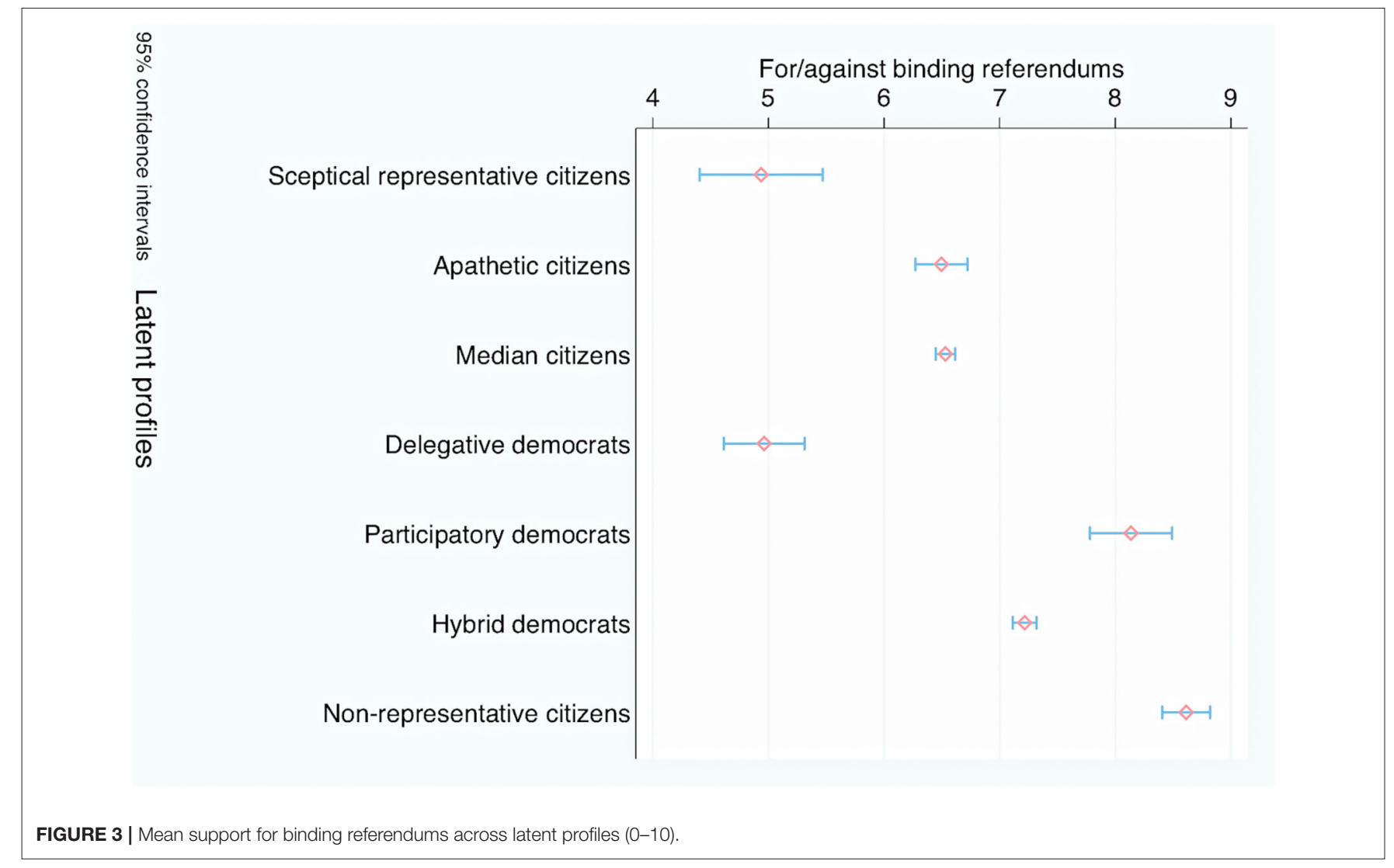

observed for consultative referenda, we see sharper differences between latent profiles. In particular, we observe two profiles that are less enthusiastic about this instrument of direct democracy: sceptical representative democrats and delegative democrats. Both latent profiles are quite sceptical about citizens' abilities as policymakers. It translates into rather negative views toward binding referendums. In that respect, they would differ from pure stealth democrats who "appear to appreciate direct democracy primarily as an instrument of control that is used as a measure of last resort" (Mohrenberg et al., 2019: 2).

By contrast, we have three groups that are more enthusiastic about binding referenda: hybrid democrats, non-representative citizens and participatory democrats. The three groups hold the most positive evaluations of citizens, which makes it logical that they are the most supportive of direct democracy. Yet, we could also stress differences between them. Participatory democrats are only positive about citizens, and not about elected politicians or experts. Non-representative citizens are positive about both citizens and experts. Hybrid democrats are also positive about citizens and experts, but are also among the least negative toward elected politicians. The diversity of these three latent profiles shows the multi-faceted nature of public support for referenda in contemporary democracies. Previous studies found indeed support for direct democracy among dissatisfied democrats and more politically engaged citizens (Bowler et al., 2007; Schuck and De Vreese, 2015). And others found a link between support for experts and for referenda (Webb, 2013; Coffé and Michels, 2014). Our findings connect with these various studies.

The third reform falls within the deliberative democracy logic and consists of setting up assemblies of citizens selected via sortition. Such assemblies are not unknown in Belgian politics. Since 2014, citizen assemblies composed by lot have been tested by four regional parliaments across the country. At the local level, several municipalities have also tested deliberative mini-publics. In total, since 2001, at least 33 citizens' assemblies including random selection of citizens took place in Belgium at the local, regional national and European level organized by state and non-state actors (Vrydagh et al., 2020) which makes it a largely used process. Belgian citizens are therefore more likely to have heard about the use of sortition in politics than citizens in many other countries.

In Figure 4, we report the mean score of support toward the creation of assemblies composed of citizens selected by lot. We see patterns that are very comparable to what was observed regarding binding referenda. Three groups are more positive toward this instrument of deliberative democracy: hybrid democrats, non-representative citizens and participatory democrats. They are the three profiles holding the most positive views toward citizens, but they differ in the evaluations of elected politicians and experts. One group is much less enthusiastic, although still slightly positive (mean score close to 5): the sceptical representative democrats. They are the ones holding the most 


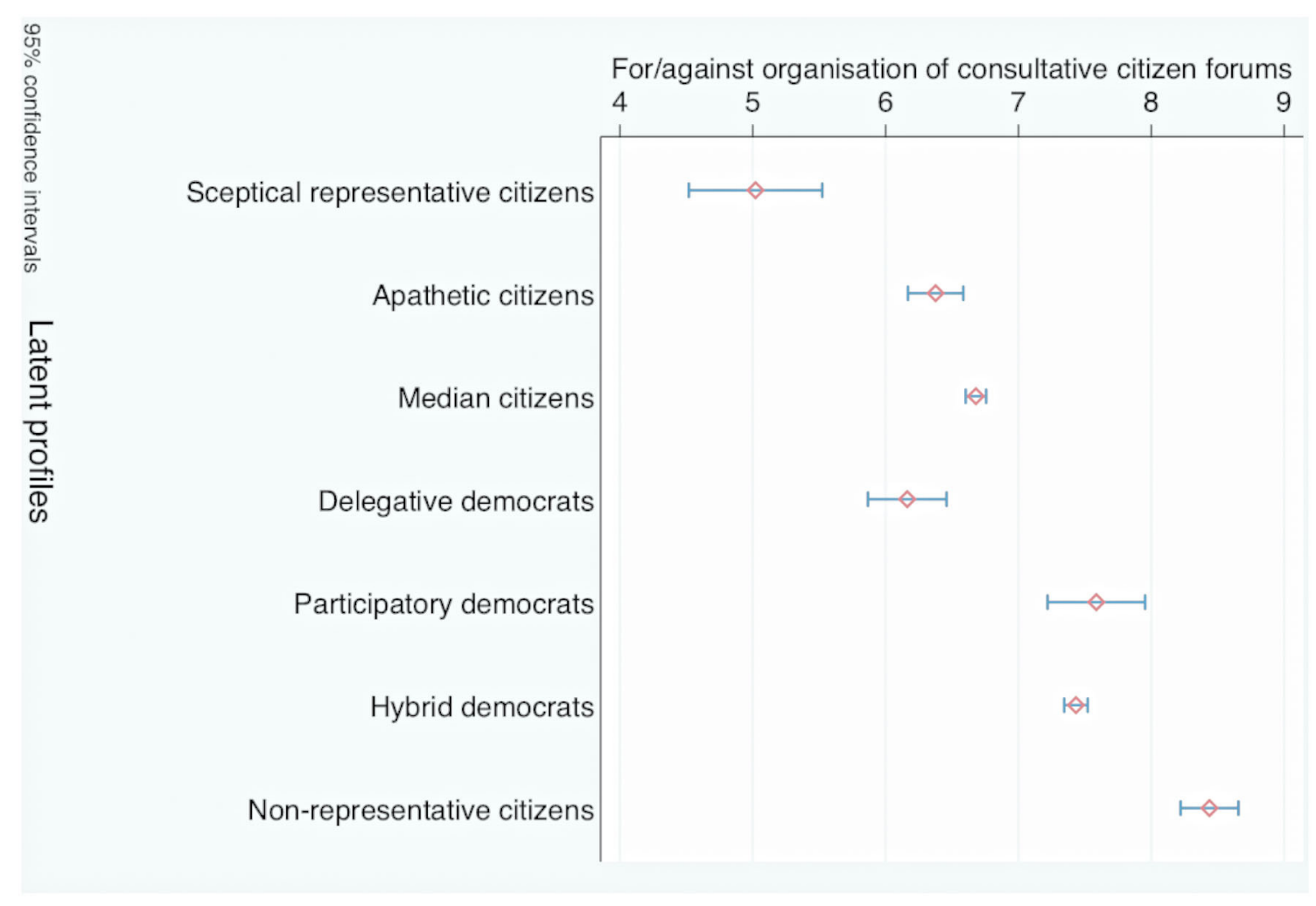

FIGURE 4 | Mean support for consultative citizens forums across latent profiles (0-10).

negative evaluations of citizens. The other latent profiles are in between but remain rather positive about the mechanism (mean scores between 6 and 7) probably because it is a consultative mechanism and elected politicians would remain in charge of the final decision. It is therefore not too frightening for delegative democrats, for example, who remain more positive toward politicians or experts than toward citizens.

Finally, in Figure 5, we report mean scores toward delegating political decision-making to a government of experts in Belgium. Here, overall support is less strong across respondents. The scale is between 1 and 4 . One and two express (strong or moderate) opposition to a government of experts. Three and four express (moderate or strong) support. Only one latent profile is clearly positive: non-representative democrats, who were very positive toward experts and citizens, while holding negative evaluations of politicians. The two other profiles that have positive evaluations of experts, delegative democrats and hybrid democrats, are more moderately supportive of a government of experts instead of a government of elected politicians. It could be explained by the fact that these two latent profiles were not too negative toward politicians, even if they were positive toward experts.

Finally, we may observe that the three latent profiles with the lowest mean scores of support are the three that are holding the most negative evaluations of experts' qualities as potential policymakers. It is the case for sceptical representative democrats who were less negatives toward elected politicians than experts or citizens, participatory democrats who were only positive toward citizens, and apathetic citizens who were negative about all three actors. ${ }^{7}$

Having analyzed successively support for four institutional reforms, we can now try to make some conclusions on what our results brings to the scholarly debate on institutional reforms that would complement, bypass or overcome representative institutions. And what we observe is that the various profiles tend to be in favor of a mix of instruments. It confirms once again the added value of a methodological approach that gives space to citizens who may hold hybrid views regarding the role of citizens, elected politicians and experts in policy-making. The most striking example are non-representative citizens and hybrid democrats. They are strongly in favor of all four instruments. It shows that they would prefer a model of democracy where both experts and citizens play a greater role. The same could be said about apathetical citizens and median citizens who are, although moderately, favorable to all four reforms. Delegative democrats also show a mixed profile. They support consultative referenda and consultative citizens assemblies, as well as governments of experts. They are only more negative toward binding referenda. Finally, only two profiles seem to be

\footnotetext{
${ }^{7}$ The main findings that we have presented have been cross-validated with a series of three multivariate regressions treating support for the four reforms as dependent variables and introducing each latent class as independent variables. Findings can be found in Appendix 5 in Supplementary Material and confirm the patterns isolated by the comparisons of means.
} 


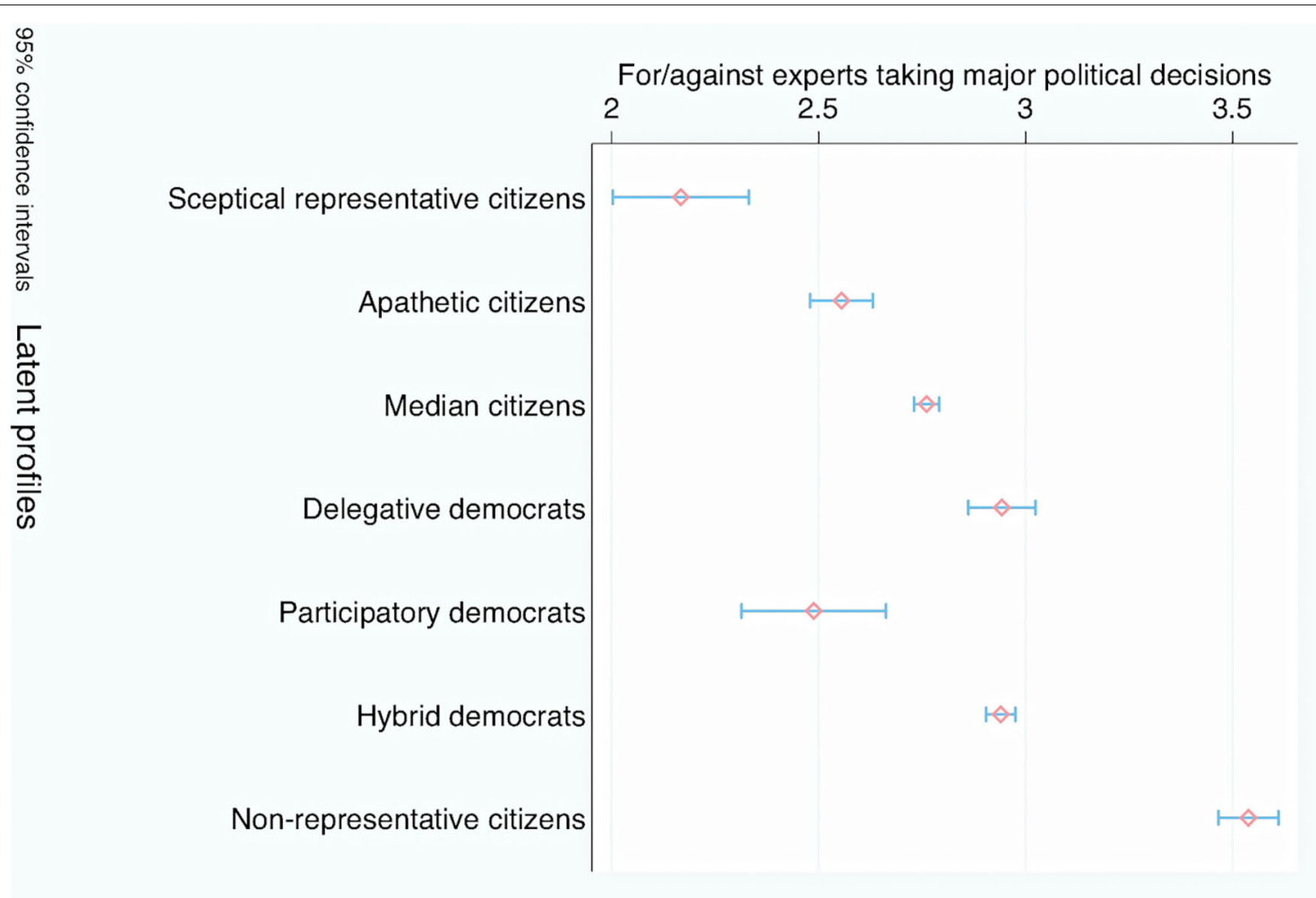

FIGURE 5 | Mean support for experts taking major political decisions across latent profiles (1-4).

in favor of one unilinear logic. First, participatory democrats only want instruments increasing citizens' participation (referenda and citizens' assemblies composed by lot), while they oppose a government of experts. Second, sceptical representative democrats are the most negative for all four instruments as they move away from the representative logic.

\section{WHO BELONGS TO THE DIFFERENT PROFILES OF CITIZENS?}

The question that we would like to pose in this section is whether the seven latent profiles that we have identified are inherently different in their profile, both socio-demographically and politically. In order to test for it, we have run multivariate analyses accounting for the effect of a series of individuallevel variables on the likelihood of belonging to one of the seven latent profiles. These variables are age, gender, level of education, professional situation (we focus on blue-collars and unemployed), region of residence, satisfaction with income, political interest, political knowledge, left-right self-placement and political trust.

These independent variables were included in a multinomial logistic regression for which the "median citizens" latent profile was the reference category. In Table 3, we report the results for the six other latent profiles. For each, we show the effect of each independent variable on belonging to that specific latent profile compared to belonging to the "median citizens." In order to facilitate interpretation, we present the relative risk ratio (RRR) for each independent variable rather than the raw coefficients. A relative risk ratio superior to 1 means that an increase of one unit in the independent variable increases the probability of belonging to the latent profile analyzed rather than to the "median citizens" latent profile by the value of the RRR. A relative risk ratio inferior to one means that one unit increase in the independent variable reduces the likelihood of belonging to the latent profile examined.

We are not going to focus on the variables that are significant for each and every profile. Yet, it should be stressed that in each case, several sociodemographic and political factors appear to be significantly associated with belonging to the latent profile considered. These findings already confirm that the seven subgroups of attitudes toward elected politicians, experts and citizens that we have identified are not purely random. They are deeply anchored socially, economically and politically. In particular, it appears that six factors play a significant role across several latent profiles: gender, satisfaction with income, education, region of residence, political interest, political knowledge and political trust. By contrast, other factors such as age, employment, or the position on the left-right spectrum seem to play a more reduced role.

Instead of detailing the effect of each variable for each latent profile, we will rather pay more attention to some findings that are relevant across several latent profiles, and that 
TABLE 3 | Multinomial logistic regression for respondents' inclusion in the various latent profiles extracted (ref. cat.: "median citizens" latent profile).

\begin{tabular}{|c|c|c|c|c|c|c|}
\hline \multirow[t]{2}{*}{ Mc fadden's adj. $R^{2}$} & \multirow{2}{*}{$\begin{array}{c}0.068 \\
\begin{array}{c}\text { Sceptical } \\
\text { citizens }\end{array}\end{array}$} & \multirow{2}{*}{$\begin{array}{l}\text { Cragg and } \\
\text { Uhlers } R^{2} \\
\begin{array}{c}\text { Apathetic } \\
\text { citizens }\end{array}\end{array}$} & \multirow{2}{*}{$\begin{array}{c}0.21 \\
\text { Delegative } \\
\text { democrats }\end{array}$} & \multicolumn{2}{|c|}{$N=7,362$} & \multirow{2}{*}{$\begin{array}{c}{ }^{*} \text { sig. }<5 \%,{ }^{* *} \text { sig. }< \\
1 \%,{ }^{* * *} \text { sig. }<1 \% 0 \\
\begin{array}{c}\text { Non-representative } \\
\text { citizens }\end{array}\end{array}$} \\
\hline & & & & $\begin{array}{l}\text { Participatory } \\
\text { democrats }\end{array}$ & $\begin{array}{c}\text { Hybrid } \\
\text { democrats }\end{array}$ & \\
\hline \multicolumn{7}{|c|}{ Relative risk ratio (RRR) coefficient with standard errors in parenthesis } \\
\hline Age groups & $1.058(0.05)$ & $1.032(0.03)$ & $0.952(0.04)$ & $1.113^{*}(0.06)$ & $1.072^{\star \star \star}(0.02)$ & $1.004(0.04)$ \\
\hline Education (low to high) & $1.055(0.11)$ & $1.049(0.07)$ & $1.660^{\star \star \star}(0.17)$ & $0.797^{*}(0.08)$ & $0.914^{\star}(0.04)$ & $0.681^{* * \star}(0.06)$ \\
\hline Woman $(=1)$ & $0.650^{\star *}(0.10)$ & $0.894(0.08)$ & $1.042(0.12)$ & $0.835(0.13)$ & $0.814^{\star \star \star}(0.05)$ & $0.694^{\star \star}(0.08)$ \\
\hline Blue collar worker $(=1)$ & $0.415(0.25)$ & $0.841(0.23)$ & $0.343(0.25)$ & $2.268^{\star}(0.72)$ & $0.706(0.14)$ & $0.827(0.27)$ \\
\hline Unemployed (=1) & $1.919^{\star \star}(0.45)$ & $0.678(0.14)$ & $1.241(0.36)$ & 1.077 (0.29) & $1.172(0.16)$ & $1.474(0.35)$ \\
\hline Income satisfaction & $0.975(0.03)$ & $0.945^{\star \star}(0.02)$ & $1.067^{\star}(0.03)$ & $0.880^{\star \star \star}(0.03)$ & $1.100^{\star \star \star}(0.02)$ & $1.112^{\star \star \star}(0.03)$ \\
\hline $\begin{array}{l}\text { Region: Brussel } \\
\text { (ref = Flanders) }\end{array}$ & $1.202(0.26)$ & $1.450^{\star *}(0.19)$ & $0.880(0.15)$ & $1.544^{\star}(0.33)$ & $0.780^{\star *}(0.07)$ & $1.407^{\star}(0.23)$ \\
\hline $\begin{array}{l}\text { Region: Wallonia } \\
\text { (ref = Flanders) }\end{array}$ & $0.919(0.14)$ & $1.320^{\star *}(0.12)$ & $1.007(0.13)$ & $1.095(0.17)$ & $0.867^{*}(0.06)$ & $0.927(0.12)$ \\
\hline Political interest & $0.975(0.03)$ & $1.037^{*}(0.02)$ & $1.074^{\star \star}(0.03)$ & $1.078^{\star \star}(0.03)$ & $1.049^{* \star *}(0.01)$ & $1.162^{\star * *}(0.03)$ \\
\hline Left-Right & $1.034(0.03)$ & 1.019 (0.02) & $1.028(0.03)$ & $1.041(0.03)$ & $0.987(0.01)$ & $1.097^{\star \star \star}(0.03)$ \\
\hline Political Knowledge & $0.937(0.04)$ & $1.041(0.03)$ & $1.240^{\star \star \star}(0.05)$ & $1.023(0.05)$ & $1.052^{* *}(0.02)$ & $0.853^{\star \star \star}(0.03)$ \\
\hline Trust-PCA score & $0.417^{\star \star \star}(0.03)$ & $0.690^{\star \star \star}(0.02)$ & $1.11{ }^{\star}(0.05)$ & $0.382^{\star \star \star}(0.03)$ & $1.239^{\star * *}(0.03)$ & $1.020(0.04)$ \\
\hline _cons & $0.040(0.02)$ & $0.123(0.03)$ & $0.006(0.00)$ & $0.033(0.01)$ & $0.248(0.05)$ & $0.058(0.02)$ \\
\hline
\end{tabular}

Bold values highlight the significant effects.

can be connected with earlier studies on public preferences regarding democracy. A first finding to be underlined within this logic concerns the effect of respondents' satisfaction with their income. Previous studies showed that citizens who were better off socio-economically support the status quo are and more reluctant regarding reforms that would reduce the role of elected politicians (Ceka and Magalhaes, 2019; Bedock and Pilet, 2020a). Our findings show a slightly different pattern. Citizens more satisfied with their income tend indeed to be less often found among participatory democrats and apathetic citizens who are very negative toward elected politicians (and experts), and only positive about citizens. Yet, we also have some findings that indicate that some more economically privileged citizens may be found in latent profiles holding more positive evaluations of citizens and experts, and who would support reforms toward direct democracy, deliberative democracy or technocracy. It is particularly the case with non-representative citizens. It is also, though to a lesser extent, the case for hybrid democrats who would like to combine the representative logic with a greater role for both citizens and experts.

In the same vein, our approach provides a more nuanced view regarding the effect of education on citizens democratic preferences. Previous studies present various, and not always congruent, findings. Coffé and Michels (2014) found that lower levels of education led to more negative evaluations of elected politicians, but also to more positive attitudes toward experts (Coffé and Michels, 2014). Other studies found that higher educated citizens would be over-represented among citizens calling for direct and deliberative democracy (Bengtsson and Mattila, 2009; Webb, 2013; Dalton, 2017). And some demonstrated that direct democracy is more supported by lower educated citizens (Schuck and De Vreese, 2015).

Our findings confirm that the relationship between education and preferences regarding who should govern is not linear. In Figure 6 we have plotted for each latent profile (except median citizens) the predicted probabilities of being within this profile for each three levels of education (primary education, secondary education, higher education). The only latent profile for which we have an upward line is for delegative democrats, meaning that this latent profile is more often associated with higher educated respondents. They are indeed the most positive in their evaluations of elected politicians, and they are the least favorable to all four institutional reforms. In parallel, we observe two profiles with downward lines: participatory democrats and non-representative citizens. For these three profiles, the effect of education is possible to interpret. Higher educated citizens are more present among those sceptical toward citizens' participation, and lower educated citizens are more present among two models that call for a greater role for citizens in policy-making. Such findings would indicate that education does not lead to a more citizen-centered models of governance like authors such as Dalton (2017) claim. Rather, supporters of such models are more often lower educated citizens. Yet, such a bold claim does not hold when we look at other latent profiles-hybrid democrats, apathic citizens, sceptical representative citizens-for which the effect of education is not linear. Moreover, it indicates that education can predict part of citizens' attitudes toward citizen-centered models of governance but patterns are less clear when it comes to support for experts or elected politicians.

Finally, our study also brings interesting insights regarding the effect of political trust. In the literature, the dominant 

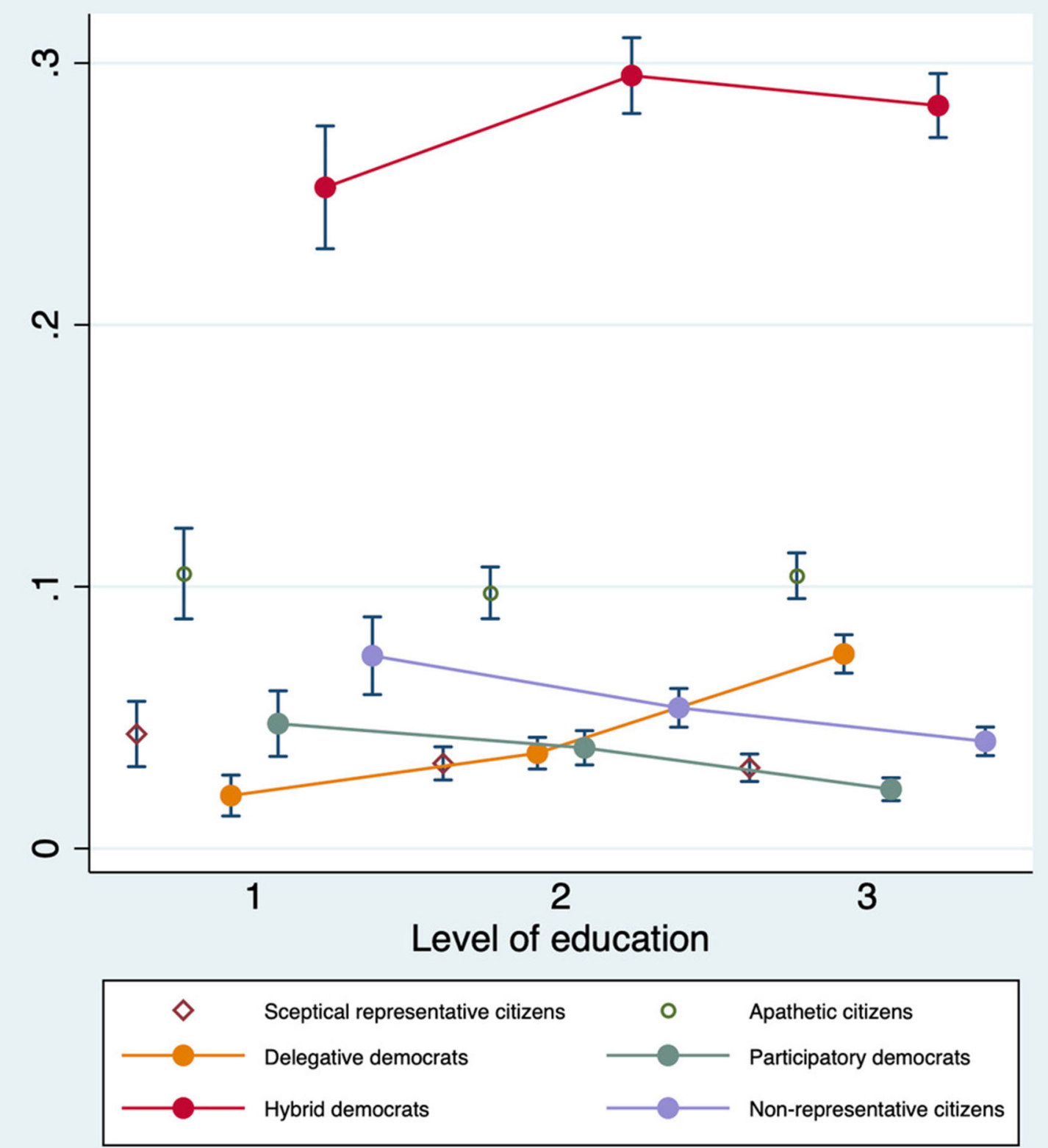

$95 \%$ confidence intervals

FIGURE 6 | Predicted probabilities of belonging to each latent profile per level of education.

hypothesis is that support for other actors than politicians-be them citizens or experts-is primarily found among respondents who distrust elected representatives (Dalton, 2004; Hibbing and Theiss-Morse, 2005; Bowler et al., 2007; Schuck and De Vreese, 2015; Bedock and Pilet, 2020b,c). What we find is slightly different and not straightforward (see Figure 7). We can confirm that lower political trust is associated with the three latent profiles that are the most negative in their evaluations of elected politicians: apathetic citizens, participatory democrats and sceptical representative citizens (downward lines). Yet, the latter group shows that being distrustful toward politicians would not systematically translate into support for alternative actors, be they citizens or experts. Sceptical representative citizens hold very negative evaluations of both citizens and experts. They are also the least enthusiastic toward referenda, citizens' assemblies and government of experts. Another interesting element from our 


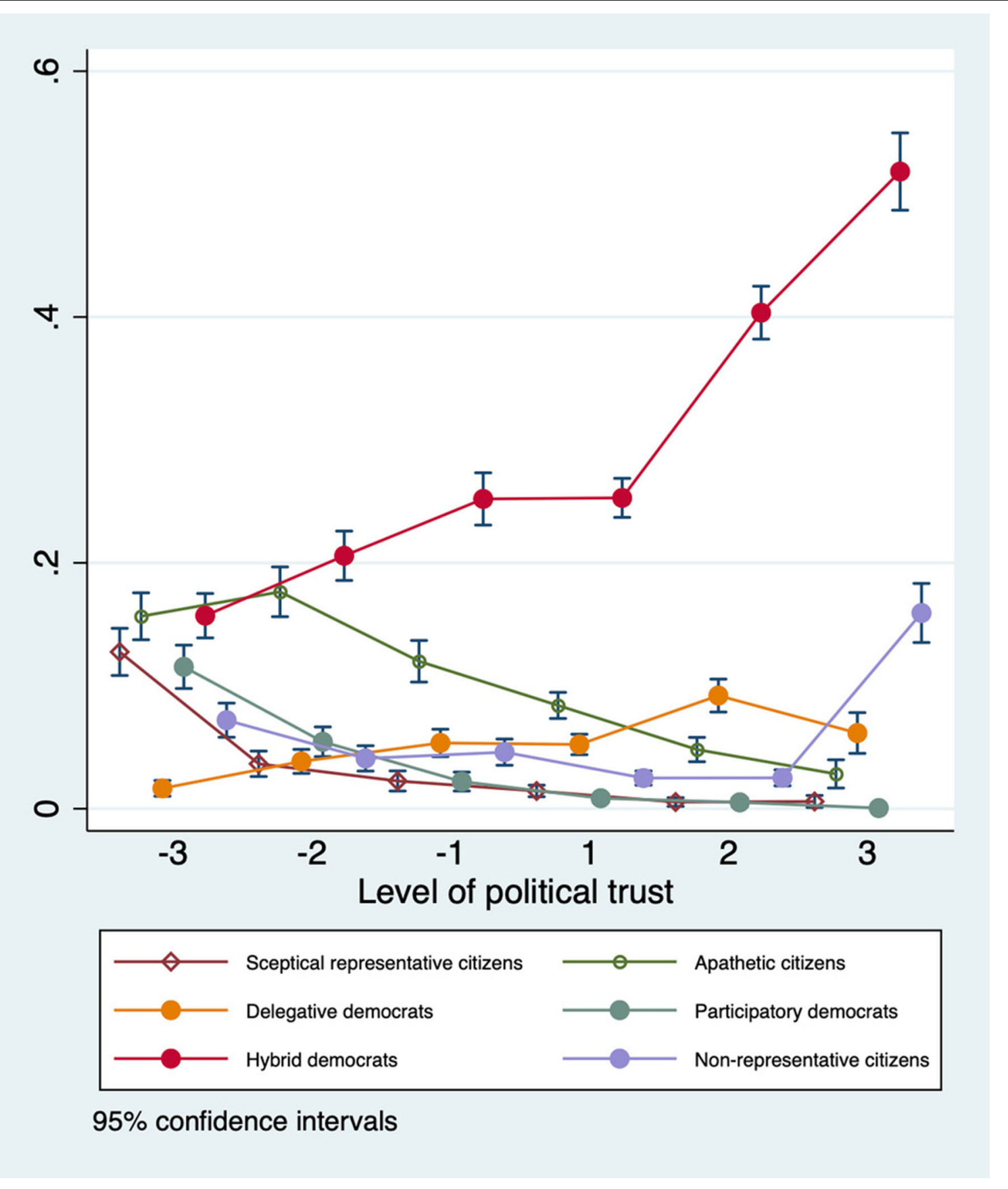

FIGURE 7 | Predicted probabilities of belonging to each latent profile per level of political trust.

findings is the positive effect of political trust on the chances of being a hybrid democrat (upward line). Citizens falling within this subgroup are indeed not the most negative toward politicians, but they are also among the most enthusiastic toward both experts and citizens. And they support strongly referenda, citizen assemblies as well as governments of experts. This finding shows that higher political trust could still be associated with demands for enriching representative democracy with other actors than elected politicians, and with decision-making logics that would complement representative institutions.

These elements of general conclusion clearly confirm, we believe, the added value of an approach that allow considering together citizens' preferences that are strongly in favor of one actor only and one model of democracy only, as well as patterns of preferences that combine support for different actors and more hybrid models of democracy. 


\section{CONCLUSION}

Studies on citizens preferences regarding who should governed have been multiplying over the last decade. The main models that have been isolated are defined primarily when it comes to who should govern: elected representatives, independent experts or technocrats, or citizens themselves. And answers to this question have been shown to determine how citizens support or oppose to institutional mechanisms such as referendums, citizens' assemblies or technocratic governments that could complement or replace the traditional representative model. Our study contributes to this body of literature and proposes to contrast between citizens pushing for a model dominated by one single actor and those calling for models of governance that combine several actors.

Using data from the 2019 Belgian Election RepResent survey, we conducted a latent profile analysis (LPA) and extracted seven latent profiles of democratic preferences. In their majority, these profiles demonstrate that most citizens hold positive evaluations of more than one actor. Actually, very few citizens belong to a profile holding particularly positive evaluations of one single actor. It is the case of sceptical representative citizens (3.3\% of the sample) who express higher levels of support only toward politicians, and of participatory democrats (3.2\%) who have a positive perception of citizens in policy-making, but a negative one of politicians or experts. By contrast, the other profiles combine support for different actors and would favor the presence of more than one actor to govern. It is the case of hybrid democrats who evaluate positively both experts and citizens as policy-makers, of delegative democrats who prefer elected representatives and experts to be in charge of politics, but do not wish for citizens to be involved in political processes, and of non-representative citizens who prefer citizens and experts over politicians We have identified thus three groups that we could call hybrid because they are positive toward more than one actor. The fifth profile are the sceptical representative democrats who tend to be quite negative toward elected politicians; yet they are even more strongly negative toward citizens and experts. Finally, our sixth profile, apathetic citizens, shares the lowest evaluations for all three set of actors.

The second step in our analyses has been to examine how these latent profiles translate into support for specific institutional reforms. We tested support for instruments of direct democracy (consultative and binding referenda), deliberative democracy (consultative citizen assemblies) and technocracy (governments of experts). And our findings have here as well-confirmed that many citizens perceived theses institutional mechanisms as complementary rather than antagonistic. Few citizens would really call for abandoning the representative logic and to replace it entirely with another model of democracy, be it centered around citizens or experts. Citizens want to complement representative democracy, rather than bypassing it. And it is observable with several latent profiles of citizens pushing for a combined introduction of referendums, citizens' assemblies and some forms of technocratic cabinets into the Belgian institutional architecture.
Finally, our study has confirmed previous studies, which had shown that there were strong socio-economic and political determinants in shaping citizens' views toward how government should be organized. In particular, three variables appear to play an overarching role in differentiating among citizens' latent profiles. First, we confirmed earlier studies which found more support for models strongly empowering citizens-participatory democrats-among the less well-off socio-economically. But we can mitigate this conclusion as we also found that a better economic position can still be associated with positive evaluations of citizens as governors, at the condition that these citizens work in association with other actors such as elected politicians or experts. Second, education has also appeared to be a crucial variable in shaping democratic preferences. Yet, what appears is that the relationship between this factor and democratic is not linear. Being less educated does have an effect on being less supportive of elected politicians, but it may lead to varying attitudes toward the two other actors: citizens and experts. Among the lower educated, we find citizens who would want citizens alone to govern; others who want citizens and experts to work hand in hand; and also some pushing for experts and citizens to work in collaboration with elected politicians. And third, our study has confirmed that lower political trust is the fertile ground to support a growing role of other actors than elected politicians. But again, it does not have a linear and univocal impact on what other actors are positively evaluated.

These elements contribute to a call for nuanced views in studying citizens' democratic preferences. Yet, we shall admit that they pave the way for more research on the topic much more than the provide final answers. In that respect, we should acknowledge some shortcomings in our study. First, despite identifying the nuances in citizens' evaluation of different actors (LPA) we cannot discern clearly what is their preferred model of governance. In particular, our study infers from respondents' positive evaluations of several actors that many citizens want mixed models associating several potential governors. But what exact shape would this mixed model take remains unclear. Goldberg et al. (2020) recent study does one step in this direction by asking German citizens to evaluate governance models that associate politicians, experts and citizens. It is probably an example to be followed. Also, we have little understanding about citizens' arguments for supporting one or two actors over the other(s). Indeed, it is not always crystal clear why one would prefer one or two set of actors over others and why they would favor one model over another. It might be interesting to address these issues using a qualitative approach. In that respect, one final element for future studies could also be to fine-graine the dimensions on which citizens are evaluating elected politicians, experts and citizens as policymakers. Here, we use questions tapping into how respondents evaluate honesty, competence and capacity of understand societal needs of the three actors. It could be interesting to look at more dimensions. We also assume that the three dimensions are given an equal value by respondents for each of the three actors. But it may very well be that some respondents give more importance to competence than to honesty or capacity to understand societal needs, for example. Future studies could try to address these questions. 


\section{DATA AVAILABILITY STATEMENT}

Publicly available datasets were analyzed in this study. This data can be found here: https://doi.org/10.17026/dans-xe8-7t78.

\section{ETHICS STATEMENT}

The studies involving human participants were reviewed and approved by Université libre de Bruxelles, ethics committee of the Faculté de Philosophie et sciences sociales. The patients/participants provided their written informed consent to participate in this study.

\section{AUTHOR CONTRIBUTIONS}

All authors listed have made a substantial, direct and intellectual contribution to the work, and approved it for publication.

\section{REFERENCES}

Armingeon, K., and Guthman, K. (2013). Democracy in crisis? the declining support for national democracy in European countries, 2007-2011. Eur. J. Polit. Res. 53, 423-442. doi: 10.1111/1475-6765.12046

Bedock, C., and Pilet, J.-B. (2020a). "Peut-on réformer la démocratie? Convergences et incompatibilités dans les préférences des citoyens quant à l'organisation de la démocratie en France," in La légitimité Démocratique en Transformation. Idéaux, Revendications et Perceptions, eds L. Damay, and V. Jacquet (Louvain-la-Neuve: EME Éditions), 155-171.

Bedock, C., and Pilet, J.-B. (2020b). Enraged, engaged, or both? A study of the determinants of support for consultative vs. binding mini-publics. Representation, 1-21. doi: 10.1080/00344893.2020.1778511

Bedock, C., and Pilet, J.-B. (2020c). Who supports citizens selected by lot to be the main policymakers? a study of French citizens. Gov. Opposition, 1-20. doi: $10.1017 /$ gov.2020.1

Bengtsson, Å., and Christensen, H. (2016). Ideals and actions: do citizens' patterns of political participation correspond to their conceptions of democracy? Gov. Opposition 51, 234-260. doi: 10.1017/gov.2 014.29

Bengtsson, Å., and Mattila, M. (2009). Direct democracy and its critics: support for direct democracy and "stealth" democracy in Finland. West Eur. Polit. 32, 1031-1048. doi: 10.1080/01402380903065256

Bertsou, E., and Pastorella, G. (2017). Technocratic attitudes: a citizens' perspective of expert decision-making. West Eur. Polit. 40, 430-458. doi: 10.1080/01402382.2016.1242046

Bowler, S., and Donovan, T., and Karp, J. A. (2007). Enraged or engaged? preferences for direct citizen participation in affluent democracies. Polit. Res. Q. 60, 351-362. doi: 10.1177/1065912907304108

Brady, H. E., Verba, S., and Scholzman, K. L. (1995). Beyond ses: a resource model of political participation. Am. Polit. Sci. Rev. 89, 271-294. doi: 10.2307/2082425

Bruckmüller, S., and Methner, N. (2018). "The "big two" in citizens' perception of politicians" in Agency and Communion in Social Psychology, eds A. E. Abele, and B. Wojciszke (London: Routledge), 154-166. doi: 10.4324/9780203703663-13

Cain, B. E., Dalton, R. J., Cain, B., Scarrow, S. E., and Scarrow, S. E. (Eds.). (2003). Democracy Transformed? Expanding Political Opportunities in Advanced Industrial Democracies. Oxford: Oxford University Press. doi: 10.1093/0199264996.001.0001

Caluwaerts, D., Biard, B., Jacquet, V., and Reuchamps, M. (2018). "What is a good democracy? citizens' support for new modes of governing" in Mind the Gap. Participation and Representation in Belgium, ed K. Deschouwer (Colchester: ECPR Press), 75-90.

Ceka, B., and Magalhaes, P. C. (2019). Do the rich and the poor have different conceptions of democracy? socioeconomic status, inequality, and the political status quo. Comp. Polit. 52, 383-412. doi: 10.5129/001041520X15670823829196

\section{FUNDING}

This research had received the financial support from the Excellence of Science Programme (EOS) co-financed by FNRS and FWO, for the project REPRESENT. It had also received funding from the European Research Council (ERC) under the European Union's Horizon 2020 research and innovation programme (grant agreement no. 772695) for the project CURE OR CURSE?

\section{SUPPLEMENTARY MATERIAL}

The Supplementary Material for this article can be found online at: https://www.frontiersin.org/articles/10.3389/fpos. 2020.567297/full\#supplementary-material

Coffé, H., and Michels, A. (2014). Education and support for representative, direct and stealth democracy. Elect. Stud. 35, 1-11. doi: 10.1016/j.electstud.2014.03.006

Dalton, R. (2004). Democratic Challenges, Democratic Choices: The Erosion of Political Support in Advanced Industrial Democracies. Oxford: Oxford University Press. doi: 10.1093/acprof:oso/9780199268436.003.0008

Dalton, R. J. (2017). The Participation Gap: Social Status and Political Inequality. Oxford: Oxford University Press. doi: 10.1093/oso/9780198733607.001.0001

Dalton, R. J., and Weldon, S. (2005). Public images of political parties: a necessary evil? West Eur. Polit. 28, 931-951. doi: 10.1080/01402380500310527

del Río, A., Navarro, C. J., and Font, J. (2016). Ciudadanía, pol?ticos y expertos en la toma de decisiones políticas: la percepción de las cualidades de los actores pol?ticos importan. Rev. Españ. Invest. Sociol. 154, 83-102. doi: $10.5477 /$ cis/reis. 154.83

Eurobarometer (2019). Standard 91, Spring 2019, Public Opinion in Europe, Wave EB91.5.

Font, J., Wojcieszak, M., and Navarro, C. (2015). Participation, representation and expertise: citizen preferences for political decision-making processes. Polit. Stud. 63, 153-172. doi: 10.1111/1467-9248.12191

Gherghina, S., and Geissel, B. (2017). Linking democratic preferences and political participation: evidence from Germany. Polit. Stud. 65, 24-42. doi: $10.1177 / 0032321716672224$

Goldberg, S., Wyss, D., and Bächtiger, A. (2020). Deliberating or thinking (twice) about democratic preferences: what German citizens want from democracy. Polit. Stud. 68, 311-331. doi: 10.1177/0032321719843967

Grönlund, K., Bächtinger, A., and Setälä, M. (Eds.). (2014). Deliberative MiniPublics: Involving Citizens in the Democratic Process. Colchester: ECPR Press.

Grossman, E., and Sauger, N. (2017). Pourquoi Détestons-nous Autant nos Politiques? Paris: Presses de Sciences Po.

Halmburger, A., Rothmund, T., Baumert, A., and Maier, J. (2019). "Trust in politicians-understanding and measuring the perceived trustworthiness of specific politicians and politicians in general as multidimensional constructs" in Wahrnehmung-Persönlichkeit-Einstellungen, eds E. Bytzek, M. Steinbrecher, and U. Rosar (Wiesbaden: Springer VS), 235-302. doi: 10.1007/978-3-658-21216-2_8

Hay, C. (2007). Why We Hate Politics. London: Polity Press.

Hibbing, J., and Theiss-Morse, E. (2005). Stealth Democracy. Americans' Beliefs About How Government Should Work. Cambridge: Cambridge University Press.

Hooghe, M., and Marien, S. (2013). A comparative analysis of the relation between political trust and forms of political participation in Europe. Euro. Soc. 15, 131-152. doi: 10.1080/14616696.2012.692807

Jackman, S. (2008). "Measurement," in The Oxford Handbook of Political Methodoloy, eds J. M. Box-Steffensmeier, H. E. Brady, and D. Collier (Oxford: Oxford Universtiy Press). doi: 10.1093/oxfordhb/9780199286546.003.0006 
Kinder, D. R. (1986). "Presidential character revisited" in Political Cognition, eds R. R. Lau, and D. O. Sears (Hillsdale: Lawrence Erlbaum), 233-255.

Klingemann, H.-D. (2013). "Dissatisfied democrats. evidence from old and new democracies" in The Civic Culture Revisited: From Allegiant to Assertive Citizens, eds R. J. Dalton, and C. Welzel (Cambridge: Cambridge University Press), 126-157.

Mansbridge, J. (2003). Rethinking representation. Am. Polit. Sci. Rev. 97, 515-528. doi: $10.1017 /$ S0003055403000856

Marien, S. (2011). "Measuring political trust across time and space" in Political Trust. Why Context Matters, eds S. Zmerli, and M. Hooghe (Colchester: ECPR Press), 13-46.

Miller, A. H., Wattenberg, M. P., and Malanchuk, O. (1986). Schematic assessments of presidential candidates. Am. Polit. Sci. Rev. 80, 521-540. doi: $10.2307 / 1958272$

Mohrenberg, S., Huber, R., and Freyburg, T. (2019). Love at first sight? Populist attitudes and support for direct democracy. Party Polit. 135406881986890. doi: $10.1177 / 1354068819868908$

Mondak, J. (1995). Competence, integrity, and the electoral success of congressional incumbents. J. Polit. 57, 1043-1069. doi: 10.2307/2960401

Neblo, M. A., Esterling, K. M., Kennedy, R. P., Lazer, D. M., and Sokhey, A. E., (2010). Who Wants To Deliberate-And Why? Am. Polit. Sci. Rev. 104, 566-583. doi: $10.1017 /$ S0003055410000298

Norris, P. (2011). Democratic Deficit: Critical Citizens Revisited. New York, NY: Cambridge University Press.

Oberski, D. (2016). "Mixture models: latent profile and latent class analysis," in Modern Statistical Methods for HCI, Human-Computer Interaction Series, eds J. Robertson, and M. Kaptein (Cham: Springer), 257-287. doi: 10.1007/978-3-319-26633-6_12

Peugh, J., and Xitao, F. (2013). Modeling unobserved heterogeneity using latent profile analysis: a Monte Carlo simulation.
Struct. Equat. Model. 20, 616-639. doi: 10.1080/10705511.2013. 824780

Schuck, A., and De Vreese, C. H. (2015). Public support for referendums in Europe: a cross-national comparison in 21 countries. Elect. Stud. 38, 149-158. doi: 10.1016/j.electstud.2015.02.012

Seyd, B. (2015). How citizens evaluate public officials. Polit. Stud. 63, 73-90. doi: 10.1111/1467-9248.12163

Spurk, D., Hirschi, A., Wang, M., Valero, D., and Kauffeld, S. (2020). Latent profile analysis: a review and "how to" guide of its application within vocational behavior research. J. Vocatl. Behav. 120:130445. doi: 10.1016/j.jvb.2020.103445

Vermunt, J. K., and Magidson, J. (2004). "Latent class analysis," in The Sage Encyclopedia of Social Sciences Research Methods, Vol. 2, 549-553.

Vrydagh, J., Devillers, S., Talukder, D., Jacquet, V., and Bottin, J. (2020). Les mini-publics en Belgique (2001-2018). Courr. Hebdomad. CRISP.

Webb, P. (2013). Who is willing to participate? Dissatisfied democrats, stealth democrats and populists in the United Kingdom. Euro. J. Polit. Res. 52, 747-772. doi: 10.1111/1475-6765.12021

Conflict of Interest: The authors declare that the research was conducted in the absence of any commercial or financial relationships that could be construed as a potential conflict of interest.

Copyright $\odot 2020$ Pilet, Talukder, Sanhueza and Rangoni. This is an open-access article distributed under the terms of the Creative Commons Attribution License (CC $B Y)$. The use, distribution or reproduction in other forums is permitted, provided the original author(s) and the copyright owner(s) are credited and that the original publication in this journal is cited, in accordance with accepted academic practice. No use, distribution or reproduction is permitted which does not comply with these terms. 


\title{
Advisory, Collaborative and Scrutinizing Roles of Deliberative Mini-Publics
}

\author{
Maija Setälä * \\ Department of Philosophy, Contemporary History and Political Science, University of Turku, Turku, Finland
}

The normative point of departure in this article is that mini-publics can "complement" representative democracy only if they enhance inclusive processes of mutual justification among elected representatives who are responsible for public decisions. This article distinguishes three different roles of mini-publics in representative decision-making. Minipublics can be 1) advisory when they provide input for collective will-formation in the representative arena, 2) collaborative when they involve elected representatives in the deliberative process, 3) scrutinizing when they check representative decision-making. The article analyzes strengths and weaknesses of these roles of mini-publics. Advisory minipublics are particularly vulnerable to "cherry-picking." While collaborative uses of minipublics may facilitate inclusive reason-giving among elected representatives, they entail risks of representative dominance. Scrutinizing use of mini-publics seem particularly promising from the normative perspective, but it requires a well-defined institutional

Edited by:

Pierre-Etienne Vandamme, Université libre de Bruxelles, Belgium

Reviewed by: Sergiu Gherghina, University of Glasgow, South United Kingdom Andrea Felicetti, Normal School of Pisa, Italy

*Correspondence: Maija Setälä maiset@utu.fi

Specialty section: This article was submitted to Elections and Representation, a section of the journal Frontiers in Political Science

Received: 05 August 2020 Accepted: 16 December 2020 Published: 25 January 2021

Citation:

Setälä M (2021) Advisory, Collaborative and Scrutinizing Roles of

Deliberative Mini-Publics.

Front. Polit. Sci. 2:591844. doi: 10.3389/fpos.2020.591844 framework. The article concludes that while there are ways to avoid problems emerging in these different roles, political context is crucial in terms of the deliberative impact of mini-publics.

Keywords: deliberative mini-public, random selection, representative democracy, inclusion, deliberative democracy

\section{INTRODUCTION}

Deliberative mini-publics are specific forums designed to enhance inclusive deliberation among randomly selected citizens (Setälä and Smith 2018). During the past few decades, mini-publics have been increasingly organized at different levels of governance around the world. The topics of minipublics have covered a wide range of policy areas, including moral and ethical issues such as abortion and same-sex marriage, scientifically and technically complex issues related, for example, to bioethics and information technology, as highly politicized issues such as European integration and climate transitions.

One of the key design features of mini-publics is that the group of participants should be broadly speaking representative in terms of socio-demographics and/or viewpoints on the issue at hand (Brown 2006). Fishkin (2009) argues that mini-publics should, by definition, be based on random selection of participants. Random selection is a highly egalitarian method giving each citizen an equal probability to be selected to serve the public. While the use of random sampling has become one of the defining characteristics of deliberative mini-publics, there are different views of whether it should be the only method of recruiting participants. There are strong arguments in favor of the view that random sampling should be combined with stratification or quota methods in order to ensure representation of diversity of societal viewpoints, including marginalized groups, and to counteract self-selection biases (see e.g., Farrell et al., 2019). 
In order to facilitate a good-quality deliberative process, interaction with expert information as well as moderated discussions in small groups are other key design features of mini-publics. While all mini-publics share these key features, there are also significant differences between various mini-public designs such as Consensus Conferences, Citizens' Juries, Deliberative Polls, and Citizens' Assemblies. Most notably, there are variations in the size and the duration of minipublics. Moreover, the output of mini-publics varies from the aggregation of individual opinions to elaborate statements agreed by all participants (for a more detailed account of the key design features of mini-publics, see Farrell et al., 2019).

This article analyzes and evaluates the possible roles of minipublics as advisory, collaborative and scrutinizing institutions within representative democratic systems. The question raised in this article therefore pertains to the uptake of mini-publics' recommendations (Dryzek and Goodin, 2006) and the connection or coupling of mini-publics with representative democratic institutions (e.g. Hendriks, 2016; Setälä, 2017; Farrell et al., 2019). Because the focus is on interaction between mini-publics and elected representatives, I will not discuss those proposals (e.g. Bouricius, 2013) that entail the replacement of elected representative institutions with randomly selected bodies.

More precisely, this article addresses the question on whether and how mini-publics, when used in different roles, can complement current practices of representative democracy. The argument that mini-publics can complement representative institutions is made frequently in the academic literature (cf. e.g., Caluwaerts and Reuchamps, 2016; Kuyper and Wolkenstein, 2019) and in public discourse to justify their use in policymaking. For example, the Scottish Commission on Parliamentary Reform (2017), (64) characterizes the role of mini-publics as follows: "They complement and inform the decision making process but, crucially, do not replace the decision taking responsibility of members."

In order to evaluate whether mini-publics complement representative democracy, normative standards need to be established. In other words, the meaning of the term "complement" needs to be specified. Like other political institutions, deliberative mini-publics can be evaluated by their outcomes as well as by procedural standards. There are hopes that mini-publics could be a vehicle for a radical environmental and societal transformation (Hammond, 2020). For many, minipublics entail a promise of progressive policy changes (cf. Neblo, 2007) - at the same time others may be critical of them precisely for the same reason. Drawing on the theory of deliberative democracy, I argue that mini-publics should be evaluated on procedural grounds or, more precisely, whether they enhance inclusive processes of mutual justification among elected representatives responsible for collective decisions.

The evaluation of roles of mini-publics based on their capacity to enhance democratic deliberation among representatives is closely related to those studies assessing the democratic legitimacy of mini-publics (Caluwaerts and Reuchamps, 2016), and the legitimizing effects of mini-publics (Suiter et al., 2016). The aim is to develop a framework to evaluate roles of mini- publics based on their capacity to enhance democratic deliberation, and not to tackle the more fundamental normative question regarding the need for democratic deliberation in representative systems (cf. Kuyper and Wolkenstein, 2019).

In the following section, I will make the case for the evaluation of mini-publics on procedural grounds, that is, whether they enhance democratic deliberation among elected representatives who are responsible for political decisions. Improved quality of public deliberation at the representative arena can also have indirect effects such as enhancing learning and reflection among public at large, but these effects are only touched upon in the course of the article. When evaluating the normative and practical issues arising when mini-publics are used in advisory, collaborative and scrutinizing roles, I will use different examples to illustrate my argument. Since my study relies on secondary research, I will mainly refer to well-studied cases, or "prototypes," of using mini-publics in different roles. Although I refer to examples with particular mini-public designs, the issues discussed in this article are likely to arise also when other types of mini-public are used in similar roles.

\section{Mini-Publics and the Promise of Deliberative Democracy Democratic Deliberation as a Procedural Goal}

Some theorists of deliberative democracy have expressed concerns about the tendency of regarding deliberative minipublics as equal to deliberative democracy (Chambers, 2009, 324). Others have pointed out mini-publics' potential to enhance the quality of public deliberation, both among elected representatives and public at large (e.g. Niemeyer, 2014; Warren and Gastil, 2015). As democratic innovations, mini-publics are often expected to complement representative democracy, that is, to improve its quality somehow. Obviously, such expectations raise questions regarding the standards of evaluation. In the present article, the theory of deliberative democracy serves as a normative standard for the assessment of the quality of public decision-making.

According to the theory of deliberative democracy, the legitimacy of public decisions depends on the extent to which they are based on inclusive processes of mutual justification. In such processes, arguments are assessed equitably by their merits (cf. Habermas, 1996). In a process of democratic deliberation, the quality of arguments should be decisive, and factors such as speakers' identities or their social hierarchies should not play a role. Moreover, democratic deliberation is clearly different from some other political practices such as bargaining where participants' power resources are decisive or aggregative mechanisms such as voting.

Theorists of deliberative democracy have somewhat different emphases when it comes to the key features of deliberative democracy as a political system, as well as the value of deliberative democracy. For many, autonomy and popular selfgovernment are the key aspects of deliberative democracy (Rostbøll, 2008; Lafont, 2015). For some, deliberative democracy is an emancipatory project, promoting "leftist" - or 
just democratic - values such as equality (cf. Neblo, 2007). Others emphasize the epistemic benefits of deliberative processes - or, in other words, the capacity of deliberative democracy to bring about better informed and just political decisions (Estlund, 2008).

Apart from such instrumental understandings of deliberative democracy, many deliberative democrats are particularly concerned about the procedural aspects of democracy such as inclusion and equality. Notably, Young (2000) analyzes the mechanisms through which different individuals and groups are marginalized in the democratic decision-making process. Young points out various mechanisms of "external" and "internal" exclusion that are problematic from the normative perspective. Following Young's emphasis on the link between democracy and justice, the normative point of departure in this article is that democratic practices should remain sensitive to the existing patterns of political exclusion and develop responsiveness to the views and voices of especially those who are marginalized.

As a normative theory, the theory of deliberative democracy thus sets certain standards for evaluating democratic decisionmaking processes, most notably in terms of inclusion and the quality of public deliberation. There are good reasons to expect that good-quality, inclusive deliberation helps develop mutual understanding, or "meta-consensus" among deliberators (Dryzek and Niemeyer, 2006) and improve the quality of public decisions (Mercier and Landemore, 2012). However, it is hard or perhaps impossible to achieve intersubjective agreement regarding the quality of political decisions because the "fact of disagreement" will prevail in politics (also despite deliberation).

The standards of good-quality deliberative process are more complex and substantial than, for example, the criteria of democracy put forward in Dahl's (1989) procedural theory of democracy. As a consequence, the theory of deliberative democracy has been criticized for being an unrealistic model of politics (e.g. Richey, 2012; Achen and Bartels, 2016, 301, 324). As a normative theory, the theory of deliberative democracy cannot be falsified based on contrary empirical evidence (Mutz, 2008). Rather, it should be regarded as an aspirational theory that can be used in the evaluation of political systems and processes.

From the normative perspective of deliberative democracy, current representative democratic procedures seem to be deficient in many respects. While elections may be a good method of ensuring peaceful transitions of power (Przeworski, 1998), they are not particularly successful in terms of motivating the political key actors to engage in democratic deliberation. Electoral campaigns are geared towards winning votes, and parties and candidates speak and act in order to mobilize support and maximize votes (Chambers, 2009). Therefore, mass participatory process such as election campaigns and referendums tend to fall short of the standards of inclusive and good-quality deliberative process (Gastil, 2014; LeDuc, 2015). While representative institutions feature some forums particularly designed to foster democratic deliberation, most notably parliamentary committees (Chambers, 2009), partisan politics and government-opposition divide play an important role also in these forums.

\section{Mini-Publics Enhancing Democratic Deliberation}

The lack of deliberation in the key processes of representative politics may be outright frustrating for those who aspire for more inclusive, better justified and fact-based policy-making processes. Against this backdrop, the interest in democratic innovations such as deliberative mini-publics seems unsurprising. Minipublics have been particularly designed to enhance aspirations of deliberative democracy, most notably the inclusion of different societal viewpoints, interaction with expert information, and inclusive and balanced processes of mutual justification among citizens. Moreover, the design features of mini-publics such as random sampling and stratification, access to information and facilitated small group discussion can be expected to counteract those patterns of external and internal exclusion that can be detected in representative systems.

Although there is some evidence that factors such as education and gender may give rise to inequalities in mini-public deliberations (Gerber et al., 2016), mini-publics have usually performed rather well judged by the standards of deliberative democracy (Setälä and Smith, 2018). Studies show that participants of mini-publics learn a great deal about the issue at hand. In addition, they tend to become more understanding of the rationales of those with different viewpoints, even in deeply divided contexts (Andersen and Hansen, 2007; Luskin et al., 2014). Participants' opinions usually change in the deliberative process, and they tend to depolarize rather than become more extreme (Grönlund et al., 2015). Moreover, participants of minipublics are usually satisfied with their experience of participation, which may encourage them to participate in politics in the future.

While empirical studies seem to confirm the capacity of minipublics to enhance democratic deliberation among participants, the role of deliberative mini-publics in representative systems remains debatable. There are concerns that mini-publics remain weak institutions that create illusions of democracy without real empowerment (Fuji-Johnson, 2015). Moreover, there are concerns that mini-publics are used in an instrumental manner that support existing power structures by enhancing governmentality. These concerns are especially justified in cases where mini-publics are used by authoritarian governments to boost their problem-solving capacity (Woo and Kübler, 2020), but also democratically elected governments may use mini-publics instrumentally to promote certain policy goals or to strengthen their position in power (Setälä, 2011). At the same time, it must be kept in mind that, instead of some hidden agendas, policy-makers may be genuinely motivated in engaging citizens in resolving pressing policy issues. Nevertheless, doubts regarding motivations behind mini-publics are likely to arise when political trust is low, and especially among those opposing the government. And even when policy-makers are sincere in their interest in engaging and hearing citizens through mini-publics, there is a risk that this undermines the role of critical civil society.

According to some critics (e.g., Hammond, 2020), minipublics can turn out to be undemocratic because they may foreclose opportunities for critical deliberation in the wider public sphere. Lafont (2015) has further argued that minipublics can be detrimental to deliberative democracy if citizens 
blindly defer their independent, critical judgments to a minipublic. The worry is that, instead of using their own judgment, citizens might use mini-publics' recommendations as "cues" or "shortcuts" to be followed (cf. Lupia and McCubbins, 1998). So far, there seems to relatively little empirical evidence of such "blind deference" among the public. A more typical situation seems to be that a mini-public and its recommendations are hardly noticed by the public at large. In general, Lafont (2015) seems to have rather high expectations of prospects of citizens' critical reflection and deliberation given the multiplicity and the variety of political issues. From the perspective of democratic theory, some kind of division of deliberative labor is a necessary feature of representative systems (Warren, 2020).

The most important point to be learned from the critics like Lafont is that the success of mini-publics should be evaluated by their capacity to foster processes of public deliberation, i.e. mutual justification, learning and reflection in policy-making among those responsible for decisions and among the public at large. The focus should thus be on procedural aspects of mini-publics, that is, their capacity to improve inclusion and quality in the deliberative processes leading to collective decisions. In other words, the kinds of inclusive processes of mutual justification, learning and reflection observed in mini-publics should be "scaled up" (Niemeyer 2014). Measuring the impact of minipublics on the inclusiveness and the quality of deliberative processes leading to collective decisions is not straightforward, however, and it is definitely more complex than simply looking at more concrete outcomes such as policy changes brought about by mini-publics.

The procedural approach proposed in this paper does not seem to provide clear-cut standards for the evaluation of success of mini-publics. Since the processes of uptake are hard to observe, taking largely place "within" policy-makers, it is difficult to assess whether mini-publics' uptake is a result of careful consideration and reflection, or "cherry-picking," i.e. selective uptake of minipublics' recommendations. Admittedly, empirical studies on cherry-picking can give some indications also on the quality of processes of dealing with citizens' input (cf. Smith, 2009, 93; Font et al., 2018).

The prospects of "scaling up" are probably best demonstrated in studies on the Citizens' Initiative Review (CIR) (e.g. Gastil, 2014). In the CIR, a Citizens' Jury is convened to gather and evaluate facts and arguments related to a ballot initiative and summarize them in a statement delivered to all voters. The aim of the CIR is thus to reduce voters' cognitive costs by providing them with accessible and reliable summary of relevant information and arguments. There are studies showing that the CIR increases voters' knowledge on the issue at hand and understanding of different viewpoints regarding the ballot initiative (Knobloch et al., 2019). Some studies suggest further that the CIR process can counteract the effects of motivated reasoning among voters (Már and Gastil, 2019) and enhance learning and reflection even in polarized contexts (Setälä et al., 2020). Although the CIR process is designed to facilitate informed and reflected judgments among voters, successful mini-publics used in conjunction with representative institutions should give rise to similar processes of learning and reflection among elected representatives.

\section{Roles of Mini-Publics in Representative Politics}

From a very broad perspective, it may be argued that mini-publics can serve different functions in democratic systems (cf. Warren, 2017; Jäske and Setälä, 2019). Mini-publics are typically expected to contribute to processes of collective will-formation by allowing randomly selected citizens to contribute to deliberative processes preceding representative decision-making. And as shown by studies on CIR, mini-publics can also boost democratic deliberation among the public at large. Sometimes minipublics serve the function of political agenda-setting by bringing in new policy proposals for public deliberation and decision-making. For example, Dahl (1989), (340-341) already proposed a system including separate randomly selected minipublics (or mini-populi) for political agenda-setting and collective will-formation.

Deliberative mini-publics are rarely given powers to actually make political decisions, although there are proposals to delegate powers to mini-publics, or even to replace elections with random selection as a method of appointing decision-makers (Bouricius, 2013). There are many reasons for the reluctance to empower mini-publics. The most obvious reason is that the powers of elected representatives are constitutionally defined, and in many representative systems it is not possible to delegate these formal powers to other institutions without constitutional changes.

From a more principled perspective, while randomly selected mini-publics are designed to enhance descriptive representation, they lack the mechanisms of authorization and accountability that are characteristics of elected representative institutions such as parliaments (Parkinson, 2006, 33). Mini-publics could feature new forms of deliberative accountability where decisions made by a mini-public would be publicly justified and scrutinized by the general public. However, one key elements of electoral accountability, namely the possibility of the public to sanction decision-makers would still be missing in such accountability relations (cf. Gastil and Wright, 2018).

While the broad question about mini-publics' potential functions in a democratic system cannot be entirely addressed within the scope of the present article, the aim is to explore minipublics in a specific context, namely representative institutions such as parliaments. In what follows, I will explore three different roles of mini-publics in the context of representative democracy, namely as bodies that give advice for elected representatives, collaborate with elected representatives, and scrutinize decisions made by representatives. The purpose is to explore how minipublics, used in these different roles, can foster inclusive processes of learning, reflection and mutual justification among elected representatives who are in charge of making collectively binding decisions. The evaluation of mini-publics in these different roles is based on the theory of deliberative democracy, and procedural standards are an essential element in the evaluation of the different roles of mini-publics. 


\section{Mini-Publics as Advisory Bodies}

Mini-publics are typically advisory bodies that should help elected representatives to make decisions on a policy issue. This is the most wide-spread role given to mini-publics. Advisory mini-publics are expected to provide policy recommendations made, for example, by voting or by summarizing key arguments related to certain policy issue. As advisory bodies, mini-publics thus contribute to the functions of political agenda-setting and collective will-formation among elected representatives. The recommendations and summaries by mini-publics can help elected representatives to ponder various viewpoints related to a policy issue (Hendriks, 2016).

While advisory mini-publics are usually held on an ad hoc manner on a particular issue, there are also some examples of more regular uses of mini-publics e.g. in particular types of issues. A prototypical example of an advisory mini-public is the Danish model of Consensus Conferences (Andersen and Jæger, 1999). The Consensus Conference is a participatory method for technology assessment that is expected to complement information provided by experts on technically complex issues, as well as help explore and evaluate ethical aspects of the use of new technologies. The Consensus Conference is tasked to deliberate on the issue and to formulate a statement including the key factual findings and normative points of view relevant to the issue. The Consensus Conference consists of 14 citizens representing different sociodemographic and geographical segments of the society.

Between 1987 and 2002, altogether 22 Consensus Conferences were held in Denmark on various technically complex issues. The Consensus Conference model was developed by an independent governmental body, the Danish Board of Technology, which also chose the topics for citizen deliberation (Andersen and Jæerer, 1999). In this respect, the Danish model of Consensus Conferences seems to have been exceptional because advisory mini-publics are usually used on issues selected by policy-makers.

Danish Consensus Conferences dealt with various technically complex issues, such as genetic technology in agriculture, air pollution, human genome mapping, chemical substances, teleworking and electronic surveillance. The regular use of Consensus Conferences after the year 1987 until 2002 made it a rather well-known, (nearly) institutionalized practice which had a role, not just in parliamentary decision-making but also in public debate on technically complex issues more broadly. The statements by Consensus Conferences were delivered to Danish parliamentarians to help their decision-making on such complex issues. According to a study by Joss (1998), Consensus Conferences were appreciated by the MPs.

The example of Consensus Conferences shows that the role of mini-publics as advisory bodies is particularly important in technically complex issues which often do not spark inclusive public deliberation in the wider public sphere. More generally speaking, one might ask what is the purpose of advisory minipublics since they are doing more of less the same thing as parliamentary and select committees are supposed to do, namely to deliberate on policies in the light of evidence and across diversity of viewpoints. There are both normative and empirical approaches to this question (for a normative approach, see Kuyper and Wolkenstein, 2019). In empirical terms, the need for such "additional" processes of citizen deliberation is most likely to arise especially in complex technical and ethical issues where there are no straightforward partisan positions. Moreover, even when parliamentary deliberations are constrained by party discipline, citizen deliberation may be called for in polarizing issues that give rise to parliamentary deadlocks.

In the case of Danish Consensus Conferences, the statements were distributed to individual parliamentarians. There is evidence that the reports were read by the Danish parliamentarians; a survey shows that a clear majority of them claimed that they had done so, at least on some particular topics (Joss, 1998). Moreover, Consensus Conferences' reports were often referred to in parliamentary debates, and sometimes they led to parliamentary initiatives. However, in this model it was entirely up to individual MPs to decide whether to consider these recommendations and how to react to them. In the Danish case, individual MPs may have been particularly receptive to the arguments by Consensus Conferences because they dealt with issues that were rarely salient in representative politics or divisive according to partisan lines. Joss (1998) finds out that when it comes to issues dealt with by the Danish Consensus Conferences, there was often no party discipline in the parliament.

Overall, the method of uptake in Consensus Conferences is particularly vulnerable to cherry-picking, that is, selective uptake of recommendations. While cherry-picking seems to be a risk always when mini-publics are used as advisory bodies, there are also ways to circumvent this risk. The most promising model for uptake of mini-publics' arguments and recommendations is to submit them to parliamentary committees (Hendriks, 2016). Committee procedures potentially help parliamentary deliberation on recommendations by mini-publics - and thus avoid the most biased and selective interpretations of recommendations among elected representatives. Parliamentary committees are likely to be most receptive for mini-publics' recommendations since committees are, by design, expected to foster deliberation across different viewpoints, and they are characteristically more deliberative than plenary debates, for example.

There is still a risk that mini-publics' recommendations are not properly considered and watered down in the representative arena, especially if processes of parliamentary deliberation are flawed, for example, because of strict party discipline or logrolling. The impact of advisory mini-publics could be further strengthened by organizing dialogues between elected representatives and the members of a mini-public. This would allow members of the mini-public give feedback on the arguments made by elected representatives before the decisions are made. Dialogues between mini-publics and elected representatives could take place either in a parliamentary committee or at the plenary. Embedding such dialogue in committee deliberations may be recommendable for the reasons stated above, although in many cases this would mean that such dialogues are organized behind closed doors. 
Public dialogues between mini-publics and representatives would enhance deliberative accountability of representatives and serve the citizenry more broadly. However, the proximity of elections may affect representatives' public reactions to minipublics' proposals. In order to strengthen the impact of minipublics further, they could also follow up and give public feedback on decisions made by elected representatives. Such arrangements would go beyond the purely advisory role of mini-publics by allowing mini-publics to intervene or to scrutinize representative decision-making.

\section{Mini-Publics as Collaborative Institutions}

Because purely advisory uses of mini-publics are so vulnerable to cherry-picking, there seems to be a need for a tighter coupling between mini-publics and elected representatives (Hendriks, 2016). One response to mini-publics' lack of impact is to involve decision-makers in the deliberative process more directly. As already pointed out, there are various possible models of organizing interactions between mini-publics and elected representatives, including hearings of representatives in mini-publics, and mini-publics' members hearings in the representative arena.

However, those responsible for decisions, i.e. elected representatives, could also directly engage in a deliberative process with a cross-section of the society. In this model, randomly selected citizens would participate in parliamentary will-formation more directly. While these types of practices have not been very common so far, there are a few important examples. Most notably, the Irish Constitutional Convention, oganized in 2012-2014, included 66 randomly selected citizens and 33 members of the Irish Parliament. The Irish Constitutional Convention deliberated on several constitutional issues ranging from electoral laws to same-sex marriage. It brought about certain important constitutional changes, most notably the legalization of same-sex marriage (Suiter et al., 2016).

There are also other models of mixing elected representatives and citizen deliberation. In the model of 'directly deliberative democracy', developed and experimented by Neblo et al. (2018), members of the US Congress engage in online deliberations with a randomly selected cross-section of their constituents. The model of "hybrid democracy" developed by Sørensen and Torfing (2019), municipal councilors deliberate on a particular policy issue together with citizens representing certain affected groups. Because "hybrid democracy" aims at the inclusion of affected groups rather than randomly selected representatives of the public at large, the model seems to be closer to stakeholder participation than mini-publics.

The inclusion of elected representatives in mini-publics could enhance inclusive processes of mutual justification in policymaking at least in three different ways. First, by engaging in minipublics' deliberations, elected representatives are likely to be exposed to a larger variety of societal viewpoints than in deliberations among representatives only. They may encounter new viewpoints and claims, including those by marginalized groups. This should also encourage representatives to reflect their own views, to correct their possible biases, and help find constructive solutions to the issues at hand.
Second, the procedural features of mini-publics such as interaction with experts, discussion rules, and moderated small group discussions are likely to help elected representatives become more open-minded to different societal viewpoints and overcome their pre-established partisan positions. In fact, the procedures applied in deliberative mini-publics are likely to be more conducive to good-quality deliberation than those applied, e.g. in parliamentary committees. Third, after engaging in such a deliberative process, representatives are likely to be more supportive of the claims and arguments developed in the deliberative process and advocate them in actual decisionmaking. This is likely to enhance the inclusion of different viewpoints and the quality of deliberation in the actual political decision-making.

While mixed deliberative bodies can be expected to improve inclusion and deliberative quality in collective will-formation among elected representatives, there are several questions that need to be taken into account when including elected representatives in deliberative mini-publics. The involvement of partisan politicians may distort the deliberative process. It may increase the tendencies towards partisan reasoning if randomly selected citizens follow the opinions of representatives of their 'own' party. And perhaps even more importantly, representatives' involvement may create inequalities and hierarchies within the deliberative forum, which may distort the deliberative process.

Professional politicians may also dominate the discussions because of their (arguably) better knowledge of the issue at stake or of politics more generally. Or professional politicians may undermine the deliberative process by using partisan rhetoric or other non-deliberative styles of persuasion that are typical in representative politics. However, certain design features of minipublics such as interaction with experts and good-quality facilitation may counteract inequalities and non-deliberative communication styles as well as alleviate such problems. In addition, attention should be paid to the ratio between the number of representatives and citizens in the deliberative forum.

Studies on the deliberative process in the Irish Constitutional Convention seem to dispel some of the concerns regarding mixed forums. There is some evidence that politicians did not dominate the deliberative process in the Constitutional Convention (Suiter et al., 2016). However, the experiences of mixing professional politicians with ordinary citizens in the UK context were less promising (Flinders et al., 2016, 36-40). There have also been concerns pertaining to the risk of selection bias among politicians participating in the deliberative forum. Yet, such biases seem not to have played an important role in case of the Irish Constitutional Convention (Farrell et al., 2019).

Since the evidence of such processes is still scarce, it is hard to draw conclusions on the contextual and design factors affecting the quality of mixed deliberation. Another problem with mixed deliberation is probably that, although elected representatives' views may actually be influenced by the arguments put forward in the mini-public, they may still remain selective in their interpretations of mini-publics arguments and recommendations. In other words, there is a risk of cherry-picking also in mixed mini-publics. For example, in the Irish Constitutional 
Convention, elected representatives seem to have been reluctant to promote policy recommendations regarding, for example, the electoral system, that are potentially against their own vested interests (cf. Farrell et al., 2019).

In the case of advisory mini-publics, it is be possible to develop opportunities for a mini-public to give feedback on the decisions made by elected representatives. However, it is hard to see how this could work in mixed mini-publics. In this respect, the lack of critical distance between mixed mini-publics and elected representatives seems to be a problem. This could also be regarded as a reason to keep mini-publics separate from elected representative institutions. While such a separation may lead to lack of impact in case of advisory mini-publics, one solution would be to use mini-publics more systematically to scrutinize the decisions already made by elected representatives.

\section{Mini-Publics Scrutinizing Representative Institutions}

There have been calls for critical mini-publics that would enhance critical reflection and deliberation among policy-makers and the public at large (Böker and Elstub, 2015). For this purpose, minipublics should perhaps remain separate and independent from elected representatives. In addition, they should be allowed to scrutinize and publicly challenge the decisions made and justifications given by elected representatives. While there are several proposals for the use of mini-publics in this kind of a scrutinizing role, the actual examples of such usages are still scarce.

However, as the model of Citizens' Initiative Review illustrates, deliberative mini-publics are apt to scrutinizing of policy proposals. While the CIR model was developed to assess the merits of ballot initiatives, it is possible to imagine a system where a mini-public would scrutinize governmental policy proposals or, for example, so-called agenda initiatives, i.e. citizens' initiatives submitted to parliament. There are also models in which mini-publics are expected to function as an ex post check on decisions that have been made by elected representatives. As pointed out already, models allowing advisory mini-publics to follow up representative decisionmaking or requirement of representatives' public response to a mini-public's recommendation would entail some elements of scrutiny.

Notably, there is at least one existing practice involving a system of mini-publics with both advisory and scrutinizing powers, namely the so-called Ostbelgien model. In this model, mini-publics have a role in both preparing policy proposals and following up the parliamentary system's response to these proposals (Reuchamps, 2019). The model includes a Citizen Council which is in charge of setting the agenda and monitoring the progress of its proposals. In addition, separate Citizen Assemblies are tasked to prepare the details of the proposals put forward by the Citizen Council. In this respect, the Ostbelgien model allows mini-publics to contribute to various democratic functions, namely agenda-setting, collective willformation and (deliberative) accountability.
The opportunity of mini-publics to exercise ex post scrutiny of elected representatives enhances deliberative accountability of elected representatives by "forcing" them to justify their views to a deliberative body representing a diverse group of citizens. Such mechanisms of deliberative accountability should encourage elected or non-elected - representatives to consider a wider range of viewpoints already in the deliberative process leading to decisions. In the Ostbelgien model, the scrutinizing role of the Citizen Council is limited to the issues that it has raised onto the political agenda. In this respect, the Citizen Council appears to be in a good position to hold the elected representative deliberatively accountable on these particular issues.

There are also other possible models of using mini-publics to scrutinize representative decision-making. Mini-publics could be used to review decision-making in certain types of decisions or in particular circumstances. For example, the Covid-19 pandemic has led many governments to resort exceptional legislation and procedures for cases of emergency, which has further emphasized the role of the executive government in policy-making. Minipublics could be used retrospectively to scrutinize the policy measures taken during the pandemic in order to develop democratic systems' preparedness for future cases of emergency. Or, mini-publics could be routinely used to evaluate the work of the government, for example, in the end of the parliamentary term.

Another way of sharpening the role of a randomly selected chamber would be to specify its scrutinizing task. MacKenzie (2020) suggests that, as a remedy to the problem of democratic myopia, randomly selected citizens could be tasked to scrutinize laws based on the mandatory posteriority impact statements that summarize the anticipated long-term consequences of legislation. In this model, a clearly defined task would give a focus to the work of the randomly selected citizens. Moreover, a systematic use of mini-publics in this kind of a scrutinizing role would encourage elected representatives to consider the long-term consequences of different policy options more carefully.

In the Ostbelgien model, mini-publics have both advisory and scrutinizing roles, which can seems to be a good model in terms of enhancing the impact of citizen deliberation without compromising their independence. Moreover, the Ostbelgien model makes mini-publics a permanent and institutionalized part of the legislative system. In this respect, it shares some features of randomly selected second chambers. Because of the careful design and the institutionalization, the Ostbelgien model is probably the promising model of how mini-publics can be given a scrutinizing role in the legislative system without formal empowerment.

\section{From Mini-Publics to Randomly Selected Second Chambers?}

There are proposals to go even further and to give randomly selected citizens some formal powers in collective decisionmaking. Various authors (e.g. Leib, 2004; MacKenzie, 2016; Vandamme and Verret-Hamelin, 2017; Gastil and Wright, 2018) have discussed the idea of a randomly selected second chamber. Of course, such formal empowerment of randomly 
selected bodies would not be possible in most representative democracies without constitutional changes.

There are different views about the extent and types of formal powers vested to randomly selected second chambers. Some of these proposals (e.g. Leib, 2004; Gastil and Wright, 2018) suggest a bicameral system were the powers of the randomly selected chamber would be more or less symmetrical with the elected legislative chamber. Others (e.g. MacKenzie, 2016) have suggested a less radical model where the randomly selected chamber would have powers to delay legislation. In this respect, randomly selected chambers would not be actual veto players in the political system, but rather something like second chambers in systems characterized by asymmetric bicameralism, such as the UK (cf. Parkinson, 2007, 380).

The justification for a randomly selected second chamber is that it would allow an inclusive deliberative process which is free from hindrances of parliamentary deliberation such as party discipline and constituency constraints. Like other institutions that have been designed to enhance inclusive public scrutiny, such as facultative referendums (El-Wakil, 2016), randomly selected second chambers with veto powers could have anticipatory effects on elected representatives. In order to avoid delays in legislation, elected representatives would need to anticipate and take into account various counterarguments to their policy views, which would enhance the inclusion of different viewpoints and the quality of deliberation among elected representatives. In case of actual challenge by the randomly selected second chamber, disagreements with elected representatives and randomly selected chambers would be articulated in the public. This could also be valuable from the perspective of deliberative democracy since it might help public at large to form their own views on the topic based on such exchanges of arguments.

MacKenzie (2016), MacKenzie (2020) argues for a randomly selected, general-purpose second chamber that has powers to scrutinize and delay any legislation passed by elected representatives. MacKenzie argues that a randomly selected second chamber would have instrumental benefits since it would help considerations of long-term policy consequences. MacKenzie would not limit the powers of such second chamber to any specific issue area, but would prefer a "general-purpose" second chamber. Consequently, randomly selected citizens would need to follow and develop competence on a range of policy areas in order to exercise the scrutinizing function in a credible manner.

To address the potential problems of competence among randomly selected citizens, Gastil and Wright (2018) suggest a long tenure for randomly selected chambers as well as similar support systems including training and professional aides as elected representatives have. However, it is still questionable whether and how randomly selected citizens could develop sufficient expertise on all relevant policy areas. Studies show that there are divisions of labor among elected representatives and parliamentarians specialize in and develop their expertise on certain issue areas e.g. by serving in particular committees (cf. Oñate and Ortega, 2019).
Of course, the institutionalization of a randomly selected second chamber goes beyond of any of the currently existing practices of mini-publics. In addition, a number of questions arise regarding the practical implementation of such institutions There are concerns that the authorization of a randomly selected chamber would put it under similar pressures as elected representatives, which would hinder constructive deliberation within the forum. Moreover, the lack of accountability of randomly selected chambers could give rise to situations where their legitimacy is challenged. As Gastil and Wright (2018) point out, these kinds of concerns could at least partly be addressed by a careful institutional design.

From the point of view of the feasibility of randomly selected second chambers, the biggest problem may be that elected representatives are likely to remain reluctant to adopt them or, even when adopted, to pay enough attention to the careful design that such institutions would require. The main reason is that such institutions could potentially undermine the role of elected representatives - or even appear as antagonistic. While the institutionalization of scrutinizing mini-publics or randomly selected second chambers may look like an excellent idea from the perspective of deliberative democracy, it may be a rather long shot in the context of representative democracies. Obviously, this is rather a practical challenge for the adoption of such institutions rather than a principled reason to object them.

\section{DISCUSSION}

The evaluation of mini-publics should be based on a procedural criterion of whether mini-publics help enhance the inclusive and good-quality deliberation among elected representatives. While inclusive deliberative processes are likely to improve the quality of public decisions (cf. Mercier and Landemore, 2012), the evaluation of the quality of decisions may only be possible "with the benefit of a hindsight."Admittedly, mini-publics are not the only way of enhancing inclusiveness and quality of deliberation among elected representatives. Parliamentary procedures could be developed to improve the quality of deliberation, and interaction and communication between parliaments and citizens could be encouraged by variety of means (cf. Leston-Bandeira, 2012).

The purpose of this article has been to analyze the potential roles of deliberative mini-publics in representative systems. It has been argued that mini-publics can be used to advise elected representatives in decision-making, to collaborate with them in making better decisions, or to scrutinize decisions they have already made. In addition, normative perspective of deliberative democracy has been applied to analyze the expected benefits and weaknesses of using mini-publics in these different roles. Table 1 summarizes the expected benefits, main weaknesses of using mini-publics in different roles, as well as possible remedies to these problems.

The risks of cherry-picking are especially high in advisory mini-publics. These risk can be potentially alleviated if parliamentary committees deliberate on mini-publics' recommendations. And even more so, cherry-picking 
TABLE 1 | The summary of benefits and weaknesses involved in different roles of mini-publics.

\begin{tabular}{|c|c|c|c|}
\hline Mini-public's role & Expected benefit & Main weakness & Remedy \\
\hline $\begin{array}{l}\text { Advisory } \\
\text { Collaborative } \\
\text { Scrutinizing }\end{array}$ & $\begin{array}{l}\text { reflection and enhanced deliberation } \\
\text { more inclusive deliberation } \\
\text { deliberative accountability }\end{array}$ & $\begin{array}{l}\text { cherry-picking } \\
\text { dominance by representatives } \\
\text { antagonizing representatives }\end{array}$ & $\begin{array}{l}\text { enhancing representative deliberation on recommendations } \\
\text { ensuring the quality of deliberation e.g. by facilitators } \\
\text { clarifying the terms of scrutiny }\end{array}$ \\
\hline
\end{tabular}

tendencies can be counteracted by involving representatives directly in the deliberative process. While models where elected representatives deliberate together with randomly selected citizens seem to be a viable way of enhancing inclusiveness and quality of deliberation, they entail a risk of representative dominance and co-optation. These problems can, in turn, be remedied by good facilitation and careful design of the deliberative process. Scrutinizing mini-publics can enhance deliberative accountability of elected representatives and the quality of representative deliberation in anticipation of minipublics.

The overall conclusion is the impact of mini-publics can be bolstered by enhancing deliberative interactions between mini-publics and elected representatives. This can be done, for example, by combining advisory with scrutinizing roles of mini-publics. At the same time, the actual impact of minipublics may remain highly contingent on the contextual factors such as the type of issue at hand and the partypolitical constellation. Advisory and collaborative minipublics can have more impact in situations where there is no strict government-opposition divide. In such situations, there is more room for parliamentary deliberation and, consequently, openness for mini-publics' arguments and recommendations. In contrast, in political contexts allowing little room for deliberation within the representative arena, due to executive dominance or strict government-opposition divide, scrutinizing mini-publics with actual veto powers may be the only way to ensure the deliberative impact of mini-publics.

\section{REFERENCES}

Achen, C. H., and Bartels, L. M. (2016). Democracy for realists. Princeton, NJ: Princeton University Press.

Andersen, I., and Jæger, B. (1999). Danish participatory models. Scenario workshops and consensus conferences: towards more democratic decision-making. Sci. Publ. Pol. 26 (5), 331-340. doi:10.3152/ 147154399781782301

Andersen, V. N., and Hansen, K. M. (2007). How deliberation makes better citizens: the Danish Deliberative Poll on the euro. Eur. J. Polit. Res. 46, 531-556. doi:10.1111/j.1475-6765.2007.00699.x

Böker, M., and Elstub, S. (2015). The possibility of critical mini-publics: realpolitick and normative cycles in democratic theory. Representation 51 (1), 125-144. doi:10.1080/00344893.2015.1026205

Bouricius, T. G. (2013). Democracy through multi-body sortition: athenian lessons for the modern day. J. Public Deliberation. 9 (1), 11. doi:10.16997/jdd.156

Brown, M. (2006). Survey article: citizen panels and the concept of representation. J. Polit. Philos. 14 (2), 203-225. doi:10.1111/j.1467-9760.2006.00245.x

Caluwaerts, D., and Reuchamps, M. (2016). Generating democratic legitimacy through deliberative innovations: the role of embeddedness and disruptiveness. Representation 52 (1), 13-27. doi:10.1080/00344893.2016.1244111
Finally, there is a need to develop methodologies of examining mini-publics' uptake among elected representatives. In order to examine the "hidden" aspects of uptake (cf. Hendriks and LeesMarshment, 2019), it is necessary to gauge whether exposure to mini-public's recommendations enhances learning and reflection on different viewpoints among elected representatives. For this purpose, it would be important to conduct carefully designed interviews and surveys among elected representatives before and after mini-publics, as well as to observe and analyze representatives' deliberation on mini-publics' recommendations.

\section{DATA AVAILABILITY STATEMENT}

The original contributions presented in the study are included in the article/Supplementary Material, further inquiries can be directed to the corresponding author.

\section{AUTHOR CONTRIBUTIONS}

The author confirms being the sole contributor of this work and has approved it for publication.

\section{FUNDING}

This work was supported by the Strategic Research Council at the Academy of Finland (grant number 312671).

Chambers, S. (2009). Rhetoric and the public sphere: has deliberative democracy abandoned mass democracy? Polit. Theor. 37 (3), 323-350. doi:10.1177/ 0090591709332336

Commission on Parliamentary Reform (2017). Report on the scottish parliament. Available at:https://spark.adobe.com/page/QKq29aXYqB6mK/ (Accessed December 8, 2020).

Dahl, R. A. (1989). Democracy and its critics. New Haven, CT and London: Yale University Press.

Dryzek, J., and Niemeyer, S. (2006). Reconciling pluralism and consensus as political ideals. Am. J. Polit. Sci. 50 (3), 634-649. doi:10.1111/j.1540-5907. 2006.00206.x

Dryzek, J. S., and Goodin, R. E. (2006). Deliberative impacts: the macro-political uptake of mini-publics. Polit. Soc. 34, 219-244. doi:10.1177/0032329206288152

El-Wakil, A. (2016). The deliberative potential of facultative referendums: Procedure and substance in direct democracy. Democratic Theory. 4, 59-78. doi:10.3167/dt.2017.040104

Estlund, D. M. (2008). Democratic authority. A philosophical framework. Princeton, NJ: Princeton University Press.

Farrell, D. M., Curato, N., Dryzek, J. S., Geißel, B., Grönlund, K., Marien, S., Niemeyer, S., et al. (2019). Deliberative mini-publics: core design features. Canberra, Australia: Centre for Deliberative Democracy \& Global Governance, University Canberra. 
Farrell, D. M., Suiter, J., Harris, C., and Cunningham, K. (2019). The effects of mixed membership in a deliberative forum: the Irish constitutional convention of 2012-2014. Polit. Stud. 68, 54-73. doi:10.1177/0032321719830936

Fishkin, J. S. (2009). When the people speak: deliberative democracy and public consultation. Oxford, UK: Oxford University Press.

Flinders, M., Ghose, K., Jennings, W., Molloy, E., Prosser, B., Renwick, A., et al. (2016). Democracy matters: lessons from the 2015 citizens' Assemblies on English devolution. Sheffield, UK: Democracy Matters.

Font, J., Smith, G., Galais, C., and Alarcon, P. (2018). Cherry-picking participation: explaining the fate of proposals from participatory processes. Eur. J. Polit. Res. 57. 615-636. doi:10.1111/1475-6765.12248

Fuji Johnson, G. (2015). Democratic illusion. Deliberative democracy in Canadian public policy. Toronto, Canada: University of Toronto Press.

Gastil, J. (2014). Beyond endorsements and partisan cues: giving voters viable alternatives to unreliable cognitive shortcuts. Good Soc. 23 (2), 145-159. doi:10. 1353/gso.2014.0014

Gastil, J., and Wright, E. O. (2018). Legislature by lot: envisioning sortition within a bicameral system. Polit. Soc. 46 (3), 303-330. doi:10.1177/0032329218789886

Gerber, M., Bächtiger, A., Shikano, S., Reber, S., and Rohr, S. (2016). Deliberative abilities and deliberative influence in a transnational deliberative poll (EuroPolis). Br. J. Polit. Sci. 48, 1098-1118. doi:10.1017/S0007123416000144

Grönlund, K., Herne, K., and Setälä, M. (2015). Does enclave deliberation polarize opinions? Polit. Behav 37 (4), 995-1020. doi:10.1007/s11109-015-9304-x

Habermas, J. (1996). Between facts and norms. Cambridge, MA: The MIT Press.

Hammond, M. (2020). Democratic innovations after the postdemocratic turn: between activation and empowerment. Crit. Pol. Stud. doi:10.1080/19460171. 2020.1733629

Hendriks, C. (2016). Coupling citizens and elites in deliberative systems: the role of institutional design. Eur. J. Polit. Res. 55 (1), 43-60. doi:10.1111/1475-6765.12123

Hendriks, C. M., and Lees-Marshment, J. (2019). Political leaders and public engagement: the hidden world of informal elite-citizen interaction. Polit. Stud. 67 (3), 597-617. doi:10.1177/0032321718791370

Jäske, M., and Setälä, M. (2019). A functionalist approach to democratic innovations. Representation 56, 1-17. doi:10.1080/00344893.2019.1691639

Joss, S. (1998). Danish consensus conferences as a model of participatory technology assessment: an impact study of consensus conference on Danish Parliament and Danish public debate. Sci. Publ. Pol. 25 (1), 2-22.

Knobloch, K., Barthel, M., and Gastil, J. (2019). Emanating effects: the impact of the Oregon citizens' initiative review on voters' political efficacy. Polit. Stud. 68, 426-445. doi:10.1177/0032321719852254

Kuyper, J. W., and Wolkenstein, F. (2019). Complementing and correcting representative institutions: when and how to use mini-publics. Eur. J. Polit. Res. 58, 656-675. doi:10.1111/1475-6765.12306

Lafont, C. (2015). Deliberation, participation and democratic legitimacy: should deliberative minipublics shape public policy? J. Polit. Philos. 23 (1), 40-63. doi:10.1111/jopp.12031

LeDuc, L. (2015). Referendums and deliberative democracy. Elect. Stud. 38, 139-148. doi:10.1016/j.electstud.2015.02.007

Leib, E. J. (2004). Deliberative democracy in America: a proposal for a popular branch of government. Park, PA: University of Pennsylvania State University Press.

Leston-Bandeira, C. (2012). Studying the relationship between parliament and citizens. J. Legis. Stud 18 (3-4), 265-274. doi:10.1080/13572334.2012. 706044

Lupia, A., and McCubbins, M. D. (1998). The democratic dilemma: can citizens learn what they need to know? Cambridge, UK: Cambridge University Press.

Luskin, R. C., O'Flynn, I., Fishkin, J. S., and Russell, D. (2014). Deliberating across deep divides. Polit. Stud. 62, 116-135. doi:10.1111/j.1467-9248.2012.01005.x

Már, K., and Gastil, J. (2019). Tracing the boundaries of motivated reasoning: how deliberative minipublics can improve voter knowledge. Polit. Psychol. 41, 107-127. doi:10.1111/pops.12591

MacKenzie, M. (2016). "A general-purpose, randomly selected chamber", in Political institutions for future generations, Editors A. Gosseries and I. González-Ricoy (Oxford, UK: Oxford University Press), 282-299.

MacKenzie, M. (2021). There is No such thing as a short-term issue. Futures 125, 102652. doi:10.1016/j.futures.2020.102652

Mercier, H., and Landemore, H. (2012). Reasoning is for arguing: understanding the successes and failures of deliberation. Polit. Psychol. 33 (2), 243-258. doi:10. $1111 / \mathrm{j} .1467-9221.2012 .00873 . \mathrm{x}$
Mutz, D. C. (2008). Is deliberative democracy a falsifiable theory? Annu. Rev. Polit. Sci. 11, 521-538. doi:10.1146/annurev.polisci.11.081306.070308

Neblo, M., Esterling, K., and Lazer, D. (2018). Politics with the people. Building a directly representative democracy. Cambridge, UK: Cambridge University Press.

Neblo, M. (2007). Family disputes: diversity in defining and measuring deliberation. Swiss Polit. Sci. Rev. 13 (4), 527-557. doi:10.1002/j.1662-6370.2007.tb00088.x

Niemeyer, S . (2014). "Scaling up deliberation to mass publics: harnessing mini-publics in a deliberative systems", in Deliberative mini-publics, Editors K. Grönlund, A. Bächtiger, and M. Setälä (Colchester, UK: ECPR Press), 177-202.

Oñate, P., and Ortega, C. (2019). Committee Parliamentary Specialization Index. Explaining MPs' specialisation in the Spanish Congreso de los Diputados. J. Legis. Stud. 25 (3), 394-408. doi:10.1080/13572334.2019.1662610

Parkinson, J. (2006). Deliberating in the real world: problems of legitimacy in deliberative democracy. Oxford, UK: Oxford University Press.

Parkinson, J. (2007). House of lords. A deliberative democracy defence. Polit. Q 78 (3), 374-381. doi:10.1111/j.1467-923X.2007.00866.x

Przeworski, Adam. (1998). "Minimalist conception of democracy: a defence." in Democracy's value. Editors I. Shapiro and C. Hacker-Cordón. (Cambridge, UK: Cambridge University Press), 23-56.

Reuchamps, M. (2019). Towards permanent deliberative democracy in Belgium: from the G1000 to the Ostbelgien Model. Canberra, Australia: School of Politics and International Relations Seminar, ANU

Richey, M. (2012). Motivated reasoning in political information processing: the death knell of deliberative democracy. Philos. Soc. Sci. 42 (4), 511-542. doi:10. 2139/ssrn.2056190

Rostbøll, C. (2008). Deliberative freedom: deliberative democracy as critical theory. Albany, NY: State University of New York Press.

Sørensen, E., and Torfing, J. (2019). Towards robust hybrid democracy in Scandinavian municipalities? Scand. Polit. Stud. 42 (1), 25-49. doi:10.1111/1467-9477.12134

Setälä, M. (2011). The role of deliberative mini-publics in democratic systems. Lessons from the experience of referendums. Representation 47 (2), 201-213.

Setälä, M. (2017). Connecting deliberative mini-publics to representative decisionmaking. Eur. J. Political Res. 56, 846-863. doi:10.1111/1475-6765.12207

Setälä, M., Christensen, H. S., Leino, M., Strandberg, K., Bäck, M., and Jäske, M. (2020). Deliberative mini-publics facilitating voter knowledge and judgement: experience from a Finnish local referendum. doi:10.1080/00344893.2020.1826565

Setälä, M., and Smith, G. (2018). "Deliberative mini-publics and deliberative democracy." in The Oxford handbook of deliberative democracy, Editors A. Bächtiger, J. Dryzek, J. Mansbridge, and M. Warren. (Oxford, UK: Oxford University Press), 300-314.

Smith, G. (2009). Democratic Innovations. Designing Institutions for Citizen Participation. Cambridge: Cambridge University Press.

Suiter, J., Farrell, D., and Harris, C. (2016). "The Irish constitutional convention: a case of 'high legitimacy'?", in Constitutional deliberative democracy in Europe, Editors M. Reuchamps and J. Suiter (Colchester: ECPR Press), 33-52.

Vandamme, P.-E., and Verret-Hamelin, A (2017). A randomly selected chamber: promises and challenges. J. Public Deliberation 13 (1), 5. doi:10.16997/jdd.271

Warren, M. E. (2017). A problem-based approach to democratic theory. Am. Polit. Sci. Rev. 111 (1), 39-53. doi:10.1017/S0003055416000605

Warren, M. E., and Gastil, J. (2015). Can deliberative minipublics address the cognitive challenges of democratic citizenship. J. Polit. 77 (2), 582-574. doi:10.1086/680078

Warren, M. E. (2020). Participatory deliberative democracy in complex mass societies. Journal of Deliberative Democracy. 16, 81-88. doi:10.16997/jdd.395

Woo, S. Y., and Kübler, D. (2020). Taking stock of democratic innovations and their emergence in (unlikely) authoritarian contexts. Polit. Vierteljahresschr. (PVS) 61, 335-355. doi:10.1007/s11615-020-00236-4

Young, I. M. (2000). Inclusion and democracy. Oxford, UK: Oxford University Press.

Conflict of Interest: The author declares that the research was conducted in the absence of any commercial or financial relationships that could be construed as a potential conflict of interest.

Copyright $\odot 2021$ Setälä. This is an open-access article distributed under the terms of the Creative Commons Attribution License (CC BY). The use, distribution or reproduction in other forums is permitted, provided the original author(s) and the copyright owner(s) are credited and that the original publication in this journal is cited, in accordance with accepted academic practice. No use, distribution or reproduction is permitted which does not comply with these terms. 
OPEN ACCESS

Edited by:

Camille Bedock,

UMR5116 Centre Émile durkheim Science Politique et Sociologie

Comparatives, France

Reviewed by:

Clodagh Harris,

University College Cork, Ireland Didier Caluwaerts,

Vrije University Brussel, Belgium Christoph Niessen,

Catholic University of Louvain, Belgium in collaboration With

reviewer DC

*Correspondence: Dimitri Courant dimitri.courant@unil.ch

Specialty section: This article was submitted to Elections and Representation, a section of the journal Frontiers in Political Science

Received: 05 August 2020 Accepted: 17 November 2020 Published: 08 January 2021

Citation:

Courant D (2021) Citizens' Assemblies for Referendums and Constitutional Reforms: Is There an "Irish Model" for Deliberative Democracy?

Front. Polit. Sci. 2:591983. doi: 10.3389/fpos.2020.591983

\section{Citizens' Assemblies for Referendums and Constitutional Reforms: Is There an "Irish Model" for Deliberative Democracy?}

\author{
Dimitri Courant ${ }^{1,2 *}$ \\ ${ }^{1}$ Laboratory for Analysis of Governance and Public Policy in Europe (LAGAPE), Faculty of Political and Social Sciences, \\ Institute of Political Studies (IEP - Institut d'Etudes Politiques), University of Lausanne, Lausanne, Switzerland, ${ }^{2}$ Urban \\ Societies and Cultures (CSU - Cultures et Sociétés Urbaines), Department of Political Science, Center for Sociological and \\ Political Research in Paris (CRESPPA), University Paris 8 Vincennes Saint-Denis, Paris, France
}

Among democratic innovations, deliberative mini-publics, that is panels of randomly selected citizens tasked to make recommendations about public policies, have been increasingly used. In this regard, Ireland stands out as a truly unique case because, on the one hand, it held four consecutive randomly selected citizens' assemblies, and on the other hand, some of those processes produced major political outcomes through three successful referendums; no other country shows such as record. This led many actors to claim that the "Irish model" was replicable in other countries and that it should lead to political "success." But is this true? Relying on a qualitative empirical case-study, this article analyses different aspects to answer this question: First, the international context in which the Irish deliberative process took place; second, the differences between the various Irish citizens' assemblies; third, their limitations and issues linked to a contrasted institutionalization; and finally, what "institutional model" emerges from Ireland and whether it can be transferred elsewhere.

Keywords: citizen participation, constitution, deliberative democracy, mini-public, democratic innovations, democracy, Ireland, referendum

\section{INTRODUCTION}

In recent years, various countries witnessed democratic innovations to include citizens in political decision-making and improve representation (Saward, 2000; Smith, 2009; Elstub and Escobar, 2019). Among those experimentations, deliberative mini-publics (DMPs) had the most impacts (Reuchamps and Suiter, 2016). Mini-publics are stratified randomly-selected panels bringing ordinary citizens together to deliberate on public policy issues (Grönlund et al., 2014). Various types have been implemented all over the world: citizens' juries, deliberative polls, or more recently, citizens' assemblies (CAs) which are increasingly being used worldwide, with varying uptakes (Courant and Sintomer, 2019; Gastil and Wright, 2019; Harris, 2019).

Ireland stands out as a truly unique case because, on the one hand, it held four consecutive randomly selected citizens' assemblies, and on the other hand, some of those processes produced major political outcomes through three successful referendums; no other country shows such 
a record. Following the deliberations of the Convention on the Constitution (CotC), bringing together 66 randomly selected citizens and 33 politicians, the 2015 referendum on marriage equality changed the Constitution and legalized same-sex marriage; following the recommendations of the Irish Citizens' Assembly (ICA), involving 99 citizens, the 2018 referendum produced another constitutional change legalizing abortion.

The real-life experimentation in Ireland seems to have provided some empirical support to the many theoretical propositions and projects for an institutionalized deliberative democracy mainly relying on randomly selected mini-publics (Leib, 2004; O'Leary, 2006; Barnett and Carty, 2008; Callenbach and Phillips, 2008; Sutherland, 2008; Buchstein, 2010; MacKenzie, 2016; Gastil and Wright, 2019). Mentioning the Irish case, Dryzek et al. $(2019,1145)$ note: “These processes reinvigorated the political landscape after the political disasters that the global financial crisis unleashed on Ireland," Those political uptakes were viewed as a "success" by many (Honohan, 2014; Renwick, 2015, 2017; Suteu, 2015; Flinders et al., 2016; Van Reybrouck, 2016), and also led several actors to claim that the "Irish model" was replicable in other countries and that it should lead to political "improvements"1. This influenced, among others, the Citizen Conventions for Climate in France and the Climate Assembly UK in the United Kingdom, as well as activists' demands, such as Extinction Rebellion. Moreover, the citizens' assemblies of Ireland are gradually becoming a reference, or even the main reference, for deliberative democracy scholars (Reuchamps and Suiter, 2016; Setälä, 2017; Dryzek et al., 2019; Gastil and Wright, 2019; Harris, 2019). Are we really facing a paradigm shift that could improve political representation globally? This optimistic claim raises interrogations and require empirical investigation. Does the "Irish model" actually exist? If so can the Irish model be replicated? And should the Irish model be replicated, that is to say, did it perform as well as advocates say? An empirical analysis of the Irish case is necessary to understand what made this deliberative process possible in the first place, in terms of international, structural, contextual, and local factors. In order to properly analyze the phenomenon, four areas must be investigated.

First, in which international context did the Irish deliberative process take place? It is crucial to locate Ireland's innovations within the global trend of deliberative mini-public and to grasp the transfer and inspiration that the Irish case took from other mini-publics worldwide. Moreover, citizens' assemblies already took place in other countries, so what could possibly make Ireland "better" than its foreign predecessors?

Second, is there such thing as an "Irish model" given the differences between its various mini-publics? How were those different deliberative mini-publics created? What is the contrasted dynamic of this institutionalization process, from informal margins to official center? What processes, actors, and contexts turn democratic innovations into new

\footnotetext{
${ }^{1}$ For an academic instance see White (2017); for instances in the press see Humphreys (2016), Barroux (2019), Benedictus (2019), Brown (2019), Caldwell (2019), Farrell (2019). On the contrary, for a rare but stimulating critical analysis see Carolan (2015).
}

democratic institutions? This article studies the "incomplete" institutionalization process of deliberative democracy in Ireland by comparing the successive assemblies, their ruptures and continuities, and their articulation. The most notable change requiring explanation is the presence then absence of politicians between assemblies. It is important to study the "deliberative system" (Parkinson and Mansbridge, 2012) within which the Irish mini-publics fitted.

Third, is the Irish experience an "absolute success" or are there limitations worth investigating, and if so, which ones? How did those citizens' assemblies function and dysfunction? If those deliberative innovations provided some major uptakes and were widely celebrated, careful examination reveals several shortcomings and problems which should be taken into account as most applies to mini-publics worldwide. Conversely, many elements in the Irish assemblies offer insights of efficient practices and subtle design. For political representation to be truly "improved" it is necessary to critically assess democratic innovation real-life cases through informed and empirically grounded research.

Finally, is Ireland actually crafting new democratic institutions transferable to other countries, or is it merely a local exception? What "institutional model" could emerge from the Irish case? Given the empirical analysis, careful hypothesis and theories can be made about the impact of Ireland beyond its borders.

As we will see, supporters of the "Irish model" claim it is a "success" often without good knowledge of the cases and while remaining vague as to the criteria for assessing the said "success." They tend to focus on the mere fact that Irish mini-publics saw some of their recommendations approved by referendums, and that those recommendations were judged "good" or "progressive" by the commentators. In answering the four research areas listed above, I refer to a theoretical framework commonly used in the evaluation of mini-publics distinguishing between input, throughput and output legitimacy (Bekkers and Edwards, 2007; Papadopoulos and Warin, 2007; Caluwaerts and Reuchamps, 2015; Reuchamps and Suiter, 2016). Input legitimacy refers to the quality of representation, the openness of the agenda and the level of information. Throughput legitimacy includes the quality of participation, the quality of decision making, and the contextual independence. Output legitimacy encompasses public endorsement, the weight of the results, and responsiveness and accountability. This framework integrates the dimensions highlighted by others scholars, like the analysis of representativeness, citizen control over the process, and decision-making impact (Böker and Elstub, 2015, 133-134), or the distinction between participant selection, communication and decision, and authority and power (Fung, 2006). I also try go beyond mere design features to look at the actual practice in its concrete reality (Geissel and Gherghina, 2016).

The Irish mini-publics have been mentioned a lot, but very few scientists have actually conducted research on them. A core group of a few researchers published the vast majority of articles on those cases. If several very interesting and stimulating scientific papers and books' chapters have been written by those few authors on the Irish cases, most took a quantitative approach (Farrell et al., 2013; Suiter et al., 2016a,b; O’Malley et al., 2020). 
Moreover, the authors being directly involved in the organization and promotion of several of the Irish CAs, their own role as actors is not analyzed. Most of the time the authors mention their involvement in a footnote rather than opting for reflexivity and making their own actions an object of the study. Their papers, even when more descriptive than quantitative (Farrell et al., 2018), tend to focus on one of the three assemblies rather than all of them and their connections.

Therefore, there is a gap in the literature at two levels. On the one hand, in terms of methodology, qualitative methods have been largely underused. On the other, in terms of position and approach, an exploration of the long and dynamic process between the cases has also received less analysis than other aspects, such as opinion changes or the impact of talking in the assemblies. This paper considers all actors in these process, including the crucial actions of the political scientists, who were interviewed as part of this research. In this regard, this paper adopts some of the features of a process-tracing approach (Bezes et al., 2018; Beach and Pedersen, 2019). Another relative originality of my research is my position, contrary to a fair share of scientists adopting an "involved position," I am not studying assemblies I actively advocated for or organized, which lends itself to a more "external" point of view. However, because I have conducted a long qualitative fieldwork, I remain "connected" to the case and avoid the "disconnected position" that other researchers adopt as they write on cases they have not empirically studied themselves. ${ }^{2}$

In order to answer the questions asked above and to offer an original approach, this paper adopts a critical political sociology approach relying on a qualitative case-study based on: a comprehensive fieldwork in Ireland, hundreds of hours of direct ethnographic observation spread over 48 days out of a total of 75 days of fieldwork, but also 44 semi-directives in depth interviews ranging from 1 to $2 \mathrm{~h}$ for most and around $30 \mathrm{~min}$ for a minority (with randomly selected citizens, politicians, organizers, etc. see Table 1), as well as content analysis of over 300 various sources such as press articles, official documents, reports, video records of debates, and statements. Analysis and coding were conducted using Computer-assisted qualitative data analysis software (CAQDAS) and more specifically NVivo, and mixing deductive codes and inductive ones, following a framework analysis approach (Ritchie et al., 2014; Saldana, 2016). Adopting a qualitative methodological framework is "particularly suited to answer three types of questions (...). How democratic innovations emerge? How is deliberation framed by the organizers and participants of these events? What are the effects of democratic innovations on participants and public policies?" (Talpin, 2019, 487). This design matches the research questions and the diversity of data allowed for a strong triangulation (Richards, 2015).

First, I start by presenting the context within which the Irish case arises. It is crucial to put the Irish citizens' assemblies (ICAs)

\footnotetext{
${ }^{2}$ Both the "involved" and "disconnected" positions have of course their advantages and disadvantages. The point here is not to pretend that the "external but connected" position would somehow be "better" but to notice that it is not the most widespread, hence its originality.
}

TABLE 1 | Types of actors and number of interviews.

\begin{tabular}{lc}
\hline Type of actors & Number of interviews \\
\hline Participants citizens & 24 \\
Secretariat & 5 \\
Facilitators & 5 \\
Others (stakeholders, expert advisor, pollster) & 7 \\
Participants politicians & 3 \\
Total & $\mathbf{4 4}$ \\
\hline
\end{tabular}

into context, by highlighting they are the latest chapter of a long trend involving deliberative mini-publics and as a product of international transfers, in order to break the illusion that "all was invented in Ireland"-as several press articles cited before may lead to believe. Secondly, I analyze the institutionalization process of deliberative democracy in Ireland by studying the successive assemblies, their ruptures and continuities, and their articulation. Finally, in light of the empirical insights, I discuss the progress and the limitations of the Irish case, showing that if Ireland went further than its predecessors, it did encounter new challenges and common problems that other mini-publics might face as well.

\section{LOCATING THE IRISH CASE IN ITS INTERNATIONAL CONTEXT: A SHORT HISTORY OF DELIBERATIVE MINI-PUBLICS}

Due to the importance of the political changes initiated through its democratic innovations, Ireland should be considered a trailblazer but also as the successor to a wider political trend aimed at making democracy more deliberative and inclusive through randomly selected panels of citizens (Saward, 2000; Smith, 2009; Courant and Sintomer, 2019). I distinguish six generations of deliberative mini-publics. ${ }^{3}$

First, the High Council of the Military Function (HCMF, Conseil Supérieur de la Fonction Militaire) established by the French Parliament in 1969, still active today, brings together 85 randomly selected representatives and deals with all matters related to soldiers' working conditions; it is the first and the most durable mini-public in modern history, as well as the first permanent randomly selected institution in the modern world (Courant, 2019a). Secondly, the Citizens' Juries and Planning Cells, created in the 1970 s by Ned Crosby and Peter Dienel, involve ordinary citizens in drafting a report to inform public policy decisions, spread throughout many countries but without strong institutionalization (Crosby and Nethercut, 2005; Hendriks, 2005; Vergne, 2010). Third, the Consensus Conferences on techno-scientific issues were launched in the 1980s by the Danish Board of Technology and spread

\footnotetext{
${ }^{3}$ Various deliberative devices have been assigned different missions: inclusion, consultation, information, evaluation, allocation, proposition, legislation, constitution, and long-term (Courant, 2019b, 233-234).
} 
in various EU countries as well as in Switzerland, where the TA-SWISS was officially established by Parliament to produce impartial evaluations of contested new technologies (Joss and Bellucci, 2002). Fourth, Deliberative Polling was invented by James Fishkin in the 1990s and has been tested around the world since. It aims at showing "considered opinion" contrary to traditional opinion polls that capture only "raw opinions" (Fishkin, 2009; Mansbridge, 2010). Fifth, the Citizens' Initiative Review was set up in Oregon in 2010 to have a panel produce impartial information on upcoming referendums that is sent to the voting population in order to help it cast an informed ballot (Knobloch et al., 2015); since then, the device has spread to Arizona, Colorado, Washington State, Massachusetts, and California. Finally, the new trend of this family of democratic innovations are the Citizens' Assemblies (CAs), launched in Canada in 2004 (Warren and Pearse, 2008) and then replicated with various changes in the Netherlands (Fournier et al., 2011), Australia (Carson et al., 2013), Iceland, Belgium, Ireland (Reuchamps and Suiter, 2016), and the United Kingdom (Flinders et al., 2016; Renwick, 2017; Hughes, 2018). According to Böker and Elstub (2015), deliberative polls tend to have the greatest representativeness but the least impact; citizens juries, planning cells and consensus conferences have moderate representativeness and impact; while CAs tend to have a high representativeness and the greatest impact (see also: Harris, 2019). Very often, the HCMF and the CIR are left out by scholars comparing mini-publics, but those cases display a high level of embeddedness in their respective political system.

Of those generations of mini-public based democratic innovations, the last one is now front of stage and potentially reveals a "constitutional turn for deliberative democracy" (Reuchamps and Suiter, 2016). The first citizens' assembly was established in 2004 in the Canadian province of British Columbia. The government gave to a mini-public of 158 randomly selected citizens and two hand-picked citizen natives the mission to propose a new electoral system for the province that would be submitted to a referendum (Warren and Pearse, 2008). Two years later, a similar process was put in place in the Netherlands and Ontario. However, all of the proposals failed to be implemented. The super-majority threshold of $60 \%$ for the referendum was missed by a small margin (58\%) in British Columbia and by a substantial one in Ontario (37\%), while the Dutch proposal was rejected by the government without being put to a vote (Fournier et al., 2011).

Nevertheless, in Iceland, the deliberative constitutional process obtained a popular victory at the ballot box in 2012. In the aftermath of the 2008 financial crisis, massive protests led to the resignation of the government and the election of a leftwing and ecologist coalition. A process to revise the constitution was implemented in several phases. First, in November 2009, under the impulse of a civil society movement, a National Assembly composed of 900 randomly selected citizens along with 300 representatives of civil-society associations deliberated for 1 day on the future of the country and the issues to be tackled by a constitutional reform. The government replicated the process under the name National Forum, in which 950 randomly selected citizens deliberated for a day to identify important topics. Elections were then organized, but parties were forbidden to take part in them. Of the 322 candidates, 25 were elected with a $30 \%$ turnout to form the Constitutional Assembly (or Council), whose work is widely followed online, giving birth to what some called a "crowdsourced-Constitution"-even if this is contested. The text was submitted to a referendum in 2012 and was supported by a majority of Icelanders. However, the next elections brought right-wing parties back to power, which refused to approve the "citizens' constitution" in Parliament and blocked its implementation (Bergmann, 2016).

In 2009, an NGO, the New Democracy Foundation, organized the Australian Citizens' Parliament, in which 150 randomly selected participants deliberated for 4 days before presenting its proposal to Parliament, but without much effect or implementation (Carson et al., 2013). Finally, in 2011-2012, Belgium witnessed a randomly selected assembly: the G1000, which remained completely citizen-led and extra-institutional. Hence, its political effects remained marginal in terms of concrete reform, even though its media coverage and quality made it a relative success (Jacquet et al., 2016; Caluwaerts and Reuchamps, 2018).

A useful distinction to be made is the one between statesupported citizens' assemblies and civil-society-led citizens' assemblies. The former, comprising the Canadian and Netherlandish cases, are characterized by an official mandate, important funding, and consequent time for deliberation. The latter, which include the Australian and Belgian cases, do not have institutional support, rely on crowdfunding and donations, and do not allow for long deliberation. In the Icelandic and Irish cases, there is a dynamic process, initiated by civil-society led CAs which pushes the elected representatives to implement state-supported CAs.

Studying planning cells and citizens' juries, Vergne (2010, 90) distinguishes three modes of diffusion for democratic innovations: transposition, in which the original model is directly imported without any changes; transfer, an academic collaboration that results in concrete implementation through which the original model is modified; and influence, when local actors learn the concept from a third party and only take inspiration from it for their own projects. The cases of the Netherlands and Ontario are somewhat similar to a transposition of the British Columbia model. The Irish process, however, draws from all those previous citizens' assemblies in various ways, oscillating between transfer and influence.

The main difference between most mini-publics worldwide, including other CAs, and the Irish cases it that the latter stand out in terms of policy output. In 2019, new CAs have been established, on the issue of climate change, like in the UK or in France (Courant, 2020a). Moreover, in terms of institutional linkage, Belgium has recently witnessed more advanced quasi-institutionalized forms of citizen deliberation with a permanent Citizen Council in the German-speaking Community and permanent mixed parliamentary commission in the Brussels-Capital Region. To date their output legitimacy, however, does not equal that of the Irish experiences. 


\section{A TALE OF THREE ASSEMBLIES: THE IRISH DEMOCRATIC INNOVATIONS FROM THE MARGINS TO THE FRONT STAGE \\ "We the Citizens" Pilot Assembly (2010-2011): An Original Experimentation From Civil Society}

In the follow up to the democratic innovations described above, the Republic of Ireland was the setting for major political innovations. This transfer was due in part to a worldwide academic network of political scientists. Already in 2005 and 2007, reports from the Democracy Commission and the Irish Democratic Audit, respectively, were produced by the think tank TASC and called for political reform. The Democracy Commission report called for deliberative and participatory approaches to governance, and mentions deliberative panels (Harris, 2005; Coakley, 2010), but with no concrete uptakes. Then, as the country was facing the 2008 financial crisis, a group of researchers, intellectuals and activists debated the necessity of a constitutional reform, especially on the blog politicalreform.ie linked to the Political Studies Association of Ireland. However, and to the best of my knowledge, the first record of a mention of a public advice to use a citizens' assembly in Ireland is the audition of Professor Kenneth Benoit at the parliamentary Joint Committee on the Constitution, on Wednesday 9th December 2009: "In British Columbia a citizens' electoral commission was appointed. This system would, I believe, be the most workable in the Irish case" (Oireachtas, 2009). At the time the CA is only considered for the task of electoral reform, and the Joint Committee is very receptive from the start, eventually making it one of its main recommendation in its final report in July 2010 (Joint Committee on the Constitution, 2010):

\footnotetext{
"In order to de-politicize any reform process, [the Committee] proposes the establishment of a Citizens' Assembly to examine the performance of PR-STV in Ireland, and if it deems that reforms are necessary, to propose changes (...). It is the opinion of the Committee that the establishment of such an Assembly would facilitate greater popular engagement with the democratic institutions as well as enhancing the legitimacy of any proposed reform."
}

In the month following Benoit's presentation, political parties started incorporating his suggestion in their promises, starting with Fine Gael in March 2010 (Farrell, 2010a), then Labor (Farrell, 2010b). Part of the political science community was continuing to push for a CA on electoral reform to become reality, especially the editors of the politicalreform.ie blog who also published an opinion piece in The Irish Times in November 2010 (Byrne et al., 2010). Professor Kenneth Carty, researcher on the Canadian' CAs, gave a presentation on the British Columbia $\mathrm{CA}$, at Trinity College Dublin, the month before. Moreover, the same group of Irish academics developed a "reform score card" in advance of the Irish general election-a CA was mentioned on it (Byrne et al., 2011; Suiter, 2011). As one of its initiators explained:

\begin{abstract}
"the original idea was that we would do a framework to focus on what we thought were the five key areas of political reform. We circulated that to all of the political parties to say that we are going to be ranking your manifestos, you're going to be compared to each other on the basis of these five key areas and we are going to be making it very public" (Connolly, 2011).
\end{abstract}

After some back tracking and hesitation from political leaders (Collins, 2010; Farrell, 2010c), the 2011 general election definitely opened a "window of opportunity" (Kingdon, 1995) for the CA to gain the attention of political parties, which almost all of whom included a citizen-led constitutional reform in their campaign promises, but with no specification or detail (Carney and Harris, 2011; Wall, 2011). Two of them, Fine Gael (center-right) and Labor (center-left), formed a coalition government, which had pledged to set a CA, after the once dominant Fianna Fáil lost its majority in what was called an "electoral earthquake" (Gallagher and Marsh, 2011; Suiter et al., 2016a). However, no progress was made on this point and there was fear that the design of the CA would be weak and poorly executed. As an Irish analyst noted: "The programme for government did not define what it meant by a constitutional convention, did not detail its likely composition and was silent on what would happen to any recommendations" (Whelan, 2012).

Meanwhile, the group of researchers calling for political reform contacted intellectuals and activists, founded the "We the Citizens" movement, and launched a randomly selected informal assembly in 2011-a so-called "pilot"-to show to the political class and, more broadly, to the country that the direct implication of "ordinary citizens" could be beneficial to change the constitution. One of the key actors of this process, Professor David Farrell, had been invited to give evidence by the Canadian and Dutch citizens' assemblies as an expert in electoral systems, and he was impressed by those deliberative innovations.

This civil-society movement was contacted by the Atlantic Philanthropies, an American foundation aiming to sponsor various initiatives empowering citizens. Benefiting from this financial support, "We the Citizens" held seven participatory forums based on the world café model in Ireland's major cities. Farrell explains: "We were booking conference rooms in hotels and announcing the events in the press and local radio saying: if you want to discuss the future of the country, you are welcome, we will offer you tea and snacks." 4 The goal was, as with the G1000 and the first two steps of the Icelandic process, to spring up ideas and set the agenda in a bottom-up dynamic way to foster input legitimacy, in other words, to listen to what "ordinary people" wished for the future of Ireland.

Those seven participatory meetings in various cities allowed 'We the Citizens' to spot recurring topics and to launch its Pilot Citizens' Assembly in May-June 2011 (Farrell et al., 2013; Suiter et al., 2016b; O'Malley et al., 2020). The polling company Ipsos MRBI constituted a representative sample of which 100 individuals actually were gathered for one weekend in Dublin to deliberate on three issues:

${ }^{4}$ Interview with David Farrell, Dublin, May 2015. 
1. the role of members of Parliament (connection with the constituency, electoral system, size of Parliament);

2. the identity of politicians (women, mandate limit, unelected ministers);

3. and the arbitration between tax increases or budget cuts in a time of economic crisis.

In terms of output, the pilot assembly gave "We the Citizens" the opportunity to draft a report pleading for a constitutional citizens' assembly to reform the Irish political system and more crucially to outline a process of how to do so with rigorous procedures. This report, which empirically narrates the deliberative process (We the Citizens, 2011), was used in lobbying various politicians, civil servants, and civil society representatives. This had the effect to prevent the project of Statesponsored CA to fall in oblivion and to set a high deliberative standard for its proceedings. The political scientists from "We The Citizens," David Farrell, Jane Suiter, Eoin O'Malley, were joined by fellow political scientist Clodagh Harris and a law scholar Lia O'Hegarty, on the Academic and Legal Research Group for the Convention on the Constitution.

We can distinguish a pattern here. A democratic innovation gaining institutional support is often the product of organized democratic activists with high social and symbolic capital often among which political scientists who push the proposal, which is sometimes later accepted by a newly elected government. This was the case in the Netherlands, where the action of the D66 party was crucial (Fournier et al., 2011); in Australia with the New Democracy Foundation (Carson et al., 2013); in Iceland with the input of the Anthills and the access to power of greenleft coalition (Bergmann, 2016); and in Oregon, which benefitted from the involvement of Ned Crosby, John Gastil and Healthy Democracy Oregon (Knobloch et al., 2015). To a lesser extent, in British Columbia, activists such as Nick Loenen also pushed for a randomly selected assembly, and, more crucially, the CA on electoral reform was supported by a newly elected party (Lang, 2010, 117). This illustrates a global tendency of sortition activism, in which militants defend sortition (i.e., random selection) in their discourses and sometimes implement it in their practices, as is the case in France, Belgium, the United Kingdom, Australia, and Mexico (Courant, 2018a, 2020b). Interestingly, in the Irish case, it is not mainly deliberative democracy scholars who pushed for a CA, but scholars mostly coming from electoral studies, who had heard about the Canadian and Dutch CAs because those were dealing with electoral reform.

\section{The Convention on the Constitution (2012-2014): A Hybrid Device}

The "electoral earthquake" putting an end to the longdominant party Fianna Fáil (center-right) and the winning Fine Gael/Labor coalition (Gallagher and Marsh, 2011) allowed for a negotiation around a constitutional convention between various academics, activists, and politicians. Indeed, the two wining parties disagreed on the composition of this assembly, Labor wanted an equal mix of politicians, citizens, and experts, while "We the Citizens" advocated for 100\% randomly selected citizens. Eventually, a compromise was reached: the Convention on the Constitution (CotC) was composed of 66 randomly selected citizens and 33 politicians from various political parties represented proportionally to their strength in Parliament. ${ }^{5}$ The 33 politicians were composed of 29 members of the Oireachtas (parliament) and four representatives of Northern Ireland political parties. For the 66 citizens and the 33 politicians an equivalent number of alternates were also selected so that the assembly would not be diminished in numbers in the absence of some of its members. And indeed, the politicians did rotate quite a lot: "throughout the lifetime of the Convention, there were a total of 52 members from the Irish parliament who attended its meeting" (Farrell et al., 2020). The experts would be involved in the process but by giving lectures to inform the assembly with factual data, without directly deliberating. The parties were free to choose the way their politicians members were selected. For the citizens:

\footnotetext{
"the recruitment was done door to door by the polling company, with quotas. The random element was knocking on every 16th door within an area. On the contrary, in Canada they mailed letter and then did a lottery. In Ireland there are different electoral registers, here they used the Presidential electoral register for sortition." 6
}

This assembly came together for the first time in Dublin Castle in December 2012 for its inaugural meeting, with its first deliberative session in January 2013, and had the task of proposing recommendation on eight topics, mainly linked to articles of the constitution. A crucial point is that in Ireland, any constitutional change must be approved by referendum. Hence, this institutionally constraining framework largely explains the "deliberative enthusiasm" displayed by the political class, which is an adaptation to legal imperatives and should not be too quickly viewed as a "deep participatory conviction." As it is impossible to modify the constitution without the direct approval of the people, it is therefore rational to consult a representative sample of the population before any referendum.

Its recommendations were to be transmitted to the government and parliament, which would decide if some could be submitted to a referendum. Eight items were given by the government, while two others ( 9 and 10 bellow) were chosen by the CotC via public consultations through public meetings and an online platform, leading to a hybrid input legitimacy:

1. Reduction of presidential term

2. Reduce voting age

3. Role of women in home/public life

4. Increasing women's participation in politics

5. Marriage equality

6. Electoral system

7. Votes for emigrants/N. Ireland residents in presidential elections

8. Blasphemy

9. Dáil reform

10. Economic, social, and cultural rights

\footnotetext{
${ }^{5}$ Individual interviews with David Farrell, Eoin O'Malley, Jane Suiter, and two senior MPs, Dublin, May 2015.

${ }^{6}$ Interview with David Farrell, Dublin, May 2015.
} 
This eclectic agenda was criticized for lacking coherence and ambition, with few important or divisive topics. As a commentator puts it: "There is no evidence of any kind of overarching theme or logic to the agenda-it seems to be a pick and mix of the least harmful political reform proposals put forward by the governing parties during the election campaign" (Wall, 2012).

The general deliberative model upon which the CotC was based was somewhat similar to the Canadian innovations, and in some ways to the Icelandic and Belgian cases, and more broadly to the general process of deliberative mini-publics. Under the supervision of a Chair and a senior civil servant assisted by three staff members, the participants came together one weekend a month, during which they auditioned experts and then deliberated in small groups, which were pseudorandomly shuffled each weekend. Those meetings, held in Malahide Grand Hotel (Malahide is a small city north of Dublin), benefited from paid facilitators and note takers. As the Secretary of the Convention admits: "I did most of the organizational work (...). Having note-takers and facilitators, it

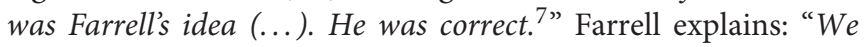
shook the trees to find facilitators to pay: PhD students, Master students and barristers (lawyers). I mainly did the recruitment process and training, with role-play sessions." ${ }^{8}$ Contrary to the fears of many commentators, surveys reveal that the 66 citizens did not perceive the debates as being dominated by the 33 politicians (Suiter et al., 2016a). After each small group deliberation, the CotC asked questions of the experts. Each topic was concluded by a vote on the recommendations the assembly wished to transmit to the government (Arnold et al., 2019). Interestingly, as the Chair notes, at the very first weekend the CotC voted to reduce the voting age to 16 while the agenda of the Government was to consider 17; "from a procedural point of view what was important was a willingness to slightly extend the... not so much the term of reference, but how you were dealing, how you were interpreting the term of reference." 9 This allowed for a robust throughput legitimacy.

The CotC's work was concluded in March 2014. Its output legitimacy is a contrasted one. While the government and Parliament directly integrated some of its recommendations into legislation, some others were not even debated (Farrell et al., 2018; see, Table 3). In this way, the elected officials conducted "selective listening" or "cherry picking," as observed in many participatory institutions (Smith, 2009; Nez and Talpin, 2010, 214). At the time, only two of its recommendations were put to a referendum: the legalization of same-sex marriage and the reduction of the age of eligibility for the presidency from 35 to 21 . Due to its importance, the first issue completely "overshadowed" the second. On 22 May 2015, the "marriage equality" referendum gained an astonishing majority of votes (61\%) in the follow-up to an intense campaign, during which most parties supported the "yes" side (Elkink et al., 2017). However, on the same day,

\footnotetext{
${ }^{7}$ Interview with Arthur O’Leary, Secretary of the CotC, Dublin, April 2018.

${ }^{8}$ Interview with David Farrell, Dublin, May 2015.

${ }^{9}$ Interview with Tom Arnold, Chair of the CotC, Dublin, January 2018.
}

the reduction of the age of eligibility for the presidency was rejected due to a lack of public awareness and media exposure, that led to most Irish citizens only discovering the existence of a second question when they came to vote. ${ }^{10}$ These results prove the limitations facing the CotC, especially the lack of awareness of its existence among the general population, which is a common feature shared by many democratic innovations, therefore restraining their impact (Crosby and Nethercut, 2005; Goodin and Dryzek, 2006; Fournier et al., 2011). After a long period of time during which none of the Convention's propositions was submitted to popular vote, the offense of blasphemy is finally removed from the Constitution with almost $65 \%$ support in the 26 th October 2018 referendum.

\section{The Irish Citizens' Assembly (2016-2018): The Issue of Abortion Shaping Deliberative Design}

In February 2016, new elections were held, breaking the Labor/Fine Gael coalition and leaving the latter in the position of a minority government. One of the commitments of Taoiseach (Prime Minister) Enda Kenny, leader of Fine Gael, was to summon a new constitutional assembly in the follow-up to the perceived "success" of the first one. However, even though the main issue remained societal and not economic, abortion is a highly divisive issue-much more so than "marriage equality," which was broadly supported. As a deeply Catholic country, Ireland made the ban of abortion from a legal to a constitutional disposition-the 8th Amendment or Article 40.3.3-in a 1983 referendum, with the island thus becoming "the only country to inscribe the right to life of the 'unborn child' in its Constitution" (Nault, 2015).

In the fall of 2016, a second deliberative assembly was set up with significant changes compared to the previous one, which makes this "institutionalization" contrasted and complex. Composed exclusively of 99 randomly selected citizens and chaired by a Supreme Court judge, this democratic innovationsimply called the Citizens' Assembly (ICA)—was given the task of crafting recommendations on five issues:

1. The Eighth Amendment of the Constitution (abortion)

2. How we best respond to the challenges and opportunities of an aging population

3. How the state can make Ireland a leader in tackling climate change

4. The manner in which referenda are held

5. Fixed term parliaments

No reason was officially given for a major change: the nonparticipation of politicians in this new assembly. The true reason was in no way an "organizational learning" or a reaction to potential problems in the CotC, largely complimented by both citizen and politician members, but was rather linked to the very nature of the issue, as abortion is perceived as being politically dangerous. Hence, most politicians refused to take a public stance on abortion out of fear of losing votes or their seats due

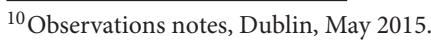


to the deep cleavage among the electorate on this question. A parliamentarian explained: "When we go canvasing, it happens that some people ask about our opinion on abortion, and they make it clear that this issue only will determine their vote." 11 The construction of this deliberative device is therefore deeply embedded in the "politics of blame avoidance" (Weaver, 1986; Hood, 2010), here the mini-public is given a task politicians refused to deal with themselves for fear of public backlash from one side or the other.

Other differences between the $\operatorname{Cot} C$ and the ICA are revealing. The number of topics was lowered from 10 to five, while the importance of the issues increased, which could allow for more efficient deliberation. However, the constitutional dimension was not necessarily obvious for the issues of the aging population or climate change. To use Hans-Liudger Dienel's distinction $(2010,108)$, the ICA's five topics were a mix of "open" and "closed problems", the former "presenting no clear cut solution" but requiring "new ideas," while the latter being "a conflictual issue imposing the search for compromise between several known solutions, but incompatible and antagonistic." Typically, climate change is an "open problem," while abortion is a "closed one." The time given to each topic differed, with an initial planning of four weekends for abortion and then one per remaining topic. Due to demands from the assembly itself, Parliament granted three additional weekends for dealing, respectively, with abortion, the aging population, and climate change, revealing that the ICA had a bit of agency. Citizen representatives also managed to move climate change from the last to the third position (Courant, 2020a). However, the ICA's agency was less than that of its predecessor, the CotC, which had the opportunity to choose two of its 10 topics. This crucial point, undermining the input legitimacy, will be discussed further in the following part.

The civil servant staff completely changed over from one assembly to another, which presented a serious risk of "loss of organizational knowledge," but the former team did communicate with the new team to explain their know-how. ${ }^{12}$ The Secretary to the ICA underlines:

\footnotetext{
"And of course you can improve on it then, because you are improving on a system that was there already, they were the ones who pioneered it. And so some of the thing that are easier for me because I have the benefits of their wisdom, which means I have time to concentrate on other things. The staff of the previous one, the secretary and the team, were incredibly helpful to us, providing us with their lessons and their learnings and pointing to potential pitfalls, things to look out for."13
}

The location was identical, but the polling company in charge of recruiting the representative sample changed in favor of Red $\mathrm{C}$, as the diversity of the CotC was deemed unsatisfactory. Indeed, some doubts were cast on the quality of the previous random selection done by Behavior \& Attitudes, as David Farrell points out:

\footnotetext{
${ }^{11}$ Interview with an Irish MP, Dublin, April 2018.

${ }^{12}$ Interview with Arthur O'Leary, Secretary of the CotC, Dublin, April 2018.

${ }^{13}$ Interview with Sharon Finegan, Secretary of the Citizens' Assembly, Malahide, July 2017
}

"some citizens in the CotC knew each other prior, which shouldn't have happened with good random selection. The opinion poll company, took shortcuts, they did a bad job, they took students, three or four were students of mine, one couple was from the same household. They came to the house and asked a first person, then a second." 14

In contrast, Red C committed to a qualitative recruitment of the panel with a more rigorously random door-to-door first contact, "even though it was expensive and time-consuming," as its director underlined. ${ }^{15}$ Beside randomness, the pollsters also had to respect representative criteria: gender, age, location, and social class-but not county which led to some counties not being represented. However, in February 2018 a random check of the recruitment process by Red C revealed that one of their employee did not follow the protocol and recruited seven persons, for replacing departing members, through telephone conversation and "through friends and family of the recruiter." As a result, "the replacement members, who attended just one session of the assembly held on January 13 and 14 dealing with "The Manner in Which Referenda are Held' have been relieved of their duties" (Bray, 2018). These two cases raise questions: can a mini-public acquire public legitimacy if doubts are cast over the random selection procedure (Courant, 2020b)? It also reveals that the "quality of representation," a part of input legitimacy, should not just be evaluated by "ticking the box" of "random selection" but by investigating qualitatively how this selection was carried out in practice.

Some facilitators involved in the previous assembly returned to the ICA but this time within a professional structure, the consultancy firm Roomax, specially set up for this event, gaining expertise through the process. ${ }^{16}$ In Ireland as in other countries, the institutionalization process of democratic innovation was followed by the "professionalization of participation" (Nonjon, 2005; Lee, 2015), which can increase throughput legitimacy. Contrary to the CotC, the ICA had two separate roles for academics. On the one hand, two "officially appointed" researchers were only there to study the mini-public through pre and post-deliberation surveys at each weekends. On the other hand, other academics were participating in the organization of ICA in an Expert Advisory Group, which had the purpose of drafting the deliberation program and proposing speakers. Previously, the two roles were mixed in the CotC. Few external researchers were also allowed to attend, but if a small number was present on occasion and mostly for just one weekend, I am the only one who observed every single session.

As with its predecessor, the inaugural meeting was held in Dublin Castle in the presence of the Taoiseach and many journalists, but party leaders and other politicians were absent this time. ${ }^{17}$ The following meetings, in Malahide, followed a very similar procedure to those of the $\operatorname{CotC}$, with one meeting every month or so, expert lectures, roundtable deliberations in small groups assisted by professional facilitators and note takers,

\footnotetext{
${ }^{14}$ Interview with David Farrell, Dublin, May 2015.

${ }^{15}$ Interview with Red C director, Dublin, April 2018.

${ }^{16}$ Individual interviews with five facilitators, Malahide and Dublin, 2017 and 2018.

${ }^{17}$ Observation notes, the ICA's official launch, Dublin, October 2016.
} 
plenary Q\&A sessions and discussions, and at the conclusion of a topic, a formal secret vote.

Fervent Catholics and pro-life activists opposed the citizens' assembly before its deliberations had even begun, through social networks and protests in front of Dublin Castle and then in Malahide, but in limited numbers-less than 30 in Dublin and between one and six in Malahide. ${ }^{18}$ More surprisingly, the prochoice far-left was quite vocal against the assembly as well, arguing that the government was "kicking the can down the road" instead of having the courage to tackle the issue directly. They argued for a debate in Parliament and a referendum, without the delay and expense involved in a deliberative device; it seemed logical as opinion polls did show that a majority of Irish citizens were in favor of legalizing abortion, but mostly under conditions. These claims were also aimed at justifying the existence and utility of small pro-choice parties and to criticize a center-right government they opposed in general. However, feminist prochoice activists from the Repeal the 8th coalition gradually lost their skepticism, as comments and questions broadcast during the livestreamed plenary sessions by the randomly selected citizens of the assembly showed their insights and accuracy. ${ }^{19}$

The citizens' assembly deliberated for five weekends on abortion, from November 2016 until April 2017. The citizens listened to many experts, representatives of advocacy groups, and individuals giving testimonies. Its website and Secretariat also gathered over 12,000 submissions from both organizations and individuals. In April 2017, ICA members had a secret ballot vote, which resulted in wide support in favor of legalizing abortion (64\%). Their recommendations were put together in a report submitted to Parliament and closely studied by a parliamentary joint committee. The latter's deliberations reached a similar result, so the repeal of the 8 th amendment was put to a referendum. This referendum was also made possible by the mobilization of activists and concerned citizens in the public sphere, especially through demonstrations, asking the Taoiseach (Prime Minister) to "Listen to the Citizens' Assembly," as written on some signs, and to accept to have a referendum. Indeed, the first reaction of the Taoiseach, Leo Varadkar, to the "liberal" recommendations of the ICA was to say that "the country is not ready for abortion on demand," arguing "I honestly don't know if the public would go as far as what the Citizens' Assembly have recommended" (Doyle, 2017; Hayden, 2017). In the follow-up to an intense campaign between pro-life and pro-choice, the Irish people voted in favor of the right to abortion in proportion somewhat similar to that of the ICA, with $66.4 \%$ "yes" and a historical turnout of almost 65\% (Elkink et al., 2020), thus granting a strong output legitimacy.

A fourth citizens' assembly, this time on gender equality, was established in July 2019 by the Parliament. However, being still in process and disrupted by the Covid19 pandemic at the time of writing, it was not possible to fully include it as a case.

\footnotetext{
${ }^{18}$ Observation notes, Dublin and Malahide, 2016-2017.

${ }^{19}$ Interview with Ailbhe Smyth, spokeswoman and convener for the Coalition to Repeal the Eighth Amendment, Malahide, February 2017. Observations notes, Dublin and Malahide, 2016-2017.
}

Nevertheless, we already know that this new CA is also made up of 99 randomly selected citizens, as the previous one, but this time the "members are being paid a stipend on a per weekend basis" (Harris et al., 2020, 9), as it often the case for mini-publics. The CA is tasked to make recommendations to the Parliament on various items:

- "challenge the remaining barriers and social norms and attitudes that facilitate gender discrimination (...);

- identify and dismantle economic and salary norms that result in gender inequalities (...);

- seek to ensure women's full and effective participation and equal opportunities for leadership (...);

- scrutinize the structural pay inequalities (...)" (Government Press Office, 2019).

Previously, in July 2019, the Citizens' Assembly Act was passed by Parliament, but despite its impressive name this one-page act only allows "for the access and use of information contained in the register of electors established under the Electoral Act 1992 for the purpose of selecting citizens of Ireland to be members of certain citizens' assemblies" (Oireachtas, 2019); without any other specification as to the shape, power or frequency of such CAs. Another CA, a local one this time, was also announced in 2019 to consider local government in Dublin but is not up and running at the time this article is being published (October 2020). Those two new assemblies angered The Irish Times (2019) as lacking the justification because relating to "purely political issue(s) which TDs (deputies) are well capable of deciding." The tendency toward using more and more CAs is not slowing down as the recent Programme for Government includes several commitments to establish others CAs on various topics (Government of Ireland, 2020). Nevertheless, for the issue of marriage equality and abortion, in the Irish case, as in many others, "the use of deliberative processes can render formerly blocked situations finally governable" (Lascoumes and Le Galès, 2012, 53). The ICA was largely described as a major success; however, the Irish "contrasted institutionalization" (see, Table 2) of democratic innovations raises problems and challenges.

\section{WHAT LIMITATIONS TO A "PARTICIPATORY SUCCESS STORY"? THE LACK OF INSTITUTIONALIZATION AND ITS PROBLEMS}

Ireland is the first country in the world where four nation-wide citizens' assemblies were held successively, and the first country were some propositions crafted by randomly selected citizens were approved by the maxi-public through referendums. Indeed, even though the British Columbia citizen assembly's proposition for electoral reform managed to reach over $58 \%$ of the vote, the $60 \%$ threshold for the referendum to be successful was missed (Warren and Pearse, 2008). The similar process in Ontario was even more clearly negative, with only $37 \%$ voting "yes" (Fournier et al., 2011). As for the new Icelandic Constitution, even though two randomly selected assemblies participated in the process, the text was drafted by an elected assembly-admittedly composed of 
TABLE 2 | Comparison of Ireland's citizens' assemblies.

\begin{tabular}{|c|c|c|c|}
\hline & We the citizens & Convention on the constitution & Citizens' assembly (2016-2018) \\
\hline Mandate & None - initiated by civil society & Given by the Parliament & Given by the Parliament \\
\hline Length & 1 weekend & 10 weekends over more than 1 year & 11 weekends over 1 year and a half \\
\hline Size & 100 citizens & 66 citizens and 33 politicians & 99 citizens \\
\hline Budget & $681.709 €$ & 1,367 million $€$ & 2,355 million $€$ \\
\hline Main outcomes & $\begin{array}{l}\text { Influence on parties, politicians and } \\
\text { administration to push for a CA with rigorous } \\
\text { deliberative procedures }\end{array}$ & $\begin{array}{l}2 \text { successful referendums on marriage equality } \\
\text { and on blasphemy. } \\
1 \text { failed referendum on the age of the } \\
\text { presidential candidates }\end{array}$ & $\begin{array}{l}1 \text { successful referendum on abortion. Some } \\
\text { influence on the } 2019 \text { Climate Action Plan } \\
\text { and } 2020 \text { Climate Action Bill }\end{array}$ \\
\hline Chair & $\begin{array}{l}\text { Fiach Mac Conghail, (at the time) Director of a } \\
\text { theater, and independent appointed Senator }\end{array}$ & $\begin{array}{l}\text { Tom Arnold, former economist, civil-servant, } \\
\text { and Chief Executive Officer of a charity }\end{array}$ & Mary Laffoy, former Supreme Court Judge \\
\hline Topics & $\begin{array}{l}\text { 1. The role of deputies (connection with the } \\
\text { constituency, electoral system, size } \\
\text { of Parliament); } \\
\text { 2. The identity of politicians (women, mandate } \\
\text { limit, unelected ministers); } \\
\text { 3. The arbitration between tax increases or } \\
\text { budget cuts in a time of economic crisis }\end{array}$ & $\begin{array}{l}\text { 1. Reduction of presidential term } \\
\text { 2. Reduce voting age } \\
\text { 3. Role of women in home/public life } \\
\text { 4. Increasing women's participation in politics } \\
\text { 5. Marriage equality } \\
\text { 6. Electoral system } \\
\text { 7. Votes for emigrants in presidential elections } \\
\text { 8. Blasphemy } \\
\text { 9. Dáil reform } \\
\text { 10. Economic, social, and cultural rights }\end{array}$ & $\begin{array}{l}\text { 1. Abortion } \\
\text { 2. Aging population } \\
\text { 3. Climate change } \\
\text { 4. The manner in which referenda are held } \\
\text { 5. Fixed term parliaments }\end{array}$ \\
\hline
\end{tabular}

non-professionals but famous and elected nonetheless. Moreover, this constitution was never approved by Parliament and has yet to be implemented (Bergmann, 2016). In that regard, the deliberative Irish process was an impressive "output success" but suffered from its own limitations and problems, directly related to its lack of institutionalization. Its limitation can be seen in all dimensions of input, throughput and output (Bekkers and Edwards, 2007; Papadopoulos and Warin, 2007; Caluwaerts and Reuchamps, 2015; Reuchamps and Suiter, 2016), which I analyze one by one, after studying first a transversal dimension: politicians' influence.

\section{Politicians' Control and the Risk of Instrumentalization}

First, as in many other instances, the elected officials had a decisive influence over the fate of the democratic innovation, on the input, throughput and output levels, which left room for arbitrary decisions and strategic self-interested orientations. Politicians have the power to decide:

1. whether they want to set up a deliberative device or not,

2. when,

3. on which topics,

4. for how long,

5. who supervise it (which influences speakers' selection),

6. its budget,

7. and more crucially, its output, what happens to the recommendations.

A striking feature of the Irish state-mandated assemblies was the absence of economic issues amongst the topics chosen by the political class. The reflection on citizen-led reforms started as the country faced an economic crisis and questioned its economic model (Farrell, 2014). Moreover, one of the three issues emerging from "We the Citizens" bottom-up participatory agenda setting was precisely the trade-off between tax increases or spending cuts (O'Malley et al., 2020). However, among the eight topics given to the CotC by politicians, none was related to the economy (e.g., voting age, removal of blasphemy as an offense, the right to vote from abroad, etc.), but because the assembly was granted the right to choose two additional issues through public consultations, the topic of "economic, social, and cultural rights" was eventually selected (Suiter et al., 2016a). However, the two recommendations on this topic were rejected outright by the Government. For the ICA, the questions of the aging population and climate change could be seen as linked to the economy; however, a structural reflection on the Irish economic model was not firmly put at the center of focus (Courant, 2020a).

So far, of the 10 topics leading to 40 recommendations by the CotC, only three were submitted to referendum, and some were rejected or proper responses such as referendum were postponed for years, possibly forever (see Tables 3, 4). Nevertheless, in the follow-up to the 8th Amendment referendum, the government seemed committed to holding more referendums on propositions coming from the two official deliberative assemblies. In terms of output, an institutionalization could render the articulation between deliberation and referendum systematic, without giving the political class the opportunity to decide whether they want to give a voice to the electorate. This was the case in Canada, where governments were committed to submitting the assemblies' proposals to voters before knowing what they would be.

\section{A Top-Down Agenda}

Secondly, on the input level, on the one hand the CotC had the opportunity to choose two of the topics under deliberation through public consultations while the eight others were given 
TABLE 3 | The CotC's uptakes-adapted and augmented from Farrell (2018) and Harris et al. (2020).

\begin{tabular}{|c|c|c|c|}
\hline Topic & Dates of meetings & Output & Government reaction \\
\hline 1. Reduction of presidential term & 26-27th January 2013 & 3 recommendations & $\begin{array}{l}\text { Government accepted } 1 \text { recommendation. Referendum in May } \\
2015\end{array}$ \\
\hline 2. Reduce voting age & Idem & 1 recommendation & $\begin{array}{l}\text { Government accepted this. Referendum was promised for } \\
2015 \text {, then 'deferred' }\end{array}$ \\
\hline 3. Role of women in home/public life & 16-17 February 2013 & 2 recommendations & $\begin{array}{l}\text { Ministerial task force to investigate further. Set up the Citizens } \\
\text { Assembly on Gender Equality (2020) }\end{array}$ \\
\hline $\begin{array}{l}\text { 4. Increasing women's participation in } \\
\text { politics }\end{array}$ & Idem & 3 recommendations & Idem. \\
\hline 5. Marriage equality & 13-14 April 2013 & 2 recommendations & $\begin{array}{l}\text { Government agreed to referendum and to supporting } \\
\text { legislation. Referendum in May } 2015 \text { and legislation in progress }\end{array}$ \\
\hline 6. Electoral system & 18-19 May and 08-09 June 2013 & 10 recommendations & $\begin{array}{l}\text { In December 2019, Government approved the general scheme } \\
\text { of a Bill to create an Electoral Commission following a public } \\
\text { consultation }\end{array}$ \\
\hline $\begin{array}{l}\text { 7. Votes for emigrants/N. Ireland } \\
\text { residents in presidential elections }\end{array}$ & 28-29 September 2013 & 1 recommendation & Ministerial taskforce considered options. Referendum promised \\
\hline 8. Blasphemy & 02-03 November 2013 & 2 recommendations & $\begin{array}{l}\text { Government has agreed to a referendum. Referendum held in } \\
\text { October } 2018 \text { and was successfully passed }\end{array}$ \\
\hline 9. Dáil reform & 1-2 February 2014 & 12 recommendations & $\begin{array}{l}\text { The bulk of the recommendations were implemented (by } \\
\text { changes to Dáil standing orders) in June } 2016\end{array}$ \\
\hline $\begin{array}{l}\text { 10. Economic, social and cultural } \\
\text { rights }\end{array}$ & 22-23 February 2014 & 2 recommendations & Government rejected both. \\
\hline
\end{tabular}

TABLE 4 | The citizens' assembly (2016-2018) uptakes-adapted from Farrell (2018) and Harris et al. (2020).

\begin{tabular}{|c|c|c|c|c|c|}
\hline Topic & No. of days & $\begin{array}{l}\text { Public } \\
\text { submissions }\end{array}$ & Output & $\begin{array}{l}\text { Date report sent } \\
\text { to parliament }\end{array}$ & Government reaction \\
\hline $\begin{array}{l}\text { 1. The Eighth Amendment of the } \\
\text { Constitution (abortion) }\end{array}$ & 10 days & 12.200 & $\begin{array}{l}3 \text { sets of } \\
\text { recommendations (the } \\
\text { latter two in various } \\
\text { parts) plus } 5 \text { ancillary } \\
\text { ones }\end{array}$ & 29 June 2017 & $\begin{array}{l}\text { Considered by a special parliamentary committee. } \\
\text { Government accepted proposal for a referendum. } \\
\text { Referendum passed in May } 2018\end{array}$ \\
\hline $\begin{array}{l}\text { 2. How we best respond to the } \\
\text { challenges and opportunities of } \\
\text { an aging population }\end{array}$ & 4 days & 122 & $\begin{array}{l}15 \text { recommendations } \\
\text { plus } 6 \text { ancillary ones }\end{array}$ & 8 December 2017 & $\begin{array}{l}\text { Response to a parliamentary question by the Minister } \\
\text { for Health on } 15 \text { May 2019, indicating that his } \\
\text { Department is considering some of the proposals, } \\
\text { but not accepting all }\end{array}$ \\
\hline $\begin{array}{l}\text { 3. How the state can make } \\
\text { Ireland a leader in tackling } \\
\text { climate change }\end{array}$ & 4 days & 1.185 & 13 recommendations & 18 April 2018 & $\begin{array}{l}\text { Considered by a special parliamentary committee } \\
\text { whose report led to a Dáil motion declaring a 'climate } \\
\text { emergency'. This has resulted in a government } \\
\text { report proposing steps to address climate change }\end{array}$ \\
\hline $\begin{array}{l}\text { 4. The manner in which } \\
\text { referenda are held }\end{array}$ & 2 days & 206 & 8 recommendations & 21 June 2018 & No reaction to date \\
\hline 5. Fixed term parliaments & 2 days & 8 & 7 recommendations & 21 June 2018 & No reaction to date \\
\hline
\end{tabular}

by the Government and Parliament, but on the other hand the ICA had its agency reduced and was strictly constrained to the five issues given by Parliament. This change suppressed an opportunity for deliberation between the maxi- and mini-publics. The consultations in Canada and the Netherlands (Fournier et al., 2011), the online participation in Iceland (Bergmann, 2016), and the bottom-up agenda setting in Australia (Carson et al., 2013) and Belgium (Jacquet et al., 2016; Caluwaerts and Reuchamps, 2018) were important elements of democratization. The Irish case displayed a tendency toward reducing public input. "We the Citizens" pilot assembly had its agenda set by seven participatory public meetings. For the two topics it had the right to choose, the CotC decided to consult the public to decide which would be those topics (Arnold et al., 2019). However, in the ICA, the only public input was through written submissions, without the possibility of direct interaction or deliberation; apart from presentations from a few selected interest groups' representatives. A democratic institutionalization could render the agenda-setting procedure more systematic, transparent, and open to public input. The stronger way to guarantee a strong input legitimacy would be to establish a right of initiative, a direct democracy mechanism (Papadopoulos, 1998), allowing the maxipublic to petition and gather signatures to choose the topics a CA should deliberate on. 
Moreover, in the three first CAs, the agenda was composed of items with no logical connection between them. The eclectic agenda of the CotC and of the ICA give an impression of an incoherent patchwork of issues, perhaps of which the main common thread was that the political class did not want to address them itself. The change from very different topics is one of the explanations of the high citizens' turnover in the ICA, participants were committed to follow an item from start to finish and to vote on it, but felt less inclined to start over for entirely different issues (Courant, 2018b). However, this seem to be changing as the new CA on gender equality is mono-topic, as for the French and British CAs on climate change.

The eclectic aspects of the Irish CAs' remits make it difficult to understand the intended function of those mini-publics. Dryzek (2016) distinguishes five roles for deliberation in the policy process: "a limited input into analysis of the relative merits of policy options; a means of resolving conflicts across relevant actors and interests; a form of public consultation; a unique source of valuable inputs into policy processes; a comprehensive aspiration for whole systems of governance." Because of its various topics and uneven uptakes, the Irish CAs can be considered as embracing simultaneously each of these roles, depending on the topic and its treatment. For instance, on the voting age the CotC provided " $\mathrm{a}$ limited input into analysis of the relative merits of policy options," on marriage equality it was "a means of resolving conflicts," while on abortion the ICA was "a unique source of valuable inputs."

\section{A Constrained Mini-Public}

Third, on the throughput level, my empirical ethnographic observation of the interactions within the Citizens' Assembly reveals some constraints: "call to order" and lack of agency for the citizens. Indeed, mini-publics in general and the Irish CAs especially rely on a strict "division of deliberative labor" between the following actors and tasks:

1. Sponsor (Government and Parliament): establishes a deliberative forum on topics of its own choosing, select the Secretariat and the Chair.

2. Secretariat: select the other actors and run the process, in collaboration with the Chair.

3. Chair: chair the debates, help the Secretariat in running the process, presents the report.

4. Polling company: recruit the citizens' panel.

5. Expert advisory group: monitor the process, propose, and select the speakers (experts and stakeholders), prepares the ballot.

6. Steering group: approves the program.

7. Facilitators and Note-takers: help the deliberation to be fair and efficient.

8. Experts and stakeholders: contradictory, inform the panel.

9. Randomly selected citizens: listen, learn, deliberate, recommend, and vote.

Moreover, the climate of extreme tension surrounding abortion rendered the proceedings of the ICA in some ways more coercive than those of its predecessor. The ICA's chair, the Hon. Ms. Justice Mary Laffoy, in conformity with her habitus of Supreme Court judge, led the debates with an assertive approach, leaving little space for contestation to arise among participants, which can be a problem from an "agonistic perspective of democracy" (Mouffe, 2000). Her use of time tended to favor expert lectures, which often ran over their allocated time, over the small groups and plenary session deliberation time. The governing style of a chair is affected by the actor's professional habitus. This was the case in Canada, where Jack Blaney in British Columbia adopted a "liberal approach", letting "members talk as much as they wished even if this meant going over time" (Fournier et al., 2011, 105), while in Ontario, George Thompson, a "former deputy minister and family court judge" (Fournier et al., 2011, 29), had not "granted participants with the same level of trust as Baney," according to Lang (2010, 127). Similarly, CotC's chair Tom Arnold, coming from an international charity NGO, conducted the deliberations in a way that increased the participants' agency, while Laffoy followed a stricter practice of her "role." The chair's room to maneuver could be lowered to the participants' benefit if a longterm deliberative institution were to be institutionalized, due to clearer rules and a standardization of the "role" (Lagroye and Offerlé, 2010; Dulong, 2012).

Aside from the Chair, the influence of the Expert Advisory Group (EAG) is also critical as they prepare the learning program and propose the speakers, as well as the ballot upon which the citizens vote. If the procedure for amending the ballot was spotless for the issue of abortion and of the aging population, the deliberative and procedural quality then lowered for further sessions, especially for climate change. In this session, the Chair and the EAG rejected the majority of modifications requests made by the citizens instead of letting them decide (Courant, 2020a). Contrary to the previous times, the Chair did not call for vote by a show of hand in case of dissensus but sometimes asked for a vague oral expression. This practice was criticized by a citizen member:

\begin{abstract}
"What did you think of the ballot and the voting? I think it was very sloppy... You make a suggestion and some people shout 'No'... and that's it. No vote. No show of hand. Members at my table reacted: 'How many said 'no'? We don't know'. It is very disappointing (...). The procedural mistake will damage the credibility of the process.... And the EAG, they have too much power on the ballot. It is not right. It's not just me, other citizens told me so." 20
\end{abstract}

The core problem might be as follow: there are no public deliberations for setting up deliberative mini-publics or organizing them. A lot of the choices made by the organizers are made behind closed doors and without giving reasons justifying those choices afterwards. In the Irish case few citizens members took part in steering group meetings, which is a way to address the issues but data shows that it was insufficient (Suiter et al., 2016a; Courant, 2020a). In this regard, theoretical suggestions have been made for "critical mini-publics" (Böker and Elstub, 2015) but empirical studies of existing practices remain to be conducted and institutional designs of "meta-deliberation," that

${ }^{20}$ Interview with an ICA member, male in his fifties, Malahide, November 2017. 
is deliberation on the procedures and conditions of deliberation itself, remain to be implemented (Courant, 2020a).

\section{What Public and Referendum Uptakes?}

Fourth, on the output level, the impact of the mini-publics' deliberation on the maxi-public's vote is complex. While the electorate did follow the ICA's recommendations to legalize samesex marriage and abortion, it rejected the one to reduce the age of eligibility for the presidency. Therefore, the hypothesis of systematic support toward propositions crafted by citizens' assemblies is invalidated once again. The claim that "adding politicians along citizens in mini-publics" will make the CA's recommendation impossible to reject was also invalidated.

Nevertheless, empirical quantitative studies reveal that if a citizen knows about the existence of a citizens' assembly, he or she will be more likely to support its recommendations (Warren and Pearse, 2008; Fournier et al., 2011, 132). The problem is therefore the lack of public visibility of democratic innovations. A significant part of the Irish citizenry was unaware or weakly aware of the existence of the $\operatorname{CotC}$ at the time of the referendum, but the "informed part" was influenced in favor of following the CotC's recommendations (Pilet, 2016). As Elkink et al. (2017, 371) show by checking for the awareness of the CotC with four statements: "Taking 'don't know' as a lack of knowledge, this leads to a fivepoint scale from zero to four indicating the level of awareness of the convention. In our sample, 54 per cent score up to two, a further 34 per cent have three items correct, and the remaining 12 per cent are fully aware of the Convention." They also show that "while there is no discernible impact on the likelihood of turning out to vote, there is a positive and statistically significant effect on the probability of voting yes" (Elkink et al., 2017, 372), but that the impact of the referendum campaigns was more important in explaining the outcome.

However, the Citizens' Assembly benefited from stronger media coverage, especially due to the controversial nature of its first topic. As Suiter and Reidy $(2020,550)$ underline, for the abortion referendum "66\% were aware of the mini-public." The question remains: if the ICA was known by a fair share of the electorate, how exactly did it influence the referendum's outcome? This has yet to be definitely proven, but "exit polling data suggested many voters in Ireland had made up their minds on abortion before the official campaign began" (Press Association, 2018a). However, if the majority of Irish voters were in favor of a legalization of abortion, it was under conditions (rape, health issue...) before the assembly's deliberations, which lead to its proposition: abortion without condition. This proposition was approved by referendum revealing that the opinion of the maxipublic evolved in the direction of the mini-public. Moreover, Elkink et al. $(2020,6)$ show that, once again, "knowledge of the Citizens' Assembly made one significantly more likely to vote yes" but "voters' levels of personal trust in the Citizens' Assembly, however, did not affect the vote choice." Suiter and Reidy (2020, 551) note that "the Constitutional Convention at the marriage referendum and the Citizens' Assembly at the abortion referendum also mattered by enhancing the quality of vote choice;" but, surprisingly, their analysis does not take into account the failure of the referendum on the age of eligibility for the presidency, therefore somewhat skewing their conclusion. Moreover, all credit cannot be attributed to citizens' assembly; social movements, protests, local debates, and campaigns also played a role, but also demographic factors revealing a tendency toward liberal opinions, especially church attendance and age (Elkink et al., 2020). The impact of the $\operatorname{CotC}$ on the referendum on blasphemy has not yet been demonstrated.

More crucially, in Ireland the maxi-public's vote for "yes" in the referendum on abortion was in the end higher that the mini-public's vote in the assembly. Hence, one can wonder if this does not disprove a central claim made by deliberative democracy scholars, that "the mini-public considered opinion is qualitatively superior to the opinion of the population at large" (Fishkin, 2009). If the referendums had been carried out without the CAs' deliberations beforehand, would the results have been different in a significant way? Despite some statistical studies, this question remains. Regardless, it seems likely that greater institutionalization and regularity of deliberative processes would increase the population's awareness and achieve greater uptakes (Goodin and Dryzek, 2006; Warren and Gastil, 2015). A stronger institutionalization linking deliberative mini-publics (DMPs) to referendum has been achieved further afield from Ireland, in various States of the United States with the Citizens' Initiative Review (CIR). In this process, the statement of the citizens' panel is mailed to all the voters by the official authorities (Knobloch et al., 2015). However, using the media in deliberative democracy remains a challenge for structural reasons (Parkinson, 2005).

There are two ways of looking at those "limitations." On the one hand, one might argue that the lack of institutionalization allows for greater flexibility and adaptation to various situations. In this perspective, elite decision makers need to change the shape and procedures of a democratic innovation as they see fit; therefore, appointing a judge as chair, setting up an eclectic agenda and restraining the assembly's agency might have been necessary conditions for the crucial but divisive abortion issue to be tackled efficiently. On the other hand, the lack of institutionalization is potentially what prevents certain democratic innovations from meeting great expectations. A form of institutionalization could insert deliberative procedures into the "ordinary political life," as elections are, and allow for deeper political improvements.

\section{IRELAND AS A FUTURE INSTITUTIONAL MODEL OR AS A LOCAL EXCEPTION?}

We saw that the Irish process was contrasted with great achievement but also limitations. Is Ireland actually crafting new democratic institutional models transferable abroad? And if so which ones?

\section{Beyond Procedure, Substance}

A core dimension, if not the main, of deliberative democracy is a focus on fair procedures. A decision is not just or fair because the majority is in favor of it but because the deliberative procedures to reach this decision were fostering: equality, inclusion, fairness, transparency, and an impartial weighting of all competing 
arguments (Manin, 1987; Dryzek et al., 2019). We have seen that there were some shortcomings in the Irish process, but globally its deliberative procedures and quality were good, respecting most of the usual standards (Gastil and Levine, 2005; Fishkin, 2009; Reuchamps and Suiter, 2016). However, compared to the previous CAs, the CotC and to a lesser extend the ICA were downgrades in term of deliberative quality regarding the shorter time given to each items. While the three assemblies on electoral reform in Canada and the Netherlands had dozens of weekends spread over a year to deal with one topic, the CotC did not give more than 4 days per topic. There is no documented evidence of any deliberative improvement in terms of experts auditions, small-table discussion or plenary deliberation when comparing Ireland to its predecessors, or its successors like the French Climate Convention and its 9 weekends, two of which being held online due to the pandemic (Courant, 2020a).

The main difference is that in Ireland, 3 out of 4 referendums emerging from the mini-publics were successful, even though with $58 \%$ of "yes" the British Columbia CA was only defeated by an excessive super-majority threshold. This makes Ireland a politically successful case with a quantitative approval but not necessarily a deliberative improvement. Moreover, beyond procedure one must take substance into account. Would Ireland be considered a "model" if its mini-publics had advised against marriage equality and legalizing abortion? And this even if the rest of the features were present (i.e., successful referendum, qualitative deliberation, diversity of experts...)? Isn't there a bias that "as long as mini-publics are saying what one believes, one supports them"? The fact that many commentators, activists or academics (myself included) were favorable to marriage equality and legalizing abortion prior to the CAs deliberations is likely to be an important factor for them to qualify the Irish cases as a "success" or "model;" most of those actors having actually very little knowledge of how the Irish CAs operated concretely. Deliberative mini-publics (DMPs) should be valued for the quality of their procedure, not for merely approving a policy one already believes in, otherwise they are bound to remain a marginal aspect of political life.

\section{Does Mixing Citizens and Politicians Work?}

As we have seen, there is no such thing as a clear "Irish model" given the important differences between its various CAs (see, Table 2). Nevertheless, some claimed, especially prior to the ICA 2018 successful referendum on abortion, that the main reason for "output success" in Ireland was the mixing of politicians and citizens in the CotC; contrasting it with the Icelandic "failure" (Renwick, 2015; Suteu, 2015; White, 2017). It was already proven that this claim does not hold; mainly as the recommendation on the age of the president was massively rejected by referendum and other recommendations were rejected by Government or Parliament. However, the hybrid assembly was a clear originality proper to Ireland. But does it "work," as many have said (Honohan, 2014; Van Reybrouck, 2016)? Survey results show that members of the CotC did not think that politicians dominated the debates (Suiter et al., 2016a). However, a more detailed quantitative approach, but relying on a limited " $n$ " with sometimes only 6 or 9 respondents for the politician members group, reveals that "there was a moderate liberal bias among those politicians who chose to become members of the Convention. And while this does not appear to have influenced the outcomes of its decisions (...), in one respect at least the presence of politician members does appear to have affected the outcome-on the issue of electoral reform, a matter of considerable personal interest to politicians" (Farrell et al., 2020). Indeed, I concur and argue that a mixed DMP only works under certain specific conditions, which are the following:

1. Proportion: the politicians were in minority, one out of three. Sixty-six citizens constitute already a small number in order to get a diverse sample, lowering it more would deteriorate its representativeness and its cognitive diversity.

2. Strong deliberative design: the deliberative procedures were based on those of a citizens' mini-public rather than parliament. The Chair crafted some deliberative principles that he repeated at each meeting: openness, fairness, equality of voice, efficiency, and collegiality (Arnold et al., 2019). Those principles were taken and repeated by the two following Chairs of the subsequent Irish CAs'. On the contrary, in the Australian 1998 Constitutional Convention, "the only other case (...) of a convention whose membership comprised a mix of politicians and ordinary citizens (though these were not randomly selected); there the decision was taken to operate along normal parliamentary lines" (Farrell et al., 2020). ${ }^{21}$

3. Awareness: the 14 facilitators, the Chair and the Secretariat were explicitly vigilant so that politicians did not dominate the debate. As the Secretary underlines: "The facilitators and note-takers, their job was to manage big voices at roundtable discussions, that was very important." 22 And the Chair points out:

"The equality issue then, that really was put in to address
the fact that there was concern at the very beginning that
politicians would dominate citizens. And I felt it was really
important to say from the very beginning: 'everybody here is
equal'. And that came even to a simple thing like me saying at
the very first meeting: 'nobody is going to have any title here,
your title is your first name'; so it didn't matter if you are a
Minister or a TD (member of parliament) or anything else, or
a doctor or whatever, you were going to be called by your first
name."

4. Independent Authority: the Chair, Tom Arnold, experienced leader of a well-known charity, and the Secretary, Art O'Leary, with his experience as a senior civil-servant, were respected by the politicians, and unsuspected of bias. O'Leary could call the politicians to order if they were stepping out of line or being absent, has he says himself:

"One benefit of me having come from the Parliament is that
I was able to ring the politicians on their mobile and say:
'I need you to be there tomorrow. I had this ridiculous call

${ }^{21}$ See also: Constitutional Convention (1998), Williams (1998), and Warhurst (1999).

${ }^{22}$ Interview with Arthur O'Leary, Secretary of the CotC, Dublin, April 2018.

${ }^{23}$ Interview with Tom Arnold, Chair of the CotC, Dublin, January 2018. 
from your secretary ringing in to say that you won't be there. That ain't happening. If you don't come I'm gonna ring the Taoiseach and tell him that you're refusing to go, or I'll ring the government chief whip or someone'. So there was coercion, encouragement, bullying... everything to get the politicians into the room." 24

5. Anonymity: the politicians were in principle free to speak and vote without fear of the party whip; this required that all votes were anonymous, so no distinction could be made between citizens' and politicians' votes'. Without this feature the deliberative dynamic would have likely been compromised, politicians would have followed their party lines and refused to change their minds in light of new arguments.

6. Topics: most issues debated by the CotC were consensual, however the sessions on the electoral systems and even more on Parliament reform were tense. One advantage of having "ordinary citizens" talking about constitutional reforms is that they do not have a direct vested interest in the "rule of the game," contrary to professional politicians (Thompson, 2008; Courant, 2019b). More generally, deliberation in a mixedassembly might be compromised if the issues being debated are highly divisive and leading to a strong cleavage between the political parties involved. A citizen participant of the CotC explains:

\begin{abstract}
"One of the piece we had to discuss was whether we should abolish the Seanad (Senate) or not (...). The Constitutional Convention had its tasks and interested parties could make submission for or against and that was the only way you could get your submission in, if you'd given it in advance. The Senators decided to bypass that and just bring in preprinted materials and put them on all the tables. Which was very unfair. We didn't get time to read over them, they didn't go through proper channels, and they had a vested interest, with no opposing interest. And they forced that upon the Constitutional Convention. And it wasn't right (...). That was one of the few bad things that I've experienced in the Convention, in that members of the Convention sabotaged the Convention." 25
\end{abstract}

The hybrid composition of a DMP is therefore not easy and the "CotC model" should not be transferred to any other country or context without taking those six specific conditions into account. If those six factor were changed (having more politicians than citizens, following parliamentary procedures instead of deliberative ones, removing anonymity, etc.) one can make the hypothesis that this new mixed assembly would fail. Moreover, Ireland might show specific cultural features absent from other countries. Several interviewees told me that having a beer with a member of Parliament was not uncommon in Ireland, while it certainly is in France. The degree of "elitism" among politicians should also be taken into account. Regardless, politicians tend to come from higher social classes, having more wealth, higher degrees, symbolic or social capitals and confidence

\footnotetext{
${ }^{24}$ Interview with Arthur O'Leary, Secretary of the CotC, Dublin, April 2018.

${ }^{25}$ Interview with a citizen member of the CotC, male in his forties, Dublin, April 2018.
}

in public speaking. However, Farrell et al. (2020) suggest that "an additional weakness" of the CotC was its length, which allows the members to develop "a degree of 'we' thinking, reaching shared goals and outcomes. This speaks to the need to keep such process shorter in length." Finally, mixed membership of citizens and politicians was also tested in the 2015 Democracy Matters CA, which led the involved research team to conclude: "At least in the short term, inclusion of politicians decreases the quality of deliberation (including the amount of perceived domination)" (Flinders et al., 2016, 42).

Nevertheless, Ireland experimented with another form of articulation between citizens' and politicians' deliberation. As we can see in Table 4, two separate parliamentary committees were established in response to the CA's reports, one of which addressed the abortion issue, and the other responded on climate action. More broadly, as shown in Tables 3, 4, the Parliament did hold debates on several of the CotC and CA's recommendation, especially prior to the referendums. This practice connects several "sites of deliberation" following the logic of a "deliberative system" (Parkinson and Mansbridge, 2012); it also links deliberative, representative and direct democracy in an interesting way. However, this connection was not systematic, parliamentary committees were not always established and some items were not debated. Once again, an institutionalization rendering this link systematic would reduce arbitrariness and build a more coherent and transparent system.

\section{What Future Institutional Model?}

Will the Irish deliberative process become an institutional model that is replicated in many other countries, or will it remain a local exception? A crucial explanatory element in the Irish case is the legal obligation to hold a referendum for any constitutional change. This mandatory framework constrained political actors and was a favorable condition for the development of a deliberative institution.

This context and the repetition of the mini-publics-driven constitutional reforms did lead to a form of "institutionalization in the minds," as most of the interviewed actors (e.g., citizens, civil servants, facilitators, activists, politicians, etc.) stated their belief that a similar citizens' assembly in Ireland would be repeated in the future; as this young member of the ICA says:

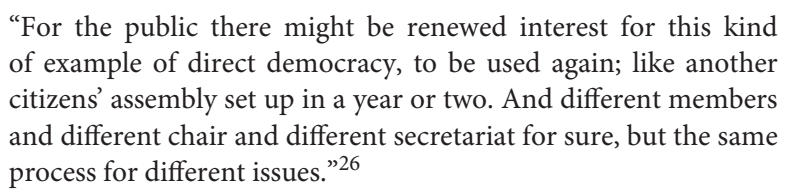

Clear evidence of this institutionalization of citizens' assemblies in the minds of the social actors was the call for a "new citizens' assembly" by three pro-life Irish MPs. Even though they were opposed to the ICA's recommendation, they did not criticize the innovation itself but asked for another one to explore "the means whereby positive alternatives to abortion can be explored ${ }^{26}$ Interview with a citizen member of the ICA, male in his twenties, Malahide,
January 2018. 
so as to fully respect and defend the rights of unborn children and their mothers and partners" (Edwards, 2017). Moreover, there is a contagion effect, as many voices are calling for a citizens' assembly to be implemented in Northern Ireland (Press Association, 2018b) and an opinion poll commissioned by an Irish senator reveals that there was a resounding response to the question of whether an all-island citizens' assembly should be established to "plan for unity and the future of Ireland." A huge 64.34\% said "Yes" (Hickey, 2018). Moreover, the recent Programme for Government pledges to establish new CAs on various topics (Government of Ireland, 2020).

The ICAs are also a source of inspiration for democratic innovators, academics, and activists, notably for the creation of a civil-society-led citizens' assembly on Brexit in the UK (Renwick, 2017), for a future State-supported device on the question, as some politicians hope (The Irish World, 2018; Brown, 2019), and more recently for the citizens' assemblies, especially dealing with climate change, in France, Wales, Scotland, and in the UK both at the local and national level. However, empirical research on the French CA reveals many differences with the Irish deliberative design, even on features that were common to all of Irelands' mini-public; for instance, the absence of facilitators at the tables, or the fact that experts' presentations in France were not of equal lengths, some speakers having $50 \mathrm{~min}$ while others only five (Courant, 2020a). Hence, there is a risk of other DMPs claiming to take inspiration from Ireland only in words but not in actions.

An uncertainty remains: will the institutionalization of deliberative mini-publics be a synonym for democratization or for governmentality? On the one hand, the greater the institutionalization, the lesser the politicians' influence and arbitrariness. Moreover, to follow Talcott Parsons, institutions are "activities governed by stable and reciprocate anticipations" (Lécuyer, 1994, 111). Stability, predictability, and continuity are necessary conditions for the development of a new form of citizenship or "civic culture," one based on participation and deliberation rather than merely on elections; thus permitting the construction of an actual "deliberative system" (Parkinson and Mansbridge, 2012). On the other hand, institutionalization could also potentially "de-democratize" democratic innovations. In studying participatory budgeting, Anja Röcke points out the risk that this participatory institution "will be drained of its political content to be reduced to a mere 'tool' for public authorities to use as they see fit." She wonders: "is participatory budgeting destined to become a simple participatory mode of public spending without fundamentally overturning the existing power relationships nor the institutional hierarchy?" (Röcke, 2010, 58-60).

A governmentality institutionalization is indeed to be feared, as more voices are criticizing the people's political competence, stating that after the Brexit vote and Trump's election, the demos is no longer to be trusted nor to rule, if it ever was. This anti-democratic temptation might prevail and lead to an institutionalization of powerless, enlightened, consultative mini-publics playing the role of the "Prince's advisor" and "consultation alibi," allowing for the suppression of direct democracy or participatory mechanisms. The only "audible" voice of the people would have to be filtered through deliberative, controlled, formal institutions, and all other claims would be deemed irrational (Courant, 2018b). ${ }^{27}$ The institutionalization of a single tailored model could then signify the death of democratic imagination and political experimentation. On the contrary, a democratic institutionalization would empower citizens in novel ways to make the citizenry as a whole evolve through political participation. This perspective rests on the "Pygmalion effect," the idea that if citizens are considered competent by institutions, they will indeed become more competent (Rosenthal and Jacobson, 1968), as is empirically the case in deliberative innovations (Courant, 2019b).

The two main indicators of this evolution would be the widening of the maxi-public inclusion regarding the input and the output (Bekkers and Edwards, 2007; Papadopoulos and Warin, 2007; Caluwaerts and Reuchamps, 2015; Reuchamps and Suiter, 2016). If Ireland, due to its legal framework, reveals a positive articulation in the output between the mini-publics' recommendations and mass referendums, then the suppression of the "public consultation phase" in the ICA-however present in all three citizens' assemblies on electoral reform as well as in the pilot assembly and the CotC-is troubling. The input legitimacy of an open agenda, strong in WTC, reduced to two items in the CotC and absent in the ICA, seems to have been traded for a stronger output legitimacy, namely the approbation of the recommendation by referendum. Will this trend continue or be reversed? This "deliberative democratic dilemma" was also studied in the G1000 case by Caluwaerts and Reuchamps $(2015,167)$ according to whom "increase in input legitimacy also undermine output legitimacy." If it is true in some cases, it is not certain to be an "universal law," and some theorists proposed designs combining both input and output legitimacies (Barber, 2009; Bouricius, 2013; Gastil and Wright, 2019). Nevertheless, one core element confirmed by the Irish case, is that minipublics need to be connected to referendum in order to build a "deliberative democracy," involving the maxi-public, not merely a "democratic deliberation" confined to a handful of randomlyselected citizens (Chambers, 2009; for another approach see Mansbridge, 2007).

Summarizing the different elements presented in this paper, a suggestion for getting out of the "incomplete institutionalization" of DMPs and moving toward an institutional deliberative system could be the following:

1. Input: allowing the maxi-public to have a say in the agenda, possibly through binding initiative petition.

2. Throughput: formalizing the "role" of the organizers, especially the Chair, and implementing "meta-deliberations" on the procedures and conditions of the deliberation itself.

3. Output: rendering systematic the articulation between the DMPs' deliberations, special parliamentary committees, debates in Parliament and, more crucially, binding referendums.

In the end, if the institutionalization of democratic innovations remains uncertain, it is due to the very nature of an

${ }^{27}$ I here draw on Foucault's concept of governmentality (2004). 
institution itself. According to Rawls (1999), an institution is not the means with which to achieve a common goal but to reach different ends for different actors. Elites might agree to the creation of deliberative institutions to get a better informed and more competent demos, while radical democrats might support those same institutions to empower the people (Courant, 2018b). However, the inclusion of novel permanent or regular democratic institutions could potentially deeply democratize current political systems and even change the "spirit of democracy."

\section{CONCLUSION}

As deliberative mini-publics (DMPs) increase in number and importance, Ireland is clearly a reference and an inspiration at the global level. Based on a detailed qualitative research, this paper has revealed several important elements. First, Ireland is one case of deliberative democracy among many others, and its CAs benefited from transfer of former mini-publics. Nonetheless, the Irish case stands out by being the first and the only country where recommendations from CAs were validated by referendums. Secondly, despite some claims, there is no such thing as a clear "Irish model" since the various CAs had many important differences. But Ireland shows a progressive, yet incomplete, institutionalization of DMPs in the ordinary political life, thanks in part to its constitutional requirement for referendum for any change of the Constitution, but also thanks to the action of committed activists, and a change of government opening a window of opportunity. Third, the Irish experience is indeed a "success" in many respects, especially in terms of output, but has its share of limitations, namely: politicians' control, top-down agenda, constrained mini-public, and unclear public impacts. Finally, regarding what institutional model is set up by the Irish CAs, uncertainty remains. Substance and progressive results regarding marriage equality and abortion might have played a bigger role than deliberative quality in the good reputation of Irish CAs. The innovation of mixing politicians with citizens is not as easily transferable as some claimed. As for the institutional model, it remains to be seen how it will actually be implemented in Ireland and beyond, and whether it will foster governmentality or a true democratization of democracy. Overall, the Irish cases offer many empirical insights as to how to improve political representation but do not give a definitive answer or a "ready to copy-paste model;" reminding us that democracy is an ideal always in motion and in debate.

\section{REFERENCES}

Arnold, T., Farrell, D., and Suiter, J. (2019). "Lessons form a hybrid sortition chamber: the 2012-2014 Irish Constitutional Convention," in Legislature by Lot, eds J. Gastil and E. O. Wright (London; New York, NY: Verso), 101-121.

Barber, B. R. (2009). Strong Democracy: Participatory Politics for a New Age, 20th anniversary Edn. Berkeley, CA: University of California Press.

Barnett, A., and Carty, P. (2008). The Athenian Option: Radical Reform for the House of Lords. Exeter: Imprint Academic.

\section{DATA AVAILABILITY STATEMENT}

The raw data supporting the conclusions of this article will be made available by the author, without undue reservation.

\section{ETHICS STATEMENT}

Informed consent was obtained in oral form but not in written form, from the individuals for the publication of any potentially identifiable images or data included in this article, as this was not required for the publication of verbatim quotations in accordance with local guidelines of Canton de Vaud, Switzerland, see LPrD (2007).

\section{AUTHOR CONTRIBUTIONS}

The author confirms being the sole contributor of this work and has approved it for publication. The author has written the article, collected, transcribed and coded the 44 interviews, collected and analyzed the documents and primary sources, and conducted the direct observation, all used as the main material for the article.

\section{ACKNOWLEDGMENTS}

Earlier content of this manuscript has been presented in part at the European Consortium for Political Research (ECPR) General Conference, University of Hamburg, 25 August 2018, as well as at the international workshop Democratic Innovations in Theory and Practice, University of Zürich, 6 December 2018. I am grateful to the participants for their questions and feedbacks. I am thankful to Guillaume Petit for co-organizing and cochairing with me the ECPR panel From Democratic Innovations to Democratic Institutions? The Challenges of Institutionalizing New Forms of Citizens' Participation, to Nicole Curato and Sofie Marien, organizers of the ECPR conference Democratic Innovations section, for accepting our panel and papers into their section, and to Yanina Welp and Martha Sandoval for inviting me to their international workshop. I especially would like to thank Vincent Jacquet, Jean-Philippe Leresche, Jane Mansbridge, and Charlotte Wagenaar for their stimulating comments, advice and discussions on earlier versions of this article. I also express my gratitude to Claire Mellier-Wilson for proofreading and correcting the English grammar of this paper. Finally, I am thankful to the reviewers for their useful remarks and suggestions.

Barroux, R. (2019). Le gouvernement met sur les rails la convention citoyenne sur la transition écologique. Le Monde. Available online at: https://www. lemonde.fr/planete/article/2019/06/04/le-gouvernement-met-sur-les-railsla-convention-citoyenne-sur-la-transition-ecologique_5471161_3244.html (accessed December 21, 2019).

Beach, D., and Pedersen, R. B. (2019). Process-Tracing Methods: Foundations and Guidelines, 2nd Edn. Ann Arbor, MI: University of Michigan Press.

Bekkers, V., and Edwards, A. (2007). "Legitimacy and democracy: a conceptual framework for assessing governance practices," in Governance and the 
Democratic Deficit: Assessing the Legitimacy of Governance Practices, eds V. Bekkers, G. Dijkstra, A. Edwards, and M. Fenger (Aldershot: Ashgate), 35-60.

Benedictus, L. (2019). Power to the people - could a citizens' assembly solve the Brexit crisis? The Guardian. Available online at: https://www.theguardian.com/ uk-news/2019/jan/17/power-to-the-people-could-a-citizens-assembly-solvethe-brexit-crisis (accessed August 26, 2019).

Bergmann, E. (2016). "Participatory constitutional deliberation in the wake of the crisis: the case of Iceland," in Constitutional Deliberative Democracy in Europe, eds M. Reuchamps and J. Suiter (Colchester: ECPR Press), 15-32.

Bezes, P., Palier, B., and Surel, Y. (eds.). (2018). Process tracing: les chemins de la causalité. Rev Française Sci. Politique 68. doi: 10.3917/rfsp.686.0961

Böker, M., and Elstub, S. (2015). The possibility of critical mini-publics: realpolitik and normative cycles in democratic theory. Representation 51, 125-144. doi: $10.1080 / 00344893.2015 .1026205$

Bouricius, T. G. (2013). Democracy through multi-body sortition: athenian lessons for the modern day. J. Public Deliberat. 9:11. doi: 10.16997/jdd.156

Bray, A. (2018). Recruiter for citizens assembly suspended after replacement members enlisted through personal contacts and not randomly. Irish Independent. Available online at: https://www.independent.ie/irish-news/ recruiter-for-citizens-assembly-suspended-after-replacement-membersenlisted-through-personal-contacts-and-not-randomly-36629881.html (accessed August 5, 2020).

Brown, G. (2019). A citizens' assembly is now the only way to break the Brexit deadlock. The Guardian. Available online at: https://www.theguardian. com/commentisfree/2019/jan/20/citizens-assembly-brexit-article-50-britain (accessed June 11, 2019).

Buchstein, H. (2010). Reviving randomness for political rationality: elements of a theory of aleatory democracy. Constellations 17, 435-454. doi: $10.1111 / j .1467-8675.2010 .00604 . x$

Byrne, E., Farrell, D., Harris, C., Gary, M., O'Malley, E., Reidy, T., et al. (2011). Reformcard.com Explanatory Memorandum. Available online at: https:// johnnyryan.files.wordpress.com/2011/02/memo-final-consolidated.pdf

Byrne, E., Farrell, D., O’Malley, E., and Wall, M. (2010). Path to rebuilding Republic should start with citizens' assembly. The Irish Times. Available online at: https://www.irishtimes.com/opinion/path-to-rebuilding-republic-shouldstart-with-citizens-assembly- 1.681962 (accessed August 2, 2020).

Caldwell, L. (2019). I took part in a citizens' assembly - it could help break the Brexit deadlock. The Guardian. Available online at: https://www. theguardian.com/commentisfree/2019/jan/16/citizens-assembly-irelandabortion-referendum (accessed June 1,2020).

Callenbach, E., and Phillips, M. (2008). A Citizen Legislature. Exeter: Imprint Academic.

Caluwaerts, D., and Reuchamps, M. (2015). Strengthening democracy through bottom-up deliberation: An assessment of the internal legitimacy of the G1000 project. Acta Politica 50, 151-170. doi: 10.1057/ap. 2014.2

Caluwaerts, D., and Reuchamps, M. (2018). The Legitimacy of Citizen-Led Deliberative Democracy. The G1000 in Belgium. Oxon: Routledge.

Carney, G., and Harris, C. (2011). Deliberative Democracy and Political Reform. Irish Politics Forum. Available online at: https://politicalreform.ie/2011/03/30/ deliberative-democracy-and-political-reform/ (accessed October 7, 2020).

Carolan, E. (2015). Ireland's Constitutional Convention: Behind the hype about citizen-led constitutional change. Int. J. Constit. Law 13, 733-748. doi: 10.1093/ICON/MOV044

Carson, L., Gastil, J., Hartz-Karp, J., and Lubensky, R. (eds.). (2013). The Australian Citizens' Parliament and the Future of Deliberative Democracy. University Park, TX: Penn State University Press.

Chambers, S. (2009). Rhetoric and the public sphere: has deliberative democracy abandoned mass democracy? Polit. Theory 37, 323-350. doi: $10.1177 / 0090591709332336$

Coakley, J. (2010). Selecting Irish Government Ministers: An Alternative Pathway? Administration 58, 1-26.

Collins, S. (2010). "We have no pre-election pact with anybody." The Irish Times. Available online at: https://www.irishtimes.com/news/we-have-no-preelection-pact-with-anybody- 1.689536 (accessed August 3, 2020).

Connolly, P. (2011). Ranking promises of political reform. Magill. Available online at: https://magill.ie/archive/ranking-promises-political-reform (accessed October 7, 2020).

Constitutional Convention (1998). Constitutional Convention 2-13 February 1998, Transcripts of Proceedings. Parliament of Australia. Available online at: https://www.aph.gov.au/Parliamentary_Business/Hansard/conv/HANCON (accessed August 4, 2020).

Courant, D. (2018a). The sortition activists. Sociology of new democratic claims. Paper presented at the CLAIMS Workshop (Paris).

Courant, D. (2018b). 'We have humility'. Perceived legitimacy and representative claims in the Irish citizens' assembly. Paper presented at the APSA Annual Conference (Boston, MA); available in IEPHI's Working Papers 72, 25-46.

Courant, D. (2019a). Délibération et tirage au sort au sein d'une institution permanente. Le Conseil Supérieur de la Fonction Militaire (1968-2016). Participations 23, 61-91. doi: 10.3917/parti.023.0061

Courant, D. (2019b). "Sortition and democratic principles: a comparative analysis," in Legislature by Lot, eds J. Gastil and E. O. Wright (London; New York, NY: Verso), 229-248.

Courant, D. (2020a). Des mini-publics délibératifs pour sauver le climat? Analyses empiriques de l'Assemblée citoyenne irlandaise et de la Convention citoyenne française. Arch. Philos. Droit 62, 485-507.

Courant, D. (2020b). "From kleroterion to cryptology. The act of sortition in the 21 st century, instruments and practices," in Sortition and Democracy. History, Tools, Theories, eds Y. Sintomer and L. Rabatel (Exeter: Imprint Academic), 343-371.

Courant, D., and Sintomer, Y. (2019). Le tirage au sort au XXIe siècle. Actualité de l'expérimentation démocratique. Participations 23, 5-32. doi: $10.3917 /$ parti.023.0005

Crosby, N., and Nethercut, D. (2005). "Citizens juries: creating a trustworthy voice of the people," in The Deliberative Democracy Handbook: Strategies for Effective Civic Engagement in the 21st Century, eds J. Gastil and P. Levine (San Francisco, CA: Jossey-Bass), 111-119.

Dienel, H.-L. (2010). "Les jurys citoyens: pourquoi sont-ils encore si rarement utilisés? (Allemagne)," in La Démocratie Participative Inachevée. Genèse, Adaptations et Diffusions, eds M.-H. Bacqué and Y. Sintomer (Paris: Yves Michel et Adels), 101-113.

Doyle, K. (2017). Leo Varadkar says the country is not ready for abortion on demand. Independent.ie. Available online at: https://www.independent. ie/irish-news/politics/leo-varadkar-says-the-country-is-not-ready-forabortion-on-demand-36136605.html (accessed December 15, 2017).

Dryzek, J. S. (2016). "Deliberative Policy Analysis," in Evidence-based Policy Making in the Social Sciences: Methods that Matter, eds G. Stoker and M. Evans (Bristol: Policy Press), 229-242. doi: 10.2307/j.ctt1t89d4k.19

Dryzek, J. S., Bächtiger, A., Chambers, S., Cohen, J., Druckman, J. N., Felicetti, A., et al. (2019). The crisis of democracy and the science of deliberation. Science 363, 1144-1146. doi: 10.1126/science.aaw2694

Dulong, D. (2012). Sociologie des Institutions Politiques. Paris: La Découverte.

Edwards, E. (2017). New citizens' assembly sought by three members of Eighth committee. TheIrishTimes.com. Available online at: https://www.irishtimes. com/news/politics/new-citizens-assembly-sought-by-three-members- ofeighth-committee- 1.3334180 ? mode $=$ amp

Elkink, J. A., Farrell, D. M., Marien, S., Reidy, T., and Suiter, J. (2020). The death of conservative Ireland? The 2018 abortion referendum. Electoral Stud. 65:102142. doi: 10.1016/j.electstud.2020.102142

Elkink, J. A., Farrell, D. M., Reidy, T., and Suiter, J. (2017). Understanding the 2015 marriage referendum in Ireland: context, campaign, and conservative Ireland. Irish Political Stud. 32, 361-381. doi: 10.1080/07907184.2016.1197209

Elstub, S., and Escobar, O. (eds.). (2019). Handbook of Democratic Innovation and Governance. Cheltenham; Northampton, MA: Edward Elgar Publishing.

Farrell, D. (2010a). Fine Gael proposes to establish a Citizen Assembly on electoral reform. Irish Politics Forum. Available online at: https://politicalreform.ie/ 2010/03/22/fine-gael-proposes-to-establish-a-citizen-assembly-on-electoralreform/ (accessed August 2, 2020).

Farrell, D. (2010b). Labour Party's proposals for constitutional reform a welcome addition to a much-needed political debate. Irish Politics Forum. Available online at: https://politicalreform.ie/2010/04/18/labour-party\%e2\%80\%99sproposals-for-constitutional-reform-a-welcome-addition-to-a-muchneeded-political-debate/ (accessed August 2, 2020).

Farrell, D. (2010c). Some of the ingredients for political reform, but still missing the most vital one. Irish Politics Forum. Available online at: https:// politicalreform.ie/2010/12/28/some-of-the-ingredients-for-political-reformbut-still-missing-the-most-vital-one/ (accessed August 3, 2020).

Farrell, D. (2018). What happens after a citizens' assembly? Irish Politics Forum. Available online at: https://politicalreform.ie/2018/07/18/what-happens-aftera-citizens-assembly/ (accessed August 5, 2020). 
Farrell, D. (2019). Politics-as-usual can't fix the climate crisis. Maybe it's time to try a citizens' assembly. The Guardian. Available online at: https:// www.theguardian.com/commentisfree/2019/aug/28/climate-crisis-citizensassembly-extinction-rebellion (accessed April 18, 2020).

Farrell, D. M. (2014). 'Stripped down' or reconfigured democracy. West European Politics 37, 439-455. doi: 10.1080/01402382.2014.887873

Farrell, D. M., Harris, C., and Suiter, J. (2018). "Bringing people into the heart of Irish constitutional design: The Irish Constitutional Convention 20122014," in Participatory Constitutional Change: The People as Amenders of the Constitution Comparative Constitutional Change, eds X. I. Kontiadēs and A. Fotiadou (London; New York, NY: Routledge), 120-135.

Farrell, D. M., O'Malley, E., and Suiter, J. (2013). Deliberative democracy in action Irish-style: the 2011 we the citizens pilot citizens' assembly. Irish Political Stud. 28, 99-113. doi: 10.1080/07907184.2012.745274

Farrell, D. M., Suiter, J., Harris, C., and Cunningham, K. (2020). The effects of mixed membership in a deliberative forum: the Irish constitutional convention of 2012-2014. Political Stud. 68, 54-73. doi: 10.1177/0032321719830936

Fishkin, J. S. (2009). When the People Speak: Deliberative Democracy and Public Consultation. New York, NY: Oxford University Press.

Flinders, M., Ghose, K., Jennings, W., Molloy, E., Prosser, B., Renwick, A., et al. (2016). Democracy Matters: Lessons From the 2015 Citizens' Assemblies on English Devolution. London: Democracy Matters.

Foucault, M. (2004). Sécurité, Territoire, Population: Cours au Collège de France, 1977-1978. Paris: Seuil: Gallimard.

Fournier, P., van der Kolk, H., Carty, K. R., Blais, A., and Rose, J. (2011). When Citizens Decide. Lessons From Citizens Assemblies on Electoral Reform. Oxford: Oxford University Press.

Fung, A. (2006). Varieties of participation in complex governance. Public Administr. Rev. 66, 66-75. doi: 10.1111/j.1540-6210.2006.00667.x

Gallagher, M., and Marsh, M. (eds.). (2011). How Ireland Voted 2011. The Full Story of Ireland's Earthquake Election. Basingstoke: Palgrave Macmillan.

Gastil, J., and Levine, P. (eds.). (2005). The Deliberative Democracy Handbook: Strategies for Effective Civic Engagement in the 21st Century. San Francisco, CA: Jossey-Bass.

Gastil, J., and Wright, E. O. (eds.). (2019). Legislature by Lot. London; New York, NY: Verso.

Geissel, B., and Gherghina, S. (2016). "Constitutional deliberative democracy and democratic innovations," in Constitutional Deliberative Democracy in Europe, eds M. Reuchamps and J. Suiter (Colchester: ECPR Press), 75-91.

Goodin, R. E., and Dryzek, J. S. (2006). Deliberative impacts: the macro-political uptake of mini-publics. Politics Society 34, 219-244. doi: $10.1177 / 0032329206288152$

Government of Ireland (2020). Programme for Government: Our Shared Future. Available online at: https://www.finegael.ie/app/uploads/2020/06/ ProgrammeforGovernment_Final_16.06.20-1.pdf (accessed November 20, 2020).

Government Press Office (2019). Dr Catherine Day appointed as the Chair of the new Citizens' Assembly. Available online at: https://www.citizensassembly. ie/en/news-publications/press-releases/dr-catherine-day-appointed-as-thechair-of-the-new-citizens-assembly.html (accessed August 5, 2020).

Grönlund, K., Bächtiger, A., and Setälä, M. (eds.). (2014). Deliberative Mini-Publics. Involving Citizens in the Democratic Process. Colchester: ECPR Press.

Harris, C. (2019). "Mini-publics: design choices and legitimacy," in Handbook of Democratic Innovation and Governance, eds S. Elstub and O. Escobar (Cheltenham: Edward Elgar Publishing), 45-59.

Harris, C. Cahillane, L., Farrell, D.M., Stone P., and Suiter, J. (2020). Ireland - Country Report Final. Cork: COST Constitution and Deliberative Democracy.

Harris, C. ed. (2005). The Report of the Democracy Commission: Engaging Citizens: The Case for Democratic Renewal in Ireland. Dublin: TASC at New Island. Available online at: https://cora.ucc.ie/handle/10468/2726

Hayden, J. (2017). An open letter to the Taoiseach who says my country isn't ready for abortion. Her.ie. Available online at: https://www.her.ie/news/open-lettertaoiseach-says-country-isnt-ready-abortion-364962 (accessed December 15, 2017).

Hendriks, C. M. (2005). "Consensus Conferences and Planning Cells: Lay Citizen Deliberations," in The Deliberative Democracy Handbook: Strategies for Effective Civic Engagement in the 21st Century, eds J. Gastil and P. Levine (San Francisco: Jossey-Bass), 80-110.
Hickey, K. (2018). Irish people want a United Ireland, see a referendum in the next 10 years. Irish Central. Available online at: https://www.irishcentral.com/news/ politics/irish-people-united-ireland-referendum-poll.

Honohan, I. (2014). What can the UK learn from the Irish constitutional convention? Open Democracy. Available online at: https://www. opendemocracy.net/en/opendemocracyuk/what-can-uk-learn-from-irishconstitutional-convention/ (accessed August 4, 2020).

Hood, C. (2010). The Blame Game Spin, Bureaucracy, and Self-Preservation in Government. Princeton, NJ: Princeton University Press.

Hughes, T. (2018). Committees to hold citizens' assembly to consider best way of funding adult social care. Involve.org. Available online at: https://www.involve. org.uk/2018/04/22/press-release-committees-to-hold-citizens-assembly-toconsider-best-way-of-funding-adult-social-care/ (accessed April 23, 2018).

Humphreys, J. (2016). Why Ireland's citizens' assembly is a model for Europe. The Irish Times. Available online at: https://www.irishtimes.com/culture/ why-ireland-s-citizens-assembly-is-a-model-for-europe- 1.2876808 (accessed August 4, 2020).

Jacquet, V., Moskovic, J., Caluwaerts, D., and Reuchamps, M. (2016). "The macro political uptake of the G1000 in Belgium," in Constitutional Deliberative Democracy in Europe, eds M. Reuchamps and J. Suiter (Colchester: ECPR Press), 53-73.

Joint Committee on the Constitution (2010). Fourth and Final Report. Available online at: https://ptfs-oireachtas.s3.amazonaws.com/DriveH/AWData/ Library3/Final_Report_PdF.pdf

Joss, S., and Bellucci, S. (eds.) (2002). Participatory Technology Assessment: European Perspectives. London: Center for the Study of Democracy.

Kingdon, J. (1995). Agendas, Alternatives and Public Policies. New York, NY: Longman.

Knobloch, K., Gastil, J., and Reitman, T. (2015). "Connecting micro-deliberation to electoral decision making: institutionalizing the oregon citizens' initiative review," in Deliberation and Democracy: Innovative Processes and Institutions, eds S. Coleman, A. Przybylska, and Y. Sintomer (Frankfurt am Main: Peter Lang), 21-40

Lagroye, J., and Offerlé, M. (eds.). (2010). Sociologie de l'institution. Paris: Belin.

Lang, A. (2010). "Quand les citoyens décident?: généalogie des assemblées citoyennes sur la réforme électorale (Canada)," in La démocratie participative inachevée. Genèse, adaptations et diffusions, eds. M.-H. Bacqué and Y. Sintomer (Paris: Yves Michel et Adels), 115-132.

Lascoumes, P., and Le Galès, P. (2012). Sociologie de l'action Publique, 2nd Edn. Paris: Armand Colin.

Lécuyer, B.-P. (1994). "Institution," in Dictionaire de la Sociologie, eds R. Boudon, P. Besnard, M. Cherkaoui, and B.-P. Lécuyer (Paris: Larousse), 111.

Lee, C. W. (2015). Do-it-Yourself Democracy: The Rise of the Public Engagement Industry. Oxford: Oxford University Press.

Leib, E. J. (2004). Deliberative Democracy in America: A Proposal for a Popular Branch of Government. Philadelphia, PA: Pennsylvania State University Press.

LPrD (2007). Loi cantonale du 11 septembre 2007 sur la protection des données personnelles.

MacKenzie, M. K. (2016). "A general-purpose, randomly selected chamber," in Institutions for Future Generations, eds I. González-Ricoy and A. Gosseries (Oxford: Oxford University Press), 282-298.

Manin, B. (1987). On legitimacy and political deliberation. Political Theory 15, 338-368. doi: $10.1177 / 0090591787015003005$

Mansbridge, J. (2007). "'Deliberative democracy' or 'democratic deliberation'?, in Deliberation, Participation and Democracy. Can the People Govern?, ed S. Rosenberg (London: Palgrave Macmillan), 251-271.

Mansbridge, J. (2010). Deliberative Polling as the Gold Standard. Good Soc. 19, 55-62. doi: 10.1353/gso.0.0085

Mouffe, C. (2000). The Democratic Paradox. New York, NY: Verso.

Nault, E. (2015). L'avortement en Irlande: 1983-2013. Frankfurt am Main: Peter Lang.

Nez, H., and Talpin, J. (2010). "Démocratie participative et communisme municipal en banlieue rouge (France)," in La Démocratie Participative Inachevée. Genèse, Adaptations et Diffusions, eds M.-H. Bacqué and Y. Sintomer (Paris: Yves Michel et Adels), 209-227.

Nonjon, M. (2005). Professionnels de la participation: savoir gérer son image militante. Politix 70, 89-112. doi: 10.3917/pox.070.0089

Oireachtas, H. (2009). Joint Committee on the Constitution, Debate, Wednesday, 9 Dec 2009. Available online at: https://www.oireachtas.ie/en/debates/debate/ 
joint_committee_on_the_constitution/2009-12-09/3 (accessed August 3, 2020).

Oireachtas, H. (2019). Citizens' Assemblies Act 2019. Available online at: https:// data.oireachtas.ie/ie/oireachtas/act/2019/25/eng/enacted/a2519.pdf.

O'Leary, K. (2006). Saving Democracy: A Plan for Real Representation in America. Stanford, CA: Stanford University Press.

O'Malley, E., Farrell, D. M., and Suiter, J. (2020). Does talking matter? A quasiexperiment assessing the impact of deliberation and information on opinion change. Int. Political Sci. Rev. 41, 321-334. doi: 10.1177/0192512118824459

Papadopoulos, Y. (1998). Démocratie Directe. Paris: Economica.

Papadopoulos, Y., and Warin, P. (2007). Are innovative, participatory and deliberative procedures in policy making democratic and effective? Eur. J. Polit. Res. 46, 445-472. doi: 10.1111/j.1475-6765.2007.00696.x

Parkinson, J. (2005). Rickety bridges: using the media in deliberative democracy. Br. J. Political Sci. 36:175. doi: 10.1017/S0007123406000093

Parkinson, J., and Mansbridge, J. (eds.). (2012). Deliberative Systems. Cambridge: Cambridge University Press.

Pilet, J.-B. (2016). Les citoyens sont-ils prêts à accepter les décisions d'une assemblée tirée au sort? Retour sur quelques expériences d'assemblée citoyenne. Paper presented at the Workshop Représentation et Tirage au Sort. Louvain: Université Catholique de Louvain.

Press Association (2018a). Data shows many voters had decided before campaign began, academics say. Daily Mail Online. Available online at: http://www.dailymail.co.uk/wires/pa/article-5774705/Data-shows-votersdecided-campaign-began-academics-say.html (accessed May 30, 2018).

Press Association (2018b). Growing calls for Citizens' Assembly to address issues including abortion. Independent.ie. Available online at: https:// www.independent.ie/breaking-news/irish-news/growing-calls-for-citizensassembly-to-address-issues-including-abortion-36472768.html (accessed August 19, 2018).

Rawls, J. (1999). A Theory of Justice, Rev. Edn. Cambridge, MA: Harvard University Press.

Renwick, A. (2015). A British constitutional convention? Political Insight 6, 8-11. doi: 10.1111/2041-9066.12093

Renwick, A. (2017). Citizens' assemblies: a better way of doing democracy? Political Insight 8, 24-27. doi: 10.1177/2041905817744632

Reuchamps, M., and Suiter, J. (eds.). (2016). Constitutional Deliberative Democracy in Europe. Colchester: ECPR Press.

Richards, L. (2015). Handling Qualitative Data: A Practical Guide, 3rd Edn. London: Sage.

Ritchie, J., Lewis, J., McNaughton Nicholls, C., and Ormoston, R. (eds.). (2014). Qualitative Research Practice. A Guide for Social Science Students \& Researchers, 2nd Edn. Thousand Oaks, CA: Sage.

Röcke, A. (2010). "Budget participatif: des initiatives locales à l'ordre du jour national (Royaume-Uni)," in La Démocratie Participative Inachevée. Genèse, Adaptations et diffusions, eds M.-H. Bacqué and Y. Sintomer (Paris: Yves Michel et Adels), 43-60.

Rosenthal, R., and Jacobson, L. (1968). Pygmalion in the Classroom: Teacher Expectation and Pupils' Intellectual Development. New York, NY: Holt, Rinehart \& Winston.

Saldana, J. (2016). The Coding Manual for Qualitative Researchers, 3rd Edn. Thousand Oaks, CA: Sage.

Saward, M. ed. (2000). Democratic Innovation. Deliberation, Representation and Association. Oxon: Routledge ECPR

Setälä, M. (2017). Connecting deliberative mini-publics to representative decision making. Eur. J. Political Res. 56, 846-863. doi: 10.1111/1475-6765.12207

Smith, G. (2009). Democratic Innovations: Designing Institutions for Citizen Participation. Cambridge: Cambridge University Press.

Suiter, J. (2011). Reformcard first scores. Irish Politics Forum. Available online at: Available online at: https://politicalreform.ie/2011/02/16/reformcard-firstscores/ (accessed October 7, 2020).

Suiter, J., Farrell, D., and Harris, C. (2016a). "The Irish Constitutional Convention: high legitimacy?", in Constitutional Deliberative Democracy in Europe, eds M. Reuchamps and J. Suiter (Colchester: ECPR Press), 33-51.

Suiter, J., Farrell, D. M., and O'Malley, E. (2016b). When do deliberative citizens change their opinions? Evidence from the Irish citizens' assembly. Int. Political Sci. Rev. 37, 198-212. doi: 10.1177/0192512114544068

Suiter, J., and Reidy, T. (2020). Does deliberation help deliver informed electorates: evidence from Irish referendum votes. Representation. 56, 539-557. doi: $10.1080 / 00344893.2019 .1704848$
Suteu, S. (2015). Constitutional conventions in the Digital Era: lessons from Iceland and Ireland. Compar. Law Rev. 38, 251-276.

Sutherland, K. (2008). A People's Parliament: A (Revised) Blueprint for a Very English Revolution. Exeter: Imprint Academic.

Talpin, J. (2019). "Qualitative approaches to democratic innovations," in Handbook of Democratic Innovation and Governance, eds S. Elstub and O. Escobar (Cheltenham: Edward Elgar Publishing), 486-500.

The Irish Times (2019). The Irish Times view on citizens' assemblies: outsourcing political decisions. The Irish Times. Available online at: https:// www.irishtimes.com/opinion/editorial/the-irish-times-view-on-citizensassemblies-out-sourcing-political-decisions-1.3924889 (accessed August 5, 2020).

The Irish World (2018). UK could follow Ireland's lead on abortion vote, says brown. The Irish World. Available online at: http://www.theirishworld.com/ gordon-brown-uk-follow-ireland-lead-abortion-vote.

Thompson, D. (2008). "Who should govern who governs? The role of citizens in reforming the electoral system," in Designing Deliberative Democracy. The British Columbia Citizens' Assembly, eds M. Warren and H. Pearse (Cambridge; New York, NY: Cambridge University Press), 20-49.

Van Reybrouck, D. (2016). Against Elections: The Case for Democracy. London: Bodley Head.

Vergne, A. (2010). "Le modèle planungzselle - citizens juries: quelles logiques de diffusion? (Allemagne, Etats-Unis)," in La Démocratie Participative Inachevée. Genèse, Adaptations et Diffusions, eds M.-H. Bacqué and Y. Sintomer (Paris: Yves Michel et Adels), 83-100.

Wall, M. (2011). Power to the people? A summary of party proposals on Citizen Assemblies. Irish Politics Forum. Available online at: https://politicalreform.ie/ 2011/02/18/power-to-the-people-a-summary-of-party-proposals-on-citizenassemblies/ (accessed August 3, 2020).

Wall, M. (2012). Confessions of a demoralised political scientist. Irish Politics Forum. Available online at: https://politicalreform.ie/2012/06/07/confessionsof-a-demoralised-political-scientist/ (accessed August 3, 2020).

Warhurst, P. J. (1999). From constitutional convention to republic referendum: a guide to the processes, the issues and the participants. Austral. Parliament. Library Paper 25:57.

Warren, M., and Pearse, H. (eds.). (2008). Designing Deliberative Democracy. The British Columbia Citizens' Assembly. Cambridge; New York, NY: Cambridge University Press.

Warren, M. E., and Gastil, J. (2015). Can deliberative minipublics address the cognitive challenges of democratic citizenship? J. Politics 77, 562-574. doi: $10.1086 / 680078$

We the Citizens (2011). Final Report: Participatory Democracy in Action - A Pilot. Dublin: We the Citizens.

Weaver, R. K. (1986). The politics of blame avoidance. J. Public Policy 6:371. doi: $10.1017 / \mathrm{S} 0143814 \mathrm{X} 00004219$

Whelan, N. (2012). Constitutional convention will have its remit severely pruned. The Irish Times. Available online at: Available online at: https:// www.irishtimes.com/opinion/constitutional-convention-will-have-its-remitseverely-pruned-1.470351 (accessed August 3, 2020).

White, S. (2017). Parliaments, constitutional conventions, and popular sovereignty. $\mathrm{Br} . \mathrm{J} . \mathrm{Politics}$ Int. Relat. 19, 320-335. doi: $10.1177 / 1369148117700657$

Williams (1998). The 1998 Constitutional Convention-First Impressions. Canberra, ACT: Parliament of Australia. Available online at: https://www.aph. gov.au/About_Parliament/Parliamentary_Departments/Parliamentary_ Library/Publications_Archive/CIB/CIB9798/98cib11 (accessed August $4,2020)$

Conflict of Interest: The author declares that the research was conducted in the absence of any commercial or financial relationships that could be construed as a potential conflict of interest.

Copyright (c) 2021 Courant. This is an open-access article distributed under the terms of the Creative Commons Attribution License (CC BY). The use, distribution or reproduction in other forums is permitted, provided the original author(s) and the copyright owner(s) are credited and that the original publication in this journal is cited, in accordance with accepted academic practice. No use, distribution or reproduction is permitted which does not comply with these terms. 


\title{
Can the Recall Improve Electoral Representation?
}

\author{
Pierre-Etienne Vandamme* \\ Cevipol, FNRS \& Université libre de Bruxelles, Brussels, Belgium
}

Empirical studies reveal many citizens' unwillingness to get rid of representative democracy. A great number of them, however, distrust their representatives and would want representation to be improved, for example by giving citizens more control over their representatives. One possible mechanism of control is the recall-the possibility to remove elected representatives from office through a vote before the end of their term. Although this democratic tool is on the rise worldwide and was supported in the past by influential figures such as Rousseau and Marx, its study has been neglected by contemporary political theorists. The aim of this contribution is to identify the main arguments for and against the use of recall mechanisms, and to assess both their normative and empirical validity. In particular, it asks whether they have the capacity to improve the quality of representation or at least the perception of representative institutions' legitimacy, and answers with a moderate "yes"-especially for the latter aspect (perceived legitimacy).

\section{OPEN ACCESS}

Edited by:

Romain Lachat,

UMR7048 Center de Recherches

Politiques de Sciences Po

(CEVIPOF), France

Reviewed by:

Raul Magni Berton,

Université Grenoble Alpes, France

Anthoula Malkopoulou,

Lund University, Sweden

${ }^{*}$ Correspondence:

Pierre-Etienne Vandamme pierre-etienne.vandamme@ulb.be

Specialty section:

This article was submitted to Elections and Representation,

a section of the journal

Frontiers in Political Science

Received: 01 May 2020

Accepted: 04 August 2020

Published: 25 September 2020

Citation:

Vandamme P-E (2020) Can the Recall Improve Electoral Representation?

Front. Polit. Sci. 2:6.

doi: 10.3389/fpos.2020.00006
Keywords: recall, representation, accountability, independence, trust, dissatisfaction, polarization

\section{INTRODUCTION}

Despite growing democratic resentment, several empirical studies reveal citizens' unwillingness to get rid of representative institutions (Fuchs and Klingemann, 1995, pp. 434-437; Ferrin, 2016; Clarke et al., 2018) ${ }^{1}$. Polls, however, frequently report that many citizens distrust their representatives and believe that they do not care about them. Thus, those who are not completely resigned would want representation to be improved, for example by giving citizens more control over their representatives (see Bedock, 2020 and Dolez, forthcoming, both in this Frontiers research topic). One possible mechanism of control, invoked for example by many Gilets jaunes in France (Bedock et al., 2019; Egger and Magni-Berton, 2020), is the recall-the possibility to remove elected representatives from office through a vote or petition before the end of their term.

The recall is an instrument dating back to the Roman Republic ${ }^{2}$, once praised by Rousseau (1762/2008) and Marx (1871/1972), and still used nowadays in several states, regions, provinces or municipalities, in different countries-especially Peru, the US, Japan, Poland, Columbia and Bolivia (Qvortrup, 2011; Welp, 2018; Welp and Whitehead, 2020). Perhaps as a result of increased dissatisfaction with existing representative institutions, recall practices are on the rise (either spreading to new levels of government or being introduced) in diverse political contexts, although this phenomenon seems to have passed "below the radar" of many analysts of democratization processes (Whitehead, 2018). Recently, the tool was even promoted in presidential campaigns in the $\mathrm{UK}^{3}$ and France ${ }^{4}$, institutionalized in a modest form

\footnotetext{
${ }^{1}$ See nonetheless (Tormey, 2015) on the diversity of movements contesting representative democracy.

${ }^{2}$ Although the practice of ostracism, in Athens, had some similarities with it (Cronin, 1989, p. 128; Tridimas, 2016; Malkopoulou, 2017).

${ }^{3}$ Before the 2010 election, all major political parties expressed support for the recall (Whitehead, 2018, pp. 1348-1349).

${ }^{4}$ During the 2017 Presidential campaign, 4 out of 11 candidates expressed their support to it (Whitehead, 2018, p. 1348).
} 
in the UK in 2015 (Tonge, 2019) and it is often praised by socalled "digital parties" such as Podemos or 5 Stelle (White and Ypi, 2020, 181-182).

Although it is often considered as an instrument of direct democracy (Cronin, 1989; Altman, 2010; Welp, 2018) it seems preferable to characterize it as an instrument of empowered representative democracy. It is not aimed at giving direct legislating or initiating power to citizens. It does not question the very idea of having representatives. Its aim is rather to improve representation-as Cronin (1989, p. 133) himself acknowledges-by making it more responsive to citizens' aspirations.

The aim of this contribution is to identify the main theoretical arguments for and against the use of recall mechanisms, and to assess both their normative and empirical validity ${ }^{5}$. More precisely, the research question is whether the tool has the capacity to improve existing representative institutions, either by increasing citizens' support for their political system or by improving the expected quality of democratic decisions. The second section introduces the mechanism, the different forms it can take, and its main purposes. The positive claims made by his defenders are systematically confronted to the available empirical evidence. The third section deals with the main objections challenging the capacity of recall mechanisms to improve representation - the value of independent representatives, the limits of majority rule, the risk of instrumentalization and polarization, the risk of permanent campaigning, and the harshness objection. These objections, I argue, warn against some uses of the recall and qualify its potential as a remedy for current challenges to representative democracy. However, I claim that they are not fatal to the proposal. Therefore, the fourth section briefly introduces different uses of this instrument with a potential to enrich existing representative institutions.

\section{THE PROSPECTS OF RECALL MECHANISMS}

Broadly defined as the possibility to remove elected representatives from office before the end of their term, the recall comes in many guises. Table 1 borrowed to Qvortrup (2011, p. 163), gives a clear preliminary picture, distinguishing recall from impeachment, and citizen-initiated from parliament-initiated recall.

What I will be concerned with, in this article, is the direct recall, thus initiated and decided by citizens. The procedure usually starts with a petition. If a defined threshold of signatures is reached, either a popular vote (also called "recall referendum" or "recall election," or "by-election") is organized (often with a required threshold of participation), or the representative is

\footnotetext{
${ }^{5}$ The empirical validity of arguments is assessed whenever there is reliable data available. This article, however, does not offer any new data. In contrast, the normative validity of a claim (such as the value of having independent representatives) is assessed in reference to widely accepted democratic norms such as political equality and the equal consideration of interests.
}

TABLE 1 | Typology of revoking mandates of elected representatives.

\begin{tabular}{llll}
\hline & \multicolumn{2}{c}{ Who initiates? } \\
\cline { 3 - 4 } & & People & Parliament \\
\hline Who decides? & People & Direct recall (e.g., California) & $\begin{array}{l}\text { Indirect recall } \\
\text { (e.g., Romania) } \\
\end{array}$ \\
\cline { 3 - 4 } & Parliament & $\begin{array}{l}\text { Citizen initiated } \\
\text { impeachment (e.g., Uganda) }\end{array}$ & $\begin{array}{l}\text { Impeachment } \\
\text { (e.g., US) }\end{array}$ \\
\hline
\end{tabular}

automatically recalled ${ }^{6}$. In such case, either new elections take place, or predefined substitutes automatically take the position.

Another version of the direct recall offers citizens a right to dissolve the whole assembly, as currently practiced in Latvia, Slovakia and in six Swiss cantons (Magni-Berton and Egger, 2019, pp. 81-82). This use, as we shall see, helps avoiding some of the problems associated with the individual recall, such as its strategic instrumentalization or its presumed harshness. It is also easier to use in PR systems. In what follows, I will mainly focus on recalling individuals, but I will come back to this collective recall later.

I will now introduce the main purposes of recall mechanisms and confront them to the empirical knowledge we currently have about their effects in a diversity of contexts. Obviously, this empirical knowledge is often very context-dependent and cannot be generalized without further question. Nevertheless, it provides interesting provisional ${ }^{7}$ insights about the validity of some arguments for and against the recall. Arguments against the mechanism are then explored in more depth in the third section.

\section{Arguments for Recall}

What are the main arguments in favor of the recall device? What benefits is it supposed to deliver? Let us start with the most interesting arguments put forward by Thomas Cronin's (1989, pp. 133-135) comprehensive study of so-called direct democracy mechanisms in the US. I will then add a new argument, based on trust and the symbolic benefits of the recall.

1. The recall provides for continuous accountability, so that voters need not wait until the next election to rid themselves of an incompetent, dishonest, unresponsive, or irresponsible public official.

Increasing citizens' "grip" on their representatives is the main purpose of recall mechanisms. Electoral representation is based on the assumption that voters should be able to get rid of unsatisfying representatives, and the recall is supposed to make this easier, thereby increasing the incentives faced by representatives to care about public opinion.

This argument sounds very plausible on paper. To the extent that elections can generate a form of accountability, more

\footnotetext{
${ }^{6}$ This is the case, for example, in British Columbia, if $40 \%$ of the voters sign the petition within 60 days (Qvortrup, 2011, p. 163).

${ }^{7}$ Provisional until the mechanism is tested in the context where the reform is considered, or in sufficiently comparable contexts.
} 
frequent opportunities to sanction elected representatives should increase accountability. What is more, candidates sometimes lie and voters sometimes make mistakes; it therefore makes sense to provide voters with an effective tool to correct their errors of appreciation (Bowler, 2004, p, 204).

However, several scholars have questioned the capacity of voters to effectively hold their representatives accountable for actions engaging their responsibility. In most democracies, voters have been found to be largely ignorant about the work (or even identity) of their representatives (Somin, 2013; Brennan, 2016; Achen and Bartels, 2017) ${ }^{8}$. Most of them also face profound difficulties "in connecting specific policy proposals to their own values and interests" (Bartels, 2008, p. 27). Therefore, they are often not properly equipped to judge their representatives' policy choices. What is more, they usually "have great difficulty making sensible attributions of responsibility for hard times" (Achen and Bartels, 2017, p. 304) ${ }^{9}$ or even to assess whether times have been good or bad during a term in office. As a result, when voters do vote retrospectively, they often seem to reward or sanction representatives for things they are not responsible for, such as droughts, floods or a suddenly changing economic dynamic in the months preceding an election (whatever the economic results of the whole term in office).

Nevertheless, the fact that citizens lack relevant information when they vote is not fatal to electoral accountability. As Achen and Bartels (2017, p. 318) themselves recognize, reelectionseeking politicians will at least "strive to avoid being caught violating consensual ethical norms in their society." Clear cases of corruption, partiality or misbehavior will usually be reported by the media and sanctioned. What is more, elected politicians usually ignore the extent to which electoral accountability is defective. Thus, the mere threat of sanction might influence them even if citizens do not sanction effectively. Therefore, to the extent that the availability of recall constitutes a serious threat, accountability could be increased by it.

In practice, the evidence that the availability of recall mechanisms leads to more responsiveness and accountability is not clearly established. One reason is that the mechanism is not used much, even when available, which reduces the threat faced by incumbents. Thus, for example, Bowler (2004, p. 208) reported that only $10 \%$ of municipalities with the recall in the US had witnessed recent attempts at recall. What is more, most of the attempts do not lead to a recall referendum (Welp, 2018, p. 456), either because the threshold of signatures is not reached or because the targeted candidate resigns to avoid public humiliation. This does not mean that the availability of recall has no effect on representatives, but it means that it is hard to measure at this stage and that we cannot assert with full confidence that it will be effective, if introduced in a new context. We should have modest expectations in this respect,

\footnotetext{
${ }^{8}$ Although the studies these authors draw on are often one-sided (Lupia, 2006) and some of their claims have been aptly refuted (see for example Christiano, 2017 or Chambers, 2018), it remains quite uncontroversial that many voters are not sufficiently informed to properly play their monitoring role.

${ }^{9}$ Especially in contexts with coalition governments and multilevel governance (Anderson, 2000).
}

at least until wider experimentation provides us with more scientific evidence.

2. The recall helps check undue influence by narrow special interests.

When introduced in the US in the early 20th century, the recall was explicitly conceived as "a means of bringing some honesty back into politics" (Bowler, 2004, p. 203). Is it a realistic expectation, though? If the problem is that money pervades politics, recall may not be the solution, as campaigning for recall is costly as well, and special interest groups may instrumentalize the recall to private ends (see Garrett, 2004; Campodonico, 2016). As brought to attention by Cronin (1989, pp. 90-124) and others, promotors of direct democracy mechanisms have often underestimated the influence of money on initiatives and referendum campaigns. Yet whatever applies to I\&R campaigns may apply to recall campaigns as well.

Empirically, though, it is not clear whether compared to policies enacted through traditional representative procedures, popular initiative referendums are better aligned with the preferences of the majority or more vulnerable to capture. Gerber (1999) and Matsusaka (2004), for example, defend the former view in the US context, but Lax and Phillips (2012), studying the same context, saw no correlation between the availability of direct democracy instruments and responsiveness to majority preferences. Beyond the US, though, scholars of direct democracy seem less pessimistic about the capture of popular initiatives by the wealthy (Altman, 2010, pp. 189-190). In any case, general considerations about this are bound to be somewhat speculative. The risk might be highly context-dependent.

Nevertheless, whether or not they are properly and effectively used in practice, recall mechanisms increase voters' opportunities to control their representatives-and hence potentially to check undue influence. Given that there is no apparent reason to expect a higher influence of private lobbies with recall than without, absent countervailing reasons we would have reasons to support this device, based on its empowering potential. Then, it is the media's role to report misbehavior and breach of promises, and it is the citizens' role to pay attention and mobilize when it proves necessary.

Besides, to reduce the risks of "capture" of recall initiatives, it seems reasonable, as suggested by Cronin (1989, p. 154), to "require sponsors of a recall, through their treasurer, to file documents listing those who contributed to their effort, as well as expenditures."

3. The recall enables jurisdictions to permit their officials to serve longer terms.

This argument is interesting insofar as it responds to two objections frequently addressed to the recall. First, it is costly, as popular votes are organized more frequently. Second, it creates a state of permanent campaigning (an objection to which we shall come back later). However, if the introduction of recall goes with an extension of the terms if office and if recalls are not too frequent, the cost might not be excessive. And more importantly, elected representatives keeping the support of their constituents 
would be able to widen their time-horizon, which is not negligible considering the current environmental crisis.

There is no empirical indication, however, that the introduction of recall is usually associated with an extension of terms. And in cases where both measures would be combined, there would be a trade-off between a recall procedure too easy to enact, which would create permanent campaigning, and a procedure too difficult to enact, which might reduce the potential for accountability.

4. The recall offers a safety-valve mechanism for intense feelings.

It is part of the nature of elections to create hope, and then to generate disappointment (Przeworski, 2018). And when disappointment is high, it can be very frustrating for voters to wait until the end of the term to be able to cause effective change. The alternative, then, is popular protest, taking the street and often hopelessly pressuring the government for a change in its policy orientation-actions generating risks of conflict and political instability.

Judged from this perspective, the recall certainly looks promising as a channel or an outlet for popular frustration (Lijphart, 1984), provided that the tool is generally known, which is not always the case (Welp and Whitehead, 2020, p. 9). Lenin himself asserted that the right of recall would have made a violent revolution unnecessary in 1917 (see Qvortrup, 2020, p. 39)!

This pacifying effect, however, is not guaranteed-and it is highly context-dependent (Whitehead, 2020, p. 238). Some uses of the recall could actually increase political conflicts. As we shall see, we should not be blind to the possibility of partisan instrumentalizations of the mechanism. If the main effect of the recall was to provide a tool for poor losers to contest elections result, the democratic gain would not be clear (Welp, 2016; White and Ypi, 2020). Frequent recalls might then lead to polarization and mutual hatred between opposing parties, provoking "spirals of ever more vitriolic recall campaigns" (Bowler, 2004, p. 207) and disincentivizing loyal opposition. We will come back to this in section The Risks of Instrumentalization and Polarization.

5. The recall might increase trust in the representative system.

This argument might come as a surprise. Some might expect the recall to create an atmosphere of permanent suspicion toward representatives, with the result of reinforcing distrust. By institutionalizing an additional mechanism to sanction representatives, are we not sending the message that the public is right to be suspicious, to mistrust elected politicians (Bauer and Fatke, 2014)?

First, we should draw a distinction between different dimensions of trust:

- Trust in the political system in general (or regime trust), which includes not only elections, but other aspects of democracy as well, and can be measured through opinion polls.

- Trust in the electoral representative system, which can be partly measured through turnout to elections (and partly through polls).

- Trust in the political class, again measurable through polls.
The effect that the recall may have on regime trust is an empirical question that remains largely open and whose answer partly depends on the particular combination of recall mechanisms with other institutions in a given context. However, consistently with what has sometimes been found about the initiative and referendum (Gherghina, 2017), empowering citizens with a new tool for political action may increase regime trust.

More important for this research topic is the issue of trust in the electoral representative system. This question is also very uncertain, but we have some empirical indications to draw on. First, from what we know about the practice of recall in the US, it seems that it reinforces trust in the electoral representative system, as expressed by levels of turnout (Qvortrup, 2011, p. 168), contrary to what has sometimes been found about citizen initiatives and referendums (Dyck, 2009; Bauer and Fatke, 2014; Peters, 2016). This result should be tested in other institutional contexts, but I see some reasons to expect a positive effect on this specific kind of trust as well.

As mentioned in the introduction, although the recall is often presented as an instrument of direct democracy (Cronin, 1989; Altman, 2010; Welp, 2018), it does not question the principle of representation (in contrast with initiatives and referendums). And it does not question electoral legitimacy (in contrast with sortition). What it does is questioning a certain understanding of electoral representation (Bowler, 2004; Whitehead, 2020)based on blind trust and the relative independence from public opinion. Yet given that many citizens are unsatisfied with that model of representation and would value more control over their representatives (see again Bedock, 2020 and Dolez, forthcoming in this Frontiers research topic), the availability of recall mechanisms is likely to increase citizens' satisfaction with their representative institutions. Citizens might gain a sense of popular power and control over their representatives, potentially increasing trust in the ability of elections to generate adequate representation.

The benefits of the recall, in this case, are mostly symbolic: it may alter the perception of the representative relationship in a desirable way. Without the recall, the assumption seems to be that citizens choose their preferred elites and then must wait patiently for the next election, where these elites will try to seduce them again. With the recall, the representative relationship becomes somewhat less hierarchical. It appears more clearly that representatives are agents of the people and cannot allow themselves to betray the confidence conferred to them by the election. As any employee, they can be fired at any time if their work is judged unsatisfying or if they commit a professional fault ${ }^{10}$. From this perspective, whether or not the availability of recall is sufficient to secure increased accountability and responsiveness to majority preferences, it could be valued by citizens and it could improve their perception of electoral representation. As seems to have been the case with the practice of ostracism in Athens (Forsdyke, 2005; Malkopoulou, 2017, p. 632), what matters in this case is not so much the frequent use of the mechanism, but its availability-a symbolic reminder that

${ }^{10}$ This argument is borrowed to Gilets jaunes members interviewed in Bedock et al. (2019). 
representatives could be removed at any time and that citizens hold the reins.

Consistently with this, though, trust in the political class may diminish. This could happen, for example, if citizens fail to appreciate the diversity of constraints faced by governments. If they systematically sanction their representatives for failures to deliver on some expectations that they simply cannot meet, the mechanism could then turn out to be unable to support trust in electoral representation. In other words, if citizens keep recalling representatives without seeing any improvement, they might end up losing faith in elections (and recalls).

Yet a benefit of the recall, in this respect, might be to encourage elected politicians to be clearer about these constraints and how they deal with them. The increased risk of sanction should incentivize them not to promise the impossible and to take the necessary time to justify themselves publicly when they have failed to honor some promises for reasons beyond their control. Again, the effect on trust might turn out to be positive. Yet this remains to be checked empirically.

\section{Taking Stock}

The main purpose of the recall is to strengthen representatives' accountability toward citizens and thereby to make them more responsive and less vulnerable to undue influence. In addition to this, it may make it easier to extend terms in office, and more importantly, it may provide an alternative channel for citizens' frustration and generate more trust in the electoral representative system.

There is no clear empirical evidence that all these benefits will necessarily result from institutionalizing recall mechanisms. Nevertheless, what can reasonably be expected is that citizens would be satisfied with the availability of an additional tool of expression and that this tool may increase accountability and responsiveness on the long run if it is sufficiently used.

It is too early, however, to conclude that the recall improves electoral representation. There are several important objections that need to be considered, including objections to the very idea of strengthening accountability on which support for the recall is usually based.

\section{OBJECTIONS}

When the first representative governments were created in Europe and the USA, it was decided explicitly not to use recall mechanisms in order to guarantee the independence of representatives, who were thought to be better positioned to judge in the name of the people, in light of circumstances sometimes unknown by citizens, what policies would serve the public interest (Manin, 1995) ${ }^{11}$. The first objection I would like to discuss is therefore the one grounded on the value of independence for representation. I will then consider a connected theoretical objection-the moral constituency objection-against the idea of increasing accountability to a specific constituency. Then, I will come to more practical objections, pointing

\footnotetext{
${ }^{11}$ Although James Madison once expressed support for this tool (Whitehead, 2018, p. 1345).
}

respectively to the risks of instrumentalization, polarization, and permanent campaigning. Finally, I will consider the harshness objection, suggesting that the prospect of public recall may turn some quality people away from politics.

\section{The Value of Independence}

The relative independence of representatives is one of the distinguishing features of modern representative governments (Manin, 1995). The thought being that elections would bring to power those who distinguish themselves from the mass, who are in some respect superior to ordinary citizens, it appeared important, at the time of creation of these new regimes, not to tie the representatives' hands too much. The imperative mandate model, where representatives receive clear and legally binding instructions from their constituents and can usually be recalled if they deviate from these instructions, would have canceled the epistemic benefits of delegating political power to those among us "whose wisdom may best discern the true interest of their country, and whose patriotism and love of justice will be least likely to sacrifice it to temporary or partial considerations" (Madison, 1787, pp. 56-57). Thus, representative governments were largely based on an elitist understanding of representation. There is however a diversity of arguments that can be provided in favor of the independence of representatives, which are not all based on such elitist premises.

The relative independence of elected representatives has historically been defended for four main reasons (Pitkin, 1967; Manin, 1995; Przeworski et al., 1999; Urbinati, 2006):

1) If conditions (economic, social, political) change during the term in office, it is important that representatives have the freedom to adapt their actions and are not strictly bound by promises made under different conditions.

2) Representatives are sometimes in a better position than constituents (not because they are wiser, but because of their full-time investment in the task) to assess certain needs or constraints. For this reason, there is an epistemic gain in giving them some leeway ${ }^{12}$.

3) The independence of representatives is crucial for the fairness of democracy in that it allows for the equal consideration of opinions. If representatives were bound by imperative mandates, the power of the majority would be strengthened at the expense of minorities (Kelsen, 1929). However, the role of representatives is not to strictly represent the interests of their electors. They probably have a moral duty to make fair decisions, considering all affected interests. Thus, here again there is a potential epistemic gain in granting them independence, but in a normative sense [increased fairness rather than accuracy of decision as in (2)].

4) With an imperative mandate, there is no longer any possibility of deliberation in parliament or negotiation, which can block decision-making processes (Urbinati, 2006, pp. 131-132).

For these reasons, it is often thought that representatives must be legally independent (from the will of their voters), but politically

\footnotetext{
${ }^{12}$ This idea probably goes back to Edmund Burke and was also defended by
} Madison, Paine and Sieyès. 
dependent on the influence of public opinion (and not merely the opinion of the majority). This is why their independence is relative: as Pitkin $(1967, \S 7)$ explains, representatives are not supposed to act completely independently of the will of those they represent. Their actions must generally comply with this will and deviations from it must be justified-by one of the reasons stated above for example.

How should we assess these arguments in light of the contemporary challenges to electoral representation? The first point seems hard to deny: voters simply cannot fully know, at the time of selection, what kind of decisions their representatives will have to deal with. They can anticipate some of them for sure, but not everything that might happen. Therefore, some degree of flexibility and thus independence is practically required.

The second argument is less obvious. The elitist version relates to Madison and Sieyès' assumption that the elected will be (somewhat) superior to the mass. The non-elitist version points to a positional (rather than intrinsic) advantage: elected representatives may not be smarter or wiser than voters, but their daily involvement in politics gives them a privileged epistemic viewpoint. They might for example have a better appreciation of political and economic constraints, overlooked by many citizens. They might be better informed, because they have strong incentives to follow the news and they are usually surrounded by all sorts of advisors ${ }^{13}$.

It seems to me that these positional advantages are credible. The strength of the argument should however be qualified. Firstly, because it will often be the case that some experts or citizens are better informed or better placed to make a judgment on a particular issue than politicians. Hence, the positional advantage is not absolute. They might just, on average, be better placed to judge some issues than ordinary citizens. Secondly, the argument must be qualified because elected representatives will also suffer from important positional (and epistemic) disadvantages:

- Given that elections tend to favor people with a certain socio-economic status (Bovens and Wille, 2017), elected representatives might not know what it means to be an unemployed person, a refugee, a poor worker, a single mother with a low income, etc. Thus, they do not have direct access to these disadvantaged standpoints.

- Given that elected representatives tend to be socialized in similar contexts, they might develop biased views which are widely shared among their peers, without being sufficiently exposed to alternative views.

It is therefore important that representatives enjoy some degree of independence from public opinion. Nevertheless, keeping in mind the risks of biases, it seems equally important that they are kept in check by citizens.

The third argument faces a similar limitation: independence theoretically allows for an equal consideration of the affected interests, but it also leaves room for biases. If we abandon elitist assumptions about the higher wisdom of the more educated,

\footnotetext{
${ }^{13}$ This seems to be in line with the way many politicians perceive themselves (compared to citizens). See Schiffino et al. (2019).
}

there is no guarantee that elected representatives will be more public-spirited or other-regarding than ordinary citizens. In a way, elected representatives are just ordinary citizens with a strong interest in politics and special traits favorable to election, such as charisma and communication skills. Yet they remain affected by the same biases as other citizens, they have interests of their own and they are as corruptible as anyone placed in a position of power. Thus, we should not assume that the independence of representatives will necessarily increase fairness. What is nonetheless true is that strict majority rule is no guarantee of fairness either-a point to which I come back in section The Moral Constituency Objection.

Finally, the fourth argument is particularly strong. The need to be able to make compromises (and thus to sacrifice some electoral promises) is particularly important in contexts of coalition governments (Manin, 1995, pp. 272-273). But it also matters more generally, in all contexts, because elections are not the only vector of popular will. Thus, it is also desirable to have a government willing to make compromises with other kinds of representatives, be it in negotiations with unions or as a response to popular protest movements. Independent representatives facing an independent public opinion allows for more dynamic representative relations. Winning elections is usually not considered as an authorization to do whatever was promised, at any cost, without any room for popular resistance. If we want to reduce the risks of a tyranny of the majority, deliberative interactions with actors of civil society appear particularly important. And an imperative mandate would make these deliberative interactions impossible.

All these arguments, properly qualified, point to the necessity of some degree of independence. They therefore make imperative mandates normatively unattractive. However, they leave open the question of the exact degree of independence that should be enjoyed by representatives. And an important point to make is that the recall, contrary to the imperative mandate, is compatible with some degree of independence (see also Malkopoulou, 2016, pp. 310-311). The key difference is that the imperative mandate "explicitly specifies the criteria to launch a recall process" (Egger and Magni-Berton, 2020, p. 51). For example, if they fail to implement policy $\mathrm{x}$ or to address issue $\mathrm{y}$, they should be recalled. In contrast, when the recall is dissociated from any imperative mandate, representatives potentially have more room for maneuver. They could be sanctioned for things that were not explicitly mentioned in an electoral "contract," but they also have more freedom to defend themselves, to argue with their constituents and to try to convince them that they are doing a good job.

I see at least two reasons why the recall and the imperative mandate are often conflated. First, it is hard to institutionalize an imperative mandate without the recall (yet the opposite is conceivable). Second, in the socialist tradition, the recall has been defended as a way of securing imperative mandates (Campodonico, 2016; Qvortrup, 2020). The link, however, is not necessary. We could conceive the recall as a tool that allows citizens to decide how much independence they want to grant to their representatives. By electing them, voters would give their representatives some leeway, but they would keep the 
power to decide when this trust has been abused, when the representatives have to justify their actions properly or must face a recall referendum. Thus, being compatible with some degree of independence, the recall is not disqualified by the four arguments considered above.

The question, then, is whether the degree of independence enjoyed by representatives in democracies without the recall can be considered as satisfactory. There are at least two ways of assessing this. One is to consider whether citizens are generally happy with the way they are represented. Yet the starting point of this article was precisely the widespread dissatisfaction with existing representative institutions. From citizens' viewpoint, then, even if several groups are happy with how they are represented, the independence enjoyed by representatives may look excessive to most. Citizens may of course be wrong about this, so it is worth also asking more objectively whether their preferences usually translate into policies. And the evidence about this is also quite negative: we can observe throughout wealthy democracies a "highly unequal distribution of political influence, with policy-makers responding powerfully to the preferences of affluent citizens but not at all (or even negatively) to the preferences of poor citizens" (Bartels, 2017; see also Bartels, 2008 and Gilens and Page, 2014 for the US more specifically; Rosset and Stecker, 2019 for the European context). The formal independence from public opinion enjoyed by elected representatives does not mean that their judgments will be independent from any external pressure, as we expect from judges for example. The fact is that elected representatives are heavily influenced in their decisions by lobbies, bureaucrats, businesses, civil associations, media and polls (White and Ypi, 2020, p. 195). And this influence is highly unequal, as also reflected by the effects of contributions to electoral campaigns and political parties on electoral results (Cagé, 2018). People are therefore not entirely being paranoid when they claim that their representatives do not care about what they want. Even if costless promises are usually honored $^{14}$, there is strong evidence showing that, for a diversity of reasons which it is not the place to study, majority preferences over key redistributive issues are usually neglected, to different degrees, in most if not all affluent democracies. It is judged from this perspective that the prospects of increased accountability to the majority that the recall potentially offers seem desirable.

\section{The Moral Constituency Objection ${ }^{15}$}

The majority's degree of satisfaction, however, is not the only criterion based on which democratic decisions should

\footnotetext{
${ }^{14}$ Empirical research in several political contexts shows that political representatives usually try to honor their promises (Naurin, 2011; Thomson et al., 2017; Guinaudeau and Persico, 2018, p. 236). What matters, however, is not only the proportion of promises that are honored, but also the intensity of popular preferences for some promises which are seldom honored, such as raising low wages or taxing the wealthy.

${ }^{15}$ White and Ypi (2020) discuss a distinct "constituency objection," from which I take inspiration here, but which is targeted at their preferred model-intra-party recall-and blames it for tying representatives to their partisan constituents at the expense of the rest of their constituents-the whole people.
}

be evaluated. One of the arguments for the independence of representatives from public opinion was based on fairness and the necessity to represent minorities as well. If representatives become so to speak "slaves" of the majority, the minorities are clearly at risk. Yet, morally speaking, representatives are not supposed to ignore the minorities.

Although imperative mandates would make it impossible for representatives to deviate from majority preferences, the recall, being compatible with a free mandate, is also compatible with a "recursive" representative relationship (Mansbridge, 2019), characterized by deliberative interactions between representatives and their constituents. It remains possible for representatives to try to convince voters to trust them, to explain their controversial choices and potential breaches of their electoral promises. Nothing in the recall is meant to cancel these deliberative interactions ${ }^{16}$. Thus, representatives would still have the freedom to take account of minority preferences and convince the majority that it is the right thing to do. Yet even taking this view of representation, it remains true that representatives have no right to force voters to accept the consequences of their convictions (Cronin, 1989, p. 150). Therefore, if they fail to be persuasive enough, the recall remains democratically legitimate.

A parallel argument could nonetheless point out the fact that, morally speaking, voters are not the only people elected representatives should care about. Other "moral constituents" that are not enfranchised include children, future generations, and more generally all the parties potentially affected or coerced by the representatives' decisions (Gutmann and Thompson, 1998; Benhabib, 2004; Goodin, 2007).

From this perspective, the worry is not so much that the recall would potentially bring representatives closer to the median voter's preferences. After all, there are no reasons to believe that minorities, in a specific constituency, will care more about the interests of outsiders and future generations than the majority. The worry is that by reducing the margin of independence of representatives, we would increase their ties to their political constituency, at the expense of other members of their moral constituency.

As argued before, there is no ground to believe that representatives will usually use their freedom to deviate from majority preferences in order to promote policies that benefit vulnerable foreigners or future generations. The argument has nevertheless some plausibility, for it does happen that representatives make morally justified decisions against the wishes of the majority of voters. Think about welcoming refugees, for example. We would not want to make it more difficult than it already is for representatives to rightly consider the interests of third parties when making decisions. The interesting empirical question here is whether there is any evidence that elected representatives care on average more about these unenfranchised affected parties

\footnotetext{
${ }^{16}$ They could even be increased if the recall was accompanied with a public hearing of both sides and a demand to recall initiators to specify their charges in order to allow the accused public officials to defend themselves (Cronin, 1989, p. 154).
} 
than the median voter, and whether that translates into policy choices.

The strength of this objection will heavily depend on this open empirical question. What the objection brings to light, in any event, is the limits of trying to improve democratic institutions by strengthening the grip of the majority. There are good reasons to trust the majority as a general rule (Estlund, 2008; Landemore, 2013; Goodin and Spiekermann, 2017). These reasons make it preferable to have collective decisions aligned with the preferences of the median voter rather than those of the wealthy, for example. However, governments make decisions that heavily affect the interests of third parties-foreigners and future generations in particular. And if we care about improving the fairness of those decisions, we will have to complement majoritarian institutions with others capable of bringing in collective deliberations the perspectives of outsiders. This, of course, goes beyond the scope of this article, but it helps recognizing the limits of the considered reform.

\section{The Risks of Instrumentalization and Polarization}

If we accept the theoretical arguments for trying to strengthen representatives' accountability through recall mechanisms, we still have to consider possible adverse effects of the instrument. The first risk to be taken seriously is that of instrumentalization of the recall by the opposition. Although citizens are supposed to be the initiators of a recall process, it is impossible to exclude opposition parties to influence the process in order to bring down an opponent. Even if they cannot formally initiate it, it would be easy for them to motivate citizens to do it, and then to support the recall in public debates. This is not necessarily a problem, because a recall procedure would still need to be largely supported by citizens to be successful. The risk, however, was briefly mentioned in the second section: we would not want the recall to be a tool for poor losers to systematically contest electoral results. Systematic recalls, rather than offering a safety-valve for intense feelings, might lead to polarization and mutual hatred between opposing parties, disincentivizing loyal opposition.

The empirical evidence about this is mixed. As Bowler (2004, p. 209) puts it, all recall elections are probably "a mixture of genuine grievance and spite." Yet analyzing 62 recall elections between 1998 and 2002, he found that the majority were driven by disputes over policies (45\%) or allegations of corruption or malfeasance $(17 \%)$ rather than personal grudges $(15 \%)$. In Peru, however, recall initiatives seem to have been more widely instrumentalized by coalitions of poor losers (Welp, 2016), which can generate a lot of frustration for the legitimate winners. Welp suggests that it results from two factors: (1) the comparatively high probability of success of Peruvian recall procedures, due to their procedural design; (2) the fragmentation of the partisan landscape (at the local level).

What could mitigate the temptation of instrumentalization is the finding that recall initiatives often result in the strengthening of the incumbent's position if he or she wins the recall referendum (Qvortrup, 2011). Considering this, opposition parties may be careful, as they sometimes are with impeachment procedures.
If one nevertheless wants to minimize the risks of inappropriately motivated recalls, a possibility is to empower a public body to assess the validity of the reasons supporting the recall initiative, as is the case for example in Minnesota (Bowler, 2004, p. 203), Ecuador (Welp, 2018) or Romania (Campodonico, 2016, p. 366). The assessment could be made by judges, as is usually the case, or a randomly selected citizen jury. In any case, it can be judged desirable to ask those starting the initiative to provide a justificatory statement, as in British Columbia (Qvortrup, 2011, p. 165). Channeling intense feelings may be desirable, but not any intense feeling is a legitimate motive for recalling representatives ${ }^{17}$.

Furthermore, to reduce the polarizing potential of recall procedures and make them more deliberative, some regulations are conceivable, such as requiring a public hearing of both sides and a "cooling-off" period between the end of the petition and the vote (Cronin, 1989, p. 154; Whitehead, 2020, pp. 241-242), during which the targeted representatives could abrogate an unpopular law, deliver on a popular promise or try to justify themselves and regain confidence.

The risks of instrumentalization and polarization should not be overlooked, but they need not be fatal to the proposal. If they are taken seriously enough, some procedural arrangements (as just indicated) may make these adverse effects less likely to occur.

\section{The Risk of Permanent Campaigning}

Another risk is that the availability of recall mechanisms would create a state of permanent campaigning (Bowler, 2004, p. 205; Welp, 2018, p. 461). It also seems to be the case in Peru (Welp, 2016), for example. And it is worrisome because elected representatives need time to act. Policymaking takes time, especially when it involves negotiations with different actors. Thus, if recall initiatives closely follow elections, or if representatives are continuously worried about the possibility of being recalled, it might become impossible for governments to rule effectively. What is more, rulers would have incentives to favor short-term results over the long term, which is not desirable if one considers the importance of protecting the environment or to make social investments, for example, whose benefits are not immediately identifiable and for which rulers may not have the possibility to claim credit during their time in office.

Considering this risk, recall procedures should not be too easy to enact-a point against "liquid democracy" (see Blum and Zuber, 2016), which enables citizens to recall their delegates at any point in time through technological means. There are different ways to make of the recall a last resort option rather than the norm, like increasing the threshold of signatures needed to initiate the process or reducing the number of acceptable motivations for a recall.

Furthermore, it would make sense to forbid recall initiatives in the first 2 years of a mandate, as is the case in several countries, to make sure that those who won the election have some time to act on their electoral promises and do not spend their time

\footnotetext{
${ }^{17}$ In particular, this could help reducing the risks of instrumentalization of the recall to exclude from politics minority groups suffering from hostile prejudices, such as ethnic minorities. On this risk, see (Malkopoulou, 2016), pp. 314-315.
} 
campaigning. Finally, as suggested above, we could imagine coupling the introduction of the recall with an extension of terms. In that way, the short-term would be less privileged, but citizens would not lose control over their representatives (provided that the recall is not impossible to enact either).

\section{The Harshness Objection}

A last objection that I would like to consider points to the fact that people might become more and more reluctant to run for public office if they have to fear the humiliating prospect of a public recall (Cronin, 1989, pp. 136-137). This is largely an empirical question, for which there is no clear available evidence so far (Welp, 2018, p. 460). It nonetheless raises two interesting normative sub-questions.

First, to what extent is it desirable to make public office attractive? One might think that as long as there are enough candidates for elections to be competitive, the attractiveness of public office is sufficient. The risk, however, if it is not very attractive, is to attract only some specific categories of candidates: hard-skinned, self-confident, fascinated by power. If the overall aim is to improve representation, this might be a problem. Electoral representation already suffers from a lack of social and cognitive diversity. Even without adhering to the conception of parliaments as "mirrors" of society, there are good reasons to prefer a diversified pool of representatives than a relatively homogeneous one. First, it increases the potential of identification of citizens with their representatives, and therefore possibly the perceived legitimacy of the latter. Second, it reduces the risks of biased decisions-decisions involuntarily ignoring some perspectives and privileging some social categories (Vandamme, 2020).

Second, is there a qualitative difference between not being (re)elected and being recalled? After all, candidates already face the potentially humiliating prospect of a very low electoral score. Would things be very different with a recall mechanism? What makes it potentially more humiliating is the fact that a representative's performance is not judged among many others, as is the case in legislative elections for example. The representative exposed to a recall procedure faces an individual public trial, probably with increased media attention. It does not change much compared to a presidential reelection, but compared to legislative elections (in PR systems in particular ${ }^{18}$ ), it does. Thus, introducing a recall mechanism might not dissuade people to run for the presidency, but it might take away people who would have been tempted by a less exposed public position such as MP or member of a local council.

Two arguments can nonetheless be presented in favor of harshness (at least in some cases). First, as highlighted by Rosanvallon (2015, pp. 373-379), public officials who abuse their power for private benefits do not only breach a professional duty; they also harm democracy by contributing to the disrepute of the political class. Harsh sanctions might then be justified by the need to protect democratic representation. Second, if one considers politics as a profession, the mandate could be compared to an employment contract with a fixed term, citizens as a whole being

\footnotetext{
${ }^{18}$ I come back to the distinction between majoritarian and PR systems in section Would it Work in PR Systems?
}

the employer, paying politicians' wages-an argument we briefly considered in section Arguments for Recall. The fact that a term has been fixed does not impede employers to fire their employees if they consider their work as insufficient, and certainly if they have committed a professional fault. Thus, why should we think that the recall is too harsh when most citizens daily face the threat of dismissal in their professions? The public character of the sanction might be a difference, but there are other differences that make dismissals harsher for most citizens than for politicians, such as the difficulty of finding new employment and the lower unemployment benefits they are on average entitled to. Thus, we come back to the question of whether public office should be made more attractive than average jobs-a question which is also at the core of public debates about politicians' remuneration and is beyond the scope of this article.

To conclude, there might sometimes be a trade-off between making public office attractive and making public officials accountable (pending empirical confirmation). This does not suffice to reject the recall, however, as its drawbacks must obviously be balanced with its benefits. Besides, the collective version of the recall-recalling the entire assembly-is immune to this problem.

The harshness objection, however, might be more powerful in the case of randomly selected representatives, as in citizen assemblies (Vandamme and Verret-Hamelin, 2017, pp. 15-16). One reason is that these randomly selected people, compared with candidates in elections, have not asked to be publicly exposed. The other is that these citizen assemblies are supposed to be much more descriptively representative than elected ones, because social and cognitive diversity is one of their main added values and justifications. Hence, making the position attractive matters even more.

\section{Taking Stock}

None of the objections discussed above seems fatal to the proposal. The recall does not suppress the independence of representatives; it is compatible with a recursive form of representation; it can be designed in a way that reduces the risks of instrumentalization, polarization and permanent campaigning; and although it may make public office less attractive to some people, this is unlikely to counterbalance its expected benefits.

As suggested by Whitehead (2018, p. 1346), perhaps "the recall is most useful when it is known to be available, but thought not to be needed." Considered as a last resort option, the recall may not be necessary if representatives pay sufficient attention to their constituents' wishes and behave ethically.

\section{POTENTIAL USES}

Although the objections are worth keeping in mind, because they qualify our assessment of the recall, there are thus sound theoretical arguments in favor of it, some of them backed up by empirical evidence. Yet what are the most interesting uses of the recall? Who should face the prospect of recall, and who should be allowed to initiate a recall procedure? The choice between the different possibilities will be highly context-dependent, but I would like to end with a brief overview of the options. 


\section{Who Could Be Recalled?}

The most common use of recall mechanisms is at the local level. However, there are no theoretical reasons to limit it to that level of government. President Hugo Chávez, in Venezuela (2004) and President Evo Morales, in Bolivia (2008) survived attempts at (respectively direct and indirect) recall, while President Traian Basescu, in Romania (2012), was removed from office after an indirect recall-an impeachment confirmed by a recall referendum (Welp, 2018, p. 458). Thus, the direct recall of an elected president, also introduced in 2019 in Mexico (Whitehead, 2020 ), is perfectly conceivable. The risks of polarization in case of frequent uses might be higher, but the tool could be valuable as a last resort instrument (as is the case with impeachment). What is more, it is usually at that level of government that the political frustration is the highest and that a safety-valve mechanism to channel this frustration might be the most welcome. As highlighted by Rosanvallon (2015, p. 20), with the current shift of power from the legislative to the executive witnessed in most democracies, the control of the executive by the society becomes the key issue. What is more, because the election of a single person does not provide the "representative correction" that comes with the election of a whole assembly (Rosanvallon, 2015, p. 160), because the risk is thus higher of having a population that does not recognize itself in its highest representative, the need for proper accountability appears particularly important.

In theory, elected representatives facing the prospect of recall could include the Mayor, the Governor, the head of government, but also members of the City council, members of Parliament or even ministers (at least when they have been elected).

Recalling heads of local, regional or national government might seem more intuitive than local councilors or MPs, as the former clearly have public visibility and a special responsibility. Nevertheless, it often happens that MPs face scandals and yet cannot be (or are usually not) sanctioned by their peers. The prospect of recall by the whole constituency might help keeping them in check as well. It is quite unlikely to see a massive popular mobilization against a MP, as would be the case against a Mayor or President, but the threshold of participation could be lower for MPs.

In the case of ministers, the recall might serve to express popular protest against very unpopular policies. The government would not fall each time a policy is rejected by voters, but recalling a minister could be a signal that the government is expected to change its plans. In such cases, however, abrogative referendums might be preferable ${ }^{19}$. The latter have the advantage of being less ad personam. We could nonetheless imagine allowing abrogative referendums and keeping the possibility to recall the government for cases of extreme discontent, when it is not a matter of one or two policies anymore, but a definitive breach of trust between a government and the majority of citizens.

\section{Would It Work in PR Systems?}

Is the recall applicable across electoral systems? The received wisdom is that the individual recall is only relevant in plurality and majority electoral systems, "because it requires

${ }^{19}$ I thank Maija Setälä for this suggestion. that each representative's constituents can be clearly identified" (Lijphart, 1984, p. 200). However, it seems to me that the mechanism is conceivable (although more challenging) in proportional representation systems as well (certainly for ministers and possibly also for MPs). And some might see it as desirable considering that accountability is usually more difficult to secure with coalition governments where parties blame each other for failures or unpopular decisions (Anderson, 2000; Shapiro, 2016, p. 175).

Two things would change, however, compared with the majoritarian use. First, a candidate could be elected by a set of voters and recalled by a totally different set. For example, we could imagine a Green pro-immigration candidate being recalled through an initiative stemming from the far right and supported by voters from the right and center, none of which having voted for her in first instance. Thus, under such system, elected officeholders might face new incentives to be more consensual, to protect themselves from major hostility. This would add a sort of majoritarian dimension to PR systems. In order to minimize the risks of recall, representatives from radical parties would probably have to moderate their discourses. The result could be a reduction of political diversity and more convergence toward the center-a loss of some benefits of PR systems. Alternatively, one could see the recall in PR systems (and beyond) as a tool allowing for democratic self-defense against extremist parties or candidates (Malkopoulou, 2016). Yet being at one extreme of a political field does not necessarily mean being antidemocratic or harmful ${ }^{20}$. So, it is not clear whether the recall would be an improvement to PR systems in this respect. It seems more plausible to acknowledge a trade-off between increasing accountability and representing a diversity of political perspectives.

Second, if a MP is recalled, in a PR system, the substitution mechanism should be rethought. It is not clear that the seat should go to another party. If the seat left empty were automatically allocated to the leading party in the given constituency, partisans of that party would face strong incentives to recall minor parties' candidates and regain their seats, which is not the purpose of a "safety-valve." The problem would be similar, although to a lesser degree, if the recall of a MP led to an empty seat: the majority would have a tool to strengthen its power at the expense of small parties. If the benefits of proportional representation are to be preserved, one could imagine that the recalled candidate be substituted by the next person on that party's list. Citizens would thus have to wait for the next elections to sanction a party, but they would already have the ability to sanction misbehaving or undesirable individual candidates (thereby sending a message to the party).

\section{Collective Recall}

In PR systems, however, the most frequent form of recall is collective-a citizens-initiated dissolution of the whole assembly, as currently practiced in Latvia, Slovakia and in six Swiss cantons

\footnotetext{
${ }^{20}$ What can be imagined, however, in all electoral systems, is a right to recall representatives on the ground that they defend anti-democratic views. This specific form of recall would make it a contemporary functional equivalent of the ancient practice of ostracism. See Malkopoulou, 2017, Malkopoulou (2016).
} 
(Magni-Berton and Egger, 2019, pp. 81-82). This collective recall, which could theoretically be used in majoritarian systems as well, is more spectacular than the individual one and forces the organization of new elections.

Compared to the individual version, it is less harsh for political actors qua individuals and it may be less vulnerable to risks of polarization. However, it could still be instrumentalized by an opposition confident enough about its chances of winning anticipated elections.

Another weakness may be the message sent by the dissolution of a whole assembly: that all representatives are equally to blame, all corrupt-the kind of populist rhetoric that is unlikely to strengthen representative institutions in the long run.

\section{Intra-Party Recall}

Finally, intra-party recall procedures should be considered as well (see White and Ypi, 2020). They have the massive advantage of avoiding the risk of instrumentalization by the opposition. Only registered members of a given party would be allowed to sanction an elected representative who would commit misbehavior or betray key party values, for example. And the representative in question would be replaced by another party member.

Such intra-party mechanism is actually compatible with a non-partisan recall procedure. One reason to want a general recall mechanism beyond the intra-party version is that it would potentially empower more people, given the low rates of party membership in many contexts. If we are looking for ways of restoring trust in representative institutions, we might currently have to look beyond party involvement ${ }^{21}$.

\section{CONCLUSION}

The classical, elitist conception of representation on which our representative governments were built is no longer unquestioned and "the demand for additional mechanisms of accountability is widespread and unceasing" (Whitehead, 2018, p. 1354). Maybe the time has come for rethinking the representative relationship and giving citizens a sense of their democratic responsibilities and opportunities. If we still believe that it is their role, in a healthy representative democracy, to closely monitor their representatives, having a say every $4-5$ years might not be enough.

Outside academic circles and politicized groups such as the Gilets jaunes in France, many people ignore the recall. When it is known and used, however, it is unsurprisingly a very popular instrument-not in the sense that recalls are often initiated, but in the sense that citizens value this possibility (Bowler, 2004). The reason is probably that it offers what many of them consider as lacking in traditional representative institutions: more control over the representatives of the people.

This article provided a general normative assessment of this democratic tool, based both on debates in democratic theory and on the empirical research about its use around

\footnotetext{
${ }^{21}$ Which does not mean that reforms aimed at improving participation and representation inside parties are not desirable.
}

the world. From a theoretical viewpoint, I argued that the tool could be considered valuable as it expands the opportunities to monitor representatives without jeopardizing their necessary independence. Thereby, it could contribute both to reconciling citizens with electoral representation and to improving the latter by strengthening accountability and responsiveness to the majority. Nevertheless, considering the available empirical evidence, I also tried to show why our expectations should be modest. Nothing suggests that the recall would radically transform representative institutions. By the fact of sharing many traits with elections, the procedure remains affected by many of elections' shortcomings (lack of information, manipulation of voters, costly campaigns, irrelevant votes). What is more, misuses and perverse effects are frequent and teach us to be careful when designing the mechanism. We should for example consider forbidding recalls in the first part of a term in office, extending terms, having recall initiatives' justifications checked by a nonpartisan body, providing a "cooling-off period," and organizing a public hearing of both sides. As Welp and Whitehead (2020, p. 21) warn, much will depend "on the details of the rules and on broader contextual factors which are also highly variable.”

Finally, it is worth reminding that bringing representatives closer to the preferences of the majority might be desirable, but that it will not suffice to improve the quality of representation. Firstly, because democracy is not reducible to majority rule. Secondly, because the fairness of democratic decisions also heavily depends on their capacity to take account of the legitimate interests of third parties such as foreigners and future generations. The recall might therefore contribute to improving electoral representation (and not only its perceived legitimacy), but provided it is part of a larger bundle of reforms aiming at making representative institutions more inclusive, more deliberative and more reflexive.

\section{DATA AVAILABILITY STATEMENT}

The original contributions presented in the study are included in the article/supplementary material, further inquiries can be directed to the corresponding author/s.

\section{AUTHOR CONTRIBUTIONS}

The author confirms being the sole contributor of this work and has approved it for publication.

\section{FUNDING}

This research was funded by the Fonds de la recherche scientifique (FNRS, Belgium).

\section{ACKNOWLEDGMENTS}

Many thanks to Camille Bedock, François Blais, Gwénaële Calvès, Laurence Morel, Jean-Benoit Pilet, Alex Sager, Maija Setälä, Ronald Van Crombrugge and the reviewers for their very helpful suggestions. 


\section{REFERENCES}

Achen, C. H., and Bartels, L. M. (2017). Democracy for Realists: Why Elections do not Produce Responsive Government. Princeton: Princeton University Press. doi: 10.1515/97814008 88740

Altman, D. (2010). Direct Democracy Worldwide. Cambridge, MA: Cambridge University Press. doi: 10.1017/CBO9780511933950

Anderson, C. J. (2000). Economic voting and political context: a comparative perspective. Electoral Studies, 19, 151-170. doi: 10.1016/S0261-3794(99)00045-1

Bartels, L. M. (2008). Unequal Democracy: The Political Economy of the New Gilded Age. Princeton: Princeton University Press.

Bartels, L. M. (2017). "Political inequality in affluent democracies: the social welfare deficit," in Center for the Study of Democratic Institutions, Working Paper. 5-2017.

Bauer, P. C., and Fatke, M. (2014). Direct democracy and political trust: enhancing trust, initiating distrust-or both? Swiss Polit. Sci. Rev. 20, 49-69. doi: $10.1111 /$ spsr.12071

Bedock, C. (2020). Citizens' contrasting aspirations about their political system: entrustment, participation, self-identification and control. Front. Polit. Sci. doi: 10.3389/fpos.2020.563351

Bedock, C., Schnatterer, T., Bonin, L., and Liochon, P. (2019). "Au-delà de la démocratie représentative: visions du système politique et réformes institutionnelles dans le mouvement des Gilets jaunes," in Paper Presented at the Congrès de l'Association Française de Science Politique, (Bordeaux).

Benhabib, S. (2004). The Rights of Others: Aliens, Residents, and Citizens (Vol. 5). Cambridge: Cambridge University Press. doi: 10.1017/CBO97805117 90799

Blum, C., and Zuber, C. I. (2016). Liquid democracy: potentials, problems, and perspectives. J. Political Philos. 24, 162-182. doi: 10.1111/jopp.12065

Bovens, M., and Wille, A. (2017). Diploma Democracy: The Rise of Political Meritocracy. Oxford: Oxford University Press. doi: 10.1093/oso/9780198790631.003.0001

Bowler, S. (2004). Recall and representation arnold schwarzenegger meets edmund burke. Representation 40, 200-212. doi: 10.1080/00344890408523266

Brennan, J. (2016). Against Democracy. Princeton: Princeton University Press. doi: $10.1515 / 9781400882939$

Cagé, J. (2018). Le prix de la Démocratie. Paris: Fayard.

Campodonico, F. (2016). Revisiting historical justifications of the recall procedures of elected representatives. Hung. J. Legal Stud.57, 348-372. doi: $10.1556 / 2052.2016 .57 .3 .7$

Chambers, S. (2018). Human life is group life: deliberative democracy for realists. Crit. Rev. 30, 36-48. doi: 10.1080/08913811.2018.1466852

Christiano, T. (2017). Review of Jason Brennan: Against Democracy. Notre Dame Philosophical Reviews. Available online at: http://ndpr.nd.edu/news/againstdemocracy

Clarke, N., Jennings, W., Moss, J., and Stoker, G. (2018). The Good Politician: Folk Theories, Political Interaction, and the Rise of Anti-Politics. Cambridge University Press. doi: 10.1017/9781108641357

Cronin, T. E. (1989). Direct Democracy: The Politics of Referendum, Initiative and Recall. Cambridge, MA: Harvard University Press.

Dolez, C. (forthcoming). Political support in times of personalized politics: A qualitative inquiry of French citizens' representations about political actors and the political regime.

Dyck, J. J. (2009). Initiated distrust: direct democracy and trust in government. Am. Politics Res. 37, 539-568. doi: 10.1177/1532673X08330635

Egger, C., and Magni-Berton, R. (2020). "The recall in France: a long standing and unresolved debate," in The Politics of Recall Elections, eds Y. Welp and L. Whitehead (Cham: Palgrave Macmillan), 49-72. doi: 10.1007/978-3-030-37610-9_4

Estlund, D. (2008). Democratic Authority: A Philosophical Framework. Princeton: Princeton University Press. doi: 10.1515/9781400831548

Ferrin, M. (2016). How Europeans View and Evaluate Democracy. Comparative Politics. New York, Oxford University Press. doi: 10.1093/acprof:oso/9780198766902.001.0001

Forsdyke, S. (2005). Exile, Ostracism, and Democracy: The Politics of Expulsion in Ancient Greece. Princeton: Princeton University Press.
Fuchs, D., and Klingemann, H. D. (Eds.). (1995). Citizens and the State. Oxford University Press.

Garrett, E. (2004). Democracy in the wake of the california recall. Univ. Pennsyl. Law Rev. 153, 239-284. doi: 10.2307/4150625

Gerber, E. R. (1999). The Populist Paradox: Interest Group Influence and the Promise of Direct Legislation. Princeton: Princeton University Press.

Gherghina, S. (2017). Direct democracy and subjective regime legitimacy in Europe. Democratization 24, 613-631. doi: 10.1080/13510347.2016.1196355

Gilens, M., and Page, B. I. (2014). Testing theories of American politics: elites, interest groups, and average citizens. Perspect. Politics 12, 564-581. doi: 10.1017/S1537592714001595

Goodin, R. E. (2007). Enfranchising all affected interests, and its alternatives. Philos. Public Affairs 35, 40-68. doi: 10.1111/j.1088-4963.2007.00098.x

Goodin, R. E., and Spiekermann, K. (2017). An Epistemic Theory of Democracy. Oxford: Oxford University Press. doi: 10.1093/oso/9780198823452.001.0001

Guinaudeau, I., and Persico, S. (2018). Tenir promesse. Revue Franç. Sci. Polit. 68, 215-237. doi: 10.3917/rfsp.682.0215

Gutmann, A., and Thompson, D. F. (1998). Democracy and Disagreement. Cambridge, MA: Harvard University Press.

Kelsen, H. (1929). The Essence and Value of Democracy. Plymouth: Rowman and Littlefield.

Landemore, H. (2013). Democratic reason: Politics, Collective Intelligence, and the Rule of the Many. Princeton University Press. doi: 10.23943/princeton/9780691155654.001.0001

Lax, J. R., and Phillips, J. H. (2012). The democratic deficit in the states. Am. J. Political Sci. 56, 148-166. doi: 10.1111/j.1540-5907.2011.00537.x

Lijphart, A. (1984). Democracies: Patterns of Majoritarian and Consensus Government in Twenty-One Countries. New Haven: Yale University Press. doi: $10.2307 / j . c t t 1 w w 3 w 2 t$

Lupia, A. (2006). How elitism undermines the study of voter competence. Crit. Rev. 18, 217-232. doi: 10.1080/08913810608443658

Madison, J. (1787). The Federalist: The Essential Essays. eds A. Hamilton, J. Madison, and J. Jay Bedford.

Magni-Berton, R., and Egger, C. (2019). RIC: le Référendum D’initiative Citoyenne Expliqué à tous. Au Cour de la Démocratie Directe. Limoges: FYP éditions.

Malkopoulou, A. (2016). De-presentation rights as a response to extremism. Crit. Rev. Intern. Soc. Polit. Philosophy 19, 301-319. doi: 10.1080/13698230.2016.1144856

Malkopoulou, A. (2017). Ostracism and democratic self-defense in Athens. Constellations 24, 623-636. doi: 10.1111/1467-8675.12285

Manin, B. (1995). Principes du gouvernement représentatif. Calmann-Lévy 2012.

Mansbridge, J. (2019). “Recursive representation," in Creating Political Presence: The New Politics of Democratic Representation, eds D. Castiglione and J. Pollack (Chicago, IL: University of Chicago Press), 298-338.

Marx, K. (1871/1972). The civil war in France. Moscow: Progress Publishers.

Matsusaka, J. G. (2004). For the Many or the Few: The Initiative, Public Policy, and American Democracy. Chicago: University of Chicago Press. doi: 10.7208/chicago/9780226510873.001.0001

Naurin, E. (2011). Election Promises, Party Behaviour and Voter Perceptions. New York, NY: Palgrave Macmillan.

Peters, Y. (2016). Zero-sum democracy? The effects of direct democracy on representative participation. Political Stud. 64, 593-613. doi: $10.1177 / 0032321715607510$

Pitkin, H. F. (1967). The Concept of Representation (Vol. 75). Univ of California Press.

Przeworski, A. (2018). Why Bother With Elections? Cambridge, MA: Polity Press.

Przeworski, A., Stokes, S. C., and Manin, B. (eds.). (1999). Democracy, Accountability, and Representation. Cambridge University Press. doi: 10.1017/CBO9781139175104

Qvortrup, M. (2011). Hasta la vista: a comparative institutionalist analysis of the recall. Representation 47, 161-170. doi: 10.1080/00344893.2011.581067

Qvortrup, M. (2020). "The political theory of the recall. A study in the history of ideas," in The Politics of Recall Elections, eds Y. Welp and L. Whitehead (Cham: Palgrave Macmillan), 29-48. doi: 10.1007/978-3-030-37610-9_3

Rosanvallon, P. (2015). Le Bon Gouvernement. Paris: Éditions du Seuil.

Rosset, J., and Stecker, C. (2019). How well are citizens represented by their governments? Issue congruence and inequality in Europe. Eur. Polit. Sci. Rev. 11, 145-160. doi: 10.1017/S1755773919000043 
Rousseau, J. -J. (1762/2008). Du Contrat Social. Paris: Flammarion.

Schiffino, N., Jacquet, V., Cogels, M., and Reuchamps, M. (2019). Les gouvernants face aux transformations de la démocratie. Le point de vue des ministres et des présidents de partis. Gouvern. Action Publique 2, 57-80. doi: 10.3917/gap.192.0057

Shapiro, I. (2016). Politics Against Domination. Cambridge, MA: Harvard University Press. doi: 10.4159/9780674970045

Somin, I. (2013). Democracy and Political Ignorance: Why Smaller Government is Smarter. Stanford: Stanford University Press.

Thomson, R., Royed, T., Naurin, E., Artés, J., Costello, R., Ennser-Jedenastik, L., et al. (2017). The fulfillment of parties' election pledges: a comparative study on the impact of power sharing. Am. J. Polit. Sci. 61, 527-542. doi: 10.1111/ajps.12313

Tonge, J. (2019). Petitions, polling stations and paisley: the first outworking of the recall of MPs act 2015. Political Q. 90, 143-147. doi: 10.1111/1467-923X.12640

Tormey, S. (2015). The End of Representative Politics. Cambridge, MA: Polity Press.

Tridimas, G. (2016). Conflict, democracy and voter choice: a public choice analysis of the Athenian ostracism. Public Choice 169, 137-159. doi: 10.1007/s11127-016-0379-7

Urbinati, N. (2006). Representative Democracy: Principles and Genealogy. Chicago: University of Chicago Press. doi: 10.7208/chicago/9780226842806.001.0001

Vandamme, P. É. (2020). What's wrong with an epistocratic council?. Politics 40, 90-105. doi: 10.1177/0263395719836348

Vandamme, P. E., and Verret-Hamelin, A. (2017). A randomly selected chamber: promises and challenges. J. Public Deliberation 13:1. doi: 10.16997/jdd.271

Welp, Y. (2016). Recall referendums in Peruvian municipalities: a political weapon for bad losers or an instrument of accountability? Democratization 23, 1162-1179. doi: 10.1080/13510347.2015.1060222
Welp, Y. (2018). "Recall referendum around the world: origins, institutional designs and current debates," in The Routledge Handbook to Referendums and Direct Democracy, eds L. Morel and M. Qvortrup (Abingdon, NY: Routledge).

Welp, Y., and Whitehead, L. (eds.). (2020). "Recall: democratic advance, safety valve or risky adventure?" in The Politics of Recall Elections (Cham: Palgrave Macmillan), 9-28. doi: 10.1007/978-3-030-37 610-9_2

White, J., and Ypi, L. (2020). "Reselection and deselection in the political party" in The Politics of Recall Elections, eds Y. Welp and L. Whitehead (Cham: Palgrave Macmillan), 179-200. doi: 10.1007/978-3-030-37 610-9_10

Whitehead, L. (2018). The recall of elected officeholders the growing incidence of a venerable, but overlooked, democratic institution. Democratization 25, 1341-1357. doi: 10.1080/13510347.2018.14 55665

Whitehead, L. (2020). On reconciling recall with representation. Welp Whitehead 2020a, 229-248. doi: 10.1007/978-3-030-37610-9_12

Conflict of Interest: The author declares that the research was conducted in the absence of any commercial or financial relationships that could be construed as a potential conflict of interest.

Copyright (c) 2020 Vandamme. This is an open-access article distributed under the terms of the Creative Commons Attribution License (CC BY). The use, distribution or reproduction in other forums is permitted, provided the original author(s) and the copyright owner(s) are credited and that the original publication in this journal is cited, in accordance with accepted academic practice. No use, distribution or reproduction is permitted which does not comply with these terms. 


\title{
Political Representation in Liquid Democracy
}

\author{
Chiara Valsangiacomo ${ }^{1,2,3 *}$ \\ ${ }^{1}$ University of Zurich, Zürich, Switzerland, ${ }^{2}$ Institute of Political Science, Faculty of Arts, University of Zurich, Zürich, Switzerland, \\ ${ }^{3}$ Chair of Political Philosophy, Zürich, Switzerland
}

OPEN ACCESS

Edited by:

Pierre-Etienne Vandamme, Université libre De Bruxelles, Belgium

Reviewed by:

Chiara Destri,

UMR7048, Centre De Recherches Politiques De Sciences Po (CEVIPOF),

France

Valeria Ottonelli,

University of Genoa, Italy

*Correspondence:

Chiara Valsangiacomo chiara.valsangiacomo@uzh.ch

Specialty section: This article was submitted to Elections and Representation,

a section of the journal Frontiers in Political Science

Received: 05 August 2020 Accepted: 15 January 2021 Published: 25 March 2021

Citation: Valsangiacomo C (2021) Political Representation in Liquid Democracy.

Front. Polit. Sci. 3:591853.

doi: 10.3389/fpos.2021.591853
This article provides an in-depth survey of political representation in Liquid Democracy (LD). More precisely, it refutes two potential criticisms: 1) LD impoverishes the concept of political representation relative to existing representative democracies; 2) LD undermines the centrality of political parties. In answer to (1), the article shows that LD is compatible with a selection model of representation, in which proxies are characterized as gyroscopic representatives, driven by intrinsic motivation and indifferent to sanctions. This claim has farreaching normative implications for the mandate-independence tradeoff, anti-elitism, and deliberation under $L D$. With regard to (2), the article examines the function of parties, arguing that, although it puts parties and interest groups on a level playing field, LD does not threaten partisanship, but rather expands the range of potential carriers of partisanship. In addressing these objections, this article demonstrates the democratic credentials of $L D$, showing that $\mathrm{LD}$ is compatible with a high-quality, democratic understanding of representation, which is surrounded by a cluster of thick concepts like commitment, intrinsic motivation, alignment of objectives, sympathy, trust, and dialogue. This turns LD into a powerful instrument for the refurbishment of representation both as a unique mode of political participation and as a practice of self-government.

Keywords: political representation, liquid democracy, substantive and gyroscopic representation, selection model of representation, political parties and interest groups, carrier of partisanship

\section{INTRODUCTION}

Liquid Democracy (LD) is a timely, alternative model of collective decision-making that challenges traditional models of electoral representation. LD can be considered a technologically enhanced democratic innovation, containing elements that could help remedy the shortcomings of existing representative-democratic systems, by opening up democracy to citizen participation outside of elections (Landemore, 2020, Ch. 5). The core idea behind LD is that, for each issue to be decided, each citizen has a single vote that can be transferred to a trusted person (or 'proxy') at will (Miller, 1969, 108). In other words, citizens can freely decide whether to cast their vote directly or to delegate it, with a given citizen potentially choosing different proxies for different topics (Blum and Zuber, 2016, $165,168-169)$. Anyone can become a proxy, meaning that the number of 'elected' representatives is potentially unlimited (Tullock, 1967, 145-146). Metadelegation, in turn, allows proxies to transfer their delegations to other proxies, with the caveat that the original voters can withdraw the delegation at any time (Ford, 2002, 4; Green-Armytage, 2015, 199). Significantly, LD uses a weighted-voting system, in which voters who cast their ballot directly have a single vote, while proxies cast all of the votes that have been transferred to them plus their own vote (New York Times, 1912; Alger, 2006). This entire process is facilitated by the use of information and communication technologies. In the present article, I adopt the following working hypothesis: In a population with universal suffrage, LD 
can be used as a voting scheme for governmental policymaking, at the local, regional, and national levels. In other words, LD can be integrated into existing democratic systems, potentially replacing existing electoral processes and reshaping current legislative mechanisms.

That LD is intrinsically concerned with representation is clear from the following concise definition: LD is a decision-making or policy-making scheme based on voluntary delegation and proxy voting, combining aspects of both direct and representative democracy (Valsangiacomo, 2020). On the one hand, LD is direct because citizens enjoy the right to represent themselves and to engage in legislative, issue-specific (German: sachunmittelbar) participation. On the other hand, the representative element in $\mathrm{LD}$ is much more equivocal: For example, can proxies be compared to today's elected members of parliament, or are they a whole new kind of representative? What is their role and what should we expect from them? How does delegation alter the relationship between citizens and representatives? In other words, it is not yet clear how representation in $\mathrm{LD}$ should be conceptualized and how it compares to existing forms of democratic representation. A study of this topic is thus needed, especially since scholars are starting to view $\mathrm{LD}$ as a potential complement to or even substitute for traditional representative democracies (e.g., Blum and Zuber, 2016; Landemore, 2020; Valsangiacomo, 2020).

The aim of this article is thus to conduct an in-depth survey of the concept of political representation in LD, in order to assess its democratic credentials, as well as to identify its role in and value for contemporary democratic theory. To this end, two specific gaps in the literature on representation in $\mathrm{LD}$ have been identified, which, if taken seriously, could make LD susceptible to criticism. The first criticism is that $\mathrm{LD}$ impoverishes the concept of political representation in contrast to the virtues associated with representative democracy. To address this objection, more needs to be said about the nature of the proxy-voter relationship, particularly the danger that LD might be reduced to a form of minimalist electoral democracy, in which representation is little more than a transaction scheme of delegations. The second criticism is that LD undermines the central role of political associations (especially parties) due to its focus on proxies and voters qua individuals. In answer to this critique, more needs to be said about political parties and partisanship in LD, particularly the problematic assumption that parties would be superfluous in LD. The article is structured as follows: In Political Representation in Danger, I lay out the groundwork and explain why we should pay attention to political representation in LD. In Of Citizens and Proxies, I address the first gap relating to the voter-proxy relationship. In $O f$ Parties and Partisanship, I examine the problem of political associations. Finally, in Conclusion, I provide a summary of the results, as well as a brief discussion of their relevance.

\section{POLITICAL REPRESENTATION IN DANGER}

LD is intrinsically concerned with representation, but not all forms of political representation are acceptable from a democratic point of view. This section therefore aims to characterize political representation in LD from various angles. It begins by showing that LD inherently fulfills the requirements of the so-called 'formalistic' and 'descriptive' aspects of political representation. ${ }^{1}$ It then provides a brief clarification of what is at stake in discussions of political representation in democracies, which supports my claim that more research is needed to understand how, if at all, representation in $\mathrm{LD}$ can be conceptualized from a more 'substantive' perspective. Finally, this section outlines the two gaps in the research that will be addressed more thoroughly in the following sections.

A clear-cut, analytic, and uncontroversial definition of political representation is absent from the extensive literature on this topic (Rehfeld, 2018, 218-221). For many political theorists of different orientations, representation is the making present (in a non-literal or non-physical sense) by some party of another party, who is absent or otherwise excluded (e.g., Pitkin, 1967, 9; Plotke, 1997, 27; Runciman, 2007; Lacey, 2017, 54; Castiglione and Pollak, 2018, Ch. 1). What distinguishes political representatives from other types of representatives is mainly their acquisition of specific social and political powers (Rehfeld, 2018, 232-235). Because representation is never an end in itself, the nature of these powers will vary depending on how the function of political representation is specified (Rehfeld, 2006, 5-6). The function at issue in this article is collective decisionmaking: Proxies are selected to legislate and their powers thus include sitting in parliament, proposing and discussing policies on behalf of other citizens, and ultimately voting. As long as an eligible citizen has received delegations from other citizens according to the rules of $\mathrm{LD}$, that person must be formally recognized as a representative with all corresponding powers. This nonnormative understanding of representation coincides with the formalistic view of representation outlined by Pitkin (1967), 39; 114: Representation is a mere institutional fact governed by specific rules, which is established at the precise moment of the granting or removal of power. Pitkin distinguishes two main formalistic understandings of representation. On the authorization view, representation results from the concession of one's right to act to somebody else. Elections and sortition are examples of institutions that make such "acts of vesting authority" possible in democracies (Pitkin, 1967, 43). On the accountability view, representation is primarily defined by the accountability of representatives toward constituents. Being subject to reelection and potential removal from office is thus the precondition for elected officials to be representatives (Pitkin, 1967, 56). ${ }^{2}$ Minimalist theories of democracy typically adopt this formalistic understanding, equating democracy with elections (Przeworski, 1999, 12). In LD, proxies are clearly representatives in the formalistic sense, since 1) they are authorized to represent via delegations, and 2) these delegations can be recalled at any time. In other words, the proxies' authority derives from the delegation of voting power, a transaction that

${ }^{1}$ Here I am using Hanna Pitkin's flashbulb metaphor, according to which complex concepts are often multidimensional. In order to reconstruct their meaning, we can approach them from different angles, each of which provides a small piece of the puzzle (Pitkin, 1967, 10-11).

${ }^{2}$ Note that this debate tends to conflate accountability with responsiveness or sanctioning (Philp, 2009). I will return to this conceptual problem below. 
constitutes the foundation of political representation in LD. This transaction can be annulled by withdrawing the delegation, with citizens thus enjoying a sort of priority rule over representatives' decisions.

Descriptive representation is the accurate correspondence or undistorted resemblance between the representative and the represented (Pitkin, 1967, 60). 'Descriptive' here can refer to visible traits (e.g., physical characteristics, biological markers, class divisions, or other social identities), but also to a more substantive, inner correspondence (e.g., standpoints, shared experiences, orientations, opinions, ideas, and the like). In the latter sense, descriptive representation can, under certain circumstances, serve to enhance substantive representation and the representation of citizens' interests (Mansbridge, 1999). ${ }^{3}$ LD seems compatible with descriptive representation of this sort for two interconnected reasons. First, by enabling strong proportionality, ${ }^{4} \mathrm{LD}$ is able to provide a highly accurate image of society and to "reflect with mathematical exactness the various divisions of the electorate" (Pitkin, 1967, 61-62). In fact, advocates of proportional representation argue that it enhances the substantive representation of interests by producing a more plural and inclusive (i.e., descriptive) parliament, Second, since representation in LD is more flexible and granular, the system maximizes citizens' chances of finding their ideal proxy-their "best hope for accurate representation" (Green-Armytage, 2015, 2020). This is the result of the free choice of the proximity basis, ${ }^{5}$ the area specificity of delegations and participation, and the low barriers to participation. Above all, the possibility to choose different proxies for different issues-a unique feature of $\mathrm{LD}$-minimizes the costs of essentialism, acknowledging the obvious impossibility that any single representative can "stand for all constituents in all the thickness of their individuality" (Young, 1997, 362). Unlike 'pure' direct democrats, who claim that only citizens who speak for themselves can advance their interests properly, liquid democrats suggest refurbishing representation and making it more flexible in accommodating individuality. This means that I, as a woman, could at times be represented by other women, but also, at other times, by proxies with whom I share completely different affinities. Overall, LD fosters strong proportionality-and hence descriptive representation-along the dimensions that are (politically) most relevant to each delegator ${ }^{6}$.

\footnotetext{
${ }^{3}$ This does not reduce the need for substantive representation: Democratic representation should aim to represent substantive interests, and this often occurs without any need for descriptive representatives.

${ }^{4} \mathrm{LD}$ enables strong proportional representation thanks to the proxy-voting principle, which requires weighted voting among proxies (Valsangiacomo, 2020 , 6). Moreover, the wasting of votes is avoided to a greater extent than in existing proportional electoral systems thanks to the open-seat parliament, with no cap on the number of possible representatives (Valsangiacomo, 2020, 18).

${ }^{5}$ The idea that the criteria for proxy selection (e.g., common interest, shared identity, geographical proximity, etc.) are left to the discretion of the citizen.

${ }^{6}$ This, I would argue, is what really sets LD apart from sortition-based models of democracy. Both schemes aim to produce high levels of descriptive representation, but LD does so by empowering citizens via flexible elections, instead of alienating them via the random selection of public officials.
}

We have seen that LD is compatible with both formalistic and descriptive understandings of representation. This understanding of liquid representation is useful, but incomplete, since it neither leads to a more substantive appreciation of representation in LD nor provides guidance with respect to the proper, substantial function and legitimacy of political representation in LD, leaving us to wonder about "the nature of the activity itself, what goes on during representing, the substance or content of acting for others" (Pitkin, 1967, 114). This is problematic, because a widespread consensus exists that not every existing form of political representation qualifies as democratic (e.g., Pitkin, 2004, 336; Urbinati, 2006, 4; Urbinati and Warren, 2008, 395-397; Rehfeld, 2018, 216-218). ${ }^{7}$ Democratic representation can be seen as a form of political representation in which the intended referent either corresponds to the audience or, at least, serves as an additional, auxiliary audience (Lacey, 2017, 58, 61). ${ }^{8} \mathrm{I}$ follow other scholars in claiming that genuine democratic representation should, ultimately, aim at improving democracy, by fostering the "establishment of meaningful practices of selfgovernment" (Castiglione and Pollak, 2018, 31) and helping "to achieve the ideal of self-rule." (Lacey, 2017, 67) In other words, political representation and representative institutions are democratic when they empower citizens, for example by offering them a powerful tool for inclusion in political life, as well as for advancing their interests in public debates and collective decision-making. Democratic representation is thus "a mode of political participation” rather than exclusion (Urbinati, 2006, 4).

This raises a number of questions: Does LD dilute the concept of representation, by interpreting it in purely formalistic and descriptive terms? If not, what is the most accurate way of understanding political representation under LD? Does LD enable high-quality, democratic representation? The fear that LD reduces representation to a purely formalistic or descriptive act is not baseless. In particular, two major theoretical gaps seem to represent obstacles to a substantive understanding of representation in LD. Since an assessment of representation in LD is hardly possible without first grappling with these two problems, they must now be addressed.

First, the nature of the voter-proxy relationship in $\mathrm{LD}$ is unclear. Traditionally, political representation has been conceptualized as a principal-agent relationship (Urbinati and Warren, 2008, 389), giving rise to an alleged dilemma about whether the agents, i.e., the representatives, should be seen as mandated representatives (delegates) or rather as independent representatives (trustees) of their principals (voters). ${ }^{9}$ For Pitkin,

\footnotetext{
${ }^{7}$ Following a Rousseauian tradition, some theorists might even claim that representation can never be completely democratic (e.g., Manin, 1996; Barber, 2014), an issue that will not be addressed here.

${ }^{8}$ The intended referent corresponds to the represented party (the constituency), whereas the audience is the "the relevant group of people who must recognize a claimant as a representative" (Rehfeld, 2006, 5).

${ }^{9}$ In this article, I use 'mandate vs. independence' and 'delegate vs. trustee' interchangeably to indicate the controversy concerning the discretion enjoyed by the representative when voting. Treating these pairs as synonyms is common in the literature (e.g., Runciman, 2007; Mansbridge, 2011; Blum and Zuber, 2016), although this practice has also been criticized (Rehfeld, 2009).
} 
the mandate-independence tradeoff requires striking the right balance to avoid a "too skewed relationship." (Pitkin, 1967, 155) There are reasons to worry that LD does not achieve this balance: On the surface, the voter-proxy relationship seems to favor the principal, who, thanks to instant recall, enjoys considerably more oversight over the agent than in traditional representative democracies. As Pitkin (1967), 153 points out, when a representative is fully mandated and only carries out orders, no representation takes place: "At most he might be said to stand for them descriptively or symbolically, but not to represent them in his activity." Is this the case with LD? This first research gap is addressed in Of Citizens and Proxies.

Second, due to its unique and innovative voting scheme, LD seems not only to have an affinity with a minimalist-aggregative view of democracy, but also with an individualist-atomistic view of society. Intuitively, LD tends toward a liberal, individualistic understanding of representation, driven by the postulate that individuals are the primary, if not the only, unit of philosophical analysis (Weale, 1981, 457). Unsurprisingly, current research on LD focuses only on citizens and proxies-both qua individual subjects. Yet, several other entities would undoubtedly participate in politics under $\mathrm{LD}$, and the atomistic approach fails to explain which main actors compose the political reality of $\mathrm{LD}$, as well as the nature of the relationship between them (Hay, 2011, 470). This raises concern about entities such as political associations under LD. What would happen to parties and interest groups? Mapping this ontological terrain is necessary in order to situate LD in a broader context and to explain whether LD is compatible with any account of representation other than the classic, liberal one. ${ }^{10}$ This second research gap is addressed in Of Parties and Partisanship.

\section{OF CITIZENS AND PROXIES}

The answer to the question about the proper relationship between citizens and representatives is "the central normative problem" of representative democracy (Rehfeld, $2009,214)$. It is therefore only natural to ask: What is the most accurate way to understand the relationship between citizens and proxies in LD? On the surface, the voter-proxy relationship in LD seems to favor the voter, who formally enjoys considerable oversight over the proxy's work-at least when compared to elected officials in traditional democracies. In light of its unique features, such as voluntary delegation and instant recall, LD might look like a great tool for enabling popular control and incentivizing responsiveness (i.e., the consistency of preferences between citizens and representatives). Unsurprisingly, the reception of these features in the

${ }^{10} \mathrm{By}$ 'classic, liberal account', I mean any theory of representation that adopts an individualist, aggregative focus, a theory that emphasizes the interests of the individuals and assumes pre-political, fixed preferences. In my understanding, this is not dissimilar to what Warren calls the "standard theory of representation" (Warren, 2017, 40). literature has mostly been positive. Yet, some might worry that representation in LD ultimately veers toward a kind of imperative mandate that effectively ties the hands of the proxies. This situation would be problematic, given that, as Vandamme (2020), 2-3 shows in his contribution to this special issue, there is a strong case to be made for some degree of discretion on the part of the representatives.

Clearly, the nature of the voter-proxy relationship under LD requires more study: Is liquid representation the new bastion of popular rule, or does it unduly reduce representation to a mere transaction scheme of delegations and predefined choices? The answer lies somewhere in the middle. For instance, Blum and Zuber (2016) propose to redefine representation in $\mathrm{LD}$ as a halfway point between pure delegation and complete trusteeship. At the end of their article, they suggest that proxies should act as both delegates and trustees, arguing that the principals should ultimately decide whether the "conflict between their interests and the actions taken by the representative" is unbearable (Blum and Zuber, 2016, 180). This section takes up the challenge of elucidating how and why this should be the case. More specifically, it proposes to use the selection model of representation as a sound normative benchmark for shaping and evaluating liquid representation. In the following paragraphs, I will introduce the selection model, explain why it is apt for-and can be transposed to- $\mathrm{LD}$ (3.1), show why the instant recall complicates this claim without undermining it (3.2), and identify the normative implications of this view (3.3).

\section{Selection in Liquid Democracy}

The selection model of representation, which is opposed to a sanction model of representation, has been resurrected by Jane Mansbridge (2009). This descriptive and normative model explains representation as follows: When voters (principals) are looking for a representative (agent), they invest time in selecting agents who can be expected to act mainly for internal reasons, in line with the principals' own preferences or interests. Mansbridge also refers to these agents as "introspective" (Mansbridge, 1999, 644) or "gyroscopic" representatives (Mansbridge, 2003, 520, 2011, 624). For this dynamic to occur, three general conditions must be satisfied: first, the availability of self-motivated agents; second, the prior alignment of principal-agent objectives; and third, a relatively unproblematic and accurate selection process (Mansbridge, 2009, 370). When institutions secure these general conditions, the balance favors a selection model rather than a sanction model, ${ }^{11}$ because it becomes more efficient for the principals "[...] to invest resources, ex ante, in selecting the required type rather than investing, ex post, in monitoring and sanctioning" (Mansbridge, 2009, 369).

Creating an environment that emphasizes and favors selection rather than sanctions is desirable, because selection is akin to an

\footnotetext{
${ }^{11}$ According to Mansbridge, the sanction model is nowadays more commonly used by political scientists to explain representation: "in this model, the interests of the principals (in politics, the constituents) are assumed to conflict with the interests of their agent (the representative). The principals must therefore monitor the agent closely, rewarding the good behavior and punishing the bad" (Mansbridge, 2009, 369).
} 
"integrity-based system of public office," which solicits virtuous behavior from the representatives (Philp, 2009, 37-38). This probity, in turn, strengthens trust in and the legitimacy of representative institutions. In the following paragraphs, I will show why LD fulfills the three abovementioned conditions, which renders selection based on mutual trust less costly and more attractive, making LD a promising means for the realization of Mansbridge's selection model of representation.

First of all, it is necessary to show that intrinsically motivated agents will be widely available in LD and that they will not be driven out by extrinsically motivated, self-interested agents. Generally speaking, public offices are likely to attract agents "[...] whose intrinsic motivations include what might be called public spirit, that is, concern with the common good and at least some willingness to make sacrifices in material interest for that good" (Mansbridge, 2009, 378). This is particularly the case when, as in $\mathrm{LD}$, running for office is open to all citizens and nobody is forced to become (or is prevented from becoming) a proxy. In other words, when the choice to run is voluntary, a self-selection process is likely to take place. Self-selection prompted by intrinsic motivations is even more likely to take place if the system is free from corruption and if the pecuniary rewards are correctly balanced. In $\mathrm{LD}$, remuneration and safety could present technical difficulties: The number of proxies could be much higher than it is today, which could lead either to an explosion in the cost of elected officials or to a fall in wages for elected public officers (Ford, 2002; Green-Armytage, 2015, 203-204). Similarly, online voting poses challenges for developers and computer scientists with regard to the trade-off between secret ballot and voter-verification (e.g., Behrens et al., 2020, 43-56; Paulin, 2019, 73). Neither issue is insurmountable and both must be addressed in order to enable self-selection. Moreover, Mansbridge (2009), 380 stresses that competence itself (or specialization) fosters greater internal motivation-a condition that LD seems inherently to satisfy. LD incentivizes the diversification of candidates, meaning that proxies can run for office either as generalists or as specialists. Generalists are the equivalent of candidates today, who present a broad (partisan) policy agenda and who are willing to represent voters in all policy domains. By contrast, other proxies might prefer to mobilize only selectively, proposing a narrower or even single-issue agenda. The figure of the 'policy area expert' further favors intrinsic motivation, as proxies can selectively pick out and invest in those areas that match their own interests and expertize (Blum and Zuber, 2016, 168). Finally, perfect proportional representation is a further incentive for proxies to follow their own convictions, political visions, and judgments (and, in turn, to be less responsive to the threat of sanctions). In fact, when the competition for seats is removed, ${ }^{12}$ the risk of strategic voting on

\footnotetext{
${ }^{12}$ Competition for seats is eliminated because, if there is no limit on the number of possible proxies, there is also no quorum to enter parliament and represent others (Valsangiacomo, 2020, 6). By contrast, competition for political and legislative success is not removed. The latter, however, is arguably very different in nature and scope from the former: Electoral success is the conditio sine qua non of any political ambitions that candidates and parties might have. Elections are about getting a seat at the decision-making table, which is why they are so much harsher and more antagonistic. By contrast, once parliamentary work starts, all elected representatives know that they must accept a certain degree of openness to debate, collaboration, and compromise.
}

the part of the voters, as well as the risk of anticipatory strategies on the part of the parties, is greatly reduced if not completely eliminated (Coleman, 1995). Overall, as would be expected to happen under "appropriate conditions," proxies could more easily "sort themselves into jobs and organizations whose aims match their own intrinsic motivation as closely as possible." (Mansbridge, 2009, 381).

For the selection model to work, it is also important that the objectives of proxies and their original voters remain aligned. Here, a series of contextual variables play a vital role, affecting supply and demand with respect to aligned interests. On the supply side, Mansbridge holds that districts should be as homogeneous as possible (Mansbridge, 2009, 380). This requirement is not needed in LD, which makes use of proportional representation and in which constituencies transcend territorial borders: Any original voter can select any proxy from anywhere in the country, an arrangement that is expected to maximize the alignment of objectives, despite the diversity of opinions. ${ }^{13}$ Moreover, norms and institutions that prevent corruption are expected to keep interests aligned during the period of representation (Mansbridge, 2009, 380). Finally, the presence of policy-area experts sets the bar for competence higher, which in turn fosters intrinsic motivation, increasing the "supply of aligned potential agents" (Mansbridge, 2009, 380). On the demand side, the need for aligned objectives depends partly on the activity that the proxy is expected to perform: The selection of agents with closely aligned goals is worthwhile when the agents are hired for long-term, creative, and complex tasks requiring adaptability, flexibility, and dedication. In these circumstances, principals are more ready to tolerate some divergence and accept the agents' "selfreliance in judgments" (Mansbridge, 2011, 621). LD provides a more demand-stimulating context than existing democracies, since the proxy-mandates are, de facto, open-ended contracts that are valid until they are recalled ${ }^{14}$.

Finally, it must be shown that LD supports "accurate selection" and accommodates "the capacity to 'de-select' easily when circumstances change" (Mansbridge, 2009, 381). The availability of intrinsically motivated agents whose goals are aligned with those of the citizens is less important in cases where citizens are poorly informed about the available options. Thus, an environment is needed that favors the circulation of reliable information, so that citizens can make informed decisions about their representatives. Generally speaking, voters can rely on shortcuts, such as costly signals, good reputations, and stereotypes in order to form an opinion of the candidates' characters and goals, with the party and media systems playing a key informational role as well (Mansbridge 2009, 381). As

\footnotetext{
${ }^{13}$ Mansbridge assumes a first-past-the-post, single-member-district electoral system akin to the American one. By contrast, LD is (by nature) a proportional-representation system, and hence supports multi-member districts. As such, districts could be rather large in order to allow voters to maximize their chances of finding an ideal representative using any proximity basis they prefer. ${ }^{14}$ In order to make sure that original voters do not neglect their political duties by delegating their votes once and for all and by alienating themselves from politics, measures could be adopted such as the regular invitation to renew or withdraw one's delegations, or the convocation of formal, nationwide elections every $\mathrm{x}$-number of years.
} 
will be seen in Of Parties and Partisanship, we have no reason to doubt that parties and partisans will act as watchdogs under LD. Just as they currently do, parties and partisans will be able to act as a check on the operations of each other's elected officeholders. Similarly, a candidate's membership in a given party or political association provides citizens with a useful heuristic for evaluating his or her motivations and goals.

Finally, I argue that a unique feature of $\mathrm{LD}$, so-called metadelegation, inherently promotes accurate (de-)selection and paves the way for a selection model of representation in two interrelated ways. First, because metadelegation provides considerable epistemic value (Valsangiacomo, 2020), citizens who wish to have a wide and diverse set of representatives do not need to feel daunted by the task of finding the ultimate representative for every issue. ${ }^{15}$ Instead, they can rely on a trusted, first-level proxy who will take care of representing them in parliament or, if need be, re-delegating their vote to a further proxy. ${ }^{16}$ This provides relief to the citizens, who might feel safer "selecting on character" rather than electoral promises, agenda or expertize (Mansbridge, 2009, 381). Second, long chains of metadelegation make the idea of post-election monitoring quite unappealing and burdensome. It is true that the original voters can easily de-select the proxies via instant recall, but why would they rationally want to enter a vicious loop of making rushed decisions, regretting their badly informed decisions, going through a costly monitoring process, sanctioning the proxy, and repeating everything all over again? On the assumption that no one wants to be systematically misrepresented, the original voters are prompted to invest, ex ante, in looking for a reliable proxy, because the costs of repeatedly monitoring, ex post, the entire metadelegation chain would be too high ${ }^{17}$.

\section{A Selection Core With a Sanction Periphery}

Mansbridge argues that for representatives to stay engaged and internally motivated, they need to feel trusted and not under constant "police-patrol oversight" (Mansbridge, 2009, 385). In a selection model of representation, in which representatives are deemed to be honest and intrinsically aligned to their constituency, citizens and civil society have reason to become alarmed only if they encounter obvious wrongdoing (e.g., as reported by the media or by political adversaries). Therefore, "transparency in rationale"-e.g., making procedures,

\footnotetext{
${ }^{15}$ Note, however, that voters are free to decide whether to split their voting power among several proxies or to delegate it entirely to a single proxy. Moreover, voters could also decide to attach various restrictions to their votes, limiting for example the number of redelegations allowed (Valsangiacomo, 2020, 9).

${ }^{16} \mathrm{~A}$ first-level proxy does not need to be someone the citizen knows personally, like a friend or a relative, but can simply be someone whom the citizen can trust according to the selection model-namely someone who, given the information available, can be expected to act on the basis of intrinsic motivations and to pursue congenial policy goals.

${ }^{17}$ This seems to hold true regardless of how transparent and accessible chains of metadelegation are, since transparency does not automatically counterbalance complexity or make information more comprehensible. The question of whether $\mathrm{LD}$ is more burdensome for citizens than traditional democracies could be a topic of future empirical research.
}

information, reasons, and facts transparent-is preferred over "transparency in process"-e.g., requiring that all committee meetings be public (Mansbridge, 2009, 386). For several reasons, some degree of systematic and ongoing public scrutiny in the process is, however, unavoidable in LD. To begin with, it has been argued elsewhere that all formal decisions made by proxies (about their votes or redelegations) must be public to allow for transparency (Valsangiacomo, 2020, 14-15). In line with the "golden rule" of vote transparency (Hardt and Lopes, 2016), the original voter in LD enjoys the right to supervise the entire chain of delegation and can thus keep track of the whole process and of all the decisions made by his or her proxies at all levels of delegation. Furthermore, the sessions of the liquid parliament would be open in order to allow all individual, original voters to participate. There might be instances where representatives meet and deliberate privately, ${ }^{18}$ but the LD model tends to favor full transparency.

In an ideal selection model, not only is the close monitoring of elected officeholders considered a second-order priority, but sanctions are also seen as an option of last resort. In contrast to an ideal sanction model, where accountability is usually replaced by or even equated with full responsiveness or punishment, accountability in a selection model means rather explaining one's conduct and giving reasons for divergence. ${ }^{19}$ Whereas principals do not constantly threaten to throw agents out of office, whenever the latter's actions deviate from the former's preferences on certain issues, the agent has a duty to be narratively or deliberatively accountable and to provide reasonable explanations for this deviation to the constituency. ${ }^{20}$ However, there is one aspect of LD that appears to contradict and potentially inhibit this dynamic. The instant-recall principle puts the representatives under a sword of Damocles, since their delegations can be easily withdrawn at any time and without appeal. This creates room for a "harshness objection," to the effect that such a powerful sanctioning tool serves as an individual public trial that ultimately renders the prospect of becoming a proxy unattractive (Vandamme, 2020, 13-14). Yet, I suspect that this critique underestimates the importance and efficacy of other mechanisms that typically ensure the fulfillment of the duty of accountability in democracy, such as exposure on social media, pressure from political opponents and public opinion, systemic checks and balances, subjection to the rule of law, anti-corruption audits, and so on. Ultimately, the instant recall is an additional, lastresort option available to citizens in case of extreme misconduct or obstinacy in concealing information by the proxies.

\footnotetext{
${ }^{18}$ For instance, in the case of informal, personal meetings, but even in formal situations, if the agents deem it useful and productive. In this regard, an important, open issue concerns how to regulate the work done in and by parliamentary commissions.

${ }^{19}$ This corresponds to accountability as defined by Philp (2009), 32.

${ }^{20}$ This happens by publicly addressing the constituency at large (e.g., during a rally, at a press conference or in a public interview, on both traditional and social media, etc.), as well as in more targeted, private settings (e.g., answering messages and calls from individuals and groups, meeting with supporters, etc.).
} 
Still, one might wonder whether the ideas of instant recall and gyroscopic proxies are fundamentally compatible. Proxies might initially be self-reliant in their judgment but, over time, can their intrinsic motivations be pushed out by the pressure put on them through the looming presence of instant recall? Although this possibility cannot be ruled out at the moment, the answer seems to depend on the strength of the proxies' passionate commitment and on the ability of the instant recall to systematically undermine integrity and judgment. I suspect that 1 ) it is not the mere possibility of being recalled per se that reduces self-motivation, but rather the effective and systemic use that is made of monitoring and sanctioning and that 2) the effective, systemic resort to instant recall depends, in turn, on the ethical culture within the public system. This implies that a loop might be occur in either direction: If $\mathrm{LD}$ is implemented in a way that rather supports the sanction model, the instant recall undermines autonomy, insofar as it can be too easily seen and used as a tool for pushing the proxy into producing a predetermined result (vicious loop). By contrast, if LD is implemented in a way that supports the selection model, the instant recall does not undermine-and might even reinforce-proxies' integrity and autonomy of judgment, because their motivations are not extrinsic (virtuous loop). The core of the selection model is the assumption that, if the context permits it, voters will naturally tend to select representatives who are trustworthy, intrinsically motivated, and aligned with their own goals. By definition, these gyroscopic proxies will not change their behavior simply to avoid the potential recall of delegations, just as honest employees will not stop doing a good job only because their company could fire them at any time. Similarly, it is unclear why voters who chose gyroscopic proxies in the first place would recall their delegations over any single instance of divergence, just as it is unclear why an employer who tries to hire honest, independent employees would fire them whenever they act differently than the employer would have done. ${ }^{21}$ Therefore, by enabling open-ended mandates, the main function of the instant recall is simply to turn delegations into a kind of permanent employment contract.

To sum up, the potential dissonance between instant recall and selection should be taken as a serious and major concern. At the same time, it seems that the possibility of recalling proxies is compatible with their relative independence, when the instant recall is used in a context that favors selection in the first place. The analysis presented in the previous section shows that this is not unlikely, since there seem to be enough factors that make LD akin to Mansbridge's selective model of representation. Of course, this does not imply that the alignment of objectives is always absolute or that internal motivation is never corruptible. Even though LD promotes a selection model of representation, it is not necessary for aspects of the sanction model to disappear

\footnotetext{
${ }^{21}$ Of course, discretion can sometimes backfire: grave mistakes could still be made and the code of ethics could be infringed upon. There is no doubt that this misconduct should and would be punished, but the point of selection is that voters will largely select trustworthy and honest representatives in the first place. Moreover, it is clear that, even in a selection model, safety mechanisms, such as the rule of law or checks and balances still need to be preserved.
}

(Mansbridge, 2011, 622). Hence, even under a selection model of representation, the instant recall could be interpreted as "an additional opportunity for citizens to keep their representatives [proxies] in check" (Vandamme, 2020, 5). Indeed, this speaks in favor of the hypothesis that LD can strive to realize a selection core with a sanction periphery.

\section{Normative Implications of Selection}

There are a series of relevant normative implications that derive from coupling LD with a selection model of representation. In what follows, I discuss three important domains of LD affected by gyroscopic representation: the mandate-independence dilemma, the principle of anti-elitism, and the centrality of deliberation.

\section{Mandate Vs. Independence}

As argued by Blum and Zuber (2016), 180, LD should strike a balance between delegate and trustee views of representation. The selection model introduced above is helpful for understanding how LD manages to reconcile the autonomy and the interdependence of voters and proxies. In fact, selection depends on the existence of "self-reliant representatives who are relatively unresponsive to sanctions" (Mansbridge, 2011, 622). These gyroscopic representatives act on the basis of internal convictions. They have their own vision of the common good and are not driven by concerns about (re) election. Since their intrinsic goals are shared by their constituents, once selected, gyroscopic representatives can be entrusted with considerable discretion and autonomy of judgment. Unsurprisingly, Mansbridge (2011), 621 proposes to completely replace the notion of trusteeship with that of selection.

The concept of gyroscopic proxies clearly rescue LD from accusations that it disempowers representatives by reducing representation to a formal, descriptive fact. The distinctive role of gyroscopic proxies requires that they be granted a certain autonomy of judgment in order to successfully pursue their common projects in parliament, where they must deliberate, cooperate, and negotiate with others.

Nevertheless, autonomy of judgment does not imply the transformation of proxies into completely detached, independent trustees. There are three reasons for this: First, proxies remain aligned with their constituents through their intrinsic motivations. Second, they are answerable for their conduct to their constituents. Third, they remain subject to public scrutiny and, potentially, to the instant recall of their delegations. As mentioned above, autonomy of judgment and instant recall are not necessarily in conflict, as long as they are found in a context that favors selection, such as the one provided by LD. A given citizen chooses a representative on the assumption that this person "will act much the same way the voter would if placed in the legislature." (Mansbridge, 2003, 522) Through this fiduciary transaction, the original voters do not renounce their voting power, but instead use that power to select a proxy who shares their objectives and, if their goals are no longer aligned, to remove the proxy from office.

Just like representatives in Nadia Urbinati's theory of advocacy, proxy representation captures "the complex character of representation-its commitment to as well as its 
detachment from a cause" (Urbinati, 2006, 45). It is the "ideological as perspectival similarity" between citizens and proxies, induced by selection, which enables gyroscopic proxies to be different to and independent from, yet also similar and responsive to, their constituency (Urbinati, 2006, 50).

\section{Anti-elitism}

One condition for trust in selection and LD is the assumption that, had the original voter experienced the decision-making process directly (e.g., acquired first-hand knowledge of participation in parliamentary deliberation), that person would not have reached radically different conclusions from those actually reached by the proxy. Thus, gyroscopic representation emphasizes the idea of "likeness" or "resemblance" (Mansbridge, $2009,386,2011,623)$. One might say that the selection model places the "sympathy of ideas and views" at center stage, where sympathy does not presuppose the existential identity of representative and represented, but rather indicates "reflective adhesion" to the social specificity of one's own constituency (Urbinati, 2006, 45, 49). It serves the purpose of creating a "passionate link to the elector's cause," as well as of "nurtur [ing] the spirit of controversy" (Urbinati, 2006, 45). In other words, sympathy denotes the representatives' capacity to "possess the same sentiments and feelings" as their constituency (Mansbridge, 2009, 387), which is arguably a "more humanly satisfying” basis for a relationship (Mansbridge, 2009, 371).

From this claim, a second consequence follows, concerning the distinct anti-elitism endogenous to LD. I will argue that sympathy, in this sense, precludes any superiority on the part of the representative, as well as any serious distrust toward the represented masses. The notion of gyroscopic proxies challenges the principle of distinction, as well as democratic elitism as a broader prescriptive theory, according to which a good representative is necessarily an aristocrat, an alien who 'naturally ranks higher,' whether in terms of virtue, wisdom, intelligence, charisma, or talent. This anti-elitist and antipaternalistic normative position is central to $\mathrm{LD}$, in which the legislator is not always a representative. In fact, in the context of $\mathrm{LD}$, where the legislative body can be composed of both proxies and individual citizens, a principle of distinction is untenable, because it would delegitimize the individual citizen's direct participation in the legislature.

At the same, this normative position neither challenges the idea of a democratic division of labor nor rules out the possibility that certain social and psychological types might in reality be more likely to become proxies. After all, "[...] advocacy, like election [and like delegations], entails a selection because we seek to get the best defendant, not a copy of ourselves." (Urbinati, 2000, 76) As a matter of fact, LD has previously been characterized as epistemically superior to existing representative democracies, precisely because it is expected to mobilize more policy-area expertize (Blum and Zuber, 2016, 167-169).

Nonetheless, becoming a proxy is not a prerogative of experts or charismatic individuals. Even when citizens choose to be represented by a proxy, what matters in $\mathrm{LD}$ is the connection that such a selection enables. Proxies can differ in important respects from their constituencies and still be responsive, because they are, to a large extent, similar to them. This aspect could not be accounted for by elitist understandings of democracy. In fact, gyroscopic representation-and hence LD-eschews the hierarchy endorsed by thinkers like Edmund Burke and Joseph Schumpeter (Mansbridge, 2009, 386, 2011, 623).

Overall, “when voters say they want to select a 'good man' or 'good woman' as a representative, they often seem to want someone like them, but with the interest, competence, and honesty to be a legislator" (Mansbridge, 2009, 387). Proxies are not elected aristocrats, but trusted defendants who will advance, reproduce, and author claims within the political discourse in the name of their voters. Hence, the principle of difference in LD should be qualified, if at all, as profoundly antielitist and democratic.

\section{Deliberation}

Another important implication of the selection model is that it enables the reconciliation of LD with central tenets of deliberative democracy and, more generally, with the constructivist turn (Warren, 2017, 44). To explain why this is the case, consider first how a selection model shifts the focus from 'control over the representative' to 'control over the legislature.' In the extreme case, "a pure selection model" (Mansbridge, 2009, 390), the voters cannot be seen as properly controlling the autonomous, gyroscopic representatives. That is, voters do not aim to influence the views of their proxies. The latter are the chosen instrument through which citizens influence decision-making: "[V]oters get the legislature to do what it would otherwise not do by placing in it a representative who will pursue the policies that they favor. The voters' ultimate goal is not control over a particular representative but a fair share of control over the entire legislature." (Mansbridge, 2009, 390) Given that the pure selection model is a regulative ideal and, in practice, is often mixed with aspects of the sanction model (as in the case of LD), the shift toward 'control over the legislature' is doubly relevant for LD.

First, it further flattens out the differences between proxies and original voters, insofar as both are seen as potential legislators. It also prevents a discrepancy from emerging between those who vote directly and those who delegate. In other words, LD emphasizes collaboration in collective decision-making rather than mere participation in elections as the primordial role of citizens.

Second, deliberation once again becomes central. In the first instance, this concerns vertical communication between voters and proxies. Despite being rather unresponsive to the direct control of the represented and acting autonomously, the gyroscopic representative is not unaccountable, since they have to give an account of their actions to voters (Philp, 2009, 32). A discursive relationship-a sort of "(one-way) narrative accountability or (two-way) deliberative accountability" (Mansbridge, 2009, 384)-arizes naturally in a context in which the bond between representative and represented depends on the alignment of objectives and ideological sympathy. Here, principals can be dissatisfied with specific policies or results, but this does not really undermine trust in 
their agents as long as there exist arguments showing that the "intrinsic motivation underlying the aligned objectives remains unchanged” (Mansbridge, 2009, 384). This vertical communication implies, normatively speaking, that representatives and constituents are open to reciprocal persuasion and influence. This makes LD compatible with the notion that, beyond being an institutional matter, representation includes a dynamic, performative, and creative process as well: "Representing is performing, is action by actors" (Saward, 2006, 302). This interactive and discursive process of representation itself actively shapes the voter-proxy relationship, contributing to the construction and engagement of autonomous citizens.

At the same time, the shift of attention toward the legislature hints at the centrality of deliberation in parliament. As we have seen, proxies are expected to convey their particular views to parliament and to defend them passionately. This highlights the complex nature of the work of representatives in $\mathrm{LD}$, which goes well beyond the transmission of preferences or the mirroring of existing social configurations. In particular, gyroscopic representation presupposes the existence of a competitive parliamentary space, which is the sole forum in which representatives can meaningfully exercise their political function. In this space, gyroscopic proxies can pursue their causes, while confronting those of other representatives in accordance with the principles and procedures of democratic government. What the liquid parliament would look like and how it would work is unfortunately still unclear. What is clear is that, to rephrase Urbinati $(2006,46)$, without parliamentary deliberation, there would be no reason for gyroscopic representation or representation by proxy in LD.

\section{OF PARTIES AND PARTISANSHIP}

Even though the discussion in Of Citizens and Proxies might have already cast doubt on the ties between LD and a purely aggregative view of democracy, one might still worry about LD's affinity with a strongly individualist view of society. This concern is exemplified by the almost exclusive focus in the existing literature on citizens and proxies, both conceptualized $q u a$ individual subjects, without any reference to associational life. More questionably, an implicit assumption lingers in the literature that LD might tear down any intermediary political institutions. For example, Blum and Zuber (2016), 178 write that "[p]arties as coordinating mechanisms are superfluous since members of the community either participate directly or delegate their votes on the basis of individual relationships with their delegate."

This section therefore addresses the following questions: What happens to familiar categories of associational life, such as parties and interest groups, under LD? Does LD convert parties and party politics into zombie categories? Can the gyroscopic proxies be members of a party or must they be independent? In answer to this, I will argue that, while LD does blur the lines between parties, interest groups, and voluntary associations, it does so without necessarily eliminating party structures and, most importantly, without diluting partisanship. In what follows, I will show that the political ontology of LD can encompass more than individual citizens and proxies (4.1), outline the challenges faced by parties as organizations in LD (4.2), explain why LD does not imply the abandonment of partisanship (4.3), and discuss whether individual proxies can be partisan (4.4).

\section{Associational Life in Liquid Democracy}

The claim that LD threatens associational life as such is misleading. Unless the right of association is explicitly forbidden, no form of government can prevent the formation of groupings in civil society. It is, therefore, more meaningful to ask whether LD poses a challenge to associational life as we know it. Since it would be impossible to fully cover this broad topic here, I will restrict my analysis to political associations. This kind of association is characterized by the fact that it is usually voluntary, collective (non-intimate), and based on a common purpose, which is embodied by an extrinsic political goal (Brownlee and Jenkins, 2019). Two political organizations, in particular, stand out for their unique institutional role as political intermediaries and deserve special attention: political parties and interest groups $^{22}$.

Political parties and interest groups are among the central research topics in political science. ${ }^{23}$ From a formal point of view, they are usually conceptualized as quite similar, but nonetheless distinct entities. On the one hand, they share important attributes. For instance, both parties and groups are political associations that actively mediate the relationship between society and government. Both attract citizens and mobilize them to action and both seek to influence policymaking. On the other hand, parties and groups differ in certain respects. Most importantly, modern parties are the only political group or association explicitly organized for the sake of exercising power or governing: Only parties formally compete for offices and vie for electors' votes (White, 2006, 2-3). Analytically speaking, Rosenblum sets parties apart from other groups on the basis of three distinguishing features: 1) context, because parties emerge only in political societies where there is government and where there are offices to be held; 2) aims, because parties are institutions dedicated to ongoing political activity, which operate in public view and are able to hold office, as well as to participate in government; 3) members, because modern parties have a large partisan base, which attracts a substantial number of followers (Rosenblum, 2008, 18-21).

Legally speaking, in almost all existing democracies, political parties are legal entities whose formal role is usually protected by the constitution and/or statutory party laws (Rosenblum, 2008, 419). Parties thus differ from other political associations, insofar as they are the only entities legally permitted to participate in the electoral process. Other associations are relegated to nonelectoral representation at best, being de facto precluded from playing a direct role within the electoral process, hence organized

\footnotetext{
${ }^{22}$ Also known as interest groups, pressure groups, advocacy groups, or lobbies.

${ }^{23}$ The literature on this topic is rich and extensive and cannot be done justice here. The following discussion will necessarily be quite abstract and its conclusions will ideally be relevant for all possible cases and types of political parties and interest groups.
} 
interest groups typically seek to exert influence over policymaking by pressuring elected officials ${ }^{24}$.

LD seemingly calls this formal-legal artifact into question, because interest groups can take on a more direct role as they find new and affordable points of entry into policymaking. In fact, as a result of policy-area expertize, LD offers any pressure group the opportunity to selectively engage in electoral representation in its area of competence and interest. If, for example, members of the car-manufacturing industry support looser regulations on carbon emissions, they can select a group proxy to campaign and defend their cause, instead of lobbying an elected representative. At the same time, in place of, or in addition to, street protests to block this new law, members of environmental associations can vote en masse against it $^{25}$.

Blurring the traditional division between parties and other associations raises manifold questions: Which groups should own or join the electoral and legislative process? Is it normatively problematic to put parties and groups on a level playing field? That is, can interest groups be agents of democratic representation? The classic (legal) distinction is clearly useless for addressing these questions in the context of LD: Parties are, by definition, those associations allowed to participate in elections and lawmaking and if all groups suddenly enjoy this right, distinguishing parties from interest groups will become impossible. A clearer understanding of the role of parties in representative democracies is thus needed. Parties have both a pragmatic and a substantive value for democracy, and it is crucial to assess whether LD is at risk of losing this, by blurring the boundary between parties and interest groups. The next two subsections will address these aspects of parties, showing that LD challenges party structures without necessarily endangering partisanship itself.

\section{A Challenge for Party Structure and Its Functions}

Modern parties appear essential to democratic practice and no existing democracy seems able to do without them. Indeed "modern democracy is unthinkable save in terms of parties." (Schattschneider, 1942, 1) The list of beneficial functions typically assigned to parties is long: e.g., parties identify and trace conflict lines, create political agendas, monitor each other and check the executive, mobilize and educate voters, aggregate interests and opinions, and act as intermediaries between government and civil society (Sartori, 2005, 23-24). According to Rosenblum (2008), Ch. 3, parties have come to fulfill two valuable functions in democracy: First, they regulate competition, making managed, non-violent conflict possible-or as Fossum (2018) puts it, they enable the

\footnotetext{
${ }^{24}$ In some circumstances, interest groups can participate in policymaking via consultation. This is the case in countries that adopt elements of neocorporatism, like tripartism in many European countries or the Vernehmlassungsverfahren in Switzerland and Austria.

${ }^{25}$ Although it fails to clearly distinguish between members, partisans, and activists, this example is quite illustrative of how the political landscape might radically change under LD.
}

peaceful handling of conflict. Second, since they possess the capacity, resources, and willingness to effectively run the government, they are also responsible for governing.

Most pragmatic appreciations are based on a clear understanding of the party qua organization. The party is a collective agent that intentionally coordinates political actions, endowed with "an internal decision-making structure all its own" (Goodin, 2008, 206). In other words, its essence and value is perceived to lie in its formal, bureaucratic apparatus: "[...] the formal machinery of party ranging from local committees (precinct, ward, or town) up to state central committees, and the people who man and direct there." (White, 2006, 5) The political party therefore becomes synonymous with "The Organization" or "The Machine" that is prized for its institutional value (Rosenblum, 2008, 172-175).

In $\mathrm{LD}$, however, this machinery comes under pressure because, as we have seen, parties are no longer the sole form of association capable of participating in elections and government. Whether this would result in the elimination of party organizations is difficult to predict. I suspect, however, that this fear is overblown. LD does not do away with competition for delegations, such that the most ambitious proxies, at least, might still need to unite around common platforms in pursuit of political success. ${ }^{26}$ Moreover, if party structure represents the most successful organizational model, many smaller and informal political associations might be incentivized to reorganize themselves along these lines. The loss of parties qua organizations thus seems problematic only on the assumption that interest groups and other political associations, with their different structures, will be unable or unwilling to fulfill the functions that parties typically fulfill in a democracy. After all, if different organizational structures can produce the same outcome, the disappearance of parties is not an objection to LD. Indeed, even Goodin's imaginary "noparty democracy" could salvaged by the presence of some form of lists, slates, parties, factions, or groups that provide some intentionality and coordination (2008, 2005-206).

The opening of the parliamentary arena to associations other than political parties could nevertheless create new problems. For example, a scenario in which a myriad of different interest groups join the policymaking process qua special-interest groups would pave the way for a pluralist or corporatist theory of democracy, based on the highly contentious notion of functional representation (Couperus, 2019). This is also problematic because "[a]rrant interest group pluralism is not just chaotic and an obstacle to coherent policy; the result can be 'ungovernability."' (Rosenblum, 2008, 133). ${ }^{27}$ Future studies could further investigate these pragmatic arguments against LD.

\footnotetext{
${ }^{26}$ This idea of partisan proxies will be developed in more detail in Independent and Partisan Proxies.

${ }^{27}$ Without considering, in addition to the danger of ungovernability, other equally problematic consequences, like the aggravation of extreme inequalities among groups, the overrepresentation of small, powerful groups, and the resulting specter of oligarchy.
} 


\section{Boosting Partisanship}

Any defense of the instrumental role of parties would be incomplete without a demonstration that parties perform their function "in a way that is compatible with democratic principles." (Chapman, 2020, 3) This more substantial, 'philosophical' appreciation has been developed in recent years by a handful of political theorists (Rosenblum, 2008; White and Ypi, 2011; Muirhead, 2014; Efthymiou, 2018). These theorists agree on many points, above all on the emphasis placed on partisanship as a "regulative ideal" for democracy (Chapman, 2020, 3-5). Partisanship is variously defined as "the distinctive political identity of representative democracy" (Rosenblum, 2008, 366), as "a practice that involves citizens acting to promote certain shared normative commitments according to a distinctive interpretation of the public good" (White and Ypi, 2011, 382), as "commitment to a political party" (Efthymiou, 2018, 194), as "the political orientation of citizens who stand with a party" (Muirhead, 2006, 714), and finally as "party spirit" or spirited and prideful identification (Muirhead, 2014, x). Behind all these definitions lies the idea that partisanship bears a certain moral distinctiveness and "exhibits normatively valuable qualities" (Efthymiou, 2018, 195). According to Rosenblum (2008), 362, partisanship entails "identification with others in a system of regulated rivalry." It is a form of social identity that is more inclusive and comprehensive, rendering those who possess it more ready to compromise compared to other identities, which can be included in-but are always altered and transcended by-partisan identity. Partisans are intimately and inextricably connected to representative democracy, and representative democracy, in turn, benefits from partisans. Where partisanship is widespread, there is acceptance of opposition, awareness of the provisional nature of politics and, most importantly, acknowledgment of one's own partiality. Where partisanship emerges, politics is more stable, participative, and creative. A partisan citizen "displays a democratic sympathy, a willingness to compromise, to give and to take, and (perhaps most of all) to bear the burdens of standing with one's fellow citizens" (Muirhead, 2006, 719).

An important element that cuts across all these works is the explicit choice to conceptualize partisanship separately from parties as organizations. These thinkers all conclude that partisanship is a fundamental virtue, which should be preserved and defended in any healthy democratic system, because it is the only political identity that genuinely enables political pluralism in representative democracy. For some thinkers, a certain ethics of partisanship must be adhered to in order to realize this regulative ideal (Muirhead, 2006, 724; Rosenblum, 2008, Ch. 8). However, the implications of this conclusion for parties as organizations are not straightforward. On the one hand, none of the thinkers cited is particularly indulgent with regard to the status quo of contemporary party politics. They clearly foresee the possibility that existing party organizations may fail to live up to their regulative ideals. On the other hand, the plea for partisanship seem to entail an implicit justification of parties, insofar as partisan organizations are conceptualized as the carriers of partisanship par excellence. ${ }^{28} \mathrm{I}$

${ }^{28}$ This is argued most emblematically and convincingly in Rosenblum (2008), Ch. 7, but see also Muirhead (2014), 110, as well as White and Ypi (2011), 393. hypothesize that this conclusion is valid only under the assumption that party organizations have a legal monopoly on running for office-an assumption that disappears in LD.

At this stage, an important question remains unsettled: Are partisans the only legitimate carriers of partisanship, or can interest groups do just as well? The idea of interest groups as carriers of partisanship is likely to provoke skepticism, because groups generally "retain much of the stigma of factions in relation to the general interest." (Epstein, 1986, 25) It is implicitly assumed that interest groups do not serve the public good and do not even want to-they merely pursue their narrow, sectarian self-interest. Interestingly enough, although a party, too, represents only part of society, it is acquitted of the charge of factionalism because it advances a conception of the public good, "a comprehensive public story about the economic, social, and moral changes of the time and about national security." (Rosenblum, 2008, 358) What prevents us from drawing the same conclusion about interest groups? The existing literature on partisanship does not seem to provide a straightforward answer.

White and Ypi (2011), 384 argue that the distinction between parties and factions (and hence, between parties and interest groups) hinges on their declared aims and motivations: "[...] at stake is not whether, in the eyes of the observer, a political grouping reliably does serve the public good [...], but whether it seeks to do so given the kinds of argumentation it pursues." The effort to put forth such a comprehensive vision of the common good explains the intuitive distinction between a niche or singleissue party, like the Green Party, and any other environmental association. A party is not a party "unless it integrates [its] interests into a wider normative vision addressed to the good of the political community at large." (White and Ypi, 2011, 384) Following this logic, it appears that an interest group can be or become a party (in the sense of being a carrier of partisanship) as long as its members stand together and publicly declare that the particular policies they promote ultimately serve justice, in a broader sense, and public interest. ${ }^{29}$ This shifts the focus to justification and the necessity of publicly defending one's partisan cause against adversaries. Partisanship therefore fuels collective discussion and partisans are the agents of "trial by discussion" (Rosenblum, 2008, 7).

To summarize, LD does not seem to threaten partisanship merely by creating a level playing field between parties and interest groups, because the associational form that partisanship takes is less significant than its content or motivation. Thus, whether partisanship is expressed via interest groups or via parties is normatively irrelevant: "[...] partisanship as a practice does not always follow closely the contours of party membership: It will extend beyond the face-toface contacts of membership to a broader network of political activists seeking to advance largely the same goals, even in the absence of formal attachments." (White and Ypi, 2011, 382). The

\footnotetext{
${ }^{29}$ However, it remains unclear how comprehensive such a notion of the common good must be in order to qualify as legitimate or acceptable. In the case of niche parties, for example, this vision can be very limited, which complicates the task of differentiating parties from groups. I cannot resolve this issue here.
} 
size of the association or the number of issues on its electoral agenda should not be what distinguishes parties from groups, but rather the bona fide attempt to "persuade people of their stand on the great debate of contemporary [American] politics concerning the scope of the national government." (Muirhead, 2014, 264).

LD fosters a more pluralistic partisanship conveyed by new, non-party actors. From this, it does not follow that all interest groups will become carriers of partisanship under LD, nor is it clear why interest groups would attempt to articulate a comprehensive vision of the public good. My analysis does, however, suggest that much of the traditional differences between parties and interest groups might result from an adaptational strategy, in which different behaviors and purposes result from the opportunities given by the political system. By opening up the system and changing its rules, LD might alter the behaviors of parties and interest groups, thus forcing us to adapt our understanding of them.

\section{Independent and Partisan Proxies}

An attack on the concept of independence is the flip side Rosenblum's defense of parties. In her eyes, the independent politician is faithless and detached, consciously disavowing partisanship (Rosenblum, 2008, 327). Her core argument is that independence (particularly, the progressive, American model of independence) is morally weightless and an inappropriate democratic ideal. Their refusal of partisan identity is an admission of detachment from society, yet independents "lack the drama of radical individualism with its global rejection of association and membership-Thoreau's alienation from civil society and revulsion at the thought of joining." (Rosenblum, 2008 , 351) They simply refuse to act politically alongside others, using independence as "a mask for political vacillation, weakness, inconsistency of temperament or self-interest." (Rosenblum, 2008, 349) Nor are independents necessarily impartial or neutral. In fact, their rejection of any partisan identity makes one wonder whether they are not simply pursuing self-interest or some hidden, sectarian goal. If partisanship is the engine that drives citizens to exercise collective political agency and a source of the democratic ethos (White and Ypi, 2010), its explicit disavowal makes independents suspicious figures at best.

The puzzle remains of whether or not LD has the inexorable tendency to promote an individualist politics based on the personalities of nonpartisan proxies. Do gyroscopic proxies not resemble independents? I do not believe so, since proxies are more likely to have a collective, partisan nature.

A non-partisan or independent proxy is someone who decides to run without any affiliation to an existing party (or interest group), exercising his or her own sole judgment about the common good and free from all partisan influence. This pure independent is a zealous and romantic intellectual opponent, a self-styled impartial moderator with great moral and political integrity. While this might sound like the ideal of the gyroscopic proxy, acting out of intrinsic conviction and indifferent to (re)election or power, this is not the case. An 'independent proxy' might be supported by many voters, but he or she nonetheless stands alone like an atom, unwilling to make any "good faith effort to stand with a group striving for democratic legitimacy" (Muirhead, 2014, 89). By contrast, commitment is fundamental to partisanship, which possesses normative value precisely because the passionate commitment to a partisan cause, coupled with tight interpersonal networks, is known to promote political knowledge and participation (Mutz, 2006, 3, Ch. 5). Earlier, I defined the gyroscopic proxy as a public-spirited representative who is intrinsically committed to his or her constituents' objectives. I now argue that this commitment to a common cause is responsible for the natural affinity between gyroscopic proxies and partisanship and that-since the notion of partisanship as a social identity entails the inescapable necessity and will to act with others-it promotes a sense of community or even friendship (Efthymiou, 2018, 196). Moreover, I also argue that proxies are compatible with partisanship because the proxy-voter relationship in LD is trust-based, comprising the alignment of objectives together with sympathy and likeness. In addition to being a possible member of a partisan organization, each proxy is also a potential carrier of partisanship, who stands for "a body of men united, for promoting by their joint endeavors the national interest, upon some particular principle in which they are all agreed." (Edmund Burke, cited in White, 2006, 2).

That said, LD tends to promote a multi-party system characterized by comparatively high levels of fragmentation. Parties-understood as carriers of partisanship, whether traditional parties, interest groups, or individual proxies-could proliferate without major hurdles in LD, thanks to a series of features, such as the absence of competition for seats and the possibility to selectively engage in political representation depending on the issue. A major challenge for parties and similar partisan organizations would be to ensure the unity of their elected members in the face of such a fragmented, volatile context. Whether commitment and intrinsic motivation would suffice for partisan proxies to construct highly cohesive agglomerates of like-minded individuals is questionable. In the absence of party lists, which are entirely open in $\mathrm{LD}$, proxies would be able to campaign for votes and build their own individual constituencies without the party label, giving them more freedom for open dissent. If some members' opinions begin to diverge in a way that threatens party unity, they can simply leave the party (taking their delegations) and become independent proxies. In a context where the party leadership cannot select top candidates, steer members' career paths, control the levers of political influence, or, more generally, punish 'rebels,' the importance of building a solid "record of loyalty" toward one's own party decreases (Kam, 2014, 14). Overall, there might be a trade-off between gyroscopic proxies and party discipline, raising the question of how to guarantee some cohesion and loyalty among party members. This, in turn, raises the urgent, but unanswered question of how the legislative assembly might work in such a volatile and fragmented context. This is, however, largely an empirical matter connected to the broader institutional set-up, which deserves more attention in future research (Kam, 2014).

\section{CONCLUSION}

This article started by asking whether LD dilutes the concept of political representation, by understanding it in purely Pitkinean 
formalistic and descriptive terms. Proxies in $\mathrm{LD}$ are representative in a formalistic sense, because they are elected by voluntary delegation and held accountable by instant recall. Moreover, both the proxies and the liquid legislature are descriptively representative, thanks to proxy voting, which ensures perfectly proportional representation, as well as to other features, such as the freely chosen proximity basis and area-specific delegations. This raises the question of whether there is a more substantive way of conceptualizing political representation under LD: Is LD compatible with a highquality, democratic understanding of representation? The answer to this question is a provisional yes, on the basis of an analysis of two gaps in the literature on political representation in LD.

First, the article disentangled the substantive view of representation in the proxy-voter relationship, arguing that $\mathrm{LD}$ is compatible with a selection model of representation, in which proxies are characterized as gyroscopic representatives. This approach has several implications: 1) the centrality of aligned objectives and intrinsic motivations explain how LD strikes a balance in the mandate-independence tradeoff; 2) resemblance and the sympathy of ideals give LD a clear anti-elitist slant; 3 ) the focus on issue control places deliberation center stage, giving LD a constructivist tendency. Second, the paper examined the function of parties in LD and reached the following conclusions: Even though LD puts parties and interest groups on a level playing field, 1) it challenges but does not necessarily eliminate parties $q u a$ organizations and 2) it expands the range of possible carriers of partisanship. Moreover, 3) gyroscopic proxies have more affinity with partisanship than with independence, because they are public-spirited, intrinsically motivated, and committed to a cause.

This article also pointed to a series of difficulties to be addressed by future research, for example: 1) the unclear impact of instant recall on the behavior of proxies; 2) the destabilizing effect of interest groups on governability; 3 ) the consequences of a functional view of representation and the resulting tendency toward a pluralist-corporatist theory of democracy; 4) the effect of LD on party discipline, partisan fragmentation, coordination, and policy coherence; 5) the great expectations and burdens placed on citizens to cultivate a deep, discursive relationship with their proxies, as well as to understand the complex, liquid system; 6) the uncertain repercussions of LD on parliamentary activity within the volatile legislative assembly and, most problematically, the potential loss of a stable, visible parliament as the supreme democratic institution. Overall, the article has highlighted the need to combine this theoretical framework with empirical insights, since much rests on the successful institutionalization of LD.

To conclude, this article is an indirect attempt to test the democratic credentials of LD. It has shown that the notion of political representation in LD is ensconced in thick concepts, since it embodies commitment, promotes intrinsic motivation, presupposes the alignment of objectives, fosters sympathy and trust, and enables dialogue. This conclusion goes a step beyond the literature, which has already anticipated LD's capacity to create a close bond between voters and proxies, along with its potential to foster expertize and collective intelligence. Clearly, the representation outlined in this article is quite demanding for both the representatives and the represented. From the proxies, it requires compliance with a certain ethics of representation, as well as of partisanship. In the represented, it proposes to cultivate the capacity for democratic citizenship, aiming at an ideal of active and vigilant citizenship capable of judgment and action. As such, LD presupposes a significantly more complex, mature, and dynamic relationship between representatives and represented, in which the judgments and activities of both parts are relevant and decisive. This, I would argue, is a framework capable of turning LD into an instrument for the "establishment of meaningful practices of self-government" in the twenty-first century (Castiglione and Pollak, 2018, 31).

\section{DATA AVAILABILITY STATEMENT}

The original contributions presented in the study are included in the article, further inquiries can be directed to the corresponding author.

\section{AUTHOR CONTRIBUTIONS}

$\mathrm{CV}$ is the sole author of this article.

\section{FUNDING}

This article is part of a cumulative dissertation funded by the Swiss National Science Foundation. Grant number of the $\mathrm{PhD}$ project: 191719 (see also: http://p3.snf.ch/project-191719).

\section{ACKNOWLEDGMENTS}

I would like to express my gratitude to Pierre-Etienne Vandamme for inviting me to contribute to this special issue, as well as for providing feedback during the early stages. I am also grateful to my supervisors, Francis Cheneval and Joseph Lacey, for their continued support in polishing and steering the manuscript in the right direction. My gratitude extends to my colleagues in the Doctoral Program Democracy Studies and at the Chair of Political Philosophy at the University of Zurich for their numerous questions and helpful comments -in particular, many thanks are due to Sara Amighetti and Olivier Ruchet for astutely pinpointing the main weaknesses of the manuscript and for providing constructive recommendations. Finally, I would like to acknowledge the work of the reviewers for their rigorous and professional feedback: their thoughtful guidance helped me improve my arguments substantially. The research and publication costs were generously financed by the Swiss National Science Foundation. The English-language editing was done by Chad Jorgenson (Better English). 


\section{REFERENCES}

Alger, D. (2006). Voting by proxy. Public Choice 126, 1-26. doi:10.1007/s11127006-3059-1

Barber, B. R. (2014). Participatory democracy. Encyclopedia Polit. Thought [Epub ahead of print]. doi:10.1002/9781118474396

Behrens, J., Kistner, A., Nitsche, A., and Swierczek, B. (2020). Liquid feedback. Available at: https://liquidfeedback.org (Accessed November 10, 2020).

Blum, C., and Zuber, C. I. (2016). Liquid democracy: potentials, problems, and perspectives. J. Polit. Philos. 24, 162-182. doi:10.1111/jopp.12065

Brownlee, K., and Jenkins, D. (2019). Freedom of association. Stanford encyclopedia of philosophy. Available at: https://plato.stanford.edu/entries/ freedom-association/ (Accessed August 5, 2020).

Castiglione, D., and Pollak, J. (2018). Creating political presence - the new politics of democratic representation. Chicago, lllinois: University Of Chicago Press.

Chapman, E. B. (2020). New challenges for a normative theory of parties and partisanship. Representation [Epub ahead of print]. doi:10.1080/00344893.2020.1738539

Coleman, S. (1995). Dynamics in the fragmentation of political party systems. Qual. Quantity 29, 141-155. doi:10.1007/BF01101895

Couperus, S. (2019). Democracy not lost? Functional democracy as a panacea for crisis in interwar Europe. Eur. J. Leg. Stud. 49, 252-266. doi:10.1177/2F0047244119859166

Efthymiou, D. E. (2018). The normative value of partisanship: when and why partisanship matters. Polit. Stud 66, 192-208. doi:10.1177/0032321717707401

Epstein, L. D. (1986). Political parties in the American mold. Madison, Wisconsin: University of Wisconsin Press.

Ford, B. (2002). Delegative democracy. Available at: https://bford.info/deleg/deleg. pdf (Accessed August 5, 2020).

Fossum, J. E. (2018). "Political parties and conflict handling," in Creating political presence - the new politics of democratic representation. Editors D. Castiglione and J. Pollak (Chicago, United Kingdom: University Of Chicago Press), 86-109.

Goodin, R. E. (2008). "The place of parties,"in Innovating Democracy. Editor R. E. Goodin (oxfard, England: Oxford University Press), 1-20.

Green-Armytage, J. (2015). Direct voting and proxy voting. Const. Polit. Econ. 26, 190-220. doi:10.1007/2Fs10602-014-9176-9

Hardt, S., and Lopes, L. C. R. (2016). Google votes: a liquid democracy experiment on a corporate social network: Tech. Discl. Commons. . Available at: https:// www.tdcommons.org/dpubs_series/79.

Hay, C. (2011). "Political ontology," in The Oxford handbook of political science. Editor R. E. Goodin (Oxford: Oxford University Press), 460-478.

Kam, C. (2014). "Party discipline," in The oxford handbook of legislative studies. Editors S. Martin, T. Saalfeld, and K. W. Strøm (Oxford: Oxford University Press), 399-417.

Lacey, J. (2017). Centripetal democracy: democratic legitimacy and political identity in Belgium, Switzerland, and the European Union. Oxford, England: Oxford University Press

Landemore, H. (2020). Open democracy: reinventing popular rule for the twentyfirst century. Princeton, NJ: Princeton University Press.

Manin, B. (1996). Principes du gouvernement représentatif. Paris, France: Flammarion.

Mansbridge, J. (1999). Should blacks represent blacks and women represent women? A contingent “yes. J. Polit. 61, 628-657. doi:10.2307/2647821

Mansbridge, J. (2003). Rethinking representation. Am. Polit. Sci. Rev. 97, 515-528. doi:10.1017/S0003055403000856

Mansbridge, J. (2009). A "selection model" of political representation. J. Polit. Philos. 17, 369-398. doi:10.1111/j.1467-9760.2009.00337.x

Mansbridge, J. (2011). Clarifying the concept of representation. Am. Polit. Sci. Rev. 105, 621-630. doi:10.1017/S0003055411000189

Miller, J. C. (1969). A program for direct and proxy voting in the legislative process. Public Choice 7, 107-113. doi:10.1007/BF01718736

Muirhead, R. (2006). A defense of party spirit. Perspect. Polit. 4, 713-727. doi:10. $1017 /$ S1537592706060452

Muirhead, R. (2014). The promise of party in a polarized age. Cambridge, Massachusetts: Harvard University Press.

Mutz, D. C. (2006). Hearing the other side: deliberative versus participatory democracy. Cambridge, England: Cambridge University Press.

New York Times (1912). Government by proxy now: Oregon plan would present ideas of representative lawmaking. Available at: https://timesmachine.nytimes. com/timesmachine/1912/06/30/100586994.html?pageNumber=14 (Accessed August 5, 2020).
Paulin, A. A. (2019). "Controlling citizens or controlling the state? Apropos: the pirates \& co" in Smart city governance. Editor A. Alois (Amsterdam: Elsevier), $69-79$.

Philp, M. (2009). Delimiting democratic accountability. Polit. Stud. 57, 28-53. doi:10.1111/j.1467-9248.2008.00720.x

Pitkin, H. F. (2004). Representation and democracy: uneasy alliance. Scand. Pol. Studs. 27, 335-342. doi:10.1111/j.1467-9477.2004.00109.x

Pitkin, H. F. (1967). The concept of representation. Berkeley, California: University of California Press.

Plotke, D. (1997). Representation is democracy. Constellations 4, 19-34. doi:10. $1111 / 1467-8675.00033$

Przeworski, A. (1999). "Minimalist conception of democracy: a defense," in Democracy's value. Editors I. Shapiro and C. Hacker-Cordón (Cambridge, England: Cambridge University Press), 23-55.

Rehfeld, A. (2018). On representing: on representing. J. Polit. Philos. 26, 216-239. doi:10.1111/jopp.12137

Rehfeld, A. (2009). Representation rethought: on trustees, delegates, and gyroscopes in the study of political representation and democracy. Am. Polit. Sci. Rev. 103, 214-230. doi:10.1017/S0003055409090261

Rehfeld, A. (2006). Towards a general theory of political representation. J. Polit. 68, 1-21. doi:10.1111/j.1468-2508.2006.00365.x

Rosenblum, N. L. (2008). On the side of the angels: an appreciation of parties and partisanship. Princeton, NJ: Princeton University Press.

Runciman, D. (2007). The paradox of political representation. J. Polit. Philos. 15, 93-114. doi:10.1111/j.1467-9760.2007.00266.x

Sartori, G. (2005). Party types, organisation and functions. West. Eur. Polit. 28, 5-32. doi:10.1080/0140238042000334268

Saward, M. (2006). Representative Claim. Contemp. Polit. Theor. 5, 297-318. doi:10.1057/palgrave.cpt.9300234

Schattschneider, E. E. (1942). Party government: American government in action. Abingdon-on-Thames: Routledge.

Tullock, G. (1967). Toward a mathematics of politics. Ann Arbor: University of Michigan Press.

Urbinati, N. (2000). Representation as advocacy: a study of democratic deliberation. Polit. Theor. 28, 758-786. doi:10.1177/0090591700028006003

Urbinati, N. (2006). Representative democracy: principles and genealogy. Chicago, United States: University of Chicago Press.

Urbinati, N., and Warren, M. E. (2008). The concept of representation in contemporary democratic theory. Annu. Rev. Polit. Sci. 11, 387-412. doi:10. 1146/annurev.polisci.11.053006.190533

Valsangiacomo, C. (2020). Liquid democracy: defining a new concept in political theory.

Vandamme, P.-E. (2020). Can the recall improve electoral representation? Front. Polit. Sci. 2, 1-13. doi:10.3389/fpos.2020.00006

Warren, M. E. (2017). "How representation enables democratic citizenship," in In creating political presence - the new politics of democratic representation. Editors D. Castiglione and J. Pollak (Chicago,United States: University Of Chicago Press), 39-60.

Weale, A. P. (1981). Representation, individualism, and collectivism. Ethics 91, 457-465. doi:10.1086/292253?journalCode=et

White, J. K. (2006). "What is a political party?", in Handbook of party politics. Editors R. S. Katz and W. J. Crotty (London: SAGE Publications Ltd), 6-15.

White, J., and Ypi, L. (2011). On partisan political justification. Am. Polit. Sci. Rev. 105, 381-396. doi:10.1017/S0003055411000074

White, J., and Ypi, L. (2010). Rethinking the modern prince: partisanship and the democratic ethos. Polit. Stud 58, 809-828. doi:10.1111/j.1467-9248.2010.00837.x

Young, I. M. (1997). Deferring group representation. Nomos 39, 349-376. doi:10. $18574 / 9780814788851-015$

Conflict of Interest: The author declares that the research was conducted in the absence of any commercial or financial relationships that could be construed as a potential conflict of interest.

Copyright (c) 2021 Valsangiacomo. This is an open-access article distributed under the terms of the Creative Commons Attribution License (CC BY). The use, distribution or reproduction in other forums is permitted, provided the original author(s) and the copyright owner(s) are credited and that the original publication in this journal is cited, in accordance with accepted academic practice. No use, distribution or reproduction is permitted which does not comply with these terms. 


\title{
Claims of Representation: Between Representation and Democratic Innovations
}

\author{
Petra Guasti ${ }^{1 * t}$ and Brigitte Geissel ${ }^{2}$ \\ ${ }^{1}$ Charles University, Prague, Czechia, ${ }^{2}$ Goethe University Frankfurt, Frankfurt, Germany
}

\section{OPEN ACCESS}

Edited by:

Pierre-Etienne Vandamme, Université libre de Bruxelles, Belgium

Reviewed by:

Francisco Cantu,

University of Houston, United States

Pieter De Wilde,

Norwegian University of Science and

Technology, Norway

*Correspondence:

Petra Guasti

guasti@soz.uni-frankfurt.de

tORCID:

Petra Guasti

orcid.org/0000-0001-7129-1827

Specialty section:

This article was submitted to Elections and Representation,

a section of the journal

Frontiers in Political Science

Received: 04 August 2020 Accepted: 01 February 2021

Published: 26 March 2021

Citation:

Guasti P and Geissel B (2021)

Claims of Representation:

Between Representation and

Democratic Innovations.

Front. Polit. Sci. 3:591544.

doi: 10.3389/fpos.2021.591544
This article seeks to build a bridge between the empirical scholarship rooted in the traditional theory of political representation and constructivist theory on representation by focusing on the authorization of claims. It seeks to answer how claims can be authorized beyond elections - selecting three democratic innovations and tracing claims through the claim-making process. Different participatory democratic innovations are selected - providing various claims and taking place in different institutional contexts, i.e., (elected) members of the Council of Foreigners Frankfurt; individual citizens in participatory budgeting procedures in Münster; and citizen's associations elected politicians in the referendum campaign in Hamburg. We first analyze the claims raised by the different claim-makers to identify their claimed constituency eligible to authorize claims. In the second step, we focus on the authorization by the claimed constituency and the relevant decision-making authority. The article finds that claim-making in democratic innovations is fractured and incomplete. Nevertheless, this is not the reason to dismiss democratic innovations as possible loci of representation; on the contrary, seen through the prism of claim-making, all representation electoral and nonelectoral - is partial. Focusing on the authorization of claims in democratic innovations provides novel inferences about the potential and limits of democratic innovations for broadening democratic representation

Keywords: representation, representative claim, authorization, democratic innovation, constructivist turn

\section{INTRODUCTION}

The traditional theory of democratic representation centers on the linkage between democracy and representation. It answers the question what makes representation democratic, with two interlinked concepts - authorization and accountability (Pitkin, 1967). At the heart of democratic representation are elections - they are both an authorization mechanism (represented appoint representatives) and providing accountability (represented re-appoint "good" representatives and punish the "bad" ones). Historically, the representation literature focused on the behavior of the representative (delegate vs. trustee model), types of representation (Pitkin, 1967; Mansbridge, 2009), the distinction between representation and participation (Plotke, 1997), and methods for selecting representatives (Manin, 1997).

Recent theories of representation broadened several features (Mansbridge, 2009), the scope of the represented (to include both people and discourses, Dryzek and Simon, 2008), and the role of the representative (citizen representative, Warren and Hilary, 2008). The scholars of the representative turn - mainly constructivists - went further highlighting multiple forms and mechanisms of representation beyond elections rejecting the concept of a principle-agent relationship, and 
introducing reflexivity as a measure of legitimacy (Disch, 2011), reconsidering representation as mediation centered on voice, trust, and memory (Williams, 2000), or as advocacy. They shifted our attention from the formal procedure of election to the expressive and performative dimension of representation (Urbinati, 2000; Urbinati, 2002).

At the core of their efforts is the way in which the fractured relationship between the representatives and the represented in contemporary democracies can be repaired (Mair, 2008; Saward, 2008; Mair, 2009; Dalton et al., 2011; Biezen, 2014; Rosanvallon, 2008). Constructivist democratic theorists reconsidered what is representation and what is the relationship between the representative and the represented. Famously, the British political theorist Michael Saward reconceptualized representation as a claim-making process (Saward, 2006; Saward, 2010). He broadened the scope of representation (actors and procedures) beyond elected representatives and elections, thus bridging representation, participation, and deliberation (Guasti and Geissel, 2019). In the concept of representation as claimmaking, theorists propose to focus on the plurality of claimmakers, claims, and conditions under which claim-making occurs (Saward, 2006; Saward, 2010; Kuyper, 2016).

This development was labeled as the constructivist turn in the political representation literature. This approach offers one possible way to study and perhaps improve the fractured linkage between citizens and representatives (e.g., Disch et al., 2019). However, broadening the scope of representation beyond electoral authorization opens up a conceptual and empirical challenge. When representation is claim-making, and elections are one but not the only authorization mechanism, it is no longer evident who speaks for whom and whether and how the claims of self-selected representatives can be authorized (Warren, 2001; Urbinati and Warren, 2008; Montanaro, 2017).

However, a conceptual and analytical framework allowing to grasp the cacophony of claims and alternative forms of their authorization was missing until recently (cf. Guasti and Geissel, 2019; Guasti and Rezende de Almeida, 2019; Joschko and Glaser, 2019; de Wilde, 2020). The lack of such a framework was probably the reason why empirical research in this field is rare and limited, focusing mainly on the behavior of claim-makers (de Wilde, 2013; de Wilde, 2020) or a few studies trying to develop new mechanisms of authorization (Kuyper, 2016; Joschko and Glaser, 2019). The empirical scholarship remained primarily rooted in the traditional representative theory - focusing on elections, characteristics and the behavior of the representatives (Przeworski et al., 1999). A typology developed by Guasti and Geissel (2019) proposed a way to connect constructivist democratic theory and empirical research - a novel way to study representation as claim-making (Guasti and Geissel, 2019). What remained absent was a systematic empirical analysis of authorization.

This article seeks to build a bridge between the empirical scholarship rooted in the traditional theory of political representation and constructivist theory on representation by focusing on the authorization of claims. We select different participatory democratic innovations providing various claims and taking place in different institutional contexts, i.e., (elected) members of the Council of Foreigners Frankfurt; individual citizens in participatory budgeting procedures in Münster; and citizen's associations elected politicians in the referendum campaign in Hamburg. ${ }^{1}$ We first analyze the claims raised by the different claim-makers to identify their claimed constituency eligible to authorize claims. In the second step, we focus on the authorization by the claimed constituency and the relevant decision-making authority.

\section{CONCEPTUAL FRAMEWORK: CLAIMS ON REPRESENTATION AND AUTHORIZATION}

The constructivist turn freed representation from the sole focus on electoral politics (Manin, 1997) by emphasizing claim-making (Saward, 2006; Saward, 2010). While traditional representation is confined to the halls of parliaments, constructivist representation as claim-making is everywhere. Instead of parties competing in elections, multiple competing claims on behalf of affected groups or abstract normative schemes emerge and compete for the attention and recognition in the public sphere (Andeweg, 2003; Saward, 2006; Rosanvallon, 2008; Van Biezen and Saward, 2008; Kuyper, 2016; Montanaro, 2017; Disch et al., 2019). Elected representatives are no longer the sole actors in the representation process, and electoral politics are not the only loci of representation. This is both an opportunity and a challenge for scholars of representation. On the one hand, nonelected actors claim to represent a wide range of constituencies (Montanaro, 2017), which often fall below the radar of electoral politics (de Wilde, 2013). On the other hand, if representation is everywhere, and everybody can make claims of representation, it is difficult to grasp conceptually and empirically study something like representation (Guasti and Geissel, 2019; cf.; Näsström, 2006: 326; Phillips, 1995; Mansbridge, 1999)

Along with the question of how to cope with the variety of new claim-makers comes the question of authorization. The public sphere is full of claim-makers-some elected, others non-elected. How can these claims be authorized? And by whom? Taking the challenge to the authorization monopoly of elections seriously forces us to think beyond the existing electoral paradigm. ${ }^{2}$ This article seeks to link the constructivist focus on claims with the traditional focus on the authorization. The conceptual and analytical framework developed by Guasti and Geissel (2019) provides an avenue for systematic empirical research of who claims what and whether acceptance constitutes a possible form of authorization (on acceptance in the context of symbolic representation see Pitkin, 1967).

\section{Claims on Representation: A New Typology}

Traditional scholars of representation are currently seeking ways to improve representation. However, in their effort, they remain constrained by relying on traditional institutions (parties, elections) and actors (politicians, voters, the opposition)

\footnotetext{
${ }^{1}$ We select democratic innovations on local and state levels in Germany - the council of foreigners in Frankfurt (2005-2017), participative budgeting in Münster (2011-2016), and school reform referendum initiated by citizens in the city-state Hamburg (2008-2010). The cases were selected to include various actors and concepts, but including a formal authorization mechanism.

${ }^{2}$ Especially disputed are the categories of audience and referent (Disch, 2015).
} 
(Pitkin, 1967). For the scholars of the constructivist school, these institutions constitute some, but not the sole loci of representation. Instead, they lead an ongoing debate on representation as claim - making.

The first question in this context is: what constitutes a claim (Saward, 2006, Saward, 2010; de Wilde, 2013; Disch, 2015; Guasti and Rezende de Almeida, 2019). Most authors refer to Saward's general definition that a "representative claim" is "a claim to represent or to know what represents the interests of someone or something." (Saward, 2006). Saward's definition is theoretically sound but empirically ambivalent. Its ambivalence undermines its empirical applicability. While the traditional scholars of political representation do not see the forest for the trees, constructivist scholars of political representation walk around the forest looking for the trees. Traditional scholars do not see beyond the paradigm of electoral politics. Constructivist scholars recognize the chaos of claims but struggle with operationalization and systematic analysis. We propose to focus on the trees - claims, their acceptance, and authorization.

In an iterative process, Guasti and Geissel (2019) we developed a comprehensive typology of representative claims. Based on analyses of several real-life cases, we made five relevant points on (the analysis of) claim-making. First, claims are often incomplete, and not all elements outlined by Saward and others are necessarily included (see below; de Wilde, 2013; de Wilde, 2020). Second, claims of representation with explicit reference to a claimed constituency are rare (Guasti and Geissel, 2019). When it comes to the authorization of claims, the constructed linkage between the representative and the represented is key. Some claim-makers explicitly construct a linkage between them and the represented (e.g., "as a mother I represent mothers"), others simply imply a linkage (e.g., "mothers like me") or do not construct a linkage (e.g., "more money is needed"). The presence (or absence) of such a linkage makes a vast difference in the authorization of claims. In other words, is a constituency named (e.g., "mothers"), which could potentially authorize the claim or not (ibid. 2019; cf. Sartori, 1987; Kitschelt, 2000). Fourth, outside the electoral arena, non-elected claim-makers often challenge elected representatives. Authorization provided to the elected representatives by election does not go hand in hand with the actual representation of respective constituencies-thus claims of misrepresentation emerge (Guasti and Rezende de Almeida, 2019). Fifth, the "subject" of representation (what is represented) is often not a "human being," but a "normative scheme," e.g., justice, freedom (e.g., Dryzek and Simon, 2008; Joschko and Glaser, 2019). ${ }^{3}$

\footnotetext{
${ }^{3}$ We distinguish between two types of the claimed "constituency" - human beings and normative schemes (cf. Pitkin, 1967; Pitkin, 2004; Runciman, 2007; Mansbridge, 2011). We recognize that claims to normative schemes appeal to an actual human constituency - i.e., to those sharing the values of justice and freedom. However, the reception of this claim will be different. To accept or reject a claim, e.g., to "justice," the audience member should first assess whether justice is grounds for accepting a claim (cf. Montanaro, 2017 on affected interests; Ankersmit, 2002, Näsström, 2006 on aesthetic aspects of representation).
}

\section{Elements of Claims}

In order to empirically capture claims, we need to define the key elements of claims. Guasti and Geissel (2019) focus on what is claimed to be represented - the (claimed) constituency, who is expected to act on behalf of the claimed constituency - the claimed representative, and the linkage between the (claimed) representative and the (claimed) constituency (Table 1). ${ }^{4}$

The three categories can be applied to both electoral and nonelectoral context. For illustration, we use an example familiar to scholars of traditional electoral representation: in an electoral campaign rally, the candidate of a populist radical right party claims that the establishment parties no longer represent "true national values," and voters should instead support its candidate, a former soldier. Here, the candidate first vacates the existing linkage between the elected representatives and the constituency and claims to represent "true national values" IF elected. The constituency is those voters for whom "true national interest" is an electorally salient issue. The linkage emerges thru acceptance of the claim and is confirmed by authorization in elections (cf. Guasti and Rezende de Almeida, 2019).

In the process of claim-making, claim-makers construct constituencies (e.g., "I represent citizens with true national values"), rendering them politically present ("true national values" as a campaign theme) (cf. Disch, 2011). Claim-makers claim to make non-represented constituencies visible and audible - people previously 'left behind' (Hirst, 2013; Williams, 2000; Disch, 2011; Montanaro, 2012). We have used the example of electoral politics to make our abstract argument more comprehensible for non-constructivist scholars. However, we could also speak of Greta Thunberg, calling for climate justice on behalf of future generations and mobilizing youth within the Fridays for Future (cf. on Thunberg and Fridays for Future, Zulianello and Ceccobelli, 2020). In this example, Greta Thunberg (claim-maker) constructs her constituency (youth who mobilizes around climate justice), creating the Fridays for Future movement (nonelectoral linkage).

The object of representation - claimed constituency - is constructed in the process of claim-making. Claim making puts different "ideas" of 'the represented' into play and opens them up for contestation. (to stay with our example, climate emergency has both vocal supporters and opponents claiming to speak on behalf of future generations). A claim depicts the object of representation in a particular way, as having a particular set of interests (cf. Bourdieu, 1991; Saward, 2006; Montanaro, 2012). Fridays for Future defines future generations' interests, which they claim conflict with the

${ }^{4}$ The "representative claim" literature uses the term "object of representation to describe the represented." In contrast, the traditional representation theory speaks of the "constituency." Here, we use both terms as synonyms to depict constituency beyond the confines of the individualist approach (Pitkin, 1967) - individuals, groups, normative schemes (cf. Runciman, 2007, Mansbridge, 1999, Mansbridge, 2003; Mansbridge, 2011; Mansbridge, 2015). 
TABLE 1 | Elements of claims on representation.

\begin{tabular}{|c|c|c|}
\hline Element & Definition & Example \\
\hline Claim maker & Who speaks & I represent all citizens \\
\hline Claimed representative & Who is expected to act on behalf of the claimed constituency & Social democratic parties (should) represent workers \\
\hline Claimed constituency & On whose behalf subject claims to speak & KAV represents the muslim population of Frankfurt \\
\hline Claimed linkage & The claimed connection between the claim maker and the claimed constituency & I stand for your interests \\
\hline
\end{tabular}

Source: Guasti and Geissel (2019).

current politics. Alternatively, another example from our research, the Council of Foreigners (KAV), our Frankfurt case, demanded the introduction of special hours for women in public pools in Frankfurt. ${ }^{5}$ Thus, KAV insinuated that Muslim female foreigners have a particular interest - to have access to swimming without men's presence.

Guasti and Geissel (2019) distinguish between two types of claimed constituency - human beings and normative schemes. This distinction allows the identification of various linkages claimmaker constructs between the claimed representative and the claimed object. Both of our examples used normative schemes and showed how normative schemes are not only abstract discourses (Dryzek and Simon, 2008) but appeal to real-life people.

In the next phase (authorization of claim), this distinction provides grounds for distinguishing various authorization mechanisms. A claim to the human constituency constructs direct linkage and thus enables the claimed constituency to accept or reject the claim. Claims to normative schemes establish indirect linkage between the representative and the represented and presumed authorization by those who perceive themselves as affected as well as by decision-making authorities, who accept or reject the claim-maker as representative of the respective normative scheme (Montanaro, 2017; Guasti and Geissel, 2019).

Some claim-makers start their claim with an accusation of misrepresentation, questioning the linkage (and the legitimacy) of other claim-makers (Disch, 2009: 52). For example, in their work on claims of misrepresentation, Guasti and Rezende de Almeida (2019) show how the alternative for Germany denies the existence of linkages between social democratic parties and workers in order to present itself as the new representative of German workers. Focusing on the presence, denial, and absence of the claimed linkage between the representative and the represented allows us to distinguish various types of claims and their possible authorization modes.

\section{The Typology}

Based on a comprehensive iterative process, Guasti and Geissel (2019) identified four different types of claims based on the three elements outlined above - constituency, representative, and linkage. Some are "complete" and include all elements: The claims of representation presumably speak for a constituency and indicate linkages between the claimed representatives and the claimed constituencies. Other claims do not include all elements, e.g., claims of interest claim to speak for a community, but do not claim a linkage, and so on (see Table 2).

\section{Conceptual Framework for Empirical Analysis of the Authorization of Claims}

The acceptance of claims is central to the constructivist literature - it is a form of authorization - legitimizing the claim-maker to represent the constituency (Saward, 2006; Disch, 2015; Montanaro, 2017). Classical literature uses the term authorization, which is reserved for elections and eligible actors, i.e., members of the government, members of parliament, and the president (Pitkin, 1967). Since the constructivist scholars proposed to go beyond elections as sole authorization mechanisms, the literature on representative claims discusses alternative forms of authorization (Montanaro, 2012; Severs, 2012; Saward, 2009; Disch, 2015; Kuyper, 2016; Montanaro, 2017; Dryzek and Simon, 2008).

A variety of different terms evolved, for example, acknowledgment, reception, perception, absorption, engagement, legitimacy, accountability, legitimation, resonance, responsiveness, judgment, congruence, affectedness, resemblance, expertise, assessment, credibility, recognition, evaluation, inclusivity, or consequentiality (Dryzek and Simon, 2008; Saward, 2010; Montanaro, 2012; Severs, 2012; Disch, 2015; Kuyper, 2016; Montanaro, 2017). Most of these terms are used abstractly and rarely operationalized, making the empirical application difficult (see Joschko and Glaser, 2019 as an example of successful operationalization and data use). In particular, the representative turn literature places a significant emphasis on authenticity (e.g., affected interests in Montanaro, 2017, substantive representation in Severs, 2012). ${ }^{6}$ We perceive this approach as reductive and do not recognize authenticity as a functional equivalent of authorization. Authenticity as an authorization mechanism shifts the focus away from the linkage between the representatives and the represented, reducing it to a (descriptive) fit (e.g., black women represent black women) - the underlining assumption being, the better the fit, the better the representation (cf. Mansbridge, 2011; Mansbridge 2013; Heinisch and Werner, 2019; Joschko and Glaser, 2019). Guasti and Geissel (2019) proposed to seek empirical ways to assess the authorization of claims, rather than developing alternative theoretical concepts (cf. Disch, 2009).
${ }^{5}$ The constituency question has become a critical problem in the representation theory and remains largely ambivalent (Montanaro, 2017).
${ }^{6}$ For many authors, there is also a close-link between self-selected representatives and authenticity (Saward, 2008; Montanaro, 2012). 
TABLE 2 | Types of claims.

\section{Types of claims}

CLAIM OF REPRESENTATION claim maker speaks for/on behalf of the claimed constituency and indicates a linkage between him-/herself and claimed constituency CLAIM OF MISREPRESENTATION claim maker accuses another representative not to represent the claimed constituency and denies a linkage between other representative and claimed constituency

CLAIM OF INTERESTS/VALUES claim maker speaks of interests and values, referring explicitly/implicitly to a claimed constituency without indicating any linkage to claimed constituency

PROCLAMATION claim maker states a proposal without referring to a claimed constituency and without indicating any linkage to claimed constituency

\begin{tabular}{|c|c|c|}
\hline Constituency & Linkage & Example \\
\hline referenced & referenced & $\begin{array}{l}\text { We [KAV] represent the muslim population of } \\
\text { Frankfurt }\end{array}$ \\
\hline referenced & Denied & $\begin{array}{l}\text { The government [of Hamburg] does not represent } \\
\text { the interests of pupils }\end{array}$ \\
\hline referenced & Absent & $\begin{array}{l}\text { The reform is needed to improve children's } \\
\text { education }\end{array}$ \\
\hline Absent & Absent & More park benches are needed \\
\hline
\end{tabular}

Source: Guasti and Geissel (2019); examples adapted from the current case studies.

Three approaches combined conceptual advancement and empirical assessment of authorization (Kuyper, 2016; Heinisch and Werner, 2019; Joschko and Glaser, 2019). Kuyper (2016) identified key criteria for assessing nonelectoral representatives and deliberative democratic legitimacy (inclusivity, authenticity, and consequentiality). While Kuyper;s approach significantly contributes to understanding nonelectoral representation, it assesses the process as a whole. It does not allow us to zoom in on claims as key elements of representation. The remaining two approaches (Heinisch and Werner, 2019; Joschko and Glaser, 2019) used claims but focused on electoral representation. Heinisch and Werner (2019) measured claims by populist parties in their programs, whether voters accept these claims (by voting), and the extent to which elected representatives descriptively represent the claimed groups. While enriching the study of representation with some features of the constructivist approach, it remains firmly in the (narrow) space of electoral representation - providing important information about claims by populist parties and their reception by voters. However, the election remains the ultimate authorization mechanism. Joschko and Glaser (2019) sought to measure reception and validation of claims by elected representatives beyond the election. Using sophisticated methods to identify constituencies using multiple correspondence analysis and to assess validation, they used natural language processing and regression on social media data. While we appreciate this approach, such type of data is not available for most claims made outside the parliamentary arena and attention of social media. It is thus not available for most scholars of nonelectoral representation.

Who can authorize claims by non-elected representatives? For Dovi (2017), the claimed constituencies are the ultimate authority in assessing the claims. However, according to Saward (Saward, 2010: 186) and Disch (Disch, 2015: 494), a distinction ought to be made between "claimed constituency" (the constituency constructed by the claim) and "effective audience" defined as actors with resources and power, which can make a useful contribution, for example, authorities, mass media, or "the public" (cf. Saward, 2010; Disch, 2015). In assessing the claims by not-elected representatives, we distinguish between "claimed constituency" and "decision-making authority" (Guasti and Geissel, 2019, cf. Joschko and Glaser, 2019). Decision-making authority can be, for instance, a parliament, a mayor, or in case of a referendum (such as the referendum in Hamburg), the citizenry. These decision-making authorities decide which claim to accept.

A framework of analysis, considering the different types of claims and "accepting actors" (claimed constituency, decisionmaking authority), is described in Table $\mathbf{3}$ and discussed below.

The empirical application of this framework is demanding. How can we find out whether the claimed constituency and the relevant authority accepts or rejects a claim? Considering claims of representation by non-elected claim makers, Guasti and Geissel (2019) propose identifying the claimed constituency. Where claimed constituencies exist, both the authorization by "claimed constituency," and "decision-making authority" can be examined. Considering normative schemes, in our cases, authorization can only be assessed by the authorities (for an alternative approach to authorization of claims by self-selected representatives, see Montanaro, 2017; Kroeber, 2018; Guasti and Rezende de Almeida, 2019).

For example, an animal advocacy group claims to represent "justice for farm animals." This claim cannot be accepted directly. At present, we cannot grasp the notion of justice espoused by farm animals (if it exists). Furthermore, the authorization of this claim can not be measured via election (animals can not elect their representatives). The decision-making authority (e.g., the Ministry of Agriculture) can accept the claim and invite the animal advocacy group to submit a proposal on improving the well-being of farm animals.

\section{CASE STUDY DESCRIPTION AND METHODOLOGY}

To assess the authorization of claims in the context of democratic innovations, we proceed to apply our typology to three cases. ${ }^{7} \mathrm{We}$

\footnotetext{
${ }^{7}$ Three criteria were used to identify these case studies: 1) theme - issues related to various types of representation (descriptive, substantive, and critique of representation), with and without electoral authorization (elected, self-selected claim-makers); 2) scope - we include both state and municipal level debates; 3 ) comparability (our project is a part of a broader international framework, case selection was adjusted to allow for comparison of cases across various countries for example, after completing the analysis of participative budgeting in Münster, we will be able to compare the German case to France, Brazil and India; in this article, our analysis only includes the German cases).
} 
TABLE 3 | Authorization of different claims.

\begin{tabular}{|c|c|c|}
\hline Type of claim & $\begin{array}{l}\text { A. Authorization by } \\
\text { the claimed constituency }\end{array}$ & $\begin{array}{l}\text { B. Authorization by } \\
\text { the relevant decision-making } \\
\text { authority }\end{array}$ \\
\hline CLAIM OF REPRESENTATION & Yes (direct) & Yes \\
\hline CLAIM OF MISREPRESENTATION & Yes (direct) & Yes \\
\hline CLAIM OF INTERESTSNALUES & Yes (indirect) & Yes \\
\hline PROCLAMATION & No (not applicable) & Yes \\
\hline
\end{tabular}

Source: Guasti and Geissel (2019).

compare three recent democratic innovations on local and state level in Germany - participative budgeting in Münster (municipal level, 2011-2016, representation without elections), the council of foreigners (KAV) in Frankfurt (municipal level, 2006-2017, electoral representation beyond citizenship), and the school reform referendum initiated by citizens in Hamburg (state level, 2008-2010, direct democracy). ${ }^{8}$

We collect primary data (case-specific - transcripts of debates, online debates, printed media, and social media). Our analysis combines content and discourse analysis. We proceed in three steps. First, we identified all available documents related to the given topic (in the case of Münster and Frankfurt proposals by citizens (Münster) and KAV (Frankfurt) online; in the case of Hamburg, we selected two local print media and analyzed articles referring to school referenda for the period 2006-2017, as well as press releases of the various actors, etc.).

Second, we coded the three elements of the claim described above (see Table 1): the claimed representative, the claimed constituency (assigning the category of a human being or normative scheme), and the claimed linkage, respectively ${ }^{9}$.

In the next step, we focus on the authorization of claims. We open up our analysis with a democratic innovation that is the closest to traditional representative politics. Non-citizen residents of Frankfurt elect KAV, and KAV is tasked with representing this constituency of foreigners as a whole. Its outputs are claims (recommendations and requests) to the Frankfurt municipal government (decision-making authority). Tracing KAV claims through the process allows us to assess the authorization of claims both by the constituency and decision-making authority. Our second case, the participative budgeting in Münster, is a classic case of democratic innovation, which allows us to trace claims through all three stages of claim-making. Unlike in the case of KAV in Frankfurt, there is no authorization by elections. Instead, the authorization of claims by the constituency takes

${ }^{8}$ While not universally accepted, in the German context, direct democracy is recognized as a form of democratic innovation (Geißel and Joas, 2013).

${ }^{9} \mathrm{We}$ performed an intercoder reliability test to ensure the validity of our coding. Two members of the research team codded all claims separately, using pre-agreed categories. Intercoder reliability test was performed regularly, including all coded claims (Cohen's kappa, $\mathrm{K}$, where complete agreement $K=1$ ). In all intercoder reliability tests, the value of Cohen's kappa was above 0.85 . Those items where coders did not reach an agreement were subsequently discussed and recoded. place online. Subsequently, the decision-making authority assesses the claims. Finally, in the case of the Hamburg school reform referendum, voters are the ultimate decisionmaking authority.

\section{ANALYSIS}

\section{Council for Foreigners in Frankfurt}

The Council for Foreigners (Kommunale Ausländervertretung, $\mathrm{KAV}$ ) is a body for foreigners' municipal representation in Frankfurt (Germany). KAV is elected by the city's residents without a German passport to represent their interests. The electoral term is five years. KAV was first founded in 1991, and KAVs are established in all Hesse municipalities with at least 1,000 registered foreign residents.

$\mathrm{KAV}$ can make requests and questions to the municipality. We have analyzed all requests and claims between 2006 and 2017 identifying 284 claims. The most often used type of claim is claims of interests/values (52\%); the least used type are claims of misrepresentation (11\%).

\section{Claimed Constituency}

Regarding the claimed constituency, we found that the majority of claims (58\%) are related to human beings. Human beings as the claimed constituency are most often foreigners/migrants, nonGerman speakers, Muslims, asylum seekers, refugees, migrant children/youth, migrant associations, non-Christian patients in hospitals.

Normative schemes (32\%) are most often inclusiveness, diversity, integration, anti-discrimination, public safety, sustainability, multiculturalism, tolerance, equal treatment, public health and safety, and religious freedom (always vis-àvis Islam). Conceptually, we see that the distinction of constituency between human beings and normative schemes is essential. The use of the category normative schemes enables us to identify the constituency behind these normative schemes, such as here, in our example, where "religious freedom" is a frame used to push for more accommodation for Frankfurt's Muslim population.

\section{Authorization}

$\mathrm{KAV}$ is an elected body, and its constituency is the foreign population of the city. In a city with 150 nationalities, many of whom do not have voting rights, KAV is the only body of political representation. The authorization mechanism is 
elections. Over the 2 decades, the turnout in the KAV elections decreased significantly (from $7.9 \%$ in 1997 to $6.2 \%$ in 2015). The turnout in KAV elections demonstrates that KAV failed to attract its constituency.

As the KAV turnout is extremely low and further decreasing, critical voices for the abolition of KAV are strengthening. These voices cite the lack of acceptance/authorization among the foreign population and the lack of willingness of KAV to fulfill its mandate 'representing the foreign population as a whole.'

In order to assess the level of authorization of KAV claims by the relevant authority - the Frankfurt municipal government - we traced each claim individually through the process. We found that a significant number of the KAV proposals were rejected (31\%), a small number accepted (10\%), and the majority were processed by the municipality (59\%). Our analysis shows that the low acceptance and high rejection rate is not an attempt of the municipality to go against Frankfurt's foreign residents' interests. Instead, KAV's demands are often in direct opposition to the city's liberal policies.

The majority of the accepted claims $(N=16)$ were congruent with the Frankfurt City Government's desire to create an open and inclusive society. The accepted claims included introducing intercultural competence and multilingual staff in the office for seniors to improve access for non-German speaking seniors. Upon a KAV request, a stricter approach was adopted in order to impede hate crime. Some general changes included road adjustment, the location of public toilets in the city, and the improvement of the train station's ambiance.

The majority of the rejected KAV claims $(N=50)$ tend to represent specific interests of male Muslim-conservatives seeking to insulate their particular constituency from integration. This KAV demands clash with the existing policies of the City Government. These claims are also incongruent with the KAV's official mandate and do not intend to represent Frankfurt foreigners' interests as a whole. Instead, they seek to represent the interests of the (conservative) Muslim population of the city, regardless of citizenship. For example, the KAV attempts to separate swimming pool hours for Muslim women in the city's public pools.

Some rejected claims also seek to redefine KAV as representative of Muslim residents (regardless of their citizenship status - i.e., both dual citizens and foreigners). Given the frequency of these requests, over time, the City Government views KAV with growing suspicion (and contempt). The perception of KAV as able to represent the interests of the Frankfurt non-citizens population continues to deteriorate.

To summarize, the significant finding of this case study is that the KAV constituency designated by law (the foreign-population of Frankfurt) is not identical to the claimed constituency (Muslim population of Frankfurt). The failure to represent the foreign population as a whole has significant repercussions regarding the authorization of KAV claims - the KAV elections experience meager turnout, and call for its abolition are increasing. The decision-making authority rejects most KAV claims because they represent partial interest contrary to the city's values. KAV fails to represent its constituency (foreigners living in Frankfurt) - and is neither accepted by this constituency nor authorized by the authority.

\section{Participative Budgeting in Münster}

In Münster, the process of participatory budgeting is divided into five phases: 1) proposals are made public by the city municipality and discussed by participants - anyone interested can hand in proposals via telephone, in written form, or online, upon registering online. In every round, one specific thematic priority is announced; however, proposals to any other issue are also welcome; 2) the residents of Münster are invited to evaluate the submitted proposals - all proposals are published online. Residents of Münster (upon completing the online registration, the minimum age for participating in the evaluative process is 14 years) can evaluate each proposal (options: approval, rejection, neutrality, or abstention); 3) the municipality examines and documents the most popular proposals - proposals which can be realized immediately are implemented as quickly as possible. If it is not feasible, the city council explains the refusal in a written statement online (accountability); 4) residents can again comment on this announcement. Other, more far-reaching proposals are discussed in the next step, and 5) politicians debate and adopt the budget; and the municipality gives account to the citizens.

A dedicated website, run by the municipality, is used for communication from the municipality to the participants/ residents and discussion among participants in the process. We report the analysis of 20 randomly selected proposals from the 2016 debate (third of the four rounds organized to today). We have found that in 19 of the 20 proposals, the claim-maker is explicit and different from the subject. The claim-maker is the citizens, while the subject of the claim, which the maker expects to act, is the municipality. Only in one case did a participant use an impersonal claim - "xx should be done.'

\section{Claimed Constituency}

The majority of claims (16 of the 20) referred to normative schemes - mainly "common good." Only four claims referred to particular interests (including cyclists, municipality, city budget, and music lovers). In 11 cases, the maker claimed the absence of competing interests. In five cases, the maker identified a particular group affected by the proposal and have competing interests - church/religious citizens, car drivers, French literature fans, citizens renting community gardens and parents of kindergarten children.

\section{Authorization}

In Münster, similarly to Frankfurt, we traced the proposals through the whole process to assess the authorization of claims. In tracing the claims, we proceeded in three steps; first, we assessed whether it was regarded as relevant by the participants (first stage). Second, we analyzed if the claim was accepted/rejected by the city council (second stage). Third, we identified whether the proposed claim was taken up and implemented by the local administration (third stage).

The perception of relevance - eight of the twenty claims were perceived as relevant by the participants (voted into the "best of" 
list online). Regarding authorization by the city council, eight proposals/claims were accepted, and the city council rejected four. Three of the eight accepted proposals/claims were also implemented. We found only partial, but not full, overlap between authorization by the participants and by the city council. Overall, $40 \%$ of the citizens' proposals were taken up, and $15 \%$ were taken up and implemented. Only $20 \%$ of the proposals were rejected.

To summarize, Münster PB highlights that the design of a democratic innovation is decisive for the process of claimmaking. Further analysis of the relationship between institutional design and claim-making is beyond the scope of this article. Münster PB clearly illustrates the relationship between the authorization of claims by the intended constituency and the decision-making authority. The Münster municipality reviewed claims regarded as relevant by the participants of the online participative budgeting and implemented some. In the end, $15 \%$ of claims made by the participants were accepted by both the participants and the municipality and implemented. In Münster, the decisionmaking authority did not consider claim makers as representatives. Instead, effectiveness and feasibility emerge as authorization framework.

\section{School Reform Referendum in Hamburg}

The institution of a referendum is a part of a set of direct democratic devices (Volksgesetzgebung, citizen lawmaking) introduced in Hamburg in $1996^{10}$. Between 1996 and 2018, four citizens" initiatives were directly related to our case, the Hamburg school reform. Three finished in the citizen legal initiative stage by not reaching the quorum; one organized by the initiative 'We want to learn' (WWL, Wir Wollen Lernen) succeeded. On July 27, 2010, overruled the school reform adopted by the Hamburg parliament. In this case study, we focus on this last procedure.

The focus of this case study was the debate and subsequent referendum on school reform in Hamburg. The core of the debate occurred between 2008 and 2010 on the local and state levels (Hamburg is a city-state). Both the debate and the outcome of the referendum also echoed on the federal level. ${ }^{11}$

The Hamburg debate was extremely polarized along two dividing lines: politics and policy. The political dividing line was between the governing coalition (CDU-GAL) and the

\footnotetext{
${ }^{10}$ It is historically rooted in the 1921 Hamburg Constitution, which included two types of citizen participatory devices: citizen legal initiative (Volksbegehren) authorizing citizens to bring legislation to the parliament by collecting signatures referendum (Volksentscheid) challenging decisions and legal norms adopted by the parliament. This tradition was interrupted by the national socialist regime, and not restored in the 1952 Hamburg Constitution was reintroduced in 1996 (Articles 48 and 50 of the Hamburg Constitution), and reformed in 2004 (in effect since 2005, introduced new thresholds) and 2007 (removing thresholds added in 2004).

${ }^{11}$ Many federal states saw the Hamburg school reform as a test case for a potential broader overhaul of the German educational system. The coalition between the Christian Democrats (CDU) and the Greens (GAL) was the first of its kind in Hamburg and was perceived as a potential model for a similar coalition on a federal level.
}

opposition (parliamentary opposition SPD and Linke, and extra-parliamentary opposition FDP and NPD). On policy, the dividing line was between the proponents (GAL, CDU, citizen initiatives such as Prima School, Pro-Reform, trade union GWE, Student and parent groups) and opponents (SPD, to a lesser degree Linke for whom the reform did not go far enough, FDP and even NPD for whom it went too far and especially the citizen's initiative WWL).

In spring 2010, when it became clear there will be a referendum and its outcome is less than secure, all parliamentary political parties (CDU, GAL, SPD, and Linke) agreed to support and campaign for the reform. After the failed referenda, the resignation of the Mayor (CDU), fall of the CDU-GAL coalition, the new CDU leadership renounced the reform and, in a U-turn (attempt to win back its base), nominated the WWL leader onto the fifth place on the ballot in the 2011 (preliminary) elections.

\section{Claimed Constituency}

In Hamburg, we analyzed 70 claims throughout 2008-2010 Both the number and the types of claims fluctuate over time. Overall, the most often used type of claim is a claim of misrepresentation (43\%); the least used category is the claim of representation (19\%).

Regarding the claimed constituency, we found that most claims (55\%) are related to human beings - children, pupils, students, parents, including underprivileged children (poor, children with migration background). The claims to normative schemes $(45 \%)$ were mostly related to social inclusion, social integration, and justice. The opponents mostly related their claims to the human constituency (the children), while the proponents of normative schemes and human beings. Overall, $79 \%$ of claims were by proponents, $16 \%$ by opponents, and $5 \%$ were neutral.

\section{Authorization}

Given the character of the Hamburg case, the authorization took the form of voting in the referendum. The citizens could vote on both proposals: the anti-reform proposal by the citizen's initiative "We want to learn" and the Hamburg government (see Figure 1).

The outcome of the referenda differed significantly from the claims. In the end, $22 \%$ of Hamburg voters supported the WWL proposal against the reform, and only $17 \%$ supported the reform. The turnout was approximately $40 \%$ and significantly skewed by class - the turnout was extremely low in Hamburg's workingclass neighborhood and very high in upper and middle-class boroughs.

To summarize, the Hamburg school reform highlights the gap between the affected audience and the legal constituency. The school reform was an attempt by a government to improve access to education for children with a migrant and working-class

\footnotetext{
${ }^{12}$ The claims were identified in media articles and public speeches. We selected right-leaning and left-leaning newspapers and collected 53 and 113 articles, respectively.
} 


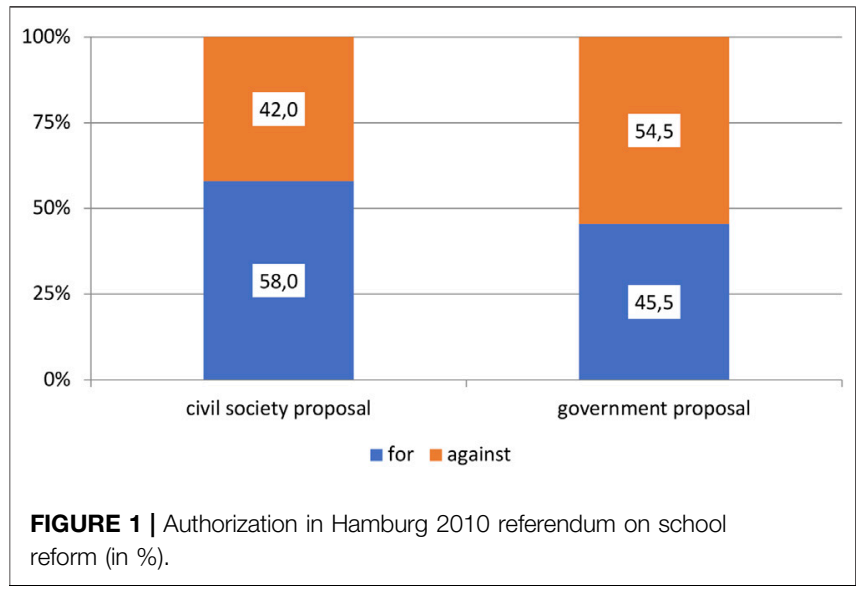

background. The Hamburg middle and upper classes were able to utilize direct democracy to maintain the status quo. In referenda, as in the case of elections, voters are the ultimate decision-making authority. In this case, the majority of those whose interests were affected were either disfranchised (nonGerman population, children, students), or their capacity to participate was limited (working class, unemployed). ${ }^{13}$ Elected representatives aiming at protecting the interests of minority and vulnerable people were challenged by those better equipped to pursue their interests. The voters - the decision-making authority - authorized the claim by the opponents of the government proposal. ${ }^{14}$

\section{Summary: Claims in Democratic Innovations}

In this part, we will compare the claims on representation in the three democratic innovations. We will focus on the three stages of claim-making - identifying the constituency, assessing authorization, and outlining acceptance (Table 4 provides a comparative overview).

\section{Claimed Constituency}

Our distinction between human beings and normative schemes has proven meaningful in our analysis, as it allowed us a better grasp of the authorization of claims. In Frankfurt and Hamburg, most claims were related to human-beings, but normative schemes were also utilized. In Münster, all claims were related to normative schemes.
The case of Frankfurt highlights the clash between the intended constituency (i.e., the foreign population of Frankfurt 'as a whole') and self-perception of KAV, and especially by the dominant KAV group (conservative Turkish males). This makes KAV extremely ineffective and unpopular with the decisionmaking authority (Municipal Council), municipal administration) and the voters.

In Hamburg, the opponents mostly related their claims to children (human constituency). Among the proponents, the specific group of claim-makers referred to inclusion and legitimacy (normative schemes), highlighting the gap between affected interests and those able to participate in authorization (due to age and citizenship restriction of the Hamburg electoral law).

\section{Authorization and Acceptance of Claims}

Studying three democratic innovations, we have found out that authorization results from a complex interplay between the constituency and decision-making authority. Through a twostep analysis (identification of constituency and authorization), we have found out that only between 10\% (Frankfurt) and $40 \%$ (Münster) claims are accepted. On the constituency, an important insight from our case studies is the need to distinguish between claimed constituency, intended constituency, and actually affected audience. In Frankfurt, the lack of overlap between claimed and intended constituency led to limited authorization. In Hamburg, the claimed constituency overlapped with the affected audience. However, only a small portion of those whose interests were affected were enfranchised and capable of participation in the authorization process (referenda). In Münster, the design of the participative budgeting pre-defined the affected interests. When it comes to the authorization via the authorities, effectiveness, and feasibility were key criteria against which the claims were measured in Münster. Thus, the process of participative budgeting was limited in the scope of interests, which could be claimed.

Our study shows that the overlap between claimed constituency and intended constituency is key for the authorization of claims by the decision-making authority. In Frankfurt and in Münster, only claims where claimed constituency overlapped with the intended constituency were accepted. In Hamburg, voting-age citizens were the decisionmaking authority; this significantly undermined the proponents of the reform and led to its failure. To fully grasp the authorization of claims beyond elections, we need to analyze both the claim-making and the authorization of claims.

\section{CONCLUSION}

citizenship. The educational expert commented on the referendum's outcome: "People without German citizenship were not allowed to vote at the Hamburg referendum. However, about 15\% of all students in Hamburg's schools do not have German citizenship. Thus, an entire population group, whose children would be directly affected by the reform, was excluded from participating in the decision. These children would probably have benefited from the extension of elementary school the most."

${ }^{14}$ In this way, the referenda acted as a corrective to the electoral politics, in a logic similar to a recall procedure Geissel and Jung (2018) and Geißel and Jung (2020).
This article aimed to answer the question, how can claims be authorized beyond elections. We have selected three democratic innovations and traced claims through three stages of the claimmaking process: the making of a claim, authorization of claims, and acceptance of claims. Building on the typology developed by Guasti and Geissel (2019), we differentiated between acceptance 
TABLE 4 | Comparative overview of authorization in three democratic innovations.

\begin{tabular}{|c|c|c|c|}
\hline Case study & Frankfurt KAV & Münster PB & Hamburg referendum \\
\hline Type & Elected representative body of foreigners & Municipal participative budgeting & Citizens initiative initiated legislative referendum \\
\hline Timing & 2006-2017 & 2016 & 2008-2010 \\
\hline Number of claims & 284 & 20 & 70 \\
\hline Authorization authority & Municipal council & Municipal council & Eligible voters \\
\hline$\%$ Of accepted claims & $10 \%$ & $40 \%$ & $22 \%$ \\
\hline
\end{tabular}

Source: CLAIMS Frankfurt.

by the claimed constituency and authorization by the relevant decision-making authority. Each of the four types of claims requires different forms of authorization. Claims of representation, as well as claims of misrepresentation, can be authorized as well by the claimed constituency as by the respective authorities. Claims of interest/values can be authorized by the authorities but only indirectly by an unclear constituency, which is not claimed explicitly. Proclamations can only be authorized by the authorities (see Table 3).

Considering authorization mechanisms by constituencies, in all three cases, voting was a form of authorization by the constituency - election (KAV), referendum (Hamburg), online voting (Münster). Authorization by the respective (claimed) constituency turned out to be more complicated than expected. We found a significant discrepancy between the claimed constituency, the actually affected audience, and the formally intended (legally enfranchised) constituency. In some cases, the gap between the affected audience and the legally enfranchised constituency was relatively wide (Hamburg); in other cases, the process itself was inclusive - i.e., those affected were enfranchised to participate in the process. However, even when those affected were enfranchised, only a small portion participated (KAV, Münster). Finally, in one case (KAV), the claim-making process served to construct a different constituency than the legally prescribed constituency (KAV).

The decision-making authority included the municipal government (KAV, Münster) and the voters (Hamburg). Decision-making authorities employed different criteria for the authorization of claims. For the Frankfurt government, the critical criteria were the overlap between claimed and intended constituency. For Münster, government effectiveness and feasibility of claims represented the main criteria. In Hamburg, the voters decided, and their affected interest were the main criteria.

Claim-making in democratic innovations is fractured and incomplete. Nevertheless, this is not the reason to dismiss democratic innovations as possible loci of representation; on the contrary, seen thorugh the prism of claim-making, all representation - electoral and nonelectoral - is partial. Focusing on the authorization of claims in democratic innovations provides novel inference about the potential and limits of democratic innovations for broadening democratic representation (cf. Plotke, 1997).

Our cases resonate with Urbinati's agonistic conception of representation as advocacy (Urbinati, 2000). Especially the cases of Frankfurt and Hamburg show that clashes within claim-making do not only include competing interests, but also who is represented within these democratic innovations. Furthermore, we also show the importance of voice for historically marginalized groups (non-citizens, children; cf. Williams, 2000); while the constituency might accept a claim-maker as its representative, the relevant authority might reject the claim-maker, his claim, or both - if the interests of the group clash with formal (legal) boundaries or rules (cf. Rehfeld, 2006). We confirm the importance of the context under which claim-making occurs (cf. Saward, 2006; Saward, 2010). These contexts (the design of democratic innovations) determine the types of claims, their acceptance, and authorization.

Our approach fills several gaps in the existing literature on authorization (Kuyper, 2016; Heinisch and Werner, 2019; Joschko and Glaser, 2019). Kuyper's approach assesses the process as a whole, while the approach outlined here enables scholars to focus on individual claims - providing inference on the performative elements of representation beyond elections. For Heinisch and Werner (2019) elections and descriptive overlap between elected representatives and claimed constituency remain core authorization mechanisms. Our approach enables scholars to study the authorization of claims beyond elections, bridging both the traditional and constructivist representation. Finally, the sophisticated data used by Joschko and Glaser (2019) to identify constituencies and asses validation, is not available for most claims made outside the parliamentary arena. Thus, our approach offers broader applicability, especially to the scholars of nonelectoral representation.

The contribution of this paper is three-fold. To the scholars of traditional representation, we want to demonstrate that representation exists beyond traditional parliamentary politics and can be systematically analyzed. To the scholars of constructivist representation, we offer a way to assess authorization systematically. Moreover, for scholars of democratic innovations, this is an invitation to use claimmaking to better understand the dynamics within democratic innovations.

Our study has important limitations. The process of tracing claims is labor-intensive and time-consuming, relies on data availability, requires in-depth qualitative research, and comparability across different types of democratic innovations is only achieved at a higher level of abstraction. 
There is a broad scope of authorization mechanisms, and authenticity or descriptive representation are only two of its many underlying logics (cf. Kuyper, 2016; Heinisch and Werner, 2019). Our study shows that distinguishing between authorization by the constituency and the decision-making authority enables us to understand the dynamics of representation better. Therefore, we propose future research to go beyond elections as the only authorization mechanism and focus on other ways claims can be authorized/accepted (Guasti and Geissel, 2019; cf. Joschko and Glaser, 2019).

\section{DATA AVAILABILITY STATEMENT}

The raw data supporting the conclusions of this article will be made available by the authors, without undue reservation.

\section{REFERENCES}

Andeweg, R. B. (2003). Beyond representativeness? Trends in political representation. Eur. Rev. 11, 147-152. doi:10.1017/S1062798703000164

Ankersmit, F. R. (2002). Political representation. Palo Alto, CA: Stanford University Press.

Biezen, I. V. (2014). The end of party democracy as we know it? A tribute to Peter Mair. Irish Polit. Stud. 29 (2), 177-193. doi:10.1080/07907184.2014.897944

Bourdieu, P. (1991). Language and symbolic power. London, UK: Harvard University Press.

Dalton, R. J., Farrell, D. M., and Ian McAllister, I. (2011). Political parties and democratic linkage: how parties organize democracy. London, UK: Oxford University Press.

de Wilde, P. (2013). Representative claims analysis: theory meets method. J. Eur. Public Pol. 20 (2), 278-294. doi:10.1080/13501763.2013.746128

de Wilde, P. (2020). The quality of representative claims: uncovering a weakness in the defense of the liberal world order. Polit. Stud. 68 (2), 271-292. doi:10.1177/ 0032321719845199

Disch, L., Van de Sande, M., and Urbinati, N. (2019). The constructivist turn in political representation. Edinburgh, UK: Edinburgh University Press.

Disch, L. (2009). The people as "presupposition" of representative democracy-An essay on the political theory of Pierre Rosanvallon. Redescriptions: Yearb. Polit. Thought, Conceptual Hist. Feminist Theor. 12, 47-71. doi:10.7227/R.12.1.4

Disch, L. (2011). Toward a mobilization conception of democratic representation. Am. Polit. Sci. Rev. 105 (1) 100-114. doi:10.4324/9781315681696-6

Disch, L. (2015). The "Constructivist Turn" in democratic representation: a normative dead-end?. Constellations 22 (4), 487-499. doi:10.1111/1467-8675.12201

Dovi, S. (2017). Representation in context: constructing victims' claims in the international criminal court. Representation 53 3-4. doi:10.1080/00344893. 2018.1434231

Dryzek, J. S., and Simon, N. (2008). Discursive representation. Am. Political Sci. Rev. 102 481-493. doi:10.1017/S0003055408080325

Geißel, B., and Joas, M. (2013). Participatory democratic innovations in Europe: improving the quality of democracy?. Leverkusen, NW: Verlag Barbara Budrich.

Geißel, B., and Jung, S. (2020). "Explaining institutional change towards recall in Germany," in The politics of recall elections, (London, UK: Palgrave Macmillan), $117-141$.

Geissel, B., and Jung, S. (2018). Recall in Germany: explaining the use of a local democratic innovation. Democratization 25 (8), 1358-1378. doi:10.1080/ 13510347.2017.1398735

Guasti, P., and Geissel, B. (2019). Saward's concept of the representative claim revisited: an empirical perspective. Polit. Governance 7 (3), 98-111. doi:10. 17645/pag.v7i3.2103

Guasti, P., and Rezende de Almeida, D. (2019). Claims of misrepresentation: a comparison of Germany and Brazil. Polit. Governance 7 (3), 152-164. doi:10. 17645/pag.v7i3.2143

\section{AUTHOR CONTRIBUTIONS}

Iterative process - both co-authors worked on all parts of the article and contributed equally to the development of the typology of claims on representation. Additionally, $\mathrm{PG}$ was responsible for data collection an analysis (90\%) and the conclusions (70\%).

\section{FUNDING}

We thank the DFG and ANR for their kind funding of the research project "(New) Political Representative Claims: A Global View (France, Germany, Brazil, India, China)". We also thank the two reviewers, the editor, and participants of the panel 'Local Democratic Innovations and Local Representative Democracy', at the 2020 ECPR Virtual General Conference August 24-28, 2020.

Heinisch, R., and Werner, A. (2019). Who do populist radical right parties stand for? Representative claims, claim acceptance and descriptive representation in the Austrian FPÖ and German Alternative for Deutschland.Representation 4, 475-492. doi:10.1080/00344893.2019.1635196

Hirst, P. (2013). Associative democracy: New forms of economic and social governance. John Wiley and Sons.

Joschko, V., and Glaser, L. (2019). A new approach to map and quantify representative claims and measure their validation: a case study analysis. Polit. Governance 7 (3), 137-151. doi:10.17645/pag.v7i3.2150

Kitschelt, H. (2000). Linkages between citizens and politicians in democratic polities. Comp. Polit. Stud. 33 (6-7), 845-879. doi:10.1177/001041400003300607

Kroeber, C. (2018). How to measure the substantive representation of traditionally excluded groups in comparative research: a literature review and new data. Representation 3, 241-259. doi:10.1080/00344893.2018.1504112

Kuyper, J. W. (2016). Systemic representation: democracy, deliberation, and nonelectoral representatives. Am. Polit. Sci. Rev. 110 (2), 308. doi:10.1017/ S0003055416000095

Mair, P. (2008). The challenge to party government. West Eur. Polit. 31 (1-2), 211-234. doi:10.1080/01402380701835033

Mair, P. (2009). Representative versus responsible government." MPIfG Working Paper 09/8.

Manin, B. (1997). The principles of representative government. London, UK: Cambridge University Press.

Mansbridge, J. (1999). Should blacks represent blacks and women represent women? A contingent" yes. J. Polit. 61 (3), 628-657. doi:10.2307/2647821

Mansbridge, J. (2003). Rethinking representation. Am. Political Sci. Rev. 97 (4), 515-528.

Mansbridge, J. (2009). A "selection model" of political representation. J. Polit. Philos. 17 (4), 369-398. doi:10.1111/j.1467-9760.2009.00337.x

Mansbridge, J. (2011). Clarifying the concept of representation. Am. Polit. Sci. Rev., 621-630. doi:10.1017/S0003055411000189

Mansbridge, J. (2013). "Common Good". In The international encyclopedia of ethics. Editor LaFollette, H., Vol. II. Malden, MA: Wiley-Blackwell.

Mansbridge, J. (2015). Should workers represent workers?. Swiss Polit. Sci. Rev. 21 (2), 261-270. doi:10.1111/spsr.12160

Montanaro, L. (2012). The democratic legitimacy of self-appointed representatives. J. Polit. 74 (4), 1094-1107. doi:10.1017/S0022381612000515

Montanaro, L. (2017). "Who elected oxfam?," in A democratic defense of selfappointed representatives. (Cambridge, UK: Cambridge University Press).

Montanaro, L. (2018). "Who counts as a democratic representative?," in Creating political presence: The new politics of democratic representation. Editors D. Castiglione and J. Pollak. University of Chicago Press, 186

Näsström, S. (2006). Representative democracy as tautology: Ankersmit and lefort on representation. Eur. J. Polit. Theor. 5 (3), 321-342. doi:10.1177/ 2F1474885106064664

Phillips, A. (1995). The politics of presence. England, UK: Clarendon Press. 
Pitkin, H. F. (1967). The concept of representation. Berkeley, CA:University of California Press.

Pitkin, H. F. (2004). Representation and democracy: uneasy alliance. Scand. Polit. Stud. 27 (3), 335-342. doi:10.1111/j.1467-9477.2004.00109.x

Plotke, D. (1997). Representation is democracy. Constellations 4 (1), 19-34. doi:10. 1111/1467-8675.00033

Przeworski, A., Stokes, S. C., and Manin, B. (1999). Democracy, accountability, and representation. London, UK: Cambridge University Press.

Rehfeld, A. (2006). Towards a general theory of political representation. J. Polit. 68 (1), 1-21. doi:10.1111/j.1468-2508.2006.00365.x

Rosanvallon, P. (2008). Counter-democracy: politics in an age of distrust. London, UK: Cambridge University Press.

Runciman, David. (2007). The paradox of political representation. J. Polit. Philos. 15 (1), 93-114. doi:10.1111/j.1467-9760.2007.00266.x

Sartori, G. (1987). The theory of democracy revisited. London, UK: Chatham House Publications.

Saward, M. (2006). The representative claim. Contemp. Polit. Theor. 5 (3), 297-318. doi:10.1057/palgrave.cpt.9300234

Saward, M. (2008). Representation and democracy: revisions and possibilities. Sociol. Compass 2 (3), 1000-1013. doi:10.1111/j.1751-9020.2008.00102.x

Saward, M. (2009). Authorisation and authenticity: representation and the unelected. J. Polit. Philos. 17 (1), 1-22. doi:10.1111/j.1467-9760.2008. 00309.x

Saward, M. (2010). The representative claim. Oxford, UK: Oxford University Press.

Severs, E. (2012). Substantive representation through a claims-making lens: a strategy for the identification and analysis of substantive claims. Representation 48 (2), 169-181. doi:10.1080/00344893.2012.683491

Urbinati, N (2002). Mill on democracy: from the Athenian polis to representative government. University of Chicago Press.
Urbinati, N., and Warren, M. E. (2008). The concept of representation in contemporary democratic theory. Annu. Rev. Polit. Sci. 11, 387-412. doi:10. 1146/annurev.polisci.11.053006.190533

Urbinati, N. (2000). Representation as advocacy: a study of democratic deliberation. Polit. Theor. 28 (6), 758-786. doi:10.1177/0090591700028006003

Van Biezen, I., and Saward, M. (2008). Democratic theorists and party scholars: why they don't talk to each other, and why they should. Perspect. Polit. 6 (1), 21-35. doi:10.1017/S1537592708080043

Warren, M. E., and Hilary, P. (2008). Designing deliberative democracy: The British Columbia citizens' assembly. Cambridge, UK: Cambridge University Press, 1-19.

Warren, M. E. (2001). Democracy and association. Princeton, NJ: Princeton University Press.

Williams, M. S. (2000). Voice, trust, and memory: marginalized groups and the failings of liberal representation. Princeton, NJ: Princeton University Press.

Zulianello, M., and Ceccobelli, D. (2020). Don't call it climate populism: on Greta thunberg's technocratic ecocentrism. The political quarterly. 91 (3), 623-631. doi:10.1111/1467-923X.12858

Conflict of Interest: The authors declare that the research was conducted in the absence of any commercial or financial relationships that could be construed as a potential conflict of interest.

Copyright $(2021$ Guasti and Geissel. This is an open-access article distributed under the terms of the Creative Commons Attribution License (CC BY). The use, distribution or reproduction in other forums is permitted, provided the original author(s) and the copyright owner(s) are credited and that the original publication in this journal is cited, in accordance with accepted academic practice. No use, distribution or reproduction is permitted which does not comply with these terms. 


\section{OPEN ACCESS}

Edited by: Jean-Benoit Pilet,

Université libre de Bruxelles, Belgium

Reviewed by:

Wouter Van Der Brug,

University of Amsterdam, Netherlands

Rodney Kenneth Smith,

The University of Sydney, Australia

*Correspondence:

Nino Junius

Nino.Junius@vub.be

Specialty section:

This article was submitted to Elections and Representation,

a section of the journal

Frontiers in Political Science

Received: 17 July 2020 Accepted: 14 October 2020 Published: 12 November 2020

Citation: Junius N, Matthieu J, Caluwaerts D and Erzeel S (2020) Is It Interests,

Ideas or Institutions? Explaining

Elected Representatives' Positions

Toward Democratic Innovations in 15

European Countries.

Front. Polit. Sci. 2:584439

doi: 10.3389/fpos.2020.584439

\section{Is It Interests, Ideas or Institutions? Explaining Elected Representatives' Positions Toward Democratic Innovations in 15 European Countries}

\author{
Nino Junius*, Joke Matthieu, Didier Caluwaerts and Silvia Erzeel \\ Department of Political Science, Vrije Universiteit Brussel, Brussels, Belgium
}

In response to the alleged legitimacy crisis, representative democracies have in recent years witnessed increased demands for democratic innovations aimed at giving citizens a more direct say in decision-making. Such initiatives, however, often rock the foundations of the model of representative democracy which assumes a more indirect link between citizens and political decisions, and which puts political power more firmly in the hands of elected representatives. In this paper, we study how these elected members of parliament (MPs)-who are key actors in representative democracy, yet potentially see their role reduced in deliberative or participatory models of democracy-think about democratic innovations. We study to what extent and why they support two common types of democratic innovations, namely referendums and deliberative events. While it is generally assumed that MPs' positions toward these initiatives are driven by their ideological predispositions, we propose and test a comprehensive framework which considers the role played by 3 "I's": ideas, interests and institutions. Using original data from the PARTIREP MP survey, this paper maps variations in MPs' preferences for democratic innovations across 15 European countries, and shows that these variations can be explained by differences in MPs' ideological (left/right) views, legitimacy perceptions and role conceptions, their strategic position in government or opposition, and their electoral incentives. The 3l framework predicts MPs' support for both types of innovations, but more strongly so for referendums than for deliberative events.

Keywords: democratic innovations, members of parliament, citizen participartion, direct democracy, deliberative democracy, comparative survey research

\section{INTRODUCTION}

The proliferation of democratic innovations in Western democracies has both complemented and challenged the predominantly representative nature of Western politics (Geißel and Joas, 2013; Grönlund et al., 2014). These democratic innovations aim to reinvigorate representative democracy by increasing and deepening citizen participation in the decision-making process, and by attempting to establish a more direct link between citizens and political outcomes (Smith, 2009). This logic of direct citizen participation in politics seems at odds with the prevailing representative logic of contemporary democracies, which assumes a more indirect link between citizens and political decisions, and which puts political power firmly in 
the hands of elected representatives. The latter, however, remain the ultimate gatekeepers and power brokers of modern politics and could therefore be reluctant to shift power from parliament to the people (Núñez et al., 2016), often resulting in democratic innovations' limited macro-level political impact (Goodin and Dryzek, 2006; Newton and Geißel, 2012; Bua, 2017; Font et al., 2018; Pogrebinschi and Ryan, 2018). The success and impact of democratic innovations thus depend in no small measure on whether these elected representatives are willing to relinquish some of their power to "ordinary" citizens. Understanding members of parliaments' positions toward democratic innovations is therefore essential to understanding their adoption and uptake.

Despite representatives' central role in adopting democratic innovations, remarkably little is known about their views and preferences on these innovations. In order to gain a better understanding of this, we study in this article how elected members of parliament (MPs) in 15 European democracies think about democratic innovations. Our central question is: To what extent and why do MPs support democratic innovations? Our focus in this article is on two of the most common types of democratic innovations, namely referendums and deliberative events (Smith, 2009).

To explain MPs' positions toward democratic innovations, we borrow a comprehensive framework from the policy sciences which focuses on ideas, interests, and institutions (Hall, 1997; Palier and Surel, 2005). This framework allows us to grasp why MPs are more or less likely to adopt democratic innovations by assessing the relative weight of each of the three I's. Additionally, this framework allows us not only to test the effect of several independent variables on a dependent variable, but also to more carefully theorize the relation between these independent variables (Hall, 1997; Palier and Surel, 2005). By proposing this 3I-framework, we move beyond the current state of the art, and complement previous studies on this topic which have conducted in-depth studies of one or two of these explanations separately or which have emphasized the role of "ideas" over "interests" and “institutions” (Bowler et al., 2006; Núñez et al., 2016).

Based on the 3I-framework, we hypothesize that MPs' support for democratic innovations will depend on: (1) their ideological considerations (left-right self-identification and party ideology), their legitimacy perceptions, and their representative role orientations (trustee vs. delegate roles), (2) their strategic interests (opposition vs. government dynamics, and perceived chances of re-election) and (3) the incentives offered by the broader institutional context (consensus vs. majoritarian institutions). These hypotheses will be tested using original survey data on individual MPs' democratic preferences, gathered by the comparative PARTIREP survey between 2008 and 2014 in 15 European countries. The study was conducted in 15 statewide and 58 meso-level legislatures, which generates sufficient contextual variation to test the impact of the different variables in one model. The PARTIREP survey was kept constant across the 15 countries, which means that we can analyze information on the positions of more than 2.000 MPs using the exact same survey questions.
In doing so, this paper breaks new ground in two ways. On the one hand, we connect the explanatory framework from the policy sciences (the 3I framework) to the literature on democratic innovations. Usually, the literatures on public policy and on democratic innovations develop largely in isolation, but here we aim to explicitly link insights from the policy sciences to preferences on democratic reform. On the other hand, our focus on individual MPs in comparative perspective is also novel. Previous studies about democratic process preferences focus on individual citizens [see e.g., Gherghina and Geißel (2020); Ferrín and Kriesi (2016)], on parties (Núñez et al., 2016), or on MPs in single countries (Jacquet et al., 2020). We offer another level of analysis by explaining MPs preferences in a cross-national comparative perspective.

In the remainder of this paper, we first discuss the complex relation between democratic innovations and elected representatives. Next, we propose the main hypotheses guiding our model of ideas, interests and institutions. Afterwards, we outline our methodology and the operationalization of the variables. Finally, we report and discuss the results of our analysis, and draw more general conclusions.

\section{ELECTED REPRESENTATIVES AND DEMOCRATIC INNOVATIONS}

The relationship between representative democracy and democratic innovations is complex. On the one hand, democratic innovations challenge the legitimacy and power of elected representatives. Because they give ordinary citizens a more direct say in political decision-making, they shake the foundations of the model of representative democracy which envisions a more indirect political role for citizens. On the other hand, democratic innovations also crucially depend on elected MPs (and other actors in the representative system) for their political uptake and their institutionalization within the political system. The origins of this difficult relationship can be traced back to the alleged crisis of representative democracy (Dalton and Weldon, 2005; Poguntke et al., 2016). Recent studies have reported a widespread dissatisfaction with the institution of representative democracy in advanced industrial democracies (Ferrín and Kriesi, 2016). Among the indicators of this critical stance are: declining party memberships (Van Haute et al., 2018), weaker party identification (Dalton, 2014), lower trust in parties (Dalton, 2004) and the rise of populist parties (Mudde, 2007; Kriesi and Pappas, 2015). This crisis proved to be fertile ground for a plethora of democratic innovations, ranging from participatory budgeting over deliberative mini-publics to direct legislation (Smith, 2009; Newton and Geißel, 2012; Elstub and Escobar, 2019). What unites all these innovations is their attempt to cure the ails of democracy with more democracy, in which "more democracy" stands for a more direct and participatory bond between citizen and government. This trend toward direct participation constitutes a paradigm shift with the indirect and representative logic in which MPs operate (Mudde, 2007; Kriesi and Pappas, 2015). 
At first sight, elected representatives and democratic innovations do stand in a contentious relationship toward one another. Despite theoretical arguments made in defense of the normative value and deliberative potential of parliaments and parties (White and Ypi, 2011; Wolkenstein, 2016), the very foundations of democratic innovation are inevitably in conflict with the logic of representation and the role played by elected MPs in the democratic system. After all, one predominant rationale behind the recourse to democratic innovations is to free politics from the shackles of partisanship and to see what happens when ordinary citizens discuss and decide on political issues, unharmed by partisan considerations or the weight of the next election (Fishkin, 2018).

Besides these normative arguments, empirical research suggests that there is a correlation between citizens' dissatisfaction with "politics as usual" and their support for democratic innovations (Ferrín and Kriesi, 2016). Dalton (2004), finds an association between a preference for direct democracy and dissatisfaction with the current system. His results seem to be confirmed by the finding that participating in referendums in Switzerland leads to a lower probability of participating in demonstrations, which suggests that democratic innovations can ease political dissatisfaction (Fatke and Freitag, 2013). Similarly, Neblo et al. (2010) find that especially those citizens that are dissatisfied with partisan politics are keener on participating in deliberative forums. Other studies show that trust in political parties is correlated with satisfaction with the functioning of MPs and representative democracy (Miller and Listhaug, 1990; Dalton and Weldon, 2005). Democratic innovations are thus most supported among those that are unhappy with the functioning and legitimacy of elected representatives.

Nevertheless, this does not depict the complete picture. Democratic innovations do not only challenge representatives, they also paradoxically depend on them in two ways. First, representatives shape the public discourse about democratic innovations and their legitimacy. They have a prominent voice in the public debate, and their megaphone can considerably influence the discussion about democratic innovations. One illustration thereof is the G1000 citizen assembly in Belgium which several political parties discredited as an antirepresentative, anti-political, and partisan enterprise. This framing delegitimized the citizen assembly and its results, while at the same time raising the threshold for future mini-publics (Caluwaerts and Reuchamps, 2015). In addition, research has shown that political elites play a key role in the structuring of public discourse about direct legislation. After all, referendums are not conducted in an aggregative vacuum and are preceded by a public debate in which the legitimacy of the procedure itself is often called into question (Budge, 2001).

Second, representatives of government parties are important actors in the political uptake of democratic innovations. Democratic innovations rarely have a direct impact, especially when they are not supported by the major institutions of representative democracy (Goodin and Dryzek, 2006). This lack of uptake is especially strong when representatives are uninvolved in the design of these innovations (Caluwaerts and Reuchamps, 2016). However, when representatives are too engaged in designing and organizing democratic innovations, some authors fear that they might instrumentalize them for their own interest (Klijn and Koppenjan, 2002). Representatives' skepticism about democratic innovations thus seems to correlate with the amount of influence they can exert on them. This is of crucial importance, as ultimately MPs will decide on the uptake of democratic innovations.

If democratic innovations are indeed intended to be workable institutional vehicles of participatory and deliberative aspirations, then we should take great interest in understanding the position of representatives toward democratic innovations. Previous studies have argued that a variety of factors can shape political actors' stance on this issue. These factors are often summarized as being linked to three "I's": ideas, interests and institutions (Palier and Surel, 2005). The notion of "ideas" assumes that political actors' democratic process preferences will reflect their broader opinions, perceptions, viewpoints, and ideological considerations on the issue at stake. In this sense, MPs will only support democratic innovations if their general worldviews and political opinions are in line with the principles and values underpinning democratic reform. The notion of “interests" assumes that MPs' support for democratic innovations will depend on their own strategic calculations. If the rise of democratic innovations indeed causes a shift in power from the representative to the citizen, from the parliament to the people, then MPs will primarily support innovations if they have something to gain from it (or at least: if they do not expect to lose too much from it). The notion of "institutions" finally assumes that the institutional context in which MPs operate will convey certain norms about what constitutes "proper" behavior and what makes a democracy. These institutional rules and norms will in turn also shape MPs' viewpoints on democratic innovations.

The next sections discuss different explanations linked to the three "I's" in more detail and will also formulate several hypotheses which will be tested empirically in the remainder of the paper.

\section{The Power of Ideas}

In a very general manner, the ideas underlying direct and deliberative democracy are grounded in a positive view on humankind and its potential for self-development. Supporters of participatory democracy reject the idea that citizens are mainly incompetent and incapable to govern themselves and society, and value principles such as self-determination, independence, and individual autonomy. They consider that democracy can empower citizens as autonomous, free, and capable individuals (Floridia, 2017). Perhaps unsurprisingly then, democratic innovations seem to have found a natural ally in leftwing ideologies. Several empirical studies have confirmed this assumption. Donovan and Karp (2006) showed for New Zealand, Norway, and Sweden a positive relation between left-wing attitudes and support for direct democracy. Only in Switzerland, there was a positive relation with right-wing attitudes. Hibbing and Theiss-Morse (2002) show a positive correlation between right-wing attitudes and a lower willingness to participate in politics in the United States. Results from Finland also confirm 
on the one hand the relationship between respondents with leftwing ideological affiliations and direct democracy, and on the other right-wing attitudes with support for stealth democracy (Bengtsson and Mattila, 2009). The same can be expected for support toward deliberative democracy. In a comment on the state of the field, Ryfe (2010, p. 1) observes that "anyone who circulates among deliberative practitioners knows that, ideologically, they tend to have a liberal progressive bent."

This progressive bent can also be expected among representatives (whose views are ideally also congruent with their constituents). In general, one's position on the left-right dimension may affect one's position toward democratic reform. On the one hand, left-wing MPs are expected to be more positive toward democratic reform that contributes to an inclusive and egalitarian society. On the other hand, right-wing MPs, especially those who support a more conservative notion of maintaining the current institutional arrangements and social order will most likely oppose democratic reform of any kind (Bowler et al., 2002; Bol, 2016; Núñez et al., 2016). Hence, we assume that:

H1: Self-identified left-wing representatives are more supportive of democratic innovations compared to self-identified rightwing representatives

However, a simple left-right distinction might be insufficient to understand the possible effects of ideology. Post-materialist ideas and values might be equally important. MPs with underlying post-materialist values emphasize political selfexpression and direct action (Bowler et al., 2006). Post-materialist attitudes are associated with left-wing ideological orientations in general, however, this is mostly embedded within green parties. As challenger parties (Doherty, 2005; Richardson and Rootes, 2006; Frankland et al., 2008), they are prominent supporters of democratic reform. One of their key distinctive features is their belief in grassroots democracy and aim to reinvigorate democracy by increasing referendums, public access to policymakers and decentralizing representative decisionmaking (Doherty, 2005). Hence, we expect that:

H2: Green representatives are more supportive of democratic innovations than other representatives

Radical right parties are also challengers of representative democracy; yet, differently so than green parties. The key ideological features of this party family-nativism, authoritarianism, and populism (Mudde, 2007)-clash with the ideological biases found in deliberative processes, i.e., liberalism, cosmopolitanism and social justice for all (Gastil et al., 2010). Hence, the proposed way to take back control from the elite to the people is not through deliberative fora, but rather through the introduction of plebiscitary democracy and referendums in specific. Such reforms are better suited to echo the preferences of the people without the elite intermingling (Mudde, 2007; Jacobs, 2018). We therefore expect radical right MPs to support referendums, but to oppose deliberative democratic innovations:

H3: Radical right representatives support referendums but oppose deliberative events

Ideational factors can also incentivize MPs to support democratic innovations in another way. Referendums and minipublics are often presented as a cure for the malaise of representative democracy (Newton and Geißel, 2012). As such, support for these innovations might depend on MPs perceptions of that malaise, and of the extent to which referendums and mini-publics can close the gap between citizens and politicians. MPs might thus support democratic innovations for principled, ideological reasons, but also out of pragmatic perceptions of the severity of the democratic disconnect.

H4: MPs who perceive a large legitimacy gap will be more supportive of democratic innovations

Finally, and in addition to MPs' ideological considerations and their perceptions of the legitimacy gap, we also assume that representatives' role orientations will shape their views on democratic reforms. Thompson (2019) suggests that how MPs conceive and understand their role as representatives explains to what extent they will support citizens' input and democratic innovations. A classical and useful distinction can be drawn between "trustee" and "delegate" roles (Pitkin, 1967). Proponents of the trustee model argue that representatives should represent the common good through their own judgement, while advocates of the delegate model defend the idea that representatives should stay as close to their constituents' preferences as possible. Given that delegates' representational work strongly depends on their constituents' inputs, we can expect that the delegate model fits better with democratic innovations which empower citizens than the trustee model.

H5: Representatives who act as "delegates" are more supportive of democratic innovations compared to representatives acting as "trustees"

\section{Strategic Interest}

A second set of explanations relates to representatives' strategic interest. Deliberative events and referendums can be binding to various degrees but in general they imply a shift of power from the professional politician to the "lay" citizen (Vandamme et al., 2018). This shift in power is most likely to be supported by those who derive a strategic advantage from it (Bowler et al., 2006). We test two strategic considerations for MPs' views on democratic innovations, namely whether they belong to a government party or an opposition party, and their expectations for the next elections.

On the one hand, we expect that belonging to an opposition party positively affects representatives' support for democratic innovations. Representatives in the majority are more likely to support current electoral arrangements and resist institutional change (Boix, 1999; Pilet and Bol, 2011; Núñez et al., 2016). There are three main reasons for this: representatives' assessment of existing institutional arrangements, their evaluation of new avenues to influence governance, and their (un)willingness to take risks.

First, when representatives are confronted with institutional or democratic reform, they will first assess how advantageous the existing arrangements are to them. MPs belonging to the majority will resist change to democratic rules when these rules are beneficial to them. MPs in opposition, on the other hand will find themselves excluded from power and will try to weaken MPs in governing parties through changing the institutional status 
quo. They will support democratic innovations to distinguish themselves from the majority (Pilet and Bol, 2011).

A second reason is that democratic innovations provide additional avenues for political actors to influence the political system. Democratic innovations have a centrifugal effect on power and provide an opportunity for political forces outside of the governing elite to influence the political agenda Democratic innovations therefore not only restrain the power of ruling parties, they also provide an opportunity for opposition parties to exert influence (Leduc, 2003; Rahat, 2009; Altman, 2010). In this sense, they have the potential to be an important tool of what Rosanvallon and Goldhammer (2008) have famously called counter-democracy. Referendums and deliberative events can thus be strategically used to push an agenda that is not supported by those in power.

Finally, risk aversion plays an important role. Representatives belonging to government parties will tend to support the status quo, even if the new reform could potentially increase their gains (MacKuen et al., 1992; Pilet and Bol, 2011). In other words, the potential advantages of democratic reforms do not outweigh the actual advantages of the current institutional setting. After all, members of government parties attained power in the current institutional setting and are therefore less keen on changing it. In contrast, dissatisfied MPs in the opposition will be more willing to take risks since they hope that referendums and deliberative events will overcome the status quo and bypass governing elites. Hence, we assume that:

H6: Representatives of opposition parties are more supportive of democratic innovations than representatives of ruling parties

On the other hand, we also assume that representatives' expectations for the upcoming elections will shape their support for democratic innovations. When representatives feel electorally vulnerable and are unsure about their chances to win at the next elections, they will focus on limiting their electoral losses. To do so, they will likely take up and support proposals that are popular among public opinion. We assume that the support for democratic innovations was strong at the time of our survey. European countries were hit by the (aftermath of) economic crisis, which also affected democratic legitimacy. Citizens who became more dissatisfied with democracy (Armingeon and Guthmann, 2014; Cordero and Simón, 2016) are likely to decrease support for traditional politics and increase their support for new forms of citizen-based democracy (Neblo et al., 2010; Jäske, 2017; Bedock and Pilet, 2020). We can therefore expect that MPs anticipating an electoral defeat are more likely to support democratic innovations as it might enable them to gain electoral support (Bowler et al., 2007; Bengtsson and Mattila, 2009; Webb, 2013). From a strategic point of view, representatives will support democratic innovations when they fear not getting re-elected. We assume that:

H7: Representatives Who are unsure about their Re-election or fear electoral defeat are more supportive of democratic innovations

\section{Institutional Incentives}

Institutions constitute a final determinant of representatives' support for democratic innovations. Scholars have argued that the institutional set-up of a country incentivizes certain kinds of politics over others (Hall, 1997; Palier and Surel, 2005). The extent to which power is shared in a democracy is widely acknowledged as a crucial institutional determinant (Vatter, 2000; Jäske, 2017). Of crucial importance in this regard is Lijphart's (1984) seminal distinction between majoritarian and consensus democracies. Its executive party dimension draws our focus to multi-party coalitions, decentralized government, and proportional electoral systems in the case of consensus democracies. In contrast, majoritarian democracies are characterized by a dominant executive, two-party systems, and majoritarian electoral systems.

We expect that MPs functioning in consensus democracies will welcome democratic innovations more than those functioning under majoritarian institutions. After all, both consensus democracies and democratic innovations are built on the principle of power sharing. The deliberative principles of inclusion, dialogue, and reason-giving seem to fit particularly well with the power sharing and cooperative mentality in consensus democracies (Steiner, 2009; Lijphart, 2019). Moreover, Lijphart (1984) argued that there is a strong link between cultural attitudes and structural institutions. The more proportional a system is, the more it forces political actors to come to a consensus. This creates a culture that resounds with the redistributive logic of democratic innovations and might foster a deliberative mindset among its representatives (Vatter and Bernauer, 2009).

There is some empirical support for the theoretical assumption that deliberation might thrive in consensus democracies. Steiner et al. (2004), for instance, find that discussions within parliaments in consensus democracies are more deliberative than these in majoritarian parliaments. Others show that consensus institutions advance deliberation in representative institutions (Bächtiger et al., 2005). Even though previous research on the occurrence of democratic innovations finds no clear link between the institutional system and the presence of democratic innovations in a country (Hendriks and Michels, 2011; Geißel and Michels, 2018), our aim is slightly different. We are interested in studying whether institutional incentives impact MPs' support of democratic innovations, which is different from their presence in specific democracies.

The literature dealing with institutional effects on referendums is nuanced, but suggests that much depends on who initiates the referendum and whether it is binding or not (Qvortrup, 2005; Setälä, 2006). While referendums, just like other innovations, disperse power from the executive elite to the people, this dynamic is much more outspoken in the case of bottom-up referendums than in the case of governmentinitiated referendums (Vatter, 2000; Vatter and Bernauer, 2009). Power sharing and a participatory culture lead to more bottom-up referendums. Additionally, the aggregative logic of referendums, as contrasted to the "talk" logic of deliberative events is arguably more in line with majoritarian systems (Geißel and Michels, 2018). Nevertheless, we will assume that generally speaking the power-sharing properties of a referendum will be more determinant than its aggregative logic, regardless of the referendum's initiator. We formulate the following hypothesis: 
H8: Representatives in consensus democracies will be more supportive of democratic innovations than representatives in majoritarian systems

\section{DATA AND METHODS}

In order to answer the research questions and test the hypotheses, we use original data from the PARTIREP comparative MP survey (Deschouwer and Depauw, 2014; Deschouwer et al., 2014) in 15 European countries: Austria, Belgium, Germany, France, Hungary, Ireland, Israel, Italy, the Netherlands, Norway, Poland, Portugal, Spain, Switzerland, and the United Kingdom. The countries were selected to represent a wide institutional variation in terms of electoral systems (proportional representation, majority/plurality, and mixed-member systems), party systems (parliaments with strong and weak left-wing parties), and state structure (unitary and federal systems). The survey targeted members of all 15 state-wide parliaments as well as members of (a selection of) 58 regional assemblies in each of these countries. The selection of regions also reflected a careful balance of central and peripheral regions, regions with weak, and strong identities and regions with a strong left-wing or right-wing party presence.

The survey was organized by a team of international scholars from the 15 countries. All members of the selected parliaments were invited to complete a questionnaire online. The questionnaire was kept constant across the different languages. MPs who had not completed the survey after the initial invitation were re-contacted at least twice, except for those who had explicitly stated that they refused to participate in the project. In cases where response rates were disappointing, additional strategies were adopted to increase the response rate, such as the use of telephone reminders or face-toface interviews. The use of a variety of methods depended on the international partners' estimation of "best practices" in the past. On average, one in four MPs responded to the survey. Supplementary Table A1 gives an overview of the response rates per country. There are no significant differences in response rates between men and women. Because some leftist parties were slightly over-represented in the dataset, we apply a weighting by parliamentary party group to correct for party differences. The MPs furthermore belong to a variety of party families, including socialist/social democratic, Christian democratic, liberal, conservative, regionalist, green, radical right, communist, agrarian, religious and single issue parties.

Our paper compares MPs' support for democratic innovations. In order to measure MPs' positions, we rely on the following survey question: "In recent years, different views on voters' distrust of politicians and political parties have inspired widely diverging suggestions for reform. Of each of the following directions that reform could take, could you indicate how desirable you consider them?":

1. To increase the number of referendums

2. To increase the number of deliberative events, where groups of ordinary citizens debate and decide on particular issues.
The first item measures innovations through direct democracy whereas the second item measures innovations through deliberative democracy. We do consider direct democracy to be a democratic innovation, even though it has a long history in some countries (e.g., United States or Switzerland). However, we follow Smith's (2009, p. 111) argument that the referendum is an innovation because "in the institutional architecture of advanced industrial democracies, it tends to be used sparingly [...] For most [governments], direct legislation is a relatively untried and untested form of governance."

For each item, MPs had to indicate on a 4-point scale whether they considered those "not at all desirable," "not very desirable," "fairly desirable," "very desirable." MPs were asked to assess the desirability of each reform separately and were not asked to weigh one reform against another, or to consider potential trade-offs between different types of reforms. Because the survey question asked respondents to indicate the desirability of an increase in democratic innovations, their answers are possibly driven by the current situation in their country. In this view, Switzerland presents itself as a different case compared to the countries in the dataset, because of its frequent application of direct-democratic procedures on all levels of the Swiss federal state (Stojanović, 2006). We therefore conduct robustness checks (see below) in which we run models with and without Switzerland to test whether results are not driven by this particular country.

In order to explain varying levels of support for democratic innovations, we examine the impact of several independent variables, linked to the 3 Is. In order to measure MPs' ideas, we use three variables: MPs' left-right ideology, their party family and their role conceptions. MPs' left-right ideology is included in the PARTIREP survey as follows: "In politics, people sometimes talk of left and right. Using the following scale, where 0 means left and 10 means right where would you place our own views?." This is a useful variable because it allows us to capture MPs' individual positioning (rather than that of their party). The downside is that this variable does not allows us to distinguish between different dimensions of "left" and "right." We therefore use "party family" as a second proxy, given that we can expect that MPs take ideological cues from their party affiliations (Kam, 2009). Parties are categorized as belonging to one of the following eight party families: socialist/social democratic, Christian democratic, liberal, conservative, green/ecologist, radical right/anti-immigrant parties, regionalist/ethnic, and "other" parties. The "other parties" category puts together smaller party families in the survey, including communist, agrarian, religious, and single-issue parties. The socialist/social democratic family is the largest category and serves as the reference category. The international experts involved in the organization of the survey were in charge of the categorization of parties according to party family. Because MPs' left-right ideology correlates too strongly with party family (Pearson $r=0.524$ ) we do not include these two variables in the same models, but run different models including each variable separately.

In order to measure MPs' perceptions of the legitimacy gap, we rely on the following survey question: "Most politicians are out of touch with people's concerns." The answers were measured 
on a 5-point scale, ranging from "strongly disagree" (score 1) to "strongly agree" (score 5).

MPs' role conceptions are measured through the following survey question: "How should, in your opinion, a Member of Parliament vote if his/her own opinion on an issue does not correspond with the opinion of his/her voters? (1) The MP should vote according to his/her own opinion, (2) The MP should vote according to the opinion of his/her voters." The first answer serves as a proxy for MPs' "trustee" role, the second answer serves as a proxy for the "delegate" role.

The three variables linked to MPs' ideas are all attitudinal variables, as is the dependent variable. Although this potentially creates endogeneity problems, we believe such problems are limited in our study. First, the dependent variables do not correlate strongly with the independent variables to begin with. The strongest correlation is found between "left-right ideology" and "support for deliberative events" (Pearson $r=-0.275^{*}$ ). Second, the explanatory attitude "leftright ideology" in particular is of a different nature than the explained attitude "support for democratic innovations." The first corresponds with MPs' deep-seated values, whereas the second refers to MPs' specific process preferences.

In order to measure MPs' interest-based considerations, we use two variables. The first is a dummy variable "majority/opposition status," which distinguishes between MPs belonging to parties in government (score 0) or in opposition (score 1). The variable "electoral vulnerability" measures MPs' perceived re-election chances. The survey question asked: "If you were to decide to stand at the next general/regional elections, how confident do you feel you would be re-elected?." The answer categories were: (1) I would surely be elected, (2) I would probably be elected, (3) It could go either way. This question was not included in Norway and the Netherlands because of the nearness of elections in those two countries (Deschouwer et al., 2014). For this reason, the variable will be included in a separate model, so that information from Norway and the Netherlands is not lost in the other models.

Finally, we measure the effect of "democratic institutions" through MPs' incentives generated by the electoral system. Even though we would have liked to have included all ten variables distinguishing consensus and majoritarian democracies, we were unable to find reliable data for the period 2008-2014. Moreover, even though the Comparative Political Data Set, 1960-2017 (Armingeon et al., 2019) does offer reliable composite variables for consensus and majoritarian democracies, they were not available for all countries in the PARTIREP dataset. We are aware that the electoral system is a mere proxy for type of democracy (consensus vs. majoritarian), but it is the one that best captures the power-sharing dimension of consensus democracies, that is central to our hypotheses (Lijphart, 2012). We use a dummy distinguishing between non-PR (majority/plurality, score 0 ) and PR electoral formula (score 1). The electoral system variable is measured at the parliament level, not the country level. This means that different parliaments in one country can receive a different score. This is the case in multi-level countries (e.g., in the United Kingdom and France, regional elections operate under different electoral formulas than federal elections). In mixed member systems (such as Germany and Hungary) the PARTIREP survey attributes different scores to MPs elected under different tiers.

Supplementary Table A2 gives an overview of the descriptives of the main dependent and independent variables.

In order to test the relative strength of ideas, interests and institutions in explaining support for democratic innovations, we ran a multivariate Analysis of Covariance (ANCOVA) including several control variables. At the individual level, we control for MPs' sex (male vs. female), age (in years), seniority (in years) and education (university vs. non-university education). At the parliament level, we control for type of parliament (regional vs. federal/national). Because individual MPs are nested in the parliamentary party group and in parliaments, the data are potentially hierarchically clustered. Ideally, we would have performed a multilevel analysis to account for the hierarchical clustering of the data but this was not possible due to the small number of cases at the highest level. We therefore include country fixed effects in the different models of the regression analyses. This is appropriate because none of the independent or control variables is measured at the country level.

\section{EMPIRICAL FINDINGS}

\section{Testing the Hypotheses}

The results of the multivariate ANCOVA are reported in Table 1 (estimating support for referendums) and 2 (estimating support for deliberative events). Each Table includes three different models allowing us to assess the effect of different independent variables. The first two models include data from all 15 countries, and hence do not include the independent variable "electoral vulnerability" as data were unavailable for Norway and the Netherlands. The first model includes MPs' "left-right ideology" but excludes "party family" because of the relatively strong correlation between the two variables (cfr. supra). The second model includes "party family" but excludes "left-right ideology." The effects of "electoral vulnerability" are tested in the third model. All models include control variables and country fixed effects.

From Table 1 it is clear that most of the independent variables have a significant and strong effect on MPs' support for referendums. When it comes to MPs' ideological considerations, "party family" in model 2 has a much stronger effect than "left-right ideology" in model 1. Changing only this variable, the explanatory power $\left(R^{2}\right)$ of the model increases from $20.1 \%$ in model 1 to $25.9 \%$ in model 2. Support for referendums indeed does not follow a simple left-right continuum, which encourages us to reject hypothesis $\mathrm{H} 1$. Whereas, center or rightwing parties like Christian democratic parties and liberal parties are more skeptical of referendums compared to socialist parties, more support is found among regionalist, radical right and even conservative parties. This provisionally confirms our hypothesis $\mathrm{H} 3$ that radical right parties might favor referendums as a way of giving voice to the people. The same argument might also extend to regionalist parties, who might support referendums as a means to advocate the right to regional self-determination. The effect for conservative parties is also positive, but the significant effect 
TABLE 1 | General linear model estimating MPs' support for referendums (with country fixed effects).

\begin{tabular}{|c|c|c|c|c|}
\hline & & $\begin{array}{c}\text { Model } 1 \\
\text { B (SE) }\end{array}$ & $\begin{array}{c}\text { Model } 2 \\
\text { B (SE) }\end{array}$ & $\begin{array}{c}\text { Model } 3 \\
\text { B (SE) }\end{array}$ \\
\hline Intercept & & $1.772(0.15)$ & $1.904(0.13)$ & $1.880(0.14)$ \\
\hline \multicolumn{5}{|l|}{ Ideas } \\
\hline Left-right ideology & & $-0.006(.01)$ & & \\
\hline \multirow[t]{8}{*}{ Party family } & Socialist & & REF & REF \\
\hline & Green & & $0.103(0.09)$ & $0.037(0.10)$ \\
\hline & Christian Dem. & & $-0.520(0.05)^{\star \star \star}$ & $-0.535(0.06)^{\star \star \star}$ \\
\hline & Liberal & & $-0.183(0.06)^{\star \star}$ & $-0.186(0.06)^{\star \star}$ \\
\hline & Regionalist & & $0.426(0.12)^{\star \star \star}$ & $0.495(0.13)^{\star \star \star}$ \\
\hline & Conservative & & $0.169(0.05)^{\star \star}$ & $0.183(0.06)^{\star \star \star}$ \\
\hline & Radical right & & $0.468(0.10)^{\star \star \star}$ & $0.334(0.11)^{\star \star}$ \\
\hline & Other & & $-0.026(0.11)$ & $-0.105(0.12)$ \\
\hline Perceived legitimacy gap & & $0.163(0.02)^{\star \star \star}$ & $0.127(0.02)^{\star * \star}$ & $0.135(0.02)^{\star \star \star}$ \\
\hline \multirow[t]{2}{*}{ Role conception } & Delegate & REF & REF & REF \\
\hline & Trustee & $-0.125(0.04)^{\star \star}$ & $-0.164(0.04)^{\star \star \star}$ & $-0.144(0.04)^{\star \star \star}$ \\
\hline \multicolumn{5}{|l|}{ Interests } \\
\hline \multirow[t]{2}{*}{ Gov-opp } & Government & REF & REF & REF \\
\hline & Opposition & $0.427(0.04)^{\star \star \star}$ & $0.268(0.04)^{\star \star \star}$ & $0.247(0.05)^{\star \star \star}$ \\
\hline \multirow[t]{3}{*}{ Electoral vulnerability } & Unsure & & & REF \\
\hline & Surely elected & & & $-0.101(0.05)+$ \\
\hline & Probably elected & & & $0.048(0.04)$ \\
\hline \multicolumn{5}{|l|}{ Institutions } \\
\hline \multirow[t]{2}{*}{ Electoral system } & Non-PR & REF & REF & REF \\
\hline & $\mathrm{PR}$ & $0.383(0.07)^{\star \star \star}$ & $0.270(0.06)^{\star \star \star}$ & $0.272(0.07)^{\star \star \star}$ \\
\hline \multicolumn{5}{|l|}{ Controls } \\
\hline \multirow[t]{2}{*}{ Sex } & Female & REF & REF & REF \\
\hline & Male & $0.04(0.04)$ & $0.051(0.04)$ & $0.045(0.04)$ \\
\hline Age & & $-0.006(0.002)^{\star \star}$ & $-0.007(0.002)^{\star \star \star}$ & $-0.007(0.002)^{\star \star \star}$ \\
\hline Seniority & & $-0.004(0.003)$ & $-0.001(0.003)$ & $-0.001(0.003)$ \\
\hline \multirow[t]{2}{*}{ Parliament } & Regional & REF & REF & REF \\
\hline & National & $0.068(0.05)$ & $0.066(0.04)$ & $0.066(0.05)$ \\
\hline$N$ & & 1,901 & 2,067 & 1,793 \\
\hline Adj. $R^{2}$ with country dummies and control variables & & 0.201 & 0.259 & 0.264 \\
\hline Adj. $R^{2}$ without country dummies & & 0.127 & 0.167 & 0.164 \\
\hline Adj. $R^{2}$ without country dummies and control variables & & 0.117 & 0.159 & 0.157 \\
\hline
\end{tabular}

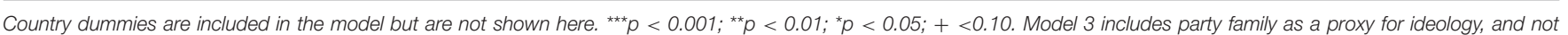

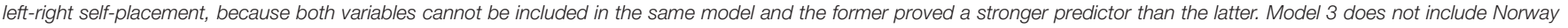
and the Netherlands because the survey question on electoral vulnerability was not asked in these countries.

disappears after we exclude Switzerland in the robustness checks (cfr infra). This suggests that this effect was mostly driven by the Swiss case [see also: Donovan and Karp (2006) for similar findings on Switzerland], and that conservative parties outside of Switzerland are not necessarily more supportive of direct democracy. Finally, green parties are not more likely to support referendums than socialist parties, which rejects hypothesis $\mathrm{H} 2$.

In addition to ideology, the variables measuring MPs' "perceptions of the legitimacy gap" and "role conceptions" also present significant effects in all models. The directions of the effects are in line with our hypotheses. In line with $\mathrm{H} 4$ we find that MPs who more strongly agree that politicians are out of touch with people's concerns are more likely to support referendums.
In line with H5, MPs who more strongly adhere to the "trustee" model-supporting the idea that representatives should prioritize their own personal opinions about the common good over those of their voters-are less in favor of referendums than MPs who consider themselves "delegates."

Turning to the interest-based explanations, the results show that "government-oppositio" dynamics are a strong predictor of support for referendums. In line with our hypothesis H6, we find that support is much higher among those in the opposition than among members of government parties. This suggests that empowering citizens through referendums can act as a way for opposition members to side-line their political rivals in office. We tested separately whether this effect was moderated by the 
electoral system (not shown here), but this was not the case. In line with H7, MPs who are very sure of their re-election offer less support for referendums compared to MPs who are unsure about their chances to get re-elected. The former might have more to lose, or less to win, with the adoption of democratic innovations.

Finally, the variable electoral formula generates a significant effect. MPs operating under PR rules are more supportive of referendums than MPs operating under non-PR rules. This is in line with hypothesis $\mathrm{H} 8$ that power-sharing institutions, such as the electoral system, offer incentives to MPs and convey norms about the acceptability and desirability of democratic innovations. PR systems, arguably because they are more often adopted in countries where political institutions are designed to foster consensus and the inclusion of broader segments in society, encourage MPs to support initiatives that aim to directly involve citizens in decision-making.

The explanatory power of the different models in Table $\mathbf{1}$ is quite high, with $R^{2}$ ranging between 20.1 and $26.4 \%$ for the full models, and between 11.7 and $15.9 \%$ for the models without country dummies and control variables. The control variables hardly increase the explanatory power of the models at all. After comparing the different effect sizes of the independent variables, we find that the idea-based and interest-based variables generate the strongest effects. The highest partial eta-squared in model 3 are found for party family $\left(\eta^{2}=0.078\right)$, the perceived legitimacy gap $\left(\eta^{2}=0.034\right)$ and opposition status $\left(\eta^{2}=0.017\right)$. Additional tests for diagnosing collinearity, performed on model 3 (as this was the model with the highest number of independent variables), revealed no problems with multicollinearity. The highest VIF score (VIF electoral system $=1.830$ ) remains below value 10 , and the lowest Tolerance rate (Tolerance electoral system $=0.546$ ) remains much higher than 0.1 (Meyers et al., 2016).

When we compare the results in Table 2 to Table 1, it first of all becomes clear that the overall explanatory power of the models is lower in Table 2. The effects of the independent variables are somewhat weaker, indicating that the independent variables do a better job in estimating MPs' support for referendums than their support for deliberative events. One reason might be that deliberative events were less common than referendums in Europe at the time when the survey was conducted (OECD, 2020). Their unfamiliarity with deliberative models of democracy might have tempered MPs' support for deliberative events.

When we test the idea-based hypotheses for MPs' support for deliberative events, the results are slightly different from what we found for referendums. MPs' self-placement on a leftright scale has a significant effect, in line with $\mathrm{H} 1$, with support decreasing when MPs position themselves more the right. This is mirrored in model 2 where the effect of party family is tested. Compared to socialist parties, green parties are equally likely to support deliberative events, but other party families (including Christian democratic, liberal, conservative and radical right parties) are less likely to find deliberative events desirable. The effect for regionalist parties is not significant. Together, these findings indicate that MPs' support for deliberative events is much more structured along a traditional and unidimensional left-right scale. Radical right parties, despite their stronger support for referendums, offer the lowest approval of deliberative events, which confirms H3. Additionally, MPs' perceptions of the legitimacy gap and their role orientations also play a role. The effects in Table 2 run parallel to the those in Table 1 but the effects are overall weaker. In line with H4, MPs who believe more strongly that politicians are out of touch with citizens find deliberative events more desirable. Trustees are also less likely to lend support to deliberative events than delegates, which confirms $\mathrm{H} 5$ that delegates, whose work is more directly linked to their constituents, would be more supportive of democratic innovations.

Regarding the interest-based explanations, we find that the "government-opposition" variable is the strongest predictor of support for deliberative democracy. In particular, we findconfirming hypothesis H6-that MPs from opposition parties are more supportive of deliberative innovations than those of parties in government. This again lends support to the assumption that those in power (and hence, those benefitting from the status quo) are less willing to share power with ordinary citizens and change the status quo. Regarding the variable "electoral vulnerability," we hypothesized based on the classical electoral cycle that MPs would want to give voters what they wanted if they are unsure about their re-election prospects (H7). However, we find no support for this.

Finally, turning to the impact of the electoral system, the models reveal no significant differences between PR and non-PR systems, rejecting $\mathrm{H} 8$. To the extent that $\mathrm{PR}$ rules convey norms about inclusion, we find that they do not stretch to shape MPs' support for deliberative events. MPs operating under PR rules are equally likely to find deliberative events desirable compared to MPs in non-PR systems. Given the more limited power of the electoral system (and electoral vulnerability) in Table 2 compared to Table 1, we conclude that support for deliberative events is not driven by MPs' electoral incentives.

When we compare the different effect sizes of the independent variables, the idea-based and interest-based variables again appear to generate the strongest effects. This holds in particular for the variables "left-right ideology" (partial $\eta^{2}=0.050$ ), "government-opposition" (partial $\eta^{2}=0.009$ ) and "perceived gap" (partial $\eta^{2}=0.008$ ). Collinearity diagnostics for the final model in Table 2 again did not reveal any problems with multicollinearity. The highest VIF score (VIF electoral system $=1.842$ ) remains below value 10 , and the lowest Tolerance rate (Tolerance electoral system $=0.543$ ) remains higher than 0.1 (Meyers et al., 2016).

\section{Robustness Checks}

In order to strengthen the analyses, we conducted two additional robustness checks which are reported in the online Supplemental Materials file. The first check tests whether the results remain the same if we remove Switzerland from the analysis. Indeed, Switzerland presents itself as a slightly different case compared to the other countries in the dataset, because of its application of direct-democratic procedures (Stojanović, 2006). We therefore ran the models once more without Switzerland to test whether results were not driven by this particular country. The results are presented in Supplementary Table A3. Overall, the results 
TABLE 2 | General linear model estimating MPs' support for deliberative events (with country fixed effects).

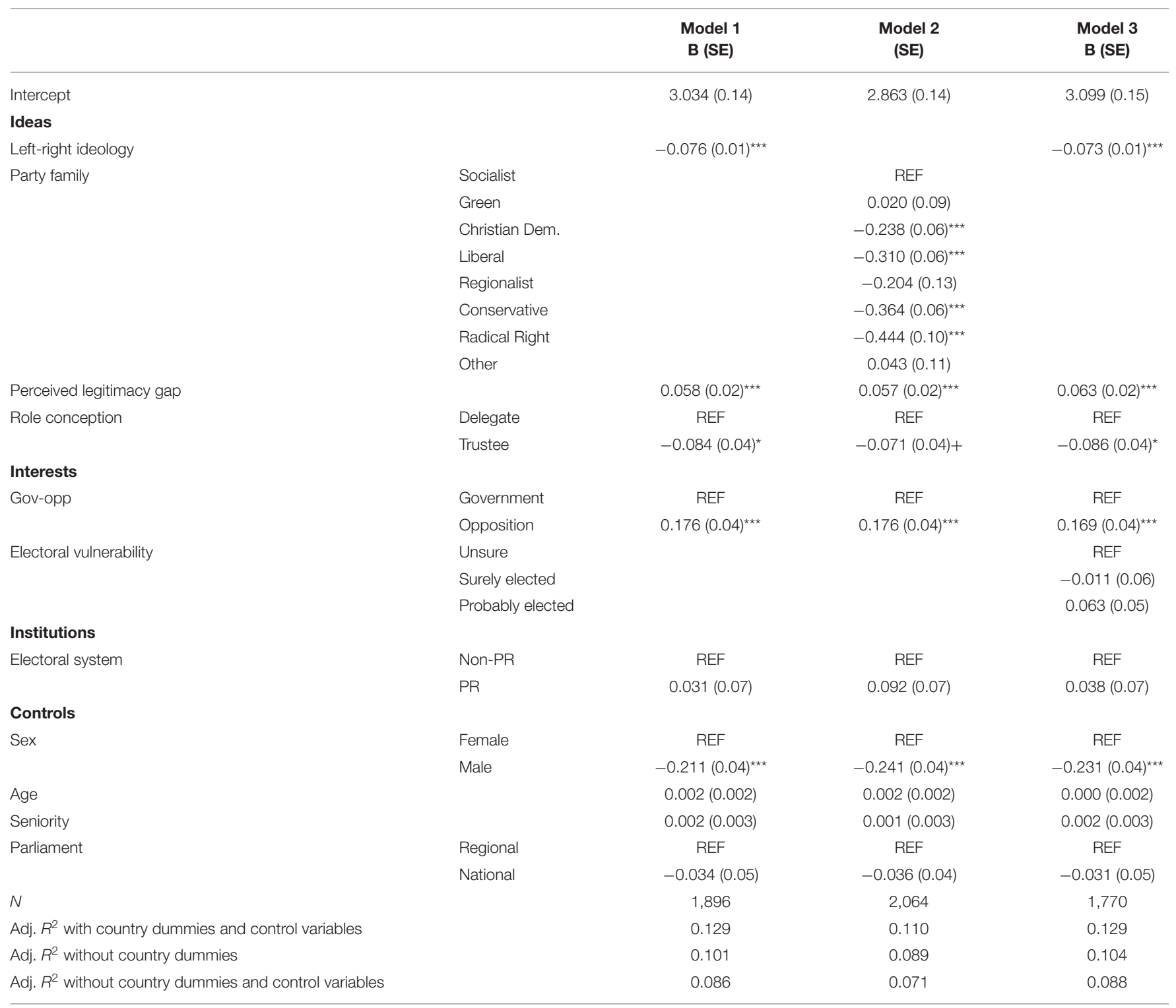

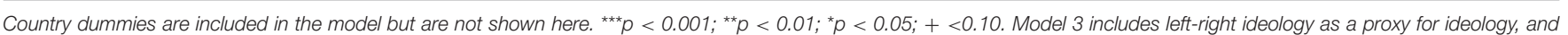

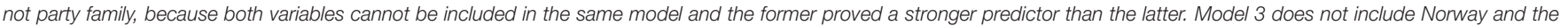
Netherlands because the survey question on electoral vulnerability was not asked in these countries.

remain largely the same compared to the results in Tables 1, 2, with the exception of the variable "party family" in the model estimating MPs' support for referendums. Radical right parties and regionalist parties continue to be more supportive of referendums than socialist parties if we remove Switzerland from the equation, but the significant effect for conservative parties disappears [see also: Donovan and Karp (2006)].

As a second robustness check, we also recoded the continuous dependent variable in Tables 1, 2 into a binary variable estimating MPs support $(=1)$ compared to non-support $(=0)$ for democratic innovations. Score 1 means that MPs find the proposed democratic innovations "fairly desirable" or "very desirable," score 0 indicates that MPs find these "not at all desirable" or "not very desirable." The results are reported in Supplementary Table A4. The results again confirm the initial results discussed in Tables 1, 2.

\section{DISCUSSION AND CONCLUSION}

In response to the alleged legitimacy crisis, modern democracies have increasingly started to adopt democratic innovations as a way of reconnecting with citizens. These innovations aim to give "lay" citizens a more direct say in democratic decision-making, 
and therefore contrast with the indirect nature of representative democracy. In this paper, we asked whether and why elected representatives-as the ultimate political power brokers-support democratic innovations which both challenge and complement representative democracy. We hypothesized that 3Is-ideas, interests and institutions-account for MPs' positions toward democratic innovations. The findings of this paper paint a nuanced picture with several key findings.

First of all, we found that ideas are powerful indicators of support for democratic innovations. Ideological selfidentification is significantly related to support for deliberative events and party family is significantly related to support for referendums. In particular, we found that left-wing parties (socialist and green parties) were most supportive of democratic innovations. However, we did not find any significant difference between green parties and other left-wing parties as expected in our second hypothesis. As expected, conservative, liberal and Christian democratic parties were less supportive of democratic innovations. Radical right parties were strongly against deliberation but strongly in favor of referendums, which proved in line with our expectations. Moreover, we found that MPs' own legitimacy perceptions are related to their support for democratic innovations. MPs who more believe that politicians are out of touch with citizens consider the adoption of more referendums and deliberative events desirable. This indeed suggests that MPs consider democratic innovations to be a cure to the malaise of representative democracy and a way or restoring legitimate processes of democratic linkage. In addition, representatives who consider themselves as "delegates" are more supportive of both referendums and deliberative events compared to representatives acting as "trustees." This confirms our hypothesis that "trustees" are less supportive of citizen-empowering democratic innovations than "delegates." This might be explained by the idea that trustees prefer to represent the people in an indirect way through their own deliberations in parliament, rather than by trusting citizens to directly make collective decisions amongst themselves (Pitkin, 1967).

Secondly, the strong effect of ideas does not mean that we should discount MPs' strategic interest, on the contrary. Representatives who are unsure about their re-election or fear electoral defeat, are more supportive of referendums, although not of deliberative events. Moreover, we found strong support for the expectation that MPs in majority parties are less supportive of referendums and deliberative events than members of opposition parties. Hence, our study shows that democratic innovations provide an opportunity to opposition members to side-line the majority (Goodwin and Milazzo, 2015). The findings furthermore suggest that representatives in opposition parties are more willing to employ democratic innovations as a powerful tool of "counterdemocracy;" as a check on majority rule and to countervail the concentration of power (Rosanvallon and Goldhammer, 2008).

Thirdly, our analysis showed that institutions matter as well. MPs functioning under a system of proportional representation, i.e., MPs in consensus democracies, are more likely to support referendums but not deliberative events. The finding that there is an effect for referendums but not for deliberative events, could be explained by the fact that the rise of deliberative democratic innovations is a recent development and therefore not yet fully engrained in a specific institutional culture.

A final, transversal finding is that, while the 3I-framework predicts MP' positions toward democratic innovations quite well, the 3Is generate slightly differential effects on support for referendums and deliberative events. Support for referendums is mainly affected by ideology, representative role orientations, government-opposition dynamics, electoral vulnerability, and the electoral system. Support for deliberative events is strongly determined by representatives' ideas as well, but the electoral system and electoral vulnerability, in contrast, do not significantly affect MPs' position toward deliberative events.

Despite these interesting findings, we should be aware of the limitations of our results. First of all, we took a rather static perspective in which we study whether MPs at one point in time support different democratic innovations. However, as a recent OECD (2020) report has shown, experience with democratic innovations has significantly increased in the last couple of years and an increasing number of innovations have been institutionalized. Even though our hypotheses were framed in a static manner, future research should take a more dynamic approach assuming that MPs views can change with growing experience. E.g., if conservative politicians experience that the recommendations of mini-publics are generally not that outlandish and revolutionary, they might become more inclined to support them over time. A more dynamic approach outlining changes in MPs positions over time might paint a more accurate picture. Moreover, despite the enduring tensions between representative democracy and democratic innovations, as the examples of institutionalization show, MPs are in some cases willing to adopt far-reaching reforms, which could fundamentally undermine their own power basis. Further research should examine these specific cases in more detail to see which set of ideas, interests and institutions led to their adoption.

A second limitation, is that the MP survey was administered from 2008 to 2012, whereas deliberative mini-publics as a democratic tool only gained recognition through several experiments organized during or after this period. The respondents' knowledge of the pros and cons of deliberative events might not have been fully crystallized, which accounts for the relatively low explained variance. Future research might contribute to this study by not only analyzing support for democratic innovations, but also MPs' knowledge about democratic innovations.

Thirdly, we were limited by the formulation of the questions in the survey, which did not allow us to distinguish between binding and advisory innovations. Previous research (e.g., Caluwaerts et al., 2020; Jacquet et al., 2020) found that the binding nature of the innovation matters greatly, with support for binding referendums or mini-publics being 
lower than for advisory ones. However, the formulation of the items in the questionnaire remains vague on this issue, in the sense that it is not clear whether the referendums or mini-publics needed to be binding or advisory. Future research should definitely distinguish between these modalities.

A final limitation consists of the fact that our operationalization of the institutional factors was fairly limited. The lack of readily available institutional variables for the period and the set of countries under investigation, means that we had to rely solely on the electoral system as a proxy. Even though our institutional hypotheses were largely confirmed, future research should include more institutional variation to map how democratic innovations interact with a country's institutional infrastructure.

Despite these limitations, our study shows that the support for democratic innovations can be explained by the 3Iframework. Democratic innovations have been increasingly stirring public opinion and will remain at the forefront of ideational, strategic and institutional struggles in years to come.

\section{DATA AVAILABILITY STATEMENT}

Publicly available datasets were analyzed in this study. The PARTIREP MP Survey research team is owner of the data. The data are not stored in any online repository, but can be accessed upon request to kris.deschouwer@vub.be.

\section{REFERENCES}

Altman, D. (2010). Direct Democracy Worldwide. New York, NY: Cambridge University Press.

Armingeon, K., and Guthmann, K. (2014). Democracy in crisis? The declining support for national democracy in European countries, 2007-2011. Eur. J. Polit. Res. 53, 423-442. doi: 10.1111/1475-6765.12046

Armingeon, K., Wenger, V., Wiedemeier, F., Isler, C., Knöpfel, L., Weisstanner, D., et al. (2019). Comparative Political Data Set 1960-2017. Zurich: Institute of Political Science, University of Zurich.

Bächtiger, A., Spörndli, M., Steenbergen, M. R., and Steiner, J. (2005). The deliberative dimensions of legislatures. Acta Polit. 40, 225-238. doi: $10.1057 /$ palgrave.ap. 5500103

Bedock, C., and Pilet, J.-B. (2020). Enraged, engaged, or both? A study of the determinants of support for consultative vs. binding mini-publics. Representation. doi: 10.1080/00344893.2020.1778511. [Epub ahead of print].

Bengtsson, Å., and Mattila, M. (2009). Direct democracy and its critics: support for direct democracy and 'stealth' democracy in Finland. West Eur. Polit. 32, 1031-1048. doi: 10.1080/01402380903065256

Boix, C. (1999). Setting the rules of the game: the choice of electoral systems in advanced democracies. Am. Polit. Sci. Rev. 93, 609-624. doi: 10.2307/2585577

Bol, D. (2016). Electoral reform, values and party self-interest. Party Polit. 22, 93-104. doi: 10.1177/1354068813511590

Bowler, S., Donovan, T., and Karp, J. A. (2002). When might institutions change? Elite support for direct democracy in three nations. Polit. Res. Q 55, 731-754. doi: 10.1177/106591290205500401

Bowler, S., Donovan, T., and Karp, J. A. (2006). Why politicians like electoral institutions: self-interest, values, or ideology? J. Polit. 68, 434-446. doi: $10.1111 /$ j.1468-2508.2006.00418.x

\section{AUTHOR CONTRIBUTIONS}

JM and NJ focussed on the theoretical part of the paper. SE and DC focussed on the empirical analysis. All authors revised and finalized the paper together.

\section{FUNDING}

The data used in this publication were collected by the PARTIREP MP Survey research team. The PARTIREP project was funded by the Belgian Federal Science Policy (BELSPO-Grant No. P6/37). Neither the contributors to the data collection nor the sponsors of the project bear any responsibility for the analyses conducted or the interpretation of the results published here.

\section{ACKNOWLEDGMENTS}

The authors would like to thank the PARTIREP MP Survey research team and all persons who have contributed to the data collection. They also wish to thank Julien Vrydagh for his contributions to, and Camille Bedock, Pierre-Etienne Vandamme and the reviewers for their comments on, earlier drafts of this paper.

\section{SUPPLEMENTARY MATERIAL}

The Supplementary Material for this article can be found online at: https://www.frontiersin.org/articles/10.3389/fpos. 2020.584439/full\#supplementary-material

Bowler, S., Donovan, T., and Karp, J. A. (2007). Enraged or engaged? Preferences for direct citizen participation in affluent democracies. Polit. Res. Q 60, 351-362. doi: 10.1177/1065912907304108

Bua, A. (2017). Scale and policy impact in participatory deliberative democracy: lessons from a multi-level process. Public Admin. 95, 160-177. doi: $10.1111 /$ padm.12297

Budge, I. (2001). "Political parties in direct democracy," in Referendum Democracy: Citizens, Elites and Deliberation in Referendum Campaigns, eds. M. Mendelsohn and A. Parkin (Basingstoke: Palgrave Macmillan), 67-87.

Caluwaerts, D., Kern, A., Reuchamps, M., and Valcke, T. (2020). Between party democracy and citizen democracy: explaining attitudes of flemish local chairs towards democratic innovation. Polit. Low Countries 2, 192-213. doi: 10.5553/PLC/258999292020002002005

Caluwaerts, D., and Reuchamps, M. (2015). Strengthening democracy through bottom-up deliberation: an assessment of the internal legitimacy of the G1000 project. Acta Polit. 50, 151-170. doi: 10.1057/ap.2014.2

Caluwaerts, D., and Reuchamps, M. (2016). Generating democratic legitimacy through deliberative innovations: the role of embeddedness and disruptiveness. Representation 52, 13-27. doi: 10.1080/00344893.2016.1244111

Cordero, G., and Simón, P. (2016). Economic crisis and support for democracy in Europe. West Eur. Polit. 39, 305-325. doi: 10.1080/01402382.2015. 1075767

Dalton, R. J. (2004). Democratic Challenges, Democratic Choices. Oxford: Oxford University Press.

Dalton, R. J. (2014). Interpreting partisan dealignment in Germany. German Polit. 23, 134-144. doi: 10.1080/09644008.2013.853040

Dalton, R. J., and Weldon, S. A. (2005). Public images of political parties: a necessary evil? West Eur. Polit. 28, 931-951. doi: 10.1080/01402380500310527 
Deschouwer, K., and Depauw, S. (2014). Representing the People: a Survey Among Members of Statewide and Substate Parliaments. Oxford: Oxford University Press.

Deschouwer, K., Depauw, S., and Andr,é, A. (2014). "Representing the people in parliaments," in Representing the People. A Survey Among Members of Statewide and Substate Parliaments, eds. K. Deschouwer and S. Depauw (Oxford: Oxford University Press), 1-18.

Doherty, B. (2005). Ideas and Actions in the Green Movement. London: Routledge.

Donovan, T., and Karp, J. A. (2006). Popular support for direct democracy. Party Polit. 12, 671-688. doi: 10.1177/1354068806066793

Elstub, S., and Escobar, O. (2019). Handbook of Democratic Innovation and Governance. Cheltenham: Edward Elgar Publishing.

Fatke, M., and Freitag, M. (2013). Direct democracy: protest catalyst or protest alternative? Polit. Behav. 35, 237-260. doi: 10.1007/s11109-012-9194-0

Ferrín, M., and Kriesi, H. (2016). How Europeans View and Evaluate Democracy. Oxford: Oxford University Press.

Fishkin, J. S. (2018). Democracy When the People Are Thinking P: Revitalizing Our Politics Through Public Deliberation. Oxford: Oxford University Press.

Floridia, A. (2017). From Participation to Deliberation: A Critical Genealogy of Deliberative Democracy. Colchester: Ecpr Press.

Font, J., Smith, G., Galais, C., and Alarcon, P. (2018). Cherry-picking participation: explaining the fate of proposals from participatory processes. Eur. J. Polit. Res. 57, 615-636. doi: 10.1111/1475-6765.12248

Frankland, E. G., Lucardie, P., and Rihoux, B. (2008). Green Parties in Transition: The End of Grass-Roots Democracy? Surrey: Ashgate Publishing, Ltd.

Gastil, J., Bacci, C., and Dollinger, M. (2010). Is deliberation neutral? patterns of attitude change during'the deliberative polls ${ }^{\mathrm{TM}}$, J. Public Deliber. 6:3. doi: $10.16997 /$ jdd.107

Geißel, B., and Joas, M. (2013). Participatory Democratic Innovations in Europe: Improving the Quality of Democracy? Berlin: Barbara Budrich

Geißel, B., and Michels, A. (2018). Participatory developments in majoritarian and consensus democracies. Representation 54, 129-146. doi: 10.1080/00344893.2018.1495663

Gherghina, S., and Geißel, B. (2020). Support for direct and deliberative models of democracy in the UK: understanding the difference. Polit. Res. Exchange 2:1809474. doi: 10.1080/2474736X.2020.1809474

Goodin, R. E., and Dryzek, J. S. (2006). Deliberative impacts: the macro-political uptake of mini-publics. Polit. Soc. 34, 219-244. doi: 10.1177/0032329206288152

Goodwin, M., and Milazzo, C. (2015). UKIP: Inside the Campaign to Redraw the Map of British Politics. Oxford: Oxford University Press.

Grönlund, K., Bächtiger, A., and Setälä, M. (2014). Deliberative Mini-Publics: Involving Citizens in the Democratic Process. Colchester: ECPR Press.

Hall, P. A. (1997). "The role of interests, institutions, and ideas in the comparative political economy of the industrialized nations," in Comparative Politics: Rationality, Culture, and Structure, eds. M. I. Lichbach and A. S. Zuckerman (Cambridge: Cambridge University Press), 174-207.

Hendriks, F., and Michels, A. (2011). Democracy transformed? Reforms in Britain and the Netherlands (1990-2010). Int J Public Admin. 34, 307-317. doi: 10.1080/01900692.2011.557815

Hibbing, J. R., and Theiss-Morse, E. (2002). Stealth Democracy: Americans' Beliefs About How Government Should Work. New York: Cambridge University Press.

Jacobs, K. (2018). Referendums in times of discontent. Acta Polit. 53, 489-495. doi: 10.1057/s41269-018-0116-y

Jacquet, V., Niessen, C., and Reuchamps, M. (2020). Sortition, its advocates and its critics: an empirical analysis of citizens' and MPs' support for random selection as a democratic reform proposal. Int. Polit. Sci. Rev. doi: 10.1177/0192512120949958. [Epub ahead of print].

Jäske, M. (2017). 'Soft'forms of direct democracy: explaining the occurrence of referendum motions and advisory referendums in finnish local government. Swiss Polit. Sci. Rev. 23, 50-76. doi: 10.1111/spsr.12238

Kam, C. J. (2009). Party Discipline and Parliamentary Politics. Cambridge: Cambridge University Press.

Klijn, E.-H., and Koppenjan, J. F. (2002). "Rediscovering the citizen: new roles for politicians in interactive policy making," in Public Participation and Innovations in Community Governance, ed. M. Peter (London: Routledge), 141-163.
Kriesi, H., and Pappas, T. S. (2015). "Populism in Europe during crisis: an introduction," in Populism in the Shadow of the Great Recession, eds. H. Kriesi and T. S. Pappas (Cambridge: Cambridge University Press), 1-19.

Leduc, L. (2003). The Politics of Direct Democracy Referendums in Global Perspective. Toronto, ON: University of Toronto Press.

Lijphart, A. (1984). Democracies: Patterns of Majoritarian and Consensus Government in Twenty-One Countries. Yale: Yale University Press.

Lijphart, A. (2012). Patterns of Democracy: Government Forms and Performance in Thirty-Six Countries. Yale: Yale University Press.

Lijphart, A. (2019). Deliberation and consociation: joint pathways to peace in divided societies. J. Deliber. Democr. 15, 1-2. doi: 10.16997/ jdd. 348

MacKuen, M. B., Erikson, R. S., and Stimson, J. A. (1992). Peasants or bankers? The American electorate and the U.S. economy. Am. Polit. Sci. Rev. 86, 597-611. doi: $10.2307 / 1964124$

Meyers, L. S., Gamst, G., and Guarino, A. J. (2016). Applied Multivariate Research: Design and Interpretation. Thousand Oaks: Sage.

Miller, A. H., and Listhaug, O. (1990). Political parties and confidence in government: a comparison of Norway, Sweden and the United States. Br. J. Polit. Sci. 20:2. doi: 10.1017/S0007123400005883

Mudde, C. (2007). Populist Radical Right Parties in Europe. Cambridge: Cambridge University Press.

Neblo, M. A., Esterling, K. M., Kennedy, R. P., Lazer, D. M. J., and Sokhey, A. E. (2010). Who wants to deliberate-and why? Am. Polit. Sci. Rev. 104, 566-583. doi: $10.1017 /$ S0003055410000298

Newton, K., and Geißel, B. (2012). Evaluating Democratic Innovations: Curing the Democratic Malaise? New York: Routledge.

Núñez, L., Close, C., and Bedock, C. (2016). Changing democracy? Why inertia is winning over innovation. Representation 52, 341-357. doi: 10.1080/00344893.2017.1317656

OECD (2020). Innovative Citizen Participation and New Democratic Institutions: Catching the Deliberative Wave. Paris: OECD Publishing.

Palier, B., and Surel, Y. (2005). Les «trois I》 et l'analyse de l'État en action. Revue Française Sci. Polit. 55, 7-32. doi: 10.3917/rfsp.551.0007

Pilet, J.-B., and Bol, D. (2011). Party preferences and electoral reform: how time in government affects the likelihood of supporting electoral change. West Eur. Polit. 34, 568-586. doi: 10.1080/01402382.2011.555984

Pitkin, H. F. (1967). The Concept of Representation. Berkeley: University of California Press.

Pogrebinschi, T., and Ryan, M. (2018). Moving beyond input legitimacy: when do democratic innovations affect policy making? Eur. J. Polit. Res. 57, 135-152. doi: 10.1111/1475-6765.12219

Poguntke, T., Scarrow, S. E., Webb, P. D., Allern, E. H., Aylott, N., Van Biezen, I., et al. (2016). Party rules, party resources and the politics of parliamentary democracies: how parties organize in the 21st century. Party Polit. 22, 661-678. doi: $10.1177 / 1354068816662493$

Qvortrup, M. (2005). A Comparative Study of Referendums: Government by the People. Manchester: Manchester University Press.

Rahat, G. (2009). "Elite motivations for initiating referendums: avoidance, addition and contradiction," in Referendums and Representative Democracy: Responsiveness, Accountability and Deliberation, eds. M. Setälä and T. Schiller (London: Routledge), 98-116.

Richardson, D., and Rootes, C. (2006). The Green Challenge: The Development of Green Parties in Europe. New York, NY: Routledge.

Rosanvallon, P., and Goldhammer, A. (2008). Counter-Democracy: Politics in an Age of Distrust. Cambridge: Cambridge University Press.

Ryfe, D. M. (2010). Comment: a step forward on a vital issue. J. Public Deliber. 6:2. doi: $10.16997 /$ jdd.106

Setälä, M. (2006). On the problems of responsibility and accountability in referendums. Eur. J. Polit. Res. 45, 699-721. doi: $10.1111 / j .1475-6765.2006 .00630 . x$

Smith, G. (2009). Democratic Innovations: Designing Institutions for Citizen Participation. Cambridge: Cambridge University Press.

Steiner, J. (2009). "In search of the consociational "spirit of accommodation"," in Consociational Theory: McGarry and O'Leary and the Northern Ireland Conflict, ed. R. Taylor (New York: Routledge), 196-205. 
Steiner, J., Bächtiger, A., Spörndli, M., and Steenbergen, M. R. (2004). Deliberative Politics in Action: Analyzing Parliamentary Discourse. Cambridge: Cambridge University Press.

Stojanović, N. (2006). Do multicultural democracies really require PR? Counterevidence from Switzerland. Swiss Polit. Sci. Rev. 12, 131-157. doi: 10.1002/j.1662-6370.2006.tb00063.x

Thompson, N. (2019). "The role of elected representatives in democratic innovations," in Handbook of Democratic Innovation and Governance, eds. S. Elstub and O. Escobar (Cheltenham: Edward Elgar Publishing).

Van Haute, E., Paulis, E., and Sierens, V. (2018). Assessing party membership figures: the MAPP dataset. Eur. Polit. Sci. 17, 366-377. doi: 10.1057/s41304-016-0098-Z

Vandamme, P.-É., Jacquet, V., Niessen, C., Pitseys, J., and Reuchamps, M. (2018). Intercameral relations in a bicameral elected and sortition legislature. Polit. Soc. 46, 381-400. doi: $10.1177 / 0032329218789890$

Vatter, A. (2000). Consensus and direct democracy: conceptual and empirical linkages. Eur. J. Polit. Res. 38, 171-192. doi: 10.1111/1475-6765.00531

Vatter, A., and Bernauer, J. (2009). The missing dimension of democracy: institutional patterns in $25 \mathrm{EU}$ member states between 1997 and 2006. Eur. Union Polit. 10, 335-359. doi: 10.1177/1465116509337828
Webb, P. (2013). Who is willing to participate? Dissatisfied democrats, stealth democrats and populists in the United Kingdom. Eur. J. Polit. Res. 52, 747-772. doi: 10.1111/1475-6765.12021

White, J., and Ypi, L. (2011). On partisan political justification. Am. Polit. Sci. Rev. 105, 381-396. doi: 10.1017/S0003055411000074

Wolkenstein, F. (2016). A deliberative model of intra-party democracy. J. Polit. Philos. 24, 297-320. doi: 10.1111/jopp.1 2064

Conflict of Interest: The authors declare that the research was conducted in the absence of any commercial or financial relationships that could be construed as a potential conflict of interest.

Copyright $\odot 2020$ Junius, Matthieu, Caluwaerts and Erzeel. This is an open-access article distributed under the terms of the Creative Commons Attribution License (CC $B Y)$. The use, distribution or reproduction in other forums is permitted, provided the original author(s) and the copyright owner(s) are credited and that the original publication in this journal is cited, in accordance with accepted academic practice. No use, distribution or reproduction is permitted which does not comply with these terms. 


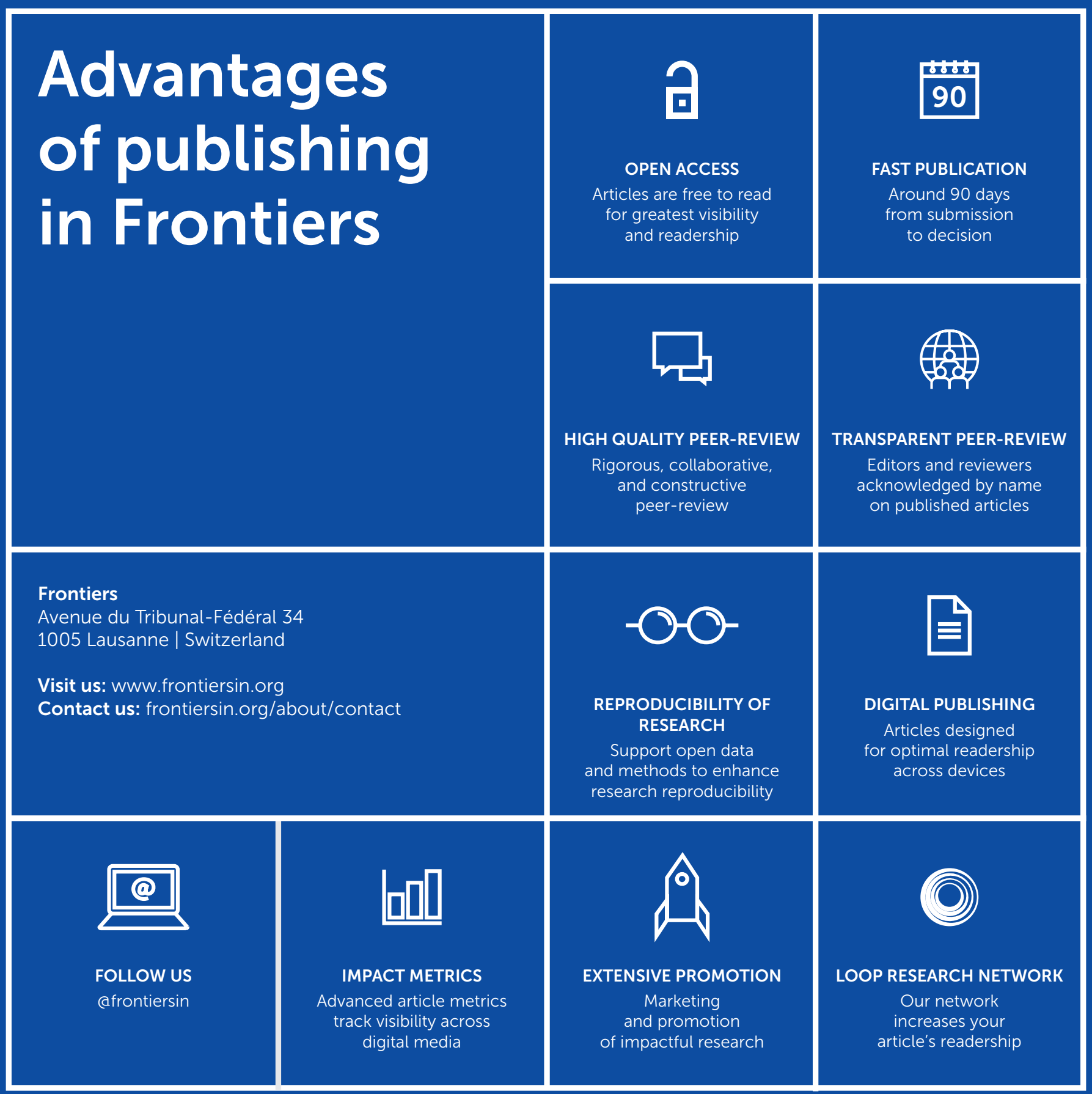

